\author{
Universidade de São Paulo \\ Instituto de Física
}

\title{
Sensoriamento remoto de aerossóis em alta resolução espacial na região amazônica
}

\author{
Silvia de Lucca \\ Dissertação de mestrado apresentada ao \\ Instituto de Física da Universidade de São \\ Paulo para a obtenção do título de Mestre em \\ Ciências
}

\section{Orientador:}

Prof. Dr. Paulo Eduardo Artaxo Netto

\section{Banca Examinadora:}

Prof. Dr. Paulo Eduardo Artaxo Netto (IF/USP)

Prof. Dr. Eduardo Landulfo (IPEN)

Prof. Dr. Mikiya Muramatsu (IF/USP) 
FICHA CATALOGRÁFICA

Preparada pelo Serviço de Biblioteca e Informação do Instituto de Física da Universidade de São Paulo

Lucca, Silva de

Sensoriamento remoto de aerossóis em alta resolução espacial na região amazônica - São Paulo, 2009

Dissertação (Mestrado) - Universidade de São Paulo. Instituto de Física - Depto. de Física Aplicada

Orientador: Prof. Dr. Paulo Eduardo Artaxo Netto

Área de Concentração: Física

Unitermos: 1. Física Experimental; 2. Radiação Atmosférica

USP/IF/SBI-095/2009 
Aos meus pais e ao infindável exercício de aprender. 
AGRADECIMENTOS

Agradeço ao Professor Paulo Artaxo, por me confiar este trabalho e por acreditar em mim, mesmo nos momentos mais turbulentos.

Existem tantos a agradecer, espero não esquecer ninguém. À Andrea, sempre solicita, pelas muitas horas dedicadas a sanar minhas dúvidas, desde o embrião deste projeto até seus momentos finais. Ao Alexandre, por me apresentar não só ao grupo de pesquisa, mas à área do conhecimento que espero trabalhar por muitos e muitos anos, além é claro da enorme paciência, e das muitas sugestões que fez a este trabalho. À Márcia que muito acrescentou ao conhecimento que possuo hoje, no contexto deste projeto, foram poucas conversas, mas das quais pude absorver muito. À Lu, que como um anjo, fez a primeira e mais árdua revisão deste trabalho. A Kenia que nos momentos finais de correção me ajudou imensamente. Ao Théo que no meu início de LFA, me fez sentir em casa. Ao Paulo Henrique, querido, pela paciência, durante meu período de iniciação, em me ensinar muito do que sabia. Ao Carlos pelos infinitos probleminhas do dia a dia que me ajudou a resolver. A Melina, companheira de sala que a convivência transformou em uma pessoa muito querida. À Iracema pelas caronas nos muitos dias trabalhados até tarde. A todos do LFA que sempre me receberam com um sorriso e/ou uma atitude solicita.

E como não falar daqueles que não necessariamente me ajudaram na parte técnica deste projeto, mas que me deram suporte para enfrentar, principalmente a fase final deste trabalho. Aos amigos do coração que entenderam minhas ausências em MUITAS ocasiões, em prol do fim deste trabalho. Aos meus pais sempre pacientes e fazendo o máximo para tornar essa fase o mais suave possível. A você Gordo, que por muitas vezes renunciou aos seus momentos de descanso para ficar ao meu lado. À Elo, grande presente que a faculdade me deu, amiga querida sempre apontando para uma luz no fim do túnel.

À FAPESP pelo apoio financeiro recebido durante este trabalho. 


\section{RESUMO}

O significativo processo de desmatamento na Amazônia acarreta a emissão atmosférica de altas quantidades de aerossóis e gases. É necessário o desenvolvimento de ferramentas que melhor quantifiquem essa carga de aerossóis e conseqüentemente o impacto gerado no clima regional, incluindo alterações no balanço radiativo terrestre e nos mecanismos de formação e desenvolvimento de nuvens.

Foram analisadas as propriedades ópticas dos aerossóis, por meio de medidas obtidas pelo fotômetro da rede AERONET (Aerosol Robotic Network) operada pela NASA, localizado na região de Ji-Paraná - Rondônia. Dois modelos ópticos de aerossol, representativos da região, foram definidos, em função do albedo simples $\left(\omega_{0}\right)$, a partir do índice de refração real e imaginário e da distribuição de tamanho dos aerossóis. No comprimento de onda de $676 \mathrm{~nm}$, os modelos ópticos possuem valores de $\omega_{0}$ entre 0,88 e 0,94 . Adaptou-se a metodologia para a obtenção da profundidade óptica dos aerossóis com alta resolução espacial a partir de observações de radiância obtidas com o sensor MODIS (ModerateResolution Imaging Spectroradiometer). Aumentou-se a resolução espacial de 10 km x $10 \mathrm{~km}$ (produto operacional da NASA para profundidade óptica de aerossóis $A O D$ ) para $1,5 \times 1,5 \mathrm{~km}$, com bons resultados. O algoritmo adaptado utiliza a propriedade de refletância crítica para determinar o modelo óptico de aerossol a ser empregado, de forma dinâmica e interativa, reduzindo a incerteza na determinação da profundidade óptica dos aerossóis com alta resolução espacial.

Os resultados de validação revelaram que os resultados de $A O D$ obtidos com alta resolução espacial e os obtidos operacionalmente pela NASA, quando comparado com as medidas de referência obtidas com radiômetro da rede AERONET apresentaram resultados satisfatórios. O método em alta resolução utilizado neste trabalho teve índice de acerto melhor em $40 \%$ dos casos, melhorando assim consideravelmente uma importante fonte de incerteza na obtenção de $A O D$ por sensoriamento remoto, que é a escolha de um modelo óptico mais adequado ao tipo de aerossol sendo determinado. A validação realizada por meio da comparação do valor médio de $A O D$ pelo MODIS comparado com o fotômetro mostrou uma equação de regressão $\mathrm{y}=(1,09 \pm 0,03) \mathrm{x}+(0,03 \pm 0,02)$, com $\mathrm{R}^{2}=0,80$. A contaminação das imagens por nuvens é sensivelmente melhorada em alta resolução, mas ainda é um problema que requer atenção científica no desenvolvimento de melhores algoritmos. 
ABSTRACT

The significant deforestation process in Amazonia results in high levels of aerosols and trace gases emitted to the atmosphere. It is necessary the development of tool that allows a better quantification of the atmospheric aerosol loading and consequently the impact on regional climate, including changes in the regional radiation balance and the mechanisms of cloud formation and development.

Aerosol optical properties were investigated through the analysis of the sunphotometer that is part of the Aerosol Robotic Network (AERONET) located in JiParaná (RO, Brazil). Two aerosol optical models, representative of that specific region were defined as a function of the single scattering albedo $\left(\omega_{0}\right)$, through the analysis of the real and imaginary refractive indexes and the aerosol size distribution. Taking into account the $676 \mathrm{~nm}$ wavelength, both models returned single scattering albedo values of $\omega_{0}(1)=0.88$ and $\omega_{0}(2)=0.94$. A well-established methodology used for urban aerosol studies through the analysis of MODIS (Moderate-Resolution Imaging Spectroradiometer) data was adapted to Amazonia. It has obtained aerosol optical depth $(A O D)$ for the Amazon region, improving the standard spatial resolution of $10 \mathrm{~km}$ x $10 \mathrm{~km}$ to $1.5 \mathrm{~km}$ x $1.5 \mathrm{~km}$ with good results. The adapted algorithm takes into account the critical reflectance to provide the appropriate aerosol optical model to be used, in an interactive and dynamical way, reducing the uncertainty in the aerosol optical depth determination with high spatial resolution.

The results of the validation analysis showed that the $A O D$ obtained with high spatial resolution and those obtained from the NASA operational product when compared with AERONET data shows very satisfactory results. The high-resolution method developed in this work had a very good agreement compared with the single aerosol optical model for $40 \%$ of the analyzed cases. This shows that an important source of uncertainty, the choice of a more appropriate optical model was reduced. The validation of the results done with sun-photometer measurements showed very good agreement, with a regression equation: $y=(1,09 \pm 0,03) \mathrm{x}+(0,03 \pm 0,02)$, with $\mathrm{R}^{2}=0,80$. The cloud contamination issue is reduced with the high-resolution method, but is still an important issue that requires further investigation. 


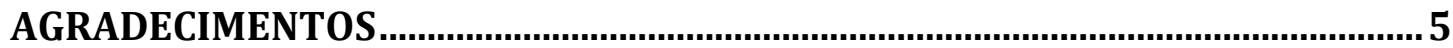

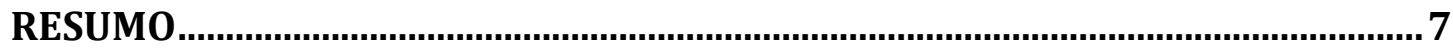

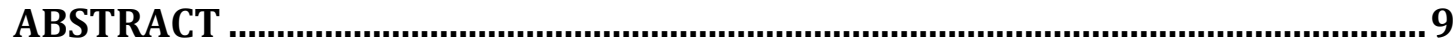

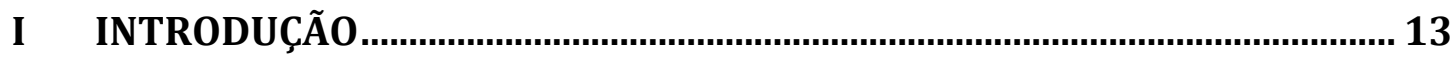

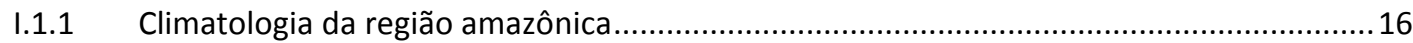

I.1.2 Desflorestamento e queimadas na região amazônica ...........................................................19

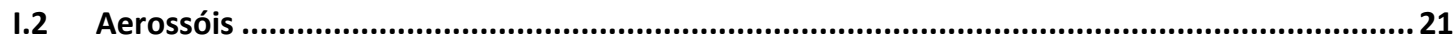

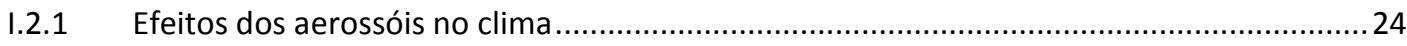

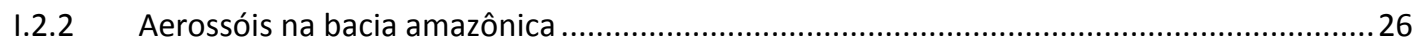

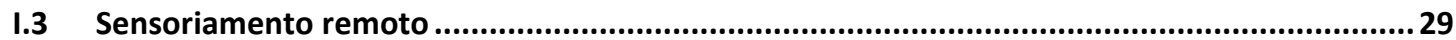

I.3.1 Sensoriamento remoto no monitoramento de aerossóis ................................................29

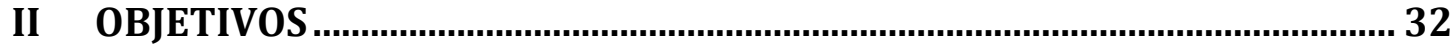

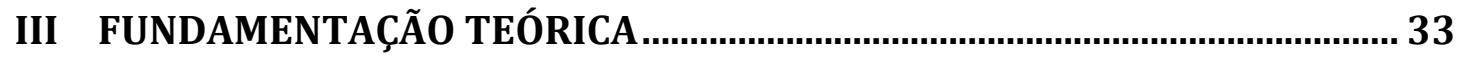

III.1 Interação da radiação solar com a atmosfera ....................................................................33

III.1.1 Absorção da radiação solar por gases presentes na atmosfera ...........................................35

III.1.2 Espalhamento da radiação solar por gases e partículas presentes na atmosfera................36

III.2 Propriedades microfísicas das partículas de aerossol .....................................................39

III.3 Propriedades ópticas das partículas de aerossol .........................................................40

III.4 Transferência radiativa na atmosfera ......................................................................4

III.5 Sensoriamento remoto de aerossóis por satélite ...........................................................48

IV INSTRUMENTAÇÃO E MÉTODOS EXPERIMENTAIS .................................. 50

IV.1 Sensor MODIS (MODerate Resolution Imaging Spectroradiometer) .................................50

IV.1.1 Descrição do sensor MODIS e seus produtos ....................................................................50

IV.1.2 Algoritmo operacional para a obtenção de profundidade óptica dos aerossóis $\left(\tau_{\alpha}\right.$ ou $\left.A O D\right)$ com resolução espacial de $10 \mathrm{~km} \times 10 \mathrm{~km}$.

IV.2 O radiômetro espectral CIMEL e a rede AERONET .......................................................54

IV.2.1 - Medidas da radiação solar direta e difusa realizadas pelo radiômetro CIMEL ..................55

IV.2.2 - Identificação das observações contaminadas pela presença de nuvens ...........................57

IV.2.3 - Incertezas das observações realizadas pelo radiômetro CIMEL ........................................57 
IV.3 - Modelo de transferência radiativa SBDART (Santa Babara DISORT Atmospheric Radiative Transfer)

V PROFUNDIDADE ÓPTICA DE AEROSSÓIS COM ALTA RESOLUÇÃO ESPACIAL- MÉTODO UTILIZADO ….................................................................60

V.1 Configuração angular do sol e do sensor em relação à região de estudo ............................64

V.2 Determinação da refletância de superfície no comprimento de onda de $2.100 \mathrm{~nm}$............66

V.3 Estimativa da refletância de superfície nos comprimentos de onda de $650 \mathrm{~nm}$ e $470 \mathrm{~nm} .68$

V.4 Determinação de um conjunto de modelos para descrição das propriedades ópticas dos

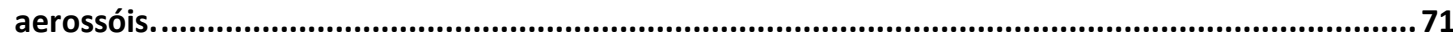

V.4.1 Variabilidade mensal das propriedades ópticas dos aerossóis na região de Ji-Paraná........71

V.4.2 - Análise das propriedades ópticas dos aerossóis na região de Ji-Paraná, no período de

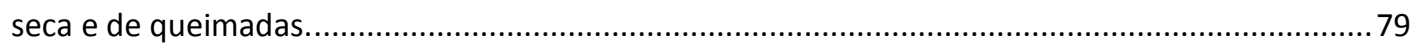

V.4.3 Determinação de um conjunto de modelos ópticos, para descrever os aerossóis da região

de Ji-Paraná. ..................................................................................................................... 87

V.4.4 - Extrapolação espectral das propriedades ópticas utilizadas na construção dos modelos ópticos 91

V.4.5 - Validação dos modelos ópticos de aerossol obtidos para a região de Ji-Paraná ..............92

V.5 Escolha do modelo óptico mais adequado para descrever os aerossóis existentes, em cada dia analisado na região de estudo .96

V.6 Equações de inversão - profundidade óptica dos aerossóis como função da radiância medida pelo sensor MODIS no topo da atmosfera

VI PROFUNDIDADE ÓPTICA DE AEROSSÓIS COM ALTA RESOLUÇÃO ESPACIAL - EXEMPLOS.

VII VALIDAÇÃO DOS VALORES DE PROFUNDIDADE ÓPTICA DOS AEROSSÓIS COM ALTA RESOLUÇÃO ESPACIAL.

CONCLUSÕES.

SIGLAS

BIBLIOGRAFIA. .125

APÊNDICE - A: PUBLICAÇÃO 139 


\section{INTRODUÇÃO}

A Amazônia é a região compreendida pela bacia do rio Amazonas com cerca de $6.900 .000 \mathrm{~km}^{2}$, sendo que mais da metade deste território situa-se em território brasileiro (Becker et al., 2001). A floresta amazônica concentra cerca de 10\% de todo o carbono presente nos ecossistemas terrestres, recicla em torno da metade da água da precipitação que ocorre sobre ela e é o quinto maior habitat de espécies vegetais e animais (Cox et al., 2008; Nepstad et al., 2008). Esses expressivos números fazem da Amazônia uma peça fundamental para preservação da biodiversidade e manutenção do sistema climático terrestre (Davidson e Artaxo, 2004).

A criação da Amazônia Legal foi estabelecida no artigo 2 da lei $n^{\circ} 5.173$, de outubro de 1966. Incentivos à ocupação da floresta amazônica criados pelo governo federal brasileiro propiciaram o aumento da intervenção antropogênica (Becker et al., 2001), como ilustra a Figura I.1. Composta por 9 estados brasileiros (Acre, Amapá, Amazonas, Mato Grosso, Pará, Rondônia, Roraima, Tocantins, parte do Maranhão e cinco municípios de Goiás), a Amazônia Legal representa 59\% do território brasileiro, distribuído por 775 municípios, onde viviam em 2000, segundo o censo demográfico do IBGE, $12,32 \%$ da população nacional. Sendo que $68,9 \%$ desse contingente residem nas zonas urbanas.

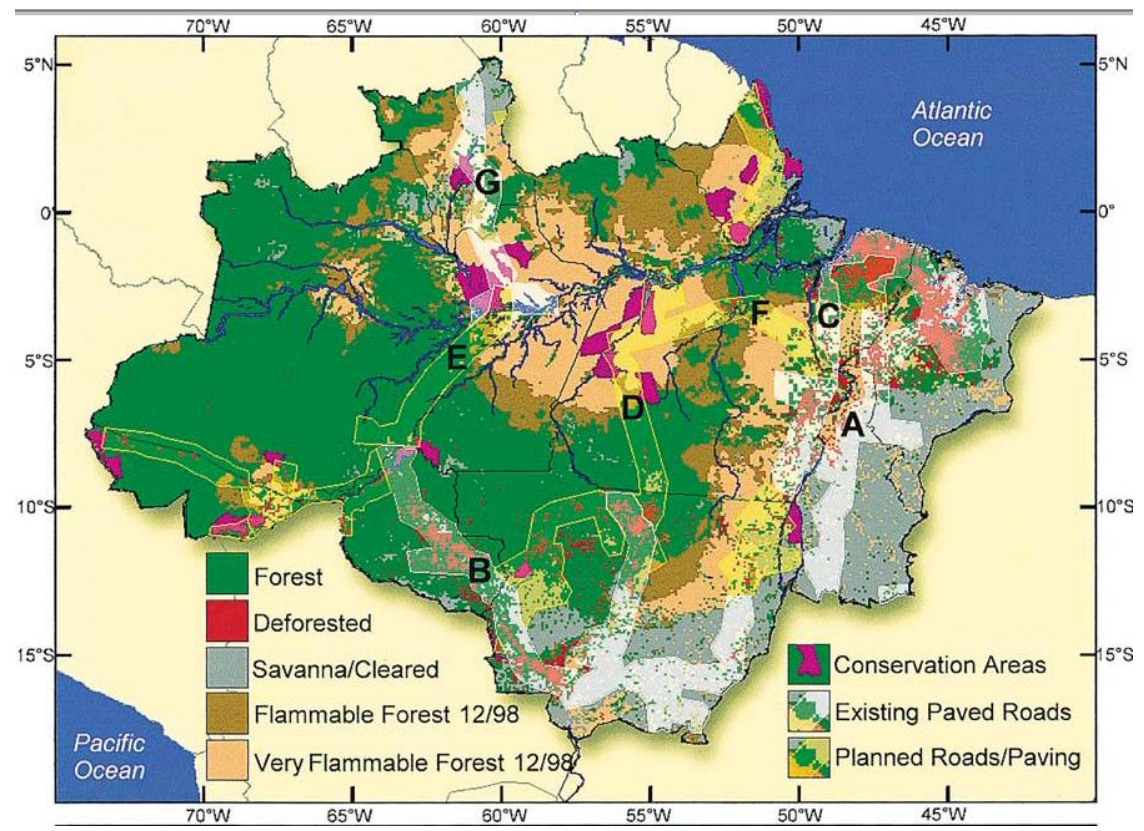

Figura I.1:Mapa da Amazônia Legal, mostrando regiões de floresta preservada, regiões desmatadas, e estradas na Amazônia (existentes e em projeto), ao redor das quais se encontram as maiores áreas de desmatamento (Nepstad et al., 2001). 
A queima da floresta foi, desde o início da sua ocupação, a forma mais utilizada para sua conversão em áreas agrícolas e de pastagens (Pereira e Setzer, 1993, Artaxo, 2008). Esse mecanismo de remoção da floresta é danoso, pois além de reduzir a cobertura vegetal, reduzindo a biodiversidade local, as queimadas podem aumentar em até oito vezes a quantidade de aerossóis (partículas líquidas e/ou sólidas em suspensão na atmosfera - uma descrição detalhada é feita no item I.2) e gases traços na atmosfera (Bowman et al., 2009). O aumento da concentração de aerossóis atmosféricos pode influenciar importantes mecanismos naturais, como o balanço radiativo regional (Schafer et al., 2002; Satheesh e Moorthy, 2005; Procópio et al., 2004) e os mecanismos de formação e desenvolvimento de nuvens (Andreae et al., 2004, 2008, Martin et al., 2009).

Atualmente, o desflorestamento concentra-se no chamado arco do desmatamento, que é essencialmente a área ao sul e leste da Amazônia. Na qual se localizam municípios do sudeste do Acre, de Rondônia, do norte de Mato Grosso, sul e leste do Pará e oeste do Maranhão. De acordo com o INPE (Instituto Nacional de Pesquisas Espaciais) e o IBAMA (Instituto Brasileiro do Meio Ambiente e dos Recursos Naturais Renováveis), a expansão da fronteira agrícola e da atividade econômica tem ocasionado em geral grandes desmatamentos e queimadas nos últimos anos. A construção de estradas também favorece o processo de desflorestamento (Filho et al., 2004; Nepstad et al., 2001), como pode ser observado na região de Rondônia (Figura I.2), onde a expansão das áreas desmatadas ocorreu em torno da rodovia BR-364 (linha tracejada em vermelho).

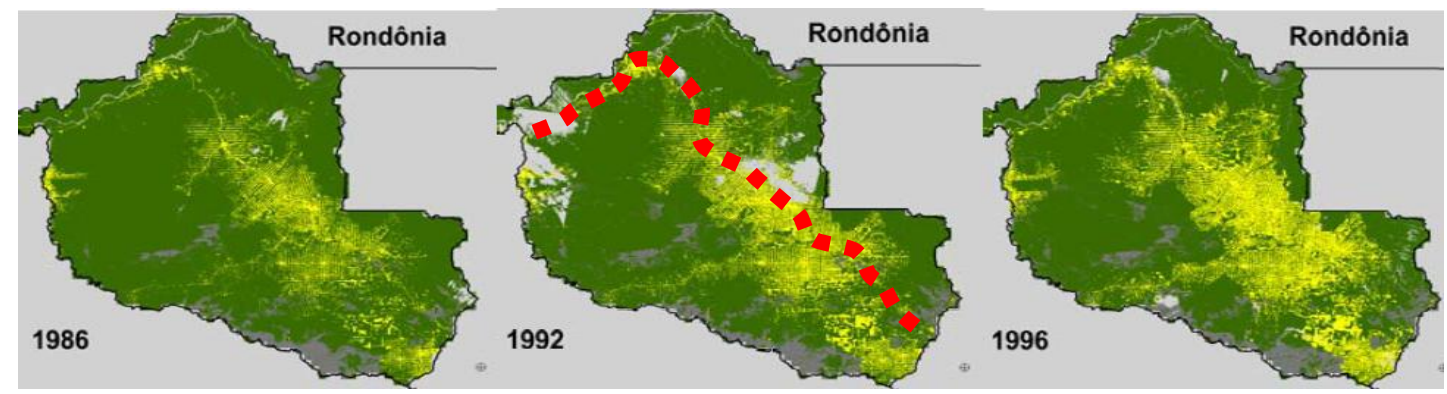

Figura I.2: Mapa da cobertura vegetal do estado de Rondônia, nos anos de 1986, 1992 e 1996. A curva tracejada representa a rodovia BR-364, em torno da qual ocorre a expansão das áreas desmatadas, indicadas em amarelo, INPE.

As expressivas quantidades de aerossóis, emitidos nos eventos de queimada, interferem no balanço radiativo terrestre por meio de efeitos diretos, isto é, absorção e 
espalhamento da radiação solar (Ramanathan et al., 2001), e de efeitos indiretos, isto é, alterações nas propriedades microfísicas das nuvens (Feingold et al., 2003). O efeito indireto tem o potencial de alterar as taxas de precipitação e o ciclo hidrológico regional (Koren et al., 2004). Os efeitos diretos e indiretos dos aerossóis serão discutidos no item I.2.1. Além disso, devido à intensa atividade convectiva observada na região, os aerossóis emitidos nas queimadas estão sujeitos ao transporte em larga escala, ampliando a interferência no balanço radiativo a escalas regionais e globais (Andreae et al., 2001; Freitas et al., 2000 e 2005)

O sensoriamento remoto por satélite com alta resolução espacial e temporal é uma ferramenta indispensável no monitoramento de áreas extensas como a região Amazônica, conforme Martins, 1999. Contribuindo assim para a ampliação do entendimento dos efeitos diretos e indiretos dos aerossóis e os impactos destes efeitos no clima regional e global (Schafer et al., 2008). Atualmente, entretanto, a baixa resolução espacial é uma grande limitação dos produtos de sensoriamento remoto. A proposta deste trabalho vai, portanto, ao encontro de diminuir essa limitação, pois um de seus objetivos é obter valores de profundidade óptica dos aerossóis, que é uma grandeza indicativa da quantidade e da eficácia da matéria oticamente ativa na direção observada, vide item III.4, com resolução espacial inferior à obtida operacionalmente pela NASA $(10 \mathrm{~km} \times 10 \mathrm{~km})$. Isso será feito por meio da adaptação para região amazônica da metodologia desenvolvida por Castanho, 2005 para a região metropolitana de São Paulo. Assim como o produto operacional da NASA, a metodologia empregada neste trabalho utiliza as observações de radiância realizadas pelo sensor MODIS. 


\section{l.1.1 Climatologia da região amazônica}

A região Amazônica está situada próximo ao Equador e, portanto a intensidade de radiação solar recebida é alta durante o ano todo. O clima é caracterizado por temperaturas médias elevadas, baixa amplitude térmica e por um ciclo hidrológico bastante ativo (Fish et al., 1996). Estudos realizados em Rondônia entre 1991 e 1996 (Feitosa et al., 1998; Culf et al., 1996) revelaram que embora a radiação solar no topo da atmosfera seja em média $20 \%$ maior na estação chuvosa em relação à seca, essa variação não é observada na superfície, seja em áreas de pastagens ou de floresta. Logo, a energia que chega é superfície é fortemente relacionada com a variação da nebulosidade, que por sua vez depende da umidade do ar e dos processos termodinâmicos de formação de nuvens (Salati et al., 2001). Durante a estação chuvosa há um aumento da nebulosidade proveniente da migração da convecção Amazônica de sudeste/noroeste, aumentando assim a quantidade de radiação que é retro-espalhanda (Horel et al., 1989). Parte da energia incidente na superfície retorna à atmosfera, de acordo com a quantidade de umidade disponível e do albedo da superfície e de duas formas: sob a forma de calor sensível, que representa aproximadamente $25 \%$ e causa aquecimento do ar, ou sob a forma de calor latente por meio da evapotranspiração, que contribui com aproximadamente $75 \%$ (Fish et al.,1996).

O regime hidrológico na região Amazônica apresenta uma clara divisão entre a estação seca e chuvosa. Entretanto, o início e o fim de cada estação podem variar de acordo com a região da floresta Amazônica, pois ocorre um deslocamento do sudeste para o noroeste do Centro de Máxima Precipitação (CMP). O CMP de dezembro a fevereiro concentra-se na parte central e sul da floresta e de julho a agosto desloca-se para noroeste, dando lugar ao período de seca na região centro e sul a partir de setembro (Fish et al.,1996).

A posição da Zona de Convergência Intertropical parece estar relacionada com esse deslocamento, devido à migração do CMP da parte central do Brasil no verão, para o setor noroeste da América do Sul no inverno, acompanhando a migração anual da convecção profunda (Marengo et al., 1995). De acordo com Rao e Hada (1990), estações experimentais localizadas no Hemisfério Norte, como Oiapoque $\left(3^{\circ} \mathrm{N}, 60^{\circ} \mathrm{W}\right)$, exibem o máximo de chuvas durante o inverno austral (junho, julho e 
agosto) e o mínimo durante o verão austral (dezembro, janeiro e fevereiro). A variabilidade espacial da precipitação amazônica pode ser observada na Figura I.3 .

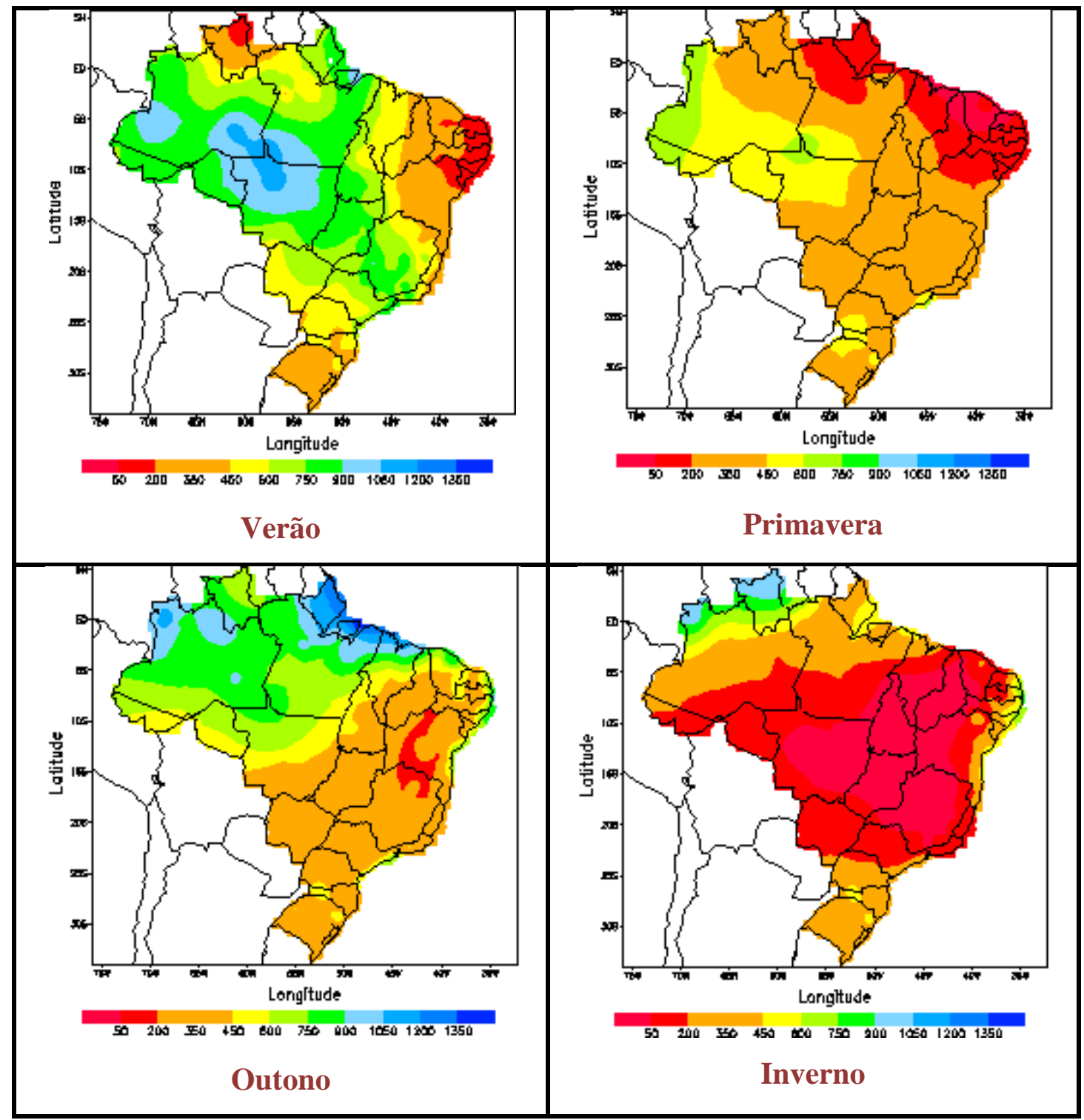

Figura I.3: Climatologia de precipitação acumulada no Brasil para as quatro estações do ano: verão (dezembro, janeiro, fevereiro, março); outono (março, abril, maio, junho); inverno (junho, julho, agosto, setembro); primavera (setembro, outubro, novembro, dezembro), realizada durante o período de 1961 a 1990. Fonte: INMET - Instituto Nacional de METeorologia.

Os altos índices de precipitação, cerca de $1.500 \mathrm{~mm} / \mathrm{ano}$ na parte leste a $3.500 \mathrm{~mm} / \mathrm{ano}$ na parte oeste e nordeste, fazem com que o fluxo de calor latente, por meio da condensação da umidade na coluna troposférica, seja duas vezes mais eficiente que o fluxo ascendente de calor sensível (Satyamurty et al., 1998). 
A água que retorna à atmosfera é responsável por cerca de $50 \%$ da precipitação na região, sendo majoritariamente constituída pela evaporação da água retida nas folhas (aproximadamente 40\%) e pela transpiração (aproximadamente 60\%) (Fish et al., 1996). O restante da precipitação é proveniente do transporte de umidade do oceano Atlântico, por meio dos ventos alísios (Malhi et al., 2002; Salati e Marques et al., 1984). Resumidamente, temos o vapor d'água vindo do oceano Atlântico tropical que provoca precipitação ao entrar pela costa norte. Parte da água precipitada retorna à atmosfera pelo processo de evapotranspiração, e juntamente com o vapor residual vindo do oceano, alimentam o ciclo de precipitação no interior do continente e parte é drenada para os igarapés (Salati et al., 2001).

A densa cobertura vegetal e a quantidade de calor latente liberado por meio da condensação de vapor d'água são fatores que se somam à alta incidência de radiação solar, gerando assim elevadas temperaturas médias, entre $24^{\circ} \mathrm{C}$ e $26^{\circ} \mathrm{C}$. Devem ser consideradas, entretanto, as implicações geradas pela alteração da cobertura vegetal por exemplo, a conversão de florestas em pastagens (Silva Dias et al., 2005). Nobre e colaboradores (1996) observaram que a absorção da radiação pela superfície é $11 \%$ maior em áreas de floresta em relação às áreas de pastagens. Devido à diferença de cobertura vegetal, as áreas de pastagens apresentam menor fluxo de calor latente (menos transpiração) e maior fluxo de calor sensível, o que causa um aumento na amplitude térmica diária (Von Randow et al., 2004; Priante-Filho et al., 2004). Essa mudança na cobertura vegetal pode aumentar em até $60 \%$ a altura da camada de mistura na estação seca (Fisch et al., 2004).

A alternância entre períodos de maior e menor atividade convectiva na Amazônia é associada às forçantes globais, que por sua vez são relacionadas ao padrão de circulação geral da atmosfera. Os principais sistemas meteorológicos que atuam na climatologia da precipitação da região Amazônica são: Zona de Convergência Intertropical (ZCIT), El Niño, Alta da Bolívia (ABO) e Linhas de Instabilidade (Lis) (Marengo, 2005). 


\section{I.1.2 Desflorestamento e queimadas na região amazônica}

O desmatamento da região Amazônica ocorre predominantemente nas fronteiras das regiões agrícolas e de pastagem, nos estados que compõem o chamado arco do desflorestamento. De acordo com a Figura I.4, a taxa de desmatamento anual observada em toda Amazônia legal até 2004 apresentou uma forte tendência de crescimento, chegando a somar uma área próxima ao estado de Minas Gerais. A partir de 2004 observou-se uma sensível redução na taxa de desmatamento, conservando, entretanto expressivos números absolutos.

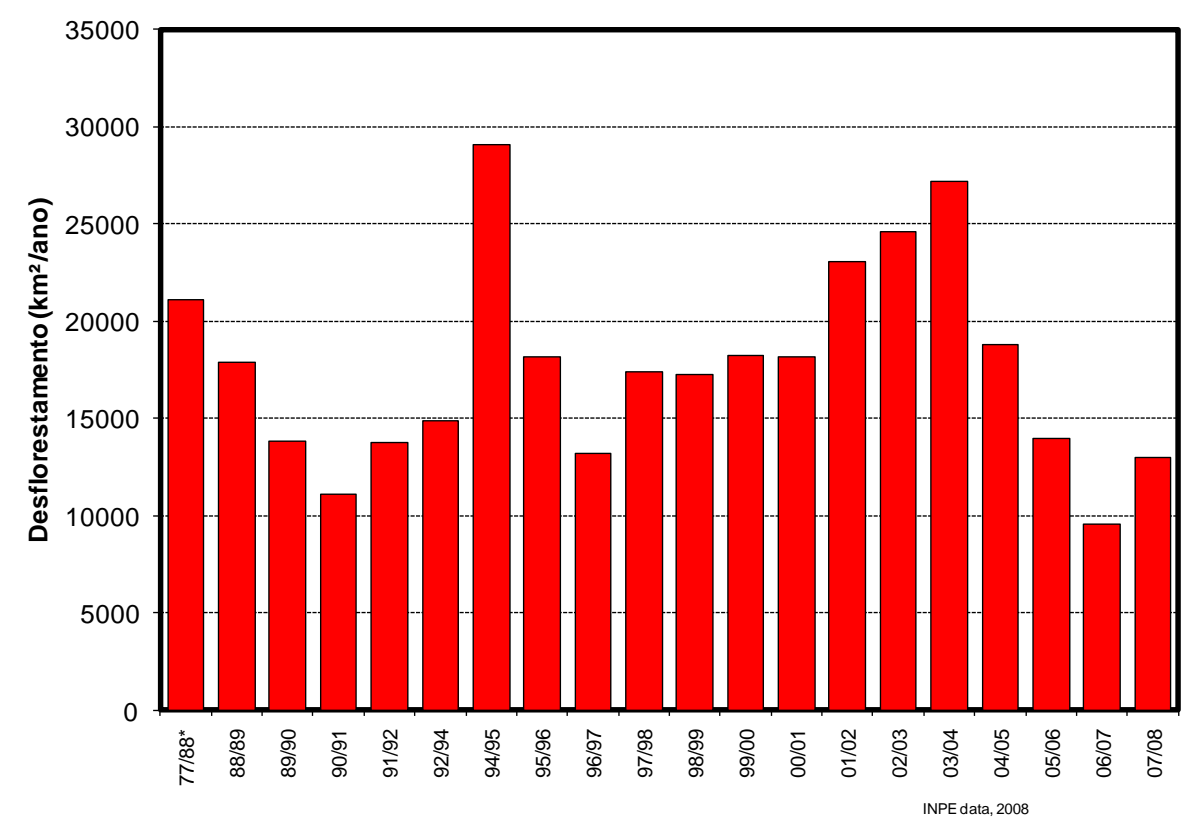

Figura I.4: Taxa de desmatamento anual na Amazônia no período de 1977 a 2008. Fonte: INPE (Instituto Nacional de Pesquisas Espaciais) /CPTEC (Centro de Previsão do Tempo e Estudos Climáticos) (2008).

Os eventos de queimadas ocorrem principalmente no final da estação seca. A variabilidade anual do número de focos está relacionada tanto a fatores antropogênicos, como por exemplo, circunstâncias sócio-econômicas, quanto a fatores naturais, tais como temperatura, cobertura de nuvens, e umidade do ar (Nepstad et al., 1999). Estes fatores naturais podem, portanto gerar focos de queimadas além de ampliar as dimensões dos focos de origem antropogênica. Além dos óbvios prejuízos ambientais, as queimadas podem causar danos econômicos, como atingir áreas de fazendas ou impossibilitar as atividades dos aeroportos. No âmbito social, as queimadas podem ocasionar doenças respiratórias (Motta et al., 2002; Nepstad et al., 1999). 
As queimadas são eventos dinâmicos, que dependem de vários fatores, como por exemplo, o tipo de combustível presente na floresta, a umidade da madeira, as condições meteorológicas. As queimadas podem ser divididas basicamente em duas etapas, conhecidas como flaming e smoldering. A primeira fase (flaming) caracterizase por temperaturas elevadas, chamas intensas e alta eficiência de combustão, liberando principalmente dióxido de carbono $\left(\mathrm{CO}_{2}\right)$ e compostos oxigenados. A segunda fase (smoldering) apresenta grande redução na eficiência de combustão e caracteriza-se pela ausência de chamas e temperaturas mais baixas. Nesta fase ocorre a liberação majoritária de material particulado, em especial o carbono elementar (black carbon é um aerossol altamente absorvedor de radiação, resultante principalmente da queima de biomassa) e produtos de combustão incompleta, com o monóxido de carbono (CO). O CO possui uma vida média da ordem de algumas semanas e por isso é comumente utilizado como traçador de queima de biomassa e para definir a razão entre as duas fases da queimada (Edwards et al.,2004). 


\section{I.2 Aerossóis}

Aerossóis atmosféricos são partículas líquidas e/ou sólidas em suspensão na atmosfera (Seinfeld e Pandis, 1998). Os aerossóis podem ser de origem natural ou antropogênica, sendo emitidos de forma direta (emissão primária) ou produzidos indiretamente (aerossóis secundários). Como exemplos de aerossóis primários, podemos citar: aerossóis marinhos, poeira de solo, emissões vulcânicas e partículas biogênicas. Os aerossóis secundários são produtos da conversão de gases em partículas. Este processo dá-se pela condensação de precursores gasosos (dióxido de enxofre, compostos orgânicos voláteis e outros) sob condições ambientais específicas (Seinfeld e Pandis, 1998).

A dimensão dos aerossóis atmosféricos abrange um largo espectro de tamanho, desde alguns nanômetros até centenas de mícron. Para facilitar a compreensão de suas propriedades físico-químicas, estas partículas são dividas em faixas de tamanho, de acordo com seu diâmetro $\left(\mathrm{D}_{\mathrm{p}}\right)$ conforme descrito a seguir:

- Moda fina $\mathrm{D}_{\mathrm{p}}<2,5 \mu \mathrm{m}$ :

- Moda de nucleação $\left(\mathrm{D}_{\mathrm{p}}<30 \mathrm{~nm}\right)$ : constituída por aerossóis secundários produzidos por precursores gasosos;

- Moda de Aitken $\left(30<\mathrm{D}_{\mathrm{p}}<120 \mathrm{~nm}\right)$ : constituída por aerossóis primários e pela coagulação ou condensação de aerossóis secundários;

○ Moda de acumulação $\left(\sim 80<\mathrm{D}_{\mathrm{p}}<\sim 1000 \mathrm{~nm}\right)$ : constituída principalmente por aerossóis da moda de Aitken que sofreram processos de crescimento tais como coagulação e condensação (Hoppel et al., 1994).

- Moda grossa. $\mathrm{D}_{\mathrm{p}}>$ 2,5 $\mu \mathrm{m}$ : constituída principalmente de partículas primárias de solo, biogênicas e marinhas.

Deste modo, os diâmetros que delimitam as modas de Aitken e de acumulação podem sobrepor-se, conforme esquematiza a Figura1.6. Considerando um volume constante de partículas, a distribuição de número é dominada pela moda fina, enquanto que a distribuição de volume (ou massa) é dominada pelos aerossóis na moda grossa. 


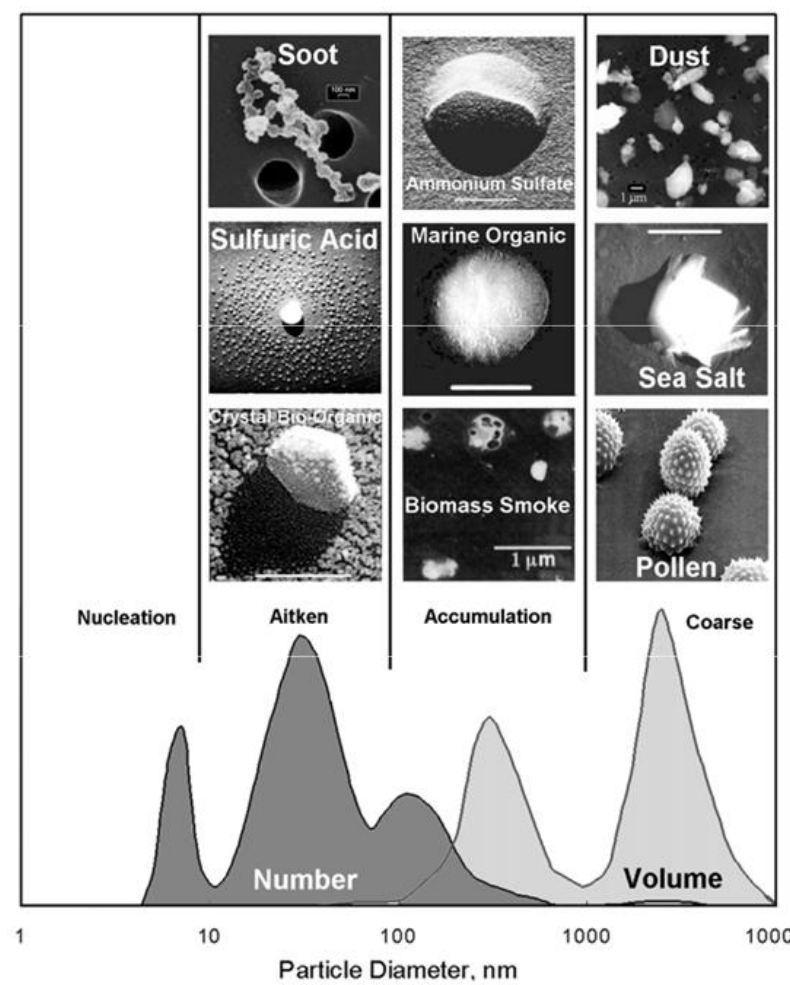

Figura I.5: Típica distribuição de tamanho de aerossóis divida em duas modas principais: fina e grossa. A moda fina é comumente subdivida em moda de nucleação, Aitken e acumulação, Brasseur et al., 2003.

Para uma caracterização quantitativa da distribuição de tamanho, é necessária a utilização de métodos matemáticos. A distribuição lognormal, isto é, a distribuição gaussiana sobre uma escala logarítmica, é uma das funções matemáticas que melhor se ajusta às modas dos aerossóis atmosféricos (Hinds et al., 1999) (vide capítulo III.1).

A composição e o tamanho dos aerossóis na atmosfera podem ser alterados por meio de reações químicas, coalescência e coagulação com outros aerossóis, evaporação ou condensação de vapores, ou mesmo por ativação de gotas de nuvens (Raes et al., 2000), conforme explicitado na Figura I.6. Desertos, por exemplo, emitem principalmente partículas de poeira. As partículas de sulfato por sua vez são típicas de regiões industrializadas.

A população de partículas pode ser caracterizada como uma "mistura externa", onde cada partícula individual apresenta morfologia e composição similar às partículas primárias, ou como uma "mistura interna", quando uma única partícula é constituída por uma mistura de várias outras partículas (Seinfeld e Pandis, 1998). 


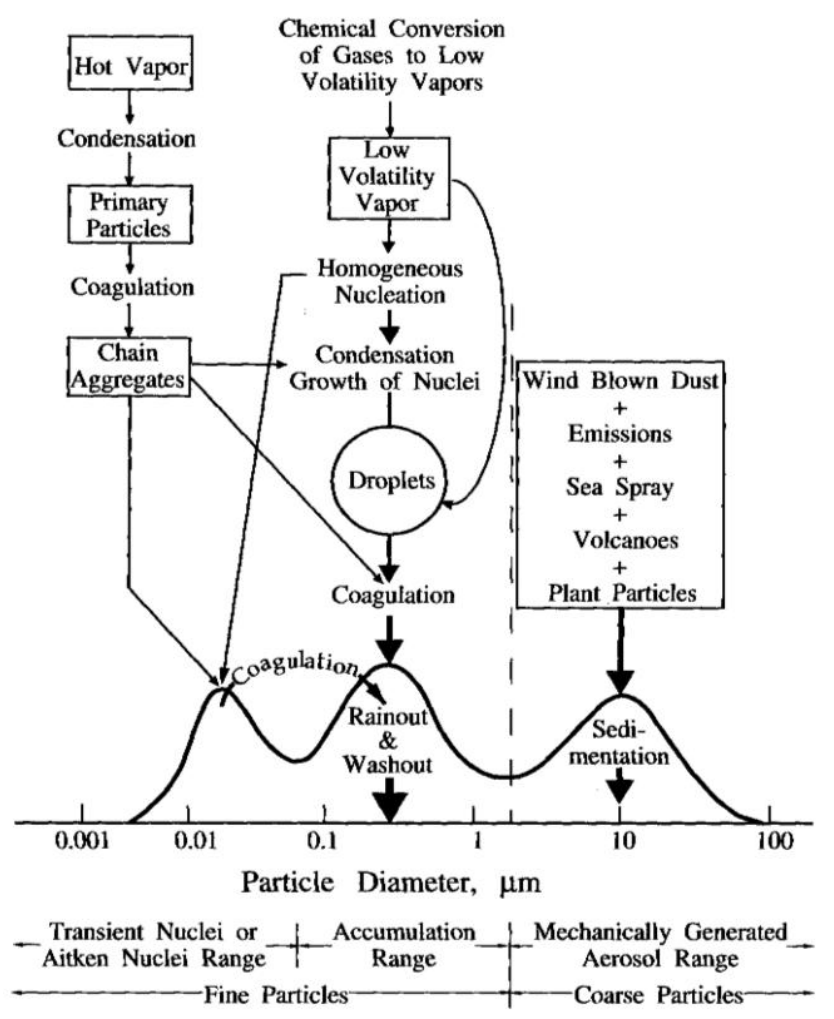

Figura I.6: Exemplo de
distribuição de tamanho de
partículas, mostrando os
principais
físicos-químicos envolvidos na
formação e remoção de
aerossóis da atmosfera
(Seinfeld e Pandis, 1998).

Os aerossóis interagem com a radiação solar espalhando-a e/ou absorvendo-a. A interação da radiação solar com a atmosfera em geral, e em especial com os aerossóis, será discutida em detalhe no capítulo III.1.

O tempo de residência dos aerossóis na atmosfera pode variar de horas a semanas (Seinfeld e Pandis, 1998). A remoção de partículas da atmosfera pode ocorrer de forma seca ou úmida (Figura I.6). A deposição seca pode ocorrer por sedimentação e impacto, processos mais eficientes na moda grossa, ou por difusão turbulenta, processo mais eficiente na moda de nucleação (Wesely e Hicks, 2000; Gallagher et al., 2002). A deposição úmida, por sua vez, ocorre quando as partículas de aerossóis são incorporadas por gotas de nuvens ou nevoeiros, ou quando são removidas por eventos de precipitação (Flossmann et al., 1985; Alheit et al., 1990; Williams e Fisher, 1997). A deposição úmida é eficiente para remoção de partículas da moda grossa e de acumulação. A remoção por meio da precipitação pode ocorrer tanto no interior das nuvens pelo processo de nucleação (washout), quanto fora das nuvens, pelo evento da precipitação em si, que promove a limpeza da atmosfera por meio da interceptação das partículas em suspensão (rainout) (Seinfeld e Pandis, 1998). 


\section{I.2.1 Efeitos dos aerossóis no clima}

Os aerossóis podem ocasionar mudanças climáticas por meio da absorção e espalhamento da radiação solar (efeitos diretos) alterando o balanço de radiação, ou atuando como núcleo de condensação de nuvens (efeitos indiretos), modificando a microfísica das nuvens (Artaxo e Andreae, 2007).

Efeitos Diretos dos aerossóis: A eficiência em espalhar a luz solar é tanto maior quanto mais próximo for o comprimento de onda da luz incidente do tamanho da partícula. Deste modo, os aerossóis da moda fina são oticamente mais ativos do que os da moda grossa (Liou, 2002), conforme será discutido no capítulo III. Adicionalmente, a capacidade de absorver a radiação solar está intimamente ligada ao estado de mistura (interno ou externo) dos componentes não absorvedores dos aerossóis, assim como à fração de black carbon presente (Dubovick et al., 2002; Jacobson et al., 2001).

A quantificação dos efeitos diretos dos aerossóis é realizada por meio de medidas de propriedades ópticas das partículas, tais como: albedo simples de espalhamento $\left(\omega_{0}\right)$, coeficiente de extinção $\left(\mathrm{k}_{\mathrm{e}}\right)$ e função de fase $(\mathrm{P})$. Essas propriedades são funções do comprimento de onda da radiação solar incidente e da umidade relativa (Ramaswamy et al., 2001). No balanço entre absorção e espalhamento da radiação solar devido à interação com os aerossóis, o espalhamento é o fenômeno predominante (Procópio et al., 2004), resultando em uma forçante radiativa negativa. As propriedades ópticas citadas serão apresentadas detalhadamente no item III.1.

Forçante radiativa é a mudança líquida da irradiância solar no topo da atmosfera ocasionada por perturbações externas impostas no balanço de energia radiativa do sistema climático terrestre (medida em W.m ${ }^{-2}$ ) (Forster et al., 2007, IPCC, 2007 - capítulo 7). Quando a forçante é negativa a perturbação resulta em um resfriamento, e quando é positiva resulta em um aquecimento. Deste modo, as forçantes são utilizadas na estimativa dos impactos climáticos causados pelo desequilíbrio do balanço de energia radiativa.

Efeitos climáticos indiretos dos aerossóis: Os efeitos indiretos dos aerossóis no clima estão ligados à capacidade de atuarem como núcleo de condensação de nuvens (do inglês Cloud Condensation Nuclei: $C C N$ ) (Freud et al., 2008). Através desse processo, os aerossóis influenciam propriedades microfísicas das nuvens, com 
possíveis efeitos nas taxas de precipitação, tempo de permanência na atmosfera e no albedo das nuvens. (Kaufman et al., 2002; Sekiguchi et al., 2003).

O primeiro efeito indireto dos aerossóis, postulado por Twomey, 1977, referese ao aumento do albedo das nuvens para um acréscimo do número de $C C N$, com o conteúdo de água líquida (do inglês liquid water content: $L W C$ ) fixo. Ocasionando a diminuição do raio efetivo das gotas, o que por sua vez gera um aumento do albedo destas, conforme esquematizado na Figura I.7 .

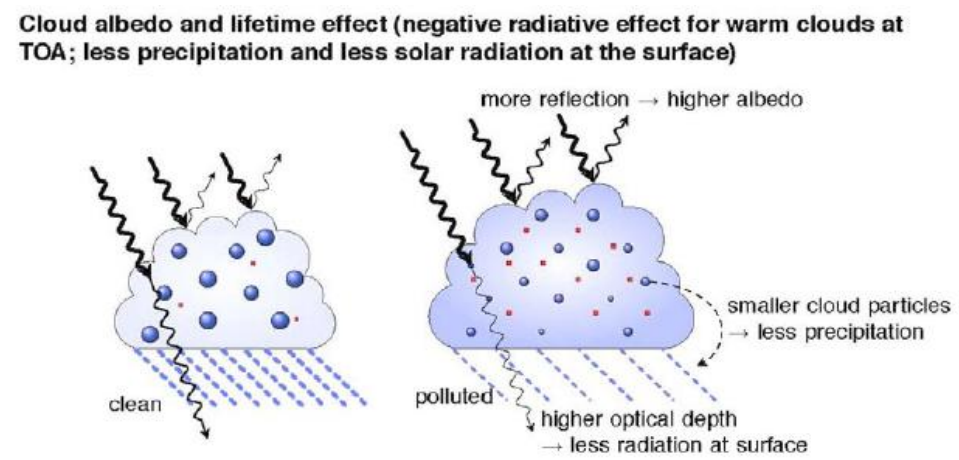

Figura 1.7: llustração do primeiro efeito indireto dos aerossóis no clima, alterando o albedo das nuvens.

O segundo efeito climático indireto dos aerossóis consiste na redução da precipitação como conseqüência do primeiro efeito indireto, e pode ser observado em escala local, tanto remotamente como com medidas in-situ. A diminuição do raio efetivo das gotas (primeiro efeito indireto) inibe o processo de coalescência, podendo aumentar a área coberta por nuvens e o tempo de vida destas na atmosfera (Lebsock et al., 2008).

Estudos apontam que tanto os efeitos climáticos diretos dos aerossóis quanto os indiretos resultam em uma forçante radiativa negativa na superfície (IPCC, 2007). Forçantes radiativas negativas resfriam a superfície, em contrapartida ao aquecimento gerado pelo efeito estufa. A elevada complexidade dos processos de transporte dos aerossóis, e de suas propriedades químicas e ópticas torna o acoplamento dos efeitos direto e indireto dos aerossóis de difícil determinação (Sekiguichi et al., 2003). Deste modo, com o objetivo de reduzir as incertezas da forçante radiativa dos aerossóis se faz necessário obter os parâmetros utilizados no seu cálculo com a maior precisão possível. Este trabalho por sua vez, contribui com a redução da incerteza da forçante radiativa, pois tem como um de seus objetivos o aprimoramento do produto para obtenção de $A O D$ a partir de observações de sensores em satélites e também o aumento da resolução espacial da $A O D$. 


\subsubsection{Aerossóis na bacia amazônica}

Os aerossóis da Amazônia são oriundos principalmente de emissões primárias da própria floresta, de queimadas e de ressuspensão de poeira do solo (Artaxo et al., 1998, 1990, 1988). A contribuição de cada fonte varia espacial e temporalmente de acordo com as características de cada região, podendo haver predominância de aerossóis naturais ou antropogênicos.

Contribuição Natural: Relevante durante a estação chuvosa e em áreas nas quais as atividades antropogênicas são pequenas. Os aerossóis de origem natural são provenientes de emissões da floresta, poeira de solo e aerossol marinho (proveniente de transporte de longas distâncias) (Longo, 1999; Yamasoe, 1999; Artaxo et al., 1990). Na estação chuvosa, os aerossóis biogênicos provenientes de emissões primárias representam de 55 a $95 \%$ do material particulado em suspensão. Cerca de $70 \%$ desta fração encontram-se na moda grossa, (Artaxo et al., 2001) e 90\% desta fração é composta por material orgânico (Guyon et al., 2004, 2003) A moda fina é originada principalmente dos processos de conversão gás-partícula, através da oxidação de compostos orgânicos voláteis (VOCs) (Claeys et al., 2004; Echalar et al., 1998; Andreae e Crutzen, 1997).

Contribuição Antropogênica: Os aerossóis de origem antropogênica são provenientes da queima de biomassa, seja de cerrado, pastagem, florestas primárias e secundárias (Artaxo et al., 1998). Esses processos ocorrem principalmente durante a estação seca (INPE, 2005; Artaxo, 2002) e seus produtos são transportados para toda a América do Sul (Anderson, 1996). As emissões concentram-se na moda fina e são compostas por cerca de $10 \%$ de black carbon, $10 \%$ de compostos inorgânicos e $80 \%$ de compostos orgânicos (Artaxo, 2002; Mayol-Bracero et al., 2002; Graham et al., 2002; Fuzzi et al., 2005).

A fração de Black carbon presente na moda fina pode aumentar até 100 vezes em massa na estação seca em comparação à chuvosa. Aumento relevante também é observado no número total de partículas, que na estação chuvosa gira em torno de 300-600 partículas $/ \mathrm{cm}^{3}$ e na estação seca em geral ultrapassa 20.000 partículas $/ \mathrm{cm}^{3}$ nas áreas próximas aos focos de queimadas (Artaxo et al., 2002, 1998 e 1994; Andreae et al., 2002). 
No período de seca e de queimadas na região amazônica, as altas concentrações de aerossóis emitidos inserem-se na circulação atmosférica cobrindo cerca de 2 a 4 milhões de quilômetros quadrados todos os anos, como foi evidenciado em diversos trabalhos científicos (Freitas, 2005; Artaxo et al., 2002; Andreae et al., 2001; Longo, 1999). A Figura I.8 apresenta uma imagem do sensor MODIS na faixa do visível, na qual foi captada uma pluma de queimadas que se estendeu por uma considerável área da América do Sul.

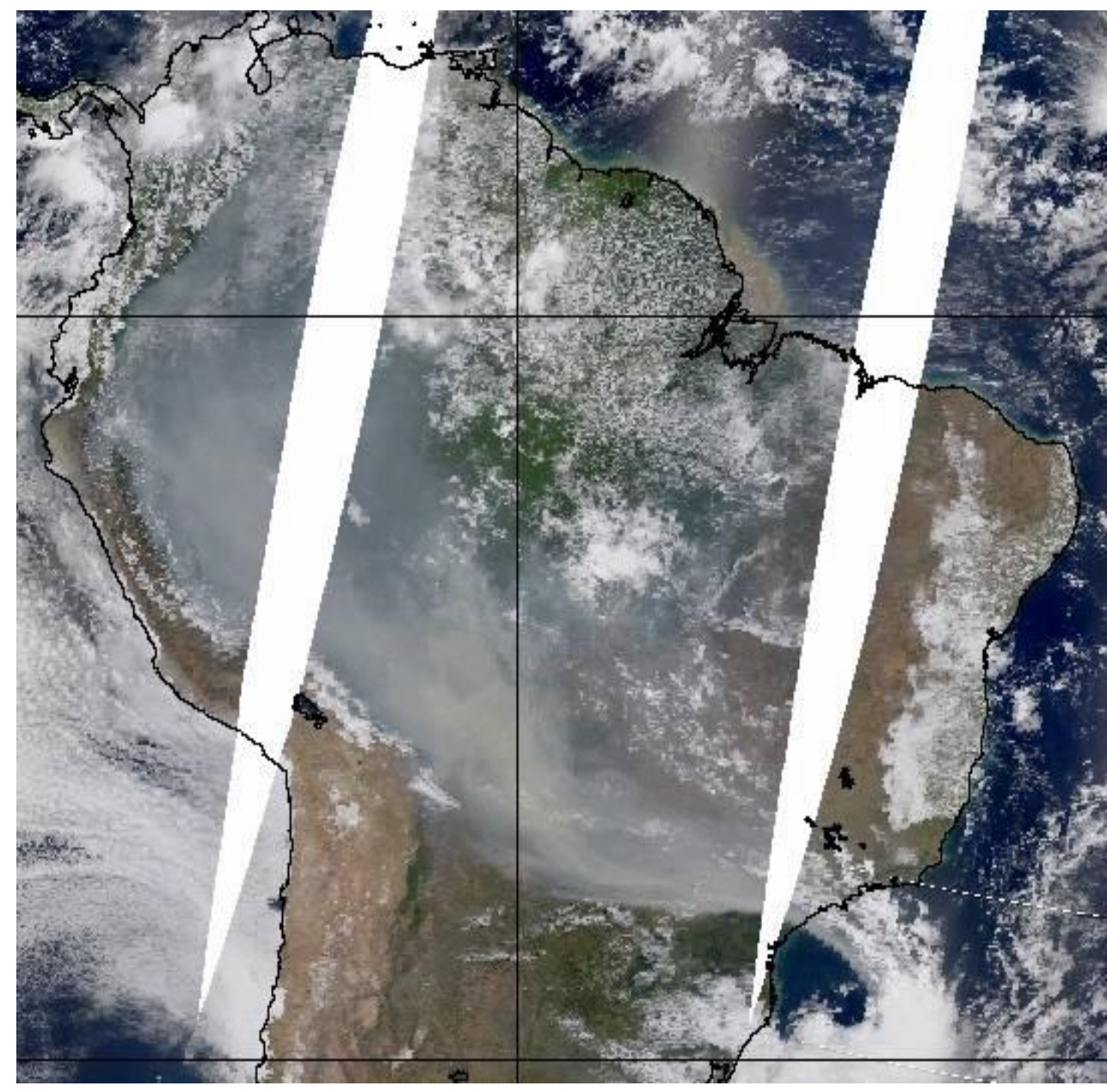

Figura 1.8: Imagem do sensor MODIS, a bordo do satélite TERRA obtida no dia 25 de setembro de 2004, na qual foi captada uma extensa pluma de queimadas, capaz de cobrir vários países da América do Sul.

A distribuição espacial da $A O D$ em $550 \mathrm{~nm}$, obtidas operacionalmente com resolução espacial de $10 \mathrm{~km} \quad \mathrm{x} \quad 10 \mathrm{~km}$, é disponibilizada pela NASA (http://daac.gsfc.nasa.gov/data/dataset/MODIS/). A Figura I.9 (a) e (b) mostra a extensão da pluma de poluentes cobrindo grande parte da região amazônica, região sul e sudeste do Brasil e países da América do Sul. A Figura I.9 (a) ilustra a grande cobertura da pluma de poluentes, que se estende por dimensões continentais, com 
$A O D$ em $550 \mathrm{~nm}$ superior a 0,4 e em torno de 1,2 na região de Rondônia. A Figura I.9 (b) ilustra um caso particular em que a pluma de queima de biomassa passou sobre a região metropolitana de São Paulo. Neste evento, não há valor definido da $A O D$ sobre a região de Rondônia, provavelmente devido à presença de nuvens, pois o fotômetro da rede AERONET não realizou observações, no sítio experimental de Ji-Paraná, com qualidade assegurada neste dia.

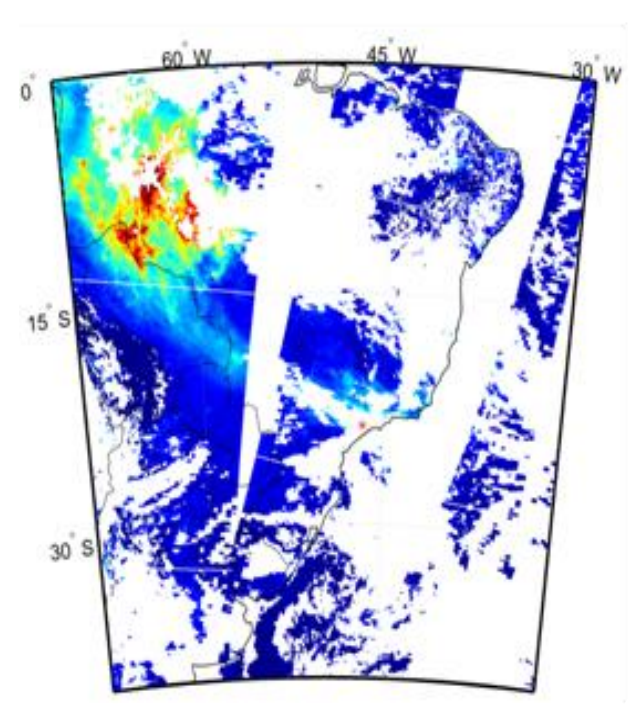

(a)

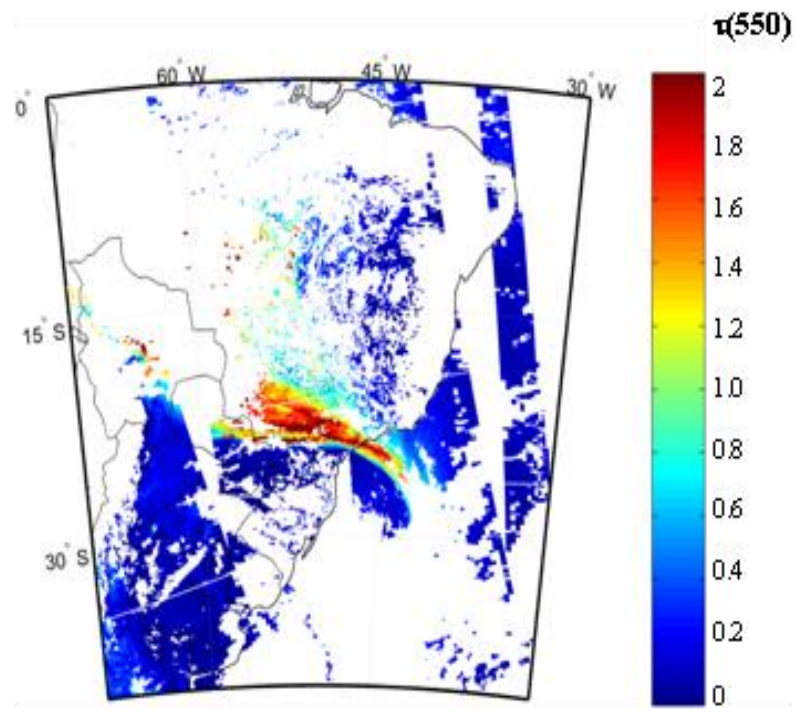

(b)

Figura I.9: Mapa de $A O D$ (550), obtida operacionalmente pelo sensor MODIS, com resolução espacial de $10 \mathrm{~km} \times 10 \mathrm{~km}$ sobre o Brasil. Valores de $A O D$ disponibilizados pela NASA, (http://daac.gsfc.nasa.gov/data/dataset/MODIS/. (a) dia 31 de agosto de 2003, imagem obtida pelo sensor MODIS a bordo do satélite TERRA. (b) dia 15 de setembro de 2004, imagem obtida pelo sensor MODIS a bordo do satélite AQUA (Castanho, 2005). 


\section{I.3 Sensoriamento remoto}

O sensoriamento remoto constitui uma técnica para obter informações de propriedades por meio de observações realizadas por instrumentos que não estejam em contato físico com os objetos investigados (Meneses, 2001). O processo envolve a detecção de radiação eletromagnética refletida ou emitida por esses objetos em diferentes comprimentos de ondas.

Existem basicamente duas técnicas de sensoriamento remoto da atmosfera terrestre: o sensoriamento remoto passivo, que mede a interação da radiação solar com os constituintes da atmosfera (gases e partículas) e o ativo, no qual a radiação é emitida em bandas específicas e mede-se a porção desta radiação que é refletida e ou retro espalhada pelos constituintes da atmosfera. Radares e Lidars ("Light Detection and Ranging") são exemplos de equipamentos de sensoriamento remoto ativo. As medidas utilizando o sensoriamento remoto podem ser realizadas na superfície, a exemplo dos radiômetros solares utilizados neste trabalho, por aviões em diferentes altitudes ou ainda por satélites em órbita em torno da Terra, a exemplo do satélite TERRA (item III.5) que será utilizado neste trabalho.

\section{I.3.1 Sensoriamento remoto no monitoramento de aerossóis}

A identificação do grande potencial dos aerossóis como contribuintes para as mudanças climáticas globais impulsionou o desenvolvimento do sensoriamento remoto via satélite, pois esta é a ferramenta de monitoramento dos aerossóis mais eficiente atualmente. Visto o curto tempo de vida dos aerossóis na atmosfera e grande heterogeneidade na sua distribuição espacial vertical e horizontal (Kaufman et al., 2002b; King et al., 2003) e a capacidade do sensoriamento remoto via satélite de realizar varreduras globais diariamente, como é o caso de sensores a bordo do satélite TERRA, que será utilizado nesse trabalho.

Inicialmente, na década de 1970, foram utilizados sensores meteorológicos com bandas espectrais no espectro visível (Griggs, 1975; Fraser, 1976). Posteriormente, descobriu-se a aplicabilidade da radiação ultravioleta para estimar a quantidade de aerossóis altamente absorvedores em superfícies marinhas ou terrestres (Torres et al., 2002). A utilização das longas séries temporais oferecidas por esses sensores para quantificação dos efeitos dos aerossóis nas mudanças climáticas tornase difícil devido às largas bandas espectrais nas quais as observações foram obtidas e 
ao baixo nível de confiança na calibração desses sensores (Tanré et al., 1997; Kaufman et al., 1997a).

O sensor MODIS (MODerate Resolution Imaging Spectroradiometer), presente nos satélites AQUA e TERRA, entre outros, marcaram o início de uma nova geração de sensores, devido à capacidade desses sensores em analisar as propriedades dos aerossóis tanto em áreas continentais quanto oceânicas, com resolução espacial e temporal muito superior a de seus antecessores (Kaufman et al., 2002b). Apesar do grande avanço em relação aos sensores antecessores, o produto para obtenção da $A O D$ a partir das observações realizadas pelo sensor MODIS, descrito em detalhes no item IV.1.2, ainda apresenta limitações de resolução espacial (10 km x $10 \mathrm{~km})$ e em relação aos modelos ópticos empregados. Isso porque em regiões com forte presença de nuvens torna-se muito difícil encontrar uma área de $10 \mathrm{~km}$ x $10 \mathrm{~km}$ livre da presença de nuvens e no cálculo da $A O D$ apenas quatro modelos ópticos de aerossóis são utilizados para descrever o material particulado do globo, sendo que Castanho, 2005 construiu cinco modelos ópticos de aerossóis para descrever o material particulado apenas da região metropolitana de São Paulo.

Os satélites TERRA (lançado em dezembro de 1999) e AQUA (lançado em maio de 2002) possuem órbita síncrona com o Sol e cobertura global a $705 \mathrm{~km}$ de altitude, com horário de passagem respectivamente às 10h30min local e 13h30min do horário local. Conceitos físicos envolvidos no sensoriamento remoto de aerossóis por satélites, e mais especificamente as características do sensor MODIS, a bordo do satélite TERRA, e seus produtos serão apresentados no capítulo IV.1.

Atualmente a NASA possui uma constelação de satélites em órbita, chamada de "A Train", como mostra a Figura I.10. As medidas realizadas por cada um dos componentes desta constelação de satélites são complementares e praticamente simultâneas, formando um conjunto de suma importância para entender e quantificar a influência dos aerossóis e nuvens no clima, com uma precisão jamais conseguida antes. Uma tabela com os sensores disponíveis em cada satélite, bem como as principais medidas realizadas pode ser encontrada no site http://wwwcalipso.larc.nasa.gov/about/atrain.php. 


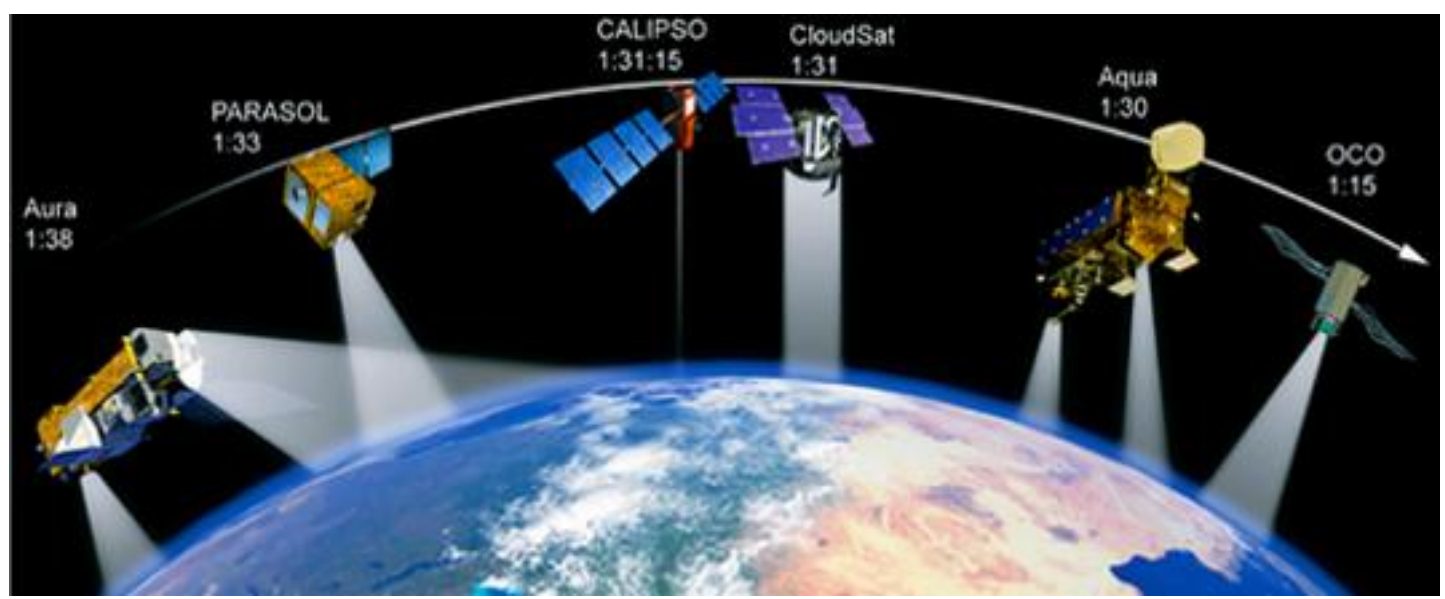

Figura I.10: "A- Train" ou constelação de satélites é formada pelos satélites Aqua, CloudSat, CALIPSO, PARASOL, e missões do satélite da aura. A constelação tem uma altura orbital nominal de 705 quilômetros e uma inclinação de 98 graus. O satélite Aqua conduzirá a constelação com passagem aproximadamente às 13h30min do horário local. A diferença de tempo entre a passagem do satélite Aqua e CloudSat e o CALIPSO é de 1 a 2 minutos permitindo observações quase que instantâneas (FONTE: http://wwwcalipso.larc.nasa.gov/about/atrain.php). 


\section{OBJetivos}

O objetivo deste trabalho consiste em obter a distribuição espacial de aerossóis da região amazônica no período de queimadas, com alta resolução espacial. O método de obtenção de profundidade óptica de aerossóis com alta resolução espacial utilizará observações de radiância, realizadas pelo sensor MODIS, conforme descrito no item IV.1, e de profundidade óptica de aerossóis pelo fotômetro solar da rede AERONET, conforme descrito no item IV.2, realizadas na região de Rondônia. A seguir, são explicitadas as principais etapas a serem seguidas ao longo deste trabalho para que seja atingido o objetivo principal deste trabalho:

- Construir modelos ópticos de aerossóis, para descrever aerossóis de queimadas da região amazônica. Validar a representatividade dos modelos ópticos construídos em descrever tais aerossóis de queimada com a rede de fotômetros solares.

- Adaptar o método para obtenção da profundidade óptica de aerossóis com alta resolução espacial, desenvolvido por Castanho, 2005 para aerossóis urbanos a aerossóis provenientes de queimadas da região Amazônica;

- Validar os valores de profundidade óptica dos aerossóis com alta resolução espacial obtidas, por meio de comparação com medidas de profundidade óptica dos aerossóis realizadas pelo fotômetro solar de superfície CIMEL da rede AERONET, na região de Ji-Paraná-RO.

O desenvolvimento de modelos ópticos de aerossóis específicos para descrever o material particulado da região amazônica na época de queimadas é de suma importância para caracterizar a camada de aerossóis de maneira mais próxima da realidade. A adaptação do método para determinação da profundidade óptica com alta resolução espacial, a partir de observações realizadas pelo sensor MODIS, será seguida de uma validação por meio da comparação medidas em solo, realizadas pelo fotômetro da rede AERONET. É importante explicitar a etapa de validação com medidas de solo, já que os novos algoritmos desenvolvidos devem ser testados antes de serem aplicados em medidas que possam ser úteis do ponto de vista ambiental. 


\section{FUndamENTAÇÃo TEÓRICA}

\section{III.1 Interação da radiação solar com a atmosfera}

O Sol emite radiação eletromagnética em todo o espectro, entretanto, a maior parte da energia emitida está na faixa do visível $(0,4$ a $0,7 \mu \mathrm{m})$. A Figura III.1 mostra o espectro da irradiância solar incidente medida no topo da atmosfera terrestre. A irradiância solar espectral $F_{B}(\lambda)$ (equação III.2) pode ser aproximadamente descrita pela função de Planck em um comprimento de onda $\lambda$ e a uma temperatura $T$ (equação III.1), equivalente à de um corpo negro ${ }^{1}$ à temperatura de $6.000 \mathrm{~K}$.

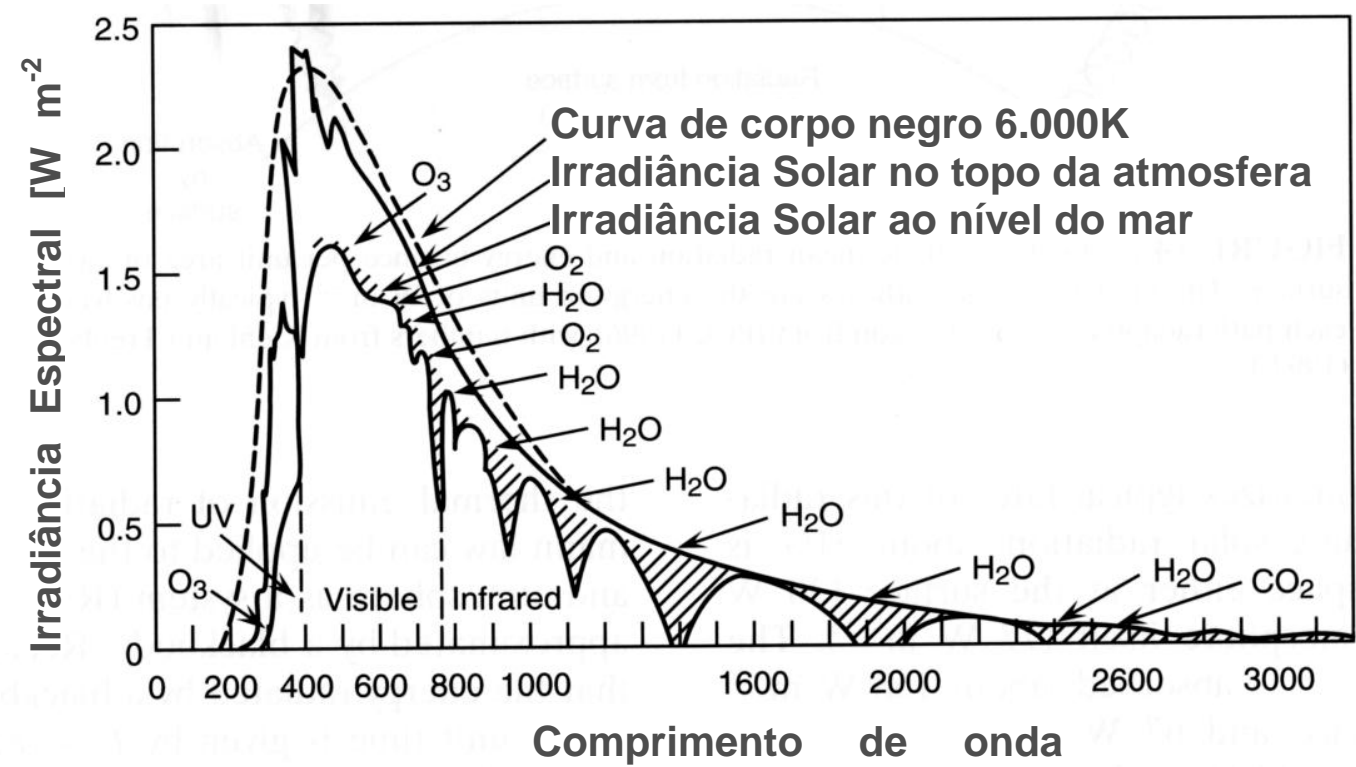

Figura III.1: Irradiância solar espectral no topo da atmosfera e na superfície ao nível do mar. A linha tracejada representa a curva correspondente de corpo negro a uma temperatura média equivalente a $6.000 \mathrm{~K}$. As regiões hachuradas representam as absorções moleculares na atmosfera (como por exemplo, ozônio, vapor de água e dióxido de carbono). Figura adaptada de Seinfeld e Pandis, 1998.

\footnotetext{
${ }^{1} \mathrm{O}$ corpo negro possui a propriedade de absorver e emitir toda a radiação sobre ele incidente, ou seja, possui taxas de emissividade e absortância iguais a 1 .
} 


$$
\begin{aligned}
& \mathrm{B}_{\lambda}(\mathrm{T})=\frac{2 \mathrm{hc}^{2}}{\lambda^{5}[\exp (\mathrm{hc} / \mathrm{k} \lambda \mathrm{T})-1]}\left[W m^{-2} s r^{-1} m^{-1}\right]
\end{aligned}
$$

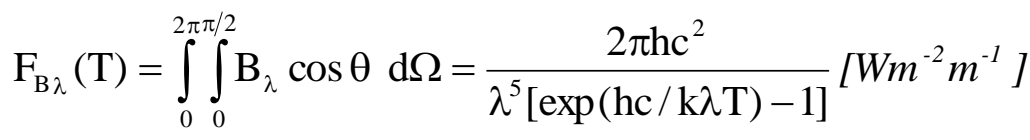

Onde: $\quad \mathrm{c}$ - velocidade da luz no vácuo $\left(\sim 310^{8} \mathrm{~m} \mathrm{~s}^{-2}\right)$;

$\mathrm{h}$ - constante de Planck $\left(6,62610^{-34} \mathrm{~J} \mathrm{~s}\right)$;

$\lambda$ - comprimento de onda $[\mathrm{m}]$;

$\mathrm{k}$ - constante de Boltzmann $\left(1,38110^{-23} \mathrm{~J} \mathrm{~K}^{-1}\right)$;

$\mathrm{T}$ - temperatura do corpo negro $[\mathrm{K}]$.

Considerando a radiação emitida pelo corpo negro como isotrópica, obtém-se a irradiância por meio da integral da radiância no ângulo sólido $\mathrm{d} \Omega=\sin \theta \mathrm{d} \theta \mathrm{d} \varphi$. Desse modo, em um hemisfério, a irradiância equivale a $\pi \mathrm{B}_{\lambda}$. Quando se compara o espectro solar no topo da atmosfera e na superfície terrestre, nota-se uma diminuição da energia incidente na superfície em alguns comprimentos de onda (Figura III.1). Isso ocorre devido à absorção por gases presentes na atmosfera $\left(\mathrm{O}_{3}\right.$, $\mathrm{H}_{2} \mathrm{O}$ ), ao espalhamento Rayleigh por moléculas de $\mathrm{N}_{2}$ e $\mathrm{O}_{2}$, e à absorção e ao espalhamento por partículas de aerossóis.

O espalhamento e a absorção são processos físicos fundamentais associados à luz e sua interação com a matéria, sendo as principais causas de atenuação da radiação na atmosfera. O espalhamento é o processo pelo qual moléculas ou pequenas partículas, com diferentes índices de refração, distribuem parte da energia eletromagnética em todas as direções. A absorção é um processo físico no qual a energia eletromagnética incidente é absorvida por gases ou partículas e convertida em outras formas de energia (térmica, por exemplo). A forma como as vibrações eletrônicas ocorrem no interior da matéria determinam as propriedades de absorção e espalhamento por partículas de aerossol e moléculas de gases. 


\section{III.1.1 Absorção da radiação solar por gases presentes na atmosfera}

Os constituintes majoritários da atmosfera, $\mathrm{N}_{2}$ e $\mathrm{O}_{2}$ (Seinfeld e Pandis, 1998), são pouco absorvedores de radiação solar, enquanto que alguns dos constituintes minoritários são eficientes absorvedores dela, como mostra a Figura III.2. Por exemplo, o $\mathrm{O}_{2}$ e o ozônio estratosférico absorvem 100\% da radiação abaixo de 290 $\mathrm{nm}$; o vapor de água e o dióxido de carbono absorvem grande parte da radiação terrestre (infravermelho termal). Essas faixas de absorção são essenciais para a manutenção da vida terrestre, pois, respectivamente, impedem a passagem de radiação ultravioleta e causam o efeito estufa natural (Wallace e Hobbs, 1977). Os comprimentos de onda nos quais não há significativa absorção da radiação solar pelos constituintes da atmosfera são denominados "janelas atmosféricas", destacando-se o intervalo entre 0,3 e $0,8 \mu \mathrm{m}$, onde quase toda a radiação é transmitida.

O conhecimento dos intervalos de comprimento de onda nos quais as moléculas de gases absorvem mais a radiação solar, as chamadas bandas de absorção, são de suma importância para análises por sensoriamento remoto. Os novos sensores de partículas com alta resolução espectral buscam utilizar as janelas atmosféricas para a análise dos aerossóis, para evitar a realização de correções que possam introduzir incertezas. A maioria dos sensores opera nas regiões do ultravioleta, visível e infravermelho próximo $(0,34-2,1 \mu \mathrm{m})$, pois são comprimentos de onda da ordem de grandeza do tamanho dos aerossóis.

De acordo com a Figura III.2, para as estreitas bandas espectrais do sensor MODIS/TERRA utilizadas neste trabalho $(650$ e $2.100 \mathrm{~nm})$ uma pequena correção referente à absorção por ozônio em $650 \mathrm{~nm}$ e por vapor de água em $2.100 \mathrm{~nm}$ se faz necessária. Essas correções que serão analisadas no capítulo V.2. 

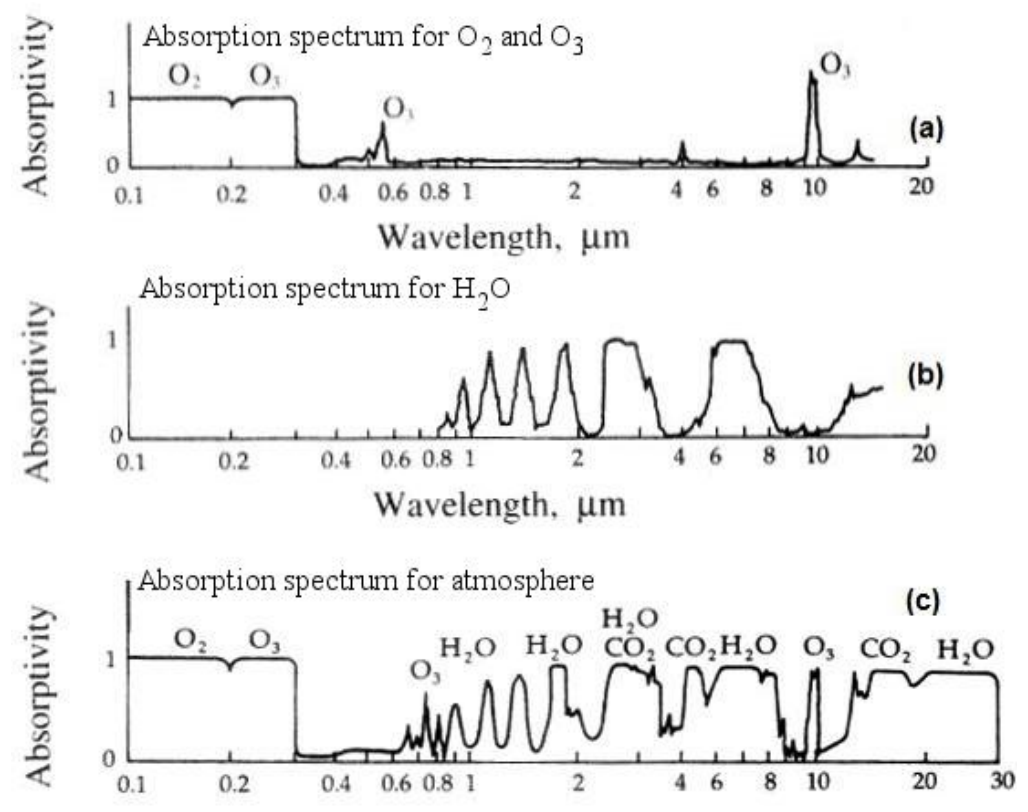

Wavelength, $\mu \mathrm{m}$

Figura III.2: Espectro de absorção para (a) o oxigênio e o ozônio, (b) o vapor d'água e (c) e a atmosfera (Seinfeld e Pandis, 1998).

\section{III.1.2 Espalhamento da radiação solar por gases e partículas presentes na atmosfera}

0 espalhamento da radiação solar varia em função do parâmetro de tamanho $(x)$ das partículas e gases espalhadores, sendo definido como a razão entre o tamanho da partícula e o comprimento de onda da radiação incidente. Para partículas esféricas, $x$ é definido por (Liou, 2002) :

$$
x=\frac{2 \pi r}{\lambda} \quad \text { III.3 }
$$

Onde: $\quad r$ - raio da partícula

$\lambda$ - comprimento de onda da luz incidente.

A variação do tipo de espalhamento sofrido pela radiação solar em função do parâmetro de tamanho é apresentada na Tabela III.1. 


\begin{tabular}{cl}
\hline$x$ & \multicolumn{1}{c}{ Tipo de espalhamento } \\
\hline \hline$<1$ & $\frac{\text { Rayleigh - espalhamento por moléculas ou partículas }}{\text { atmosféricas pequenas em relação ao } \lambda \text { incidente }}$ \\
\hline$\approx 1$ & $\frac{\text { Mie }- \text { espalhamento por partículas esféricas }}{\text { homogêneas de tamanho próximo ao } \lambda \text { incidente }}$ \\
\hline$\gg 1$ & $\frac{\text { Óptica geométrica - espalhamento por partículas }}{\text { atmosféricas grandes em relação ao } \lambda \text { incidente }}$ \\
\hline
\end{tabular}

Tabela III.1: Relação entre o tipo de espalhamento da radiação solar e o parâmetro de tamanho das partículas espalhadoras

Teoria de espalhamento Rayleigh para descrever o espalhamento da radiação solar incidente devido aos gases presentes na atmosfera

A teoria de espalhamento molecular Rayleigh é utilizada quando as partículas espalhadoras são muito menores que o comprimento de onda da radiação espalhada. Como a atmosfera é composta essencialmente por gases, a interação da radiação solar incidente com a atmosfera pode ser explicada pela teoria do espalhamento molecular Rayleigh (Goody e Yung, 1989). Para a radiação não polarizada, a intensidade de espalhamento Rayleigh pode ser escrita em função da intensidade da radiação incidente (isto é, irradiância ou fluxo de energia por unidade de área $\left.\left[\mathrm{W} \mathrm{m}^{-2}\right]\right)$ como:

$$
\begin{gathered}
I(\Theta, r)=I_{0} \frac{\alpha^{2}}{r^{2}} \frac{32 \pi^{4}}{3 \lambda^{4}} P(\Theta) \text { III.4 } \\
P(\Theta)=\frac{3}{4}\left(1+\cos ^{2} \Theta\right) \text { III.5 }
\end{gathered}
$$

A equação III.5 é a função de fase ou função que descreve a distribuição angular do espalhamento, $(\Theta)$ corresponde ao ângulo de espalhamento, $(\alpha)$ à polarizabilidade do espalhador e (r) é à distância com relação ao espalhador.

No espalhamento Rayleigh a radiação espalhada é simétrica em relação ao plano normal à direção da radiação incidente, independente do tamanho da partícula ou molécula de gás. Assim, a radiação retroespalhada é igual à pró-espalhada. A dependência do espalhamento Rayleigh com $\lambda^{-4}$ explica porque o céu é azul, pois o espalhamento molecular para $\lambda$ menores (região do espectro visível correspondente ao azul) é muito mais eficiente que em $\lambda$ maiores, sendo praticamente desprezível da região do espectro visível referente ao vermelho $(\sim 0,7 \mu \mathrm{m})$. 
Teoria de espalhamento Mie para descrever o espalhamento e absorção da radiação solar incidente por partículas de aerossol

A teoria de espalhamento Mie foi desenvolvida em 1908 por Gustav Mie e permite o cálculo de várias propriedades ópticas como: eficiência de extinção $\left(Q_{e x t}\right)$ e de espalhamento $\left(Q_{e s p}\right)$, fator de assimetria $(g)$, albedo simples de espalhamento $\left(\omega_{0}\right)$ e expoente de Ångström ( $\alpha$ ) para partículas esféricas dielétricas, finitas, de tamanhos e índices de refração arbitrários. A teoria Mie pode servir como procedimento para cálculo do espalhamento e absorção para qualquer tamanho de partícula em função do comprimento de onda, desde que a condição $x \approx 1$ (partículas de tamanho próximo ao $\lambda$ incidente) seja satisfeita.

O formalismo matemático que descreve o espalhamento elástico da radiação eletromagnética em uma partícula esférica é chamado de teoria do espalhamento Mie. A derivação da solução da teoria Mie, sobre o espalhamento da onda eletromagnética em uma partícula esférica dielétrica, é uma aplicação direta da teoria eletromagnética clássica e pode ser obtida a partir das equações de Maxwell (Bohren e Huffman, 1983; Thomas e Stamnes, 1999; Liou, 2002). A consideração de partículas esféricas demonstrou ser uma boa aproximação para as condições atmosféricas (Dubovik et al., 2000), principalmente para a moda fina. Diversos códigos computacionais de espalhamento Mie estão disponíveis para uso público. Neste trabalho utilizou-se o código Mie de Dave e Gazdag (1970).

Devido ao efeito de espalhamento traseiro e transmissão da radiação solar pelas partículas de aerossol, é possível determinar as propriedades ópticas dos aerossóis utilizando o sensoriamento remoto da atmosfera. O conjunto destas propriedades ópticas será chamado de modelos ópticos de aerossóis. O resultado da interação (absorção e espalhamento) da radiação com as partículas da atmosfera depende da forma, tamanho e composição destas, chamadas propriedades microfísicas das partículas. Neste item são descritas propriedades microfísicas como: índice de refração complexo, tamanho de uma partícula além de propriedades radiativas ou ópticas derivadas das propriedades microfísicas descritas. 


\section{III.2 Propriedades microfísicas das partículas de aerossol}

As propriedades microfísicas das partículas de aerossol relevantes para este trabalho são: o tamanho da partícula (equação III.3), e o índice de refração (m) em relação ao ar ( $\mathrm{n}_{\mathrm{o}}$ 1), dado pela equação III.6 (Seinfeld e Pandis, 1998):

$$
\mathrm{m}(\lambda)=\mathrm{n}(\lambda)+\mathrm{k}(\lambda) \mathrm{i} \text { [adimensional] III.6 }
$$

A parte real (n) e a parte imaginária (k) do índice de refração representam, respectivamente, a componente de espalhamento e a de absorção.

Para um sistema com uma distribuição polidispersa de partículas, como é o caso da atmosfera, os tamanhos das partículas são representados por distribuições de tamanho. Muitos estudos indicam que a distribuição de tamanho pode ser descrita por duas funções lognormais. A equação III.7 descreve a distribuição lognormal volumétrica de tamanho de partículas (Shettel and Fenn, 1979; Remer and Kaufman, 1998):

$$
\frac{\mathrm{dV}}{\mathrm{d} \ln \mathrm{r}}=\sum_{\mathrm{i}=1}^{2} \frac{\mathrm{C}_{\mathrm{v}, \mathrm{i}}}{\sigma_{\mathrm{i}} \sqrt{2 \pi}} \exp \left\{-\frac{\left[\ln \left(\mathrm{r} / \mathrm{r}_{\mathrm{v}, \mathrm{i}}\right)\right]^{2}}{2 \sigma_{\mathrm{i}}{ }^{2}}\right\}\left[\mu \mathrm{m}^{3} \mu \mathrm{m}^{-2}\right] \text { III.7. }
$$

Onde: $\quad$ i: representa cada uma das modas da distribuição (fina ou de acumulação e grossa);

$\mathrm{C}_{\mathrm{v}}$ concentração volumétrica;

$\mathrm{r}_{\mathrm{v}}$ : raio médio;

$\sigma_{\mathrm{i}}$ : o respectivo desvio padrão da lognormal por volume.

A distribuição de tamanho também pode ser escrita em termos de área superficial das partículas $(\mathrm{dS} / \mathrm{d} \ln (\mathrm{r}))$ e da concentração numérica de destas $(\mathrm{dN} / \mathrm{d} \ln (\mathrm{r}))$. Essas diferentes maneiras de descrever as distribuições de tamanho relacionam-se da seguinte forma:

$$
\frac{\mathrm{dV}}{\mathrm{d} \ln \mathrm{r}}=\frac{4}{3} \pi \mathrm{r}^{3} \frac{\mathrm{dN}}{\mathrm{d} \ln \mathrm{r}} e \frac{\mathrm{dS}}{\mathrm{d} \ln \mathrm{r}}=4 \pi \mathrm{r}^{2} \frac{\mathrm{dN}}{\mathrm{d} \ln \mathrm{r}} \text { III.8 }
$$

Conhecendo-se a distribuição de tamanho a priori, pode-se definir um único parâmetro que descreve a distribuição de partículas de forma independente de modelos e ajustes matemáticos, denominado raio efetivo (Liou, 2002), conforme apresentado na equação III.9.

$$
r_{\text {ef }}=\int_{r_{1}}^{r_{2}} r \pi r^{2} N(r) d r / \int_{r_{1}}^{r_{2}} \pi r^{2} N(r) d r[\mu m] \quad \text { III.9 }
$$




\section{III.3 Propriedades ópticas das partículas de aerossol}

Como propriedades ópticas dos aerossóis relevantes para este estudo, podemos citar: o ângulo de espalhamento, a função de fase, o fator de simetria, as eficiências de espalhamento e extinção e o albedo simples.

O ângulo de espalhamento $(\Theta)$ é ângulo formado entre a direção do feixe emergente com relação ao incidente. É definido em função dos ângulos zenitais $\left(\theta\right.$ e $\left.\theta_{\mathrm{o}}\right)$ e azimutais $\left(\varphi\right.$ e $\left.\varphi_{\mathrm{o}}\right)$ dos feixes emergente e incidente respectivamente, sendo:

$$
\cos (\Theta)=\cos \left(\theta_{o}\right) \cos (\theta)+\sin \left(\theta_{o}\right) \sin (\theta) \cos \left(\varphi-\varphi_{o}\right)_{\text {III.10 }}
$$

A radiação é dita pró-espalhada (espalhada frontalmente, para o hemisfério frontal) para $\Theta<\pi / 2$, e retroespalhada (espalhada para trás para o hemisfério traseiro) $\operatorname{para} \Theta>\pi / 2$.

A função de fase representa a probabilidade de espalhamento em cada direção em relação à incidente (Liou, 2002).

$$
P(\Theta, x, m, \lambda)=\frac{F(\Theta, x, m, \lambda)}{\int_{0}^{\pi} F(\Theta, x, m, \lambda) \sin \Theta d \Theta}
$$

[adimensional] III.11

A integral da função de fase em uma esfera centrada na partícula é $4 \pi$ :

$$
\int_{0}^{2 \pi} \int_{0}^{\pi} P(\Theta, x, m, \lambda) \sin \Theta d \Theta d \varphi=4 \pi
$$

III.12

Onde: $\quad \varphi$ - ângulo azimutal;

$\Theta$ - ângulo de espalhamento.

O parâmetro de assimetria ( $\mathrm{g}$ ) é derivado da função de fase e descreve o quanto da radiação é pró-espalhada em relação ao espalhamento total. Seu valor pode variar de -1 a 1 . Se o espalhamento da luz é isotrópico, ou seja, simétrico, g é nulo $(\mathrm{g}=0)$; se toda a radiação é pró-espalhada $\left(\Theta=0^{\circ}\right)$, temos que $\mathrm{g}=1$ e se a radiação é totalmente retroespalhada $\left(\Theta=180^{\circ}\right)$, temos que $g=-1$ (Liou, 2002). $\mathrm{O}$ fator de assimetria é importante na avaliação da contribuição das partículas de aerossol na transferência radiativa ao longo da atmosfera e é descrito pela equação III.13. 


$$
g(x, m)=\frac{1}{2} \frac{\int_{0}^{\pi} \cos \Theta F(\Theta) \sin \Theta d \Theta}{\int_{0}^{\pi} F(\Theta) \sin \Theta d \Theta}=\frac{1}{2} \int_{0}^{\pi} \cos \Theta P(\Theta) \sin \Theta d \Theta
$$

[adimensional] III.13

A função de fase de Henyey-Greenstein é semelhante à função de fase original da partícula. Entretanto, esta é escrita em função do parâmetro de assimetria:

$$
P_{H G}(\cos \Theta, g)=\frac{1-g^{2}}{\left(1+g^{2}-2 g \cos \Theta\right)^{3 / 2}}=\sum_{j=0}^{\infty}(2 j+1) g^{j} P_{j}(\cos \Theta)
$$

[adimensional] III.14

A função de fase pode também ser escrita em função do ângulo de espalhamento na forma de expansão em polinômios de Legendre:

$$
\mathrm{P}_{\mathrm{L}}(\cos \Theta)=\sum_{\mathrm{i}=1}^{\infty} \mathrm{W}_{\mathrm{i}}(\cos \Theta) \mathrm{P}_{\mathrm{i}} \text { [adimensional] III.15 }
$$

Conhecidos os coeficientes $\left(\mathrm{P}_{\mathrm{i}}\right)$ do polinômio de Legendre, a função de fase em cada ângulo de espalhamento pode ser escrita explicitando cada termo da somatória (Thomas e Stamnes, 1999):

$$
\begin{aligned}
P_{L}(\cos \Theta)=1+P_{1} \cos \Theta & +\frac{P_{2}}{2}(3 \cos \Theta-1)+\frac{P_{3}}{3}\left(\frac{15}{2} \cos ^{3} \Theta-\frac{9}{2} \cos \Theta\right)+ \\
& +\sum_{i=4}^{\infty} \frac{P_{i}}{i}\left[(2(i-1)+1) \cos \Theta W_{i-1}-(i-1) W_{i-2}\right]
\end{aligned}
$$

III.16

Para um determinado tipo de aerossol, Castanho (2005) comparou as funções de fase de Henyey-Greenstein $\left(\mathrm{P}_{\mathrm{HG}}\right)$ e as funções de fase definidas pela expansão da função de fase original em polinômios de Legendre $\left(\mathrm{P}_{\mathrm{PL}}\right)$, considerando 100 termos. Verificou-se que a função definida pelo polinômio de Legendre recupera satisfatoriamente a função de fase original do modelo de aerossol, apresentando pequenas oscilações $(\sim 10 \%)$ em torno dela. A função de fase obtida pela aproximação do parâmetro de assimetria $\left(\mathrm{P}_{\mathrm{HG}}\right)$ por sua vez apresenta no intervalo dos ângulos de espalhamento traseiro de $100^{\circ}$ a $140^{\circ}$, desvios em relação à função de fase original de no máximo a $20 \%$. Fora deste intervalo de ângulo de espalhamento ela pode divergir da função de fase original de 50 a $90 \%$. A configuração das posições angulares do sensor MODIS presente no satélite TERRA em relação à posição solar no período estudado apresenta ângulos de espalhamento superiores à $140^{\circ}$, devido ao ângulo solar 
zenital ser menor. Deste modo, a função de fase de espalhamento escrita em forma de polinômios de Legendre pode ser mais adequada do que a aproximação de HenyeyGreenstein.

Quando os resultados deste trabalho foram obtidos o alto custo computacional, para se obter as equações de transferência radiativa na atmosfera utilizando os polinômios de Legendre para descrever a função de fase de espalhamento, inviabilizou essa abordagem. Por esse motivo, neste trabalho os modelos de aerossol foram definidos utilizando o parâmetro de assimetria para descrever a função de fase de espalhamento, ou seja, utilizou-se a função de fase de Henyey-Greenstein.

As eficiências de espalhamento, extinção e retroespalhamento são descritas pela teoria Mie como fatores adimensionais, dados respectivamente por:

$$
\begin{aligned}
& Q_{\text {esp }}(m, x)=\frac{2}{x^{2}} \sum_{n=1}^{\infty}(2 n+1)\left(\left|a_{n}\right|^{2}+\left|b_{n}\right|^{2}\right) \\
& Q_{\text {ext }}(m, x)=\frac{2}{x^{2}} \sum_{n=1}^{\infty}(2 n+1) \operatorname{Re}\left(a_{n}+b_{n}\right) \\
& Q_{\pi}(m, x)=\frac{1}{x^{2}} \operatorname{Abs}\left[\sum_{n=1}^{\infty}(2 n+1)(-1)^{n}\left(a_{n}-b_{n}\right)\right]^{2}
\end{aligned}
$$

Onde: $\mathrm{x}$ - parâmetro de tamanho da partícula;

$a_{n}$ e $b_{n}$ - coeficientes de Mie como função do índice de refração da partícula, podem ser descritos em termos das funções de Riccati-Bessel;

$\mathrm{Q}_{\mathrm{abs}}=\mathrm{Q}_{\mathrm{ext}}-\mathrm{Q}_{\mathrm{esp}}$.

Para um conjunto de partículas polidispersas na atmosfera, o coeficiente linear de extinção $\left(\beta_{\text {ext }}\right)$, assim como de espalhamento $\left(\beta_{\text {esp }}\right)$ e de absorção $\left(\beta_{\text {abs }}\right)$ são calculados a partir das respectivas eficiências de extinção $\left(\mathrm{Q}_{\text {esp }}, \mathrm{Q}_{\mathrm{abs}}\right)$ e da distribuição de tamanho em número de partículas $(n(r)=d N(r) / d r)$, conforme a equação III.18.

$$
\beta_{\text {ext }}(\lambda)=\int_{0}^{\infty} Q_{\text {ext }}(m, x) \pi r^{2} n(r) d r\left[m^{-1}\right] \quad \text { III.18 }
$$

O coeficiente linear de extinção do conjunto de partículas é dado pela soma do coeficiente de espalhamento e absorção: $\beta_{\text {ext }}(\lambda)=\beta_{\text {esp }}(\lambda)+\beta_{\text {abs }}(\lambda)$

III.19

O albedo simples dos aerossóis na atmosfera em um determinado comprimento de onda $\lambda$ é definido como a razão entre o coeficiente de espalhamento 
e o coeficiente de extinção. O albedo simples descreve a fração da radiação que é espalhada com relação à que é extinta devido à interação da radiação com a partícula. Quanto menor o albedo simples, mais absorvedor é o aerossol.

$$
\omega_{0}(\lambda)=\frac{\beta_{\text {esp }}(\lambda)}{\beta_{\text {esp }}(\lambda)+\beta_{\text {abs }}(\lambda)}=\frac{\beta_{\text {esp }}(\lambda)}{\beta_{\text {ext }}(\lambda)} \text { [adimensio nal] } \quad \text { III.20 }
$$

Ångström, em 1929, apresentou a seguinte fórmula empírica relacionando a profundidade óptica e o comprimento de onda da radiação incidente:

$$
\tau \sim \lambda^{-\alpha} \quad \text { III.21 }
$$

O expoente ou coeficiente de Ångström ( $\alpha$ ) é um parâmetro bastante utilizado para caracterizar a dependência espectral do coeficiente de extinção ou profundidade óptica das partículas de aerossol na atmosfera, bem como para realizar uma inferência a respeito do seu tamanho (Seinfeld e Pandis, 1998). Quanto maior o expoente de Ångström, maior a dependência espectral das partículas de aerossol na atmosfera e, portanto, menores são estas partículas. Considerando dois comprimentos de onda distintos, pode-se calcular o expoente de Ångström $(\alpha)$ através da equação III.22.

$$
\alpha=-\frac{\ln \left(\beta_{\mathrm{ext}}\left(\lambda_{1}\right) / \beta_{\mathrm{ext}}\left(\lambda_{2}\right)\right)}{\ln \left(\lambda_{1} / \lambda_{2}\right)}=-\frac{\ln \left(\tau_{1} / \tau_{2}\right)}{\ln \left(\lambda_{1} / \lambda_{2}\right)} \text { [adimensio nal] }
$$

III.22

Onde: $\quad \tau_{1}$ e $\tau_{2}{ }^{-}$profundidade óptica das partículas de aerossol nos comprimentos de onda $\lambda_{1}$ e $\lambda_{2}$, respectivamente. 


\section{III.4 Transferência radiativa na atmosfera}

No item anterior, foram abordados os processos de interação da radiação solar com os constituintes da atmosfera (moléculas de gás e partículas), bem como as algumas de suas características e propriedades ópticas.

O cálculo da transferência radiativa na atmosfera permite determinar, a partir da radiância espectral incidente no topo da atmosfera, qual seria a radiância espectral observada após as interações com os constituintes da atmosfera. Comumente considera-se a atmosfera como sendo plano-paralela, ignorando assim a curvatura da Terra, já que as variações verticais de temperatura, pressão e concentrações dos constituintes atmosféricos são muito mais significativas do que as variações horizontais (Liou, 1992) (Figura III.3). Esta aproximação é bastante válida para ângulos solares zenitais não muito elevados (ou seja, com a posição do sol próximo ao horizonte não se pode considerar a esfericidade da Terra desprezível).

A lei de Beer-Lambert-Bouguer descreve a variação da radiância espectral $\mathrm{dL}(\lambda)$ em unidades de $\left[\mathrm{Wm}^{-2} \mathrm{sr}^{-1} \mu \mathrm{m}^{-1}\right]$ devido à atenuação ou extinção da radiância incidente $\mathrm{L}(\lambda)$ ao longo de um caminho óptico (ds). Mostrando assim que a intensidade da radiação cai exponencialmente ao longo do caminho óptico percorrido. A profundidade óptica de extinção fornecida pelos radiômetros CIMEL da rede AERONET baseia-se nesta lei.

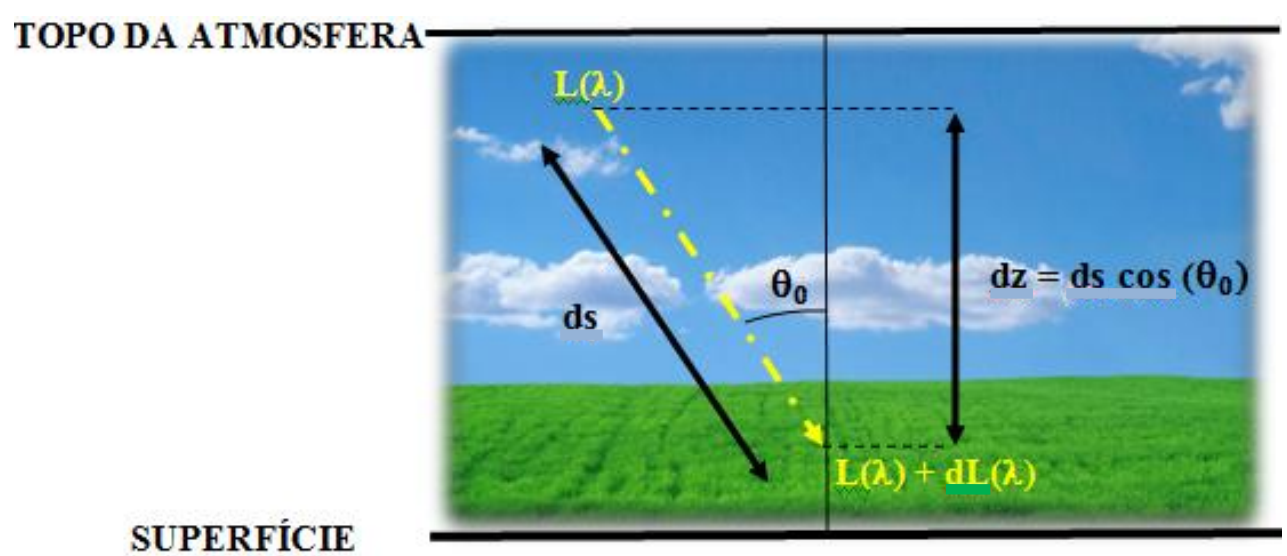

Figura III.3: Representação esquemática da atenuação da radiância incidente em um meio homogêneo. 
Pode-se escrever a variação da radiância em termos do coeficiente de extinção linear da seguinte forma:

$$
\begin{array}{lc}
d L(\lambda)=-\beta_{\text {ext }}(\lambda) L(\lambda) d s & \text { III.23 } \\
\frac{1}{L(\lambda)} d L(\lambda)=-\beta_{\text {ext }}(\lambda) d s & \text { III.24 }
\end{array}
$$

Substituindo a relação entre o caminho óptico (ds) e a direção vertical (dz) apresentada na Figura III.3 e integrando os dois lados da equação III.24 na coluna atmosférica, tem-se:

$$
\int_{L o}^{L_{1}} \frac{1}{L(\lambda)} d L(\lambda)=\frac{1}{\cos \left(\theta_{o}\right)} \int_{z 0}^{z 1}-\beta_{\text {ext }}(\lambda) d z \quad \mathbf{I I I . 2 5}
$$

A integral do coeficiente de extinção na coluna vertical z é chamada de profundidade óptica de extinção na camada ( $\tau_{\text {ext }}$, cuja notação geralmente omite o subscrito), dada pela soma da profundidade óptica de espalhamento mais absorção $\left(\tau_{\mathrm{ext}}=\tau_{\mathrm{esp}}+\tau_{\mathrm{abs}}\right)$ :

$$
\tau(\lambda)=\int_{\mathrm{z} 0}^{\mathrm{z} 1} \beta_{\mathrm{ext}} \mathrm{dz} \text { [adimensional] } \quad \text { III.26 }
$$

Resolvendo-se a integral, tem-se que a radiância que chega à superfície pode ser escrita como:

$$
\mathrm{L}_{1}(\lambda)=\operatorname{Lo}(\lambda) \exp \left(-\frac{\tau}{\cos \left(\theta_{\mathrm{o}}\right)}\right)\left[W m^{-2} s r^{-1} m \mu^{-1}\right]
$$

\section{III.27}

Esta relação pode ser generalizada, como mostra a equação a seguir. Considerando que a radiância no topo da atmosfera $\left(\mathrm{L}_{\mathrm{o}}(\lambda)\right)$ varia ao longo do ano devido à distância entre a Terra e o Sol, acrescentando um fator $\mathrm{R}^{-2}$. $\mathrm{O}$ termo envolvendo $\theta_{\mathrm{o}}$ é válido somente para $\theta_{\mathrm{o}}<80^{\circ}$, ângulo em que a atmosfera pode ser considerada plano-paralela. Para ângulos maiores do que $80^{\circ}$, devem ser consideradas correções devido à refração da atmosfera e à curvatura da Terra (Yamasoe, 1999; Schmid e Wehrli, 1995). 


$$
\mathrm{L}_{1}(\lambda)=\operatorname{Lo}(\lambda) \frac{1}{\mathrm{R}^{2}} \exp \left(-\mathrm{m}\left(\theta_{\mathrm{o}}\right) \tau(\lambda)\right)\left[W m^{-2} s r^{-1} m \mu^{-1}\right]
$$

Onde: $\quad$ R- distância da Terra ao Sol em Unidades Astronômicas

$$
\left(1 \mathrm{UA}=1,494 \times 10^{11} \mathrm{~m}\right)
$$

$$
m\left(\theta_{o}\right) \sim \frac{1}{\cos \left(\theta_{o}\right)}-\text { massa óptica para uma atmosfera plano-paralela. }
$$

A profundidade óptica de extinção representada acima é resultado da soma das atenuações devido a cada um dos constituintes da atmosfera. Neste trabalho a profundidade óptica de extinção considerada é apresentada na equação III.29.

$$
\begin{aligned}
& \tau_{\text {ext }}(\lambda)=\tau_{\text {Ext Aerossóis }}(\lambda)+\tau_{\mathrm{R} \text { Espalhamento Rayleigh }}(\lambda)+\tau_{\mathrm{O}_{3} \text { Absorção Molecular }}(\lambda) \\
& \text { Onde : } \quad \tau_{\text {ext Aerossóis }}(\lambda)=\tau_{\text {esp }_{\text {Aerossóis }}}(\lambda)+\tau_{\text {abs Aerossóis }}(\lambda)
\end{aligned}
$$

Da equação III.27, temos ainda que a razão entre a radiância que chega a superfície e a que chega ao topo da atmosfera é a chamada transmitância direta atmosférica (t):

$$
\mathrm{t}=\frac{\mathrm{L}_{1}(\lambda)}{\operatorname{Lo}(\lambda)}=\exp \left(-\frac{\tau}{\cos \left(\theta_{\mathrm{o}}\right)}\right) \text { [adimensional] } \quad \text { III.30 }
$$

Utilizando-se a Lei de Beer-Lambert-Bouguer (equação III.28), pode-se obter a atenuação da radiação do feixe direto que chega à superfície devido a espalhamento e absorção da radiação ao longo de um caminho óptico. Caso a distância entre as partículas seja suficientemente grande, se comparada com o tamanho das partículas, o espalhamento total de um conjunto de partículas pode ser calculado pela soma dos espalhamentos de cada partícula individualmente (teoria de espalhamento simples). Entretanto, se a proximidade ou o volume de partículas for grande se comparada ao tamanho destas, deve-se considerar a ocorrência de espalhamentos múltiplos.

A radiação solar ao atravessar a atmosfera interage com os constituintes que estão fora do caminho óptico considerado, sendo espalhada em todas as direções conforme o índice de reflexão. A fração que é espalhada na direção do feixe de observação pode interagir por sua vez com os constituintes do caminho óptico, acarretando um acréscimo do feixe direto. A radiação que chega à superfície é a 
resultante das parcelas que se somaram ou mesmo foram desviadas do feixe direto devido aos espalhamentos múltiplos.

A equação de transferência radiativa (ETR) é apresentada na equação III.31 (Liou, 2002). O primeiro termo corresponde ao feixe transmitido diretamente no caminho óptico considerado para um comprimento de onda $\lambda$. O segundo termo representa a intensidade da radiação adicionada ao feixe devido ao espalhamento na direção de observação decorrente do espalhamento múltiplo. O terceiro termo representa a radiação adicionada ao feixe devido à reemissão da radiação absorvida pelos constituintes da atmosfera.

$\pm \mu \frac{d L(\lambda, \tau, \pm \mu, \varphi)}{d \tau}=L(\lambda, \tau, \pm \mu, \varphi)+\left[-\varpi_{o}(\lambda, \tau) J(\lambda, \tau, \pm \mu, \varphi)\right]+\left\{-\left[1-\varpi_{o}(\lambda, \tau)\right] B_{\lambda}(\lambda, T(\tau))\right\}$ III.31

Onde: $\quad \mu=\cos \left(\theta_{o}\right)$

$$
J(\lambda, \tau, \pm \mu, \varphi)=\int_{0}^{2 \pi} \int_{0}^{\pi} L\left(\lambda, \tau, \pm \mu^{\prime}, \varphi^{\prime}\right) P(\lambda, \tau, \cos (\Theta)) \frac{d \mu^{\prime} d \varphi^{\prime}}{4 \pi} \mathbf{I I I . 3 2}
$$

A função chamada "fonte de espalhamento", $\mathrm{J}(\lambda, \tau, \pm \mu, \varphi)$, é definida como a fração radiação incidente em cada direção que é espalhada na direção da observação em uma dada profundidade óptica; $\omega_{\mathrm{o}}$ representa o albedo simples conforme equação III.20 $\tau$ é a profundidade óptica conforme equação III.26; P representa a função de fase no ângulo de espalhamento $(\Theta)$ (equação III.11); $\mathrm{B}_{\lambda}$ representa o valor da função de Planck (III.1).

Todas as grandezas da ETR, conforme fica explícito na equação III.31, são funções do comprimento de onda da radiação, e das propriedades físicas e químicas das partículas.O terceiro termo da ETR, representando a reemissão da radiação absorvida, é importante, principalmente para estudos da transferência radiativa para comprimentos de onda no infravermelho. Porém, no contexto deste trabalho, esse termo não é significativo, pois são utilizadas apenas radiâncias nos comprimentos inferiores a 2,2 $\mu \mathrm{m}$. O segundo termo ETR, que se refere às fontes de espalhamento é extremamente significativo nos processos de transferência radiativa na atmosfera, principalmente no caso de valores elevados de profundidade óptica dos aerossóis $(\tau>>0,5)$. 


\section{III.5 Sensoriamento remoto de aerossóis por satélite}

O sensoriamento remoto obtém suas observações a partir do fluxo de radiação solar que retorna ao espaço - topo da atmosfera (do inglês TOp of the Atmosphere - TOA), após sua interação com a atmosfera e com a superfície. O fluxo de radiação solar incidente pode ser refletido de volta para o espaço (retro espalhamento), sofrer espalhamento e continuar na atmosfera (pró-espalhado), ser absorvido ou mesmo ser transmitido diretamente até a superfície sem sofrer interação com a camada de aerossóis (Fraser e Kaufman, 1985). A fração correspondente a cada uma destas interações pode ser calculada com as ETR, descritas no item anterior. O tipo e a intensidade das interações dependem das propriedades ópticas da camada de aerossóis, como: albedo simples $\left(\omega_{\mathrm{o}}(\lambda)\right.$ ), parâmetro de assimetria $(\mathrm{g}(\lambda))$ (ou função de fase $\mathrm{P}(\Theta)$ ), eficiência de extinção $\left(\mathrm{Q}_{\text {ext }}(\lambda)\right)$ e a profundidade óptica da camada $\left(\tau_{\mathrm{a}}(\lambda)\right)$.

Considerando uma atmosfera plano-paralela e a superfície com refletância Lambertiana, a refletância observada no topo da atmosfera $\left(\rho_{\mathrm{TOA}}\right)$ é definida conforme a equação III.33 (Kaufman et al., 1997b). A refletância no topo da atmosfera ( $\rho_{T O A}$ (入)) é definida a partir da radiância espectral emergente no topo da atmosfera $\left(\mathrm{L}_{T O A}(\lambda)\left[\mathrm{Wm}^{-2} \mathrm{sr}^{-1} \mu \mathrm{m}^{-1}\right]\right)$, considerada isotrópica, integrada no hemisfério e dividida

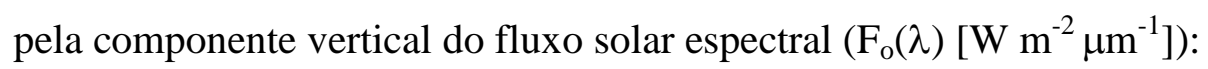

$$
\rho_{\mathrm{TOA}}\left(\lambda, \theta_{0}, \theta, \varphi_{\mathrm{o}}, \varphi\right)=\frac{\pi \mathrm{L}_{\mathrm{TOA}}\left(\lambda, \theta_{0}, \theta, \varphi_{\mathrm{o}}, \varphi\right)}{\mathrm{F}_{\mathrm{o}}(\lambda) \mu_{\mathrm{o}}}
$$

$$
\text { Onde: } \quad \begin{array}{ll}
\theta_{\mathrm{o}}-\text { ângulo zenital solar } \\
\theta-\text { ângulo zenital sensor } \\
\varphi_{\mathrm{o}} \text { - ângulo azimutal solar } \\
\varphi-\text { ângulo azimutal do sensor } \\
\mathrm{F}_{\mathrm{o}}(\lambda)-\text { fluxo solar espectral incidente no topo da atmosfera } \\
{\left[\mathrm{Wm}^{-2} \mu \mathrm{m}^{-1}\right] .}
\end{array}
$$

Analisando a equação III.34 temos que o termo $\rho_{\mathrm{o}}$ representa a refletância no topo da atmosfera devido à refletância da atmosfera (gases e partículas), para o qual se considera a refletância de superfície nula, mais a componente devido à radiância que é refletida pela superfície, que interage novamente com a atmosfera e retorna ao espaço. 
$\rho_{\mathrm{TOA}}\left(\lambda, \theta_{0}, \theta, \varphi_{\mathrm{o}}, \varphi\right)=\rho_{\mathrm{O}}\left(\lambda, \theta_{0}, \theta, \varphi_{\mathrm{o}}, \varphi\right)+\frac{\mathrm{T}_{\mathrm{d}}\left(\lambda, \theta_{0}\right) \mathrm{T}_{\mathrm{S}}(\lambda, \theta)}{\left(1-\mathrm{s}^{\prime}\right)} \rho_{\mathrm{SUP}}\left(\lambda, \theta_{0}, \theta, \varphi_{\mathrm{o}}, \varphi\right)$

Onde $\rho_{\mathrm{o}}\left(\lambda, \theta_{0}, \theta, \varphi_{\mathrm{o}}, \varphi\right)=\rho_{\mathrm{m}}\left(\lambda, \theta_{0}, \theta, \varphi_{\mathrm{o}}, \varphi\right)+\frac{\varpi_{\mathrm{o}} \tau \mathrm{P}(\lambda, \Theta)}{4 \mu \mu_{\mathrm{o}}}$

A refletância causada pela atmosfera $\left(\rho_{\mathrm{o}}\right)$ é composta pela soma das refletâncias devido às moléculas de gases $\left(\rho_{\mathrm{m}}\right)$ e a refletância devido à camada de aerossóis. A refletância na camada de aerossóis é função das propriedades de albedo simples $\left(\omega_{0}\right)$, função de fase $(\mathrm{P}(\lambda, \Theta))$, e profundidade óptica dos aerossóis da camada $(\tau)$. Observa-se também que a radiação incidente que é transmitida para a superfície $\left(T_{d}\right)$ pode retornar à atmosfera conforme a refletância da superfície $\left(\rho_{\text {sup }}\right)$. Esta fração da radiação incidente $\left(\rho_{\text {sup }} * T_{d}\right)$ por sua vez pode retornar ao topo da atmosfera de acordo com a transmitância na subida $\left(\mathrm{T}_{\mathrm{s}}\right)$, chegando ao topo a resultante $\rho_{\text {sup }} * \mathrm{~T}_{\mathbf{d}} * \mathrm{~T}_{\mathrm{s}}$, onde (s) é a razão de espalhamento traseiro da atmosfera, $\rho$ ' é a refletância de superfície média nos ângulos de visada e incidência. Finalmente, a radiação total que chega ao topo da atmosfera é dada pelo que é refletido diretamente na camada de aerossol e gases $\left(\rho_{\mathrm{o}}\right)$, mais o que volta da interação com a superfície, conforme mostra a equação III.34 (Kaufman et al., 1997b; Martins, 1999). 


\section{INSTRUMENTAÇÃO E MÉTODOS EXPERIMENTAIS}

\section{IV.1 Sensor MODIS (MODerate Resolution Imaging Spectroradiometer)}

O sensor MODIS é um instrumento multidisciplinar de pesquisa que visa contribuir para estudos da superfície terrestre. O sensor foi desenhado para monitorar: alterações de uso de solo, temperatura de superfície, cobertura de neve, propriedades de vegetações, do oceano (temperatura da superfície do mar, clorofila) e de fenômenos atmosféricos (aerossóis, propriedades de nuvens, vapor de água, perfil de temperatura). O sensor MODIS realiza uma cobertura global a cada 1 ou 2 dias e foi o primeiro sensor desenvolvido com ênfase na obtenção de observações quantitativas globais dos aerossóis com resolução espacial moderada (King et al., 2003).

\section{IV.1.1 Descrição do sensor MODIS e seus produtos}

O sensor MODIS é um instrumento constituído de um radiômetro espectral de imagem convencional com 36 bandas discretas entre 0,4 e $14,5 \mu \mathrm{m}$, com resoluções espaciais de 250x250 m (Banda 1=0,65 $\mu \mathrm{m}$ e Banda 2=0,85 $\mu \mathrm{m}$ ), 500x500 m (Banda 3=0,45 $\mu \mathrm{m}$; Banda 4=0,55 $\mu \mathrm{m}$; Banda 5=1,24 $\mu \mathrm{m}$; Banda $6=1,64$ $\mu \mathrm{m}$; Banda 7=2,11 $\mu \mathrm{m}$ ) e 1000x1000 m nas demais bandas. Possui uma elevada razão sinal/ruído (>500), e a acurácia das irradiâncias absolutas são de $\pm 5 \%$ e $\pm 1 \%$, respectivamente para as bandas de reflexão e emissão. A descrição detalhada do instrumento MODIS, como desenho óptico, características das bandas espectrais, calibração e operação pode ser obtida em Barnes et al., 1998.

Denomina-se MYD e MOD as observações fornecidas pelo sensor MODIS a bordo do satélite AQUA e TERRA respectivamente. Estas por sua vez são enviadas periodicamente para a NASA Goddard Space Flight Center (GSFC) por meio de estações de recepção terrestre, processadas pelo MODAPS (MODIS Adaptive Processing System), arquivadas e distribuídas pelo Goddard DAAC (Distributed Active Archive Center) (http://daac.gsfc.nasa.gov/data/dataset/MODIS/).

Os produtos operacionais do MODIS são gerados em três níveis (Nível 1-L1, Nível 2-L2 e Nível 3-L3) (King et al., 2003). O primeiro produto gerado é o de nível L1A (MOD01. Os arquivos deste primeiro produto apresentam uma cobertura espacial de $2.330 \mathrm{~km}$ de largura, por um comprimento de $1350 \mathrm{~km}$, que é o equivalente a 5 minutos de trajetória do satélite. O produto MOD02 (nível L1B) é gerado a partir do MOD01A e possui informações de radiâncias em 36 bandas 
espectrais que são calibradas e georreferenciadas, podendo ter resoluções espaciais de 250x250 m, 500x500 m, ou 1000x1000 m. O produto MOD03 possui os dados de georreferenciamento completos (Wolf et al., 1995) com a respectiva resolução espacial do sensor. No Nível 2 (L2), são gerados diversos produtos: os produtos de máscara de nuvens para identificação de quais pixels da imagem estão contaminados pela presença de nuvens (MOD35) (Ackerman et al., 1998; Martins et al., 2002); produto de perfil atmosférico (MOD07) (Li et al., 1999, 2000, 2001, Ma et al., 1999); produto de aerossol (MOD04) sobre terra (Kaufman et al., 1997b) e sobre oceano (Tanré et. al., 1997;1999); produto de água precipitável (MOD05) (Kaufman e Gao, 1992; Gao e Kaufman, 2003); e produto sobre propriedades de nuvens (MOD06) (Platnick et al., 2003). Por fim, são gerados os produtos de Nível 3 (MOD08) nos quais são apresentadas as estatísticas das propriedades obtidas no Nível 2 para todo o globo em áreas de $1^{\circ} \times 1^{\circ}$ diariamente e em médias a cada 8 e 30 dias (King et al., 2003).

Os produtos gerados são armazenados em arquivos formados por várias matrizes organizados de forma hierárquica, estruturados através do chamado formato hdf (Hierarchical Data File). Este formato é semelhante a uma matriz em três dimensões, sendo que cada nível desta matriz corresponde a uma variável e contém seu nome completo, intervalo de contagem válido, valores de preenchimento de cada pixel, fatores de correção para radiância, refletância e contagens, e respectivas unidades. Os locais específicos de armazenamento das informações das variáveis é chamado de SDS (Scientific Data Set). As informações de georreferenciamento (latitude, longitude, ângulos zenitais e azimutais do sensor e do Sol) são salvas nestes arquivos apenas para cada 5 pixels, sendo que no presente trabalho os valores intermediários foram recuperados por interpolação linear.

Neste trabalho, serão utilizados basicamente os produtos operacionais do sensor MODIS, a bordo do satélite TERRA, MOD021 - nível L1B (radiâncias calibradas e georreferenciadas com resolução de 500x500 m) e MOD04 - nível L2 (profundidade óptica sobre a terra e o oceano com resolução espacial de $10 \mathrm{~km}$ x 10 $\mathrm{km}$ no nadir além da latitude e longitude do local de estudo). Informações técnicas adicionais desses produtos podem ser obtidas em Castanho, 2005. 


\section{IV.1.2 Algoritmo operacional para a obtenção de profundidade óptica dos aerossóis $\left(\tau_{\alpha}\right.$ ou $\left.A O D\right)$ com resolução espacial de $10 \mathrm{~km} \times 10 \mathrm{~km}$}

O sensor MODIS utiliza um algoritmo para obter a AOD em áreas oceânicas (Tanré et al., 1997, 1999) e outro algoritmo para o cálculo da $A O D$ em áreas continentais (Kaufman et al., 1997b). Os dois algoritmos possuem resolução espacial de $10 \mathrm{~km}$ x $10 \mathrm{~km}$. Sobre o continente as bandas espectrais utilizadas são as de 470 $\mathrm{nm}, 650 \mathrm{~nm}$ e $2.110 \mathrm{~nm}$. A refletância da superfície no visível é obtida utilizando as informações de radiância observada na banda de $2.110 \mathrm{~nm}$. Isto porque, nos comprimentos de onda maiores, a interação da radiação com as partículas, via espalhamento e absorção, pode ser considerada desprezível. Assim, esta banda capta informações diretas da superfície (aproximação válida para a maioria dos aerossóis, exceto sob condições de elevadas concentrações da moda grossa). Conhecendo-se a relação entre os comprimentos de onda no visível (450 nm e $650 \mathrm{~nm}$ ) e o infravermelho próximo $(2.110 \mathrm{~nm})$ as refletâncias da superfície no visível são estimadas pelas relações empíricas propostas por Kaufman et al., 1997b e 2002a:

$$
\begin{aligned}
& \rho_{450}=\rho_{2.100} * 0,25 \\
& \rho_{650}=\rho_{2.100} * 0,50
\end{aligned}
$$

IV.1

As medidas de refletância de superfície obtidas com o MODIS são comparadas com valores tabelados (look up tables), obtidos por meio de simulações realizadas para uma grande variedade de tipos de aerossol e refletâncias de superfície, utilizando o código de transferência radiativa de Dave e Gazdag, 1970. Deste modo, para uma refletância de superfície obtida por meio das relações empíricas descritas acima é possível determinar, utilizando-se a tabela de referência, a $A O D$ que provocaria a radiância no topo da atmosfera observada pelo sensor. Isso depende da definição do melhor modelo óptico que descreve a camada de aerossóis da região.

O algoritmo operacional do sensor MODIS (coleção 4) utilizado para determinar a profundidade óptica de aerossóis utiliza 1 dentre os 4 modelos ópticos de aerossóis listados a seguir:

- Poeira do deserto (d'Almeida et al., 1987; Shettle et al., 1984);

- Aerossol de queima de biomassa (Remer et al., 1996, 1998);

- Aerossol urbano/industrial (Remer et al., 1996, 1997; Remer e Kaufman, 1998);

- Aerossol continental (Lenoble e Brogniez, 1984). 
A escolha do modelo óptico de aerossóis que melhor descreve a camada de aerossóis presente na região de interesse no dia analisado segue os seguintes passos:

1. Inicialmente os valores de $A O D$ são calculados utilizando-se o modelo continental;

2. Caso o valor de $A O D$ calculado seja superior a 0,15 , verifica-se:

a. A dependência espectral entre o azul e vermelho e esta determina se o aerossol é de poeira de deserto ou não;

b. A região do globo e a época do ano que definem se o modelo deve ser urbano/industrial ou de queimadas.

3. A partir destas decisões, os valores de $A O D$ podem então ser recalculados (Kaufman et al., 1997b).

O algoritmo operacional do sensor MODIS para o cálculo da profundidade $A O D$ aplica-se normalmente a condições totalmente livres de nuvens e refletâncias de superfície $\left(\rho_{\text {sup }}(2.110 \mathrm{~nm})\right)$ inferiores a 0,25 no nadir. Em uma área de $10 \mathrm{~km}$ x 10 km, o que corresponde a aproximadamente 100 pixels, após a seleção dos pixels sem nuvens, são descartados $20 \%$ dos pixels mais escuros e $50 \%$ dos pixels mais claros, para evitar estatisticamente a contaminação por nuvens e sombras. Para obtenção da $A O D$ na área de $10 \times 10 \mathrm{~km}$ é necessário que após os filtros aplicados reste um mínimo de 12 pixels (Kaufman et al., 1997b).

A incerteza na determinação $A O D$ sobre continente $\left(\tau_{\mathrm{a}}\right)$ pode ser calculada pela relação:

$$
\Delta \tau_{\mathrm{a}}= \pm 0,2 * \tau_{\mathrm{a}} \pm 0,05 \quad \text { IV.2 }
$$

O fator $\pm 0,05$, da equação IV.2, corresponde a um erro sistemático devido às incertezas na determinação da refletância de superfície, e o fator $\pm 0,2 * \tau_{\mathrm{a}}$ está relacionado a incertezas na determinação das propriedades físicas do aerossol (Kaufman et al. 1997b).Validações da AOD obtida operacionalmente pelo MODIS apontam que as maiores variabilidades encontradas sobre o continente estão relacionadas à refletância de superfície e ao modelo de aerossol (Remer et al., 2002; Chu et al., 2002; Ichoku et al., 2002a). Isso porque a refletância de superfície não é isotrópica, e sim bidirecional (BRDF), e os modelos de aerossol variam significativamente de região para região, devido às suas diferentes fontes de emissão e processos de formação e transformação (Dubovik, 2002a). Deste modo, apenas com a melhora da qualidade das premissas será possível representar melhor a distribuição e o tipo de aerossol detectado. 


\section{IV.2 O radiômetro espectral CIMEL e a rede AERONET}

Melhorar a estimativa do papel dos aerossóis nas mudanças climáticas globais, por meio de uma melhor caracterização de suas propriedades ópticas, é um dos principais objetivos que se pretende alcançar com a rede de radiômetros da AERONET (AErosol RObotic NETwork) (Holben et al., 1998; 2001). Coordenada pelo Dr. Brent Holben e pela NASA por meio do projeto EOS (Earth Observing System), com participação de instituições diversos países (Holben et al., 1998; 2001), a rede AERONET, nos últimos dezessete anos, acumulou mais de 600 pontos de observação. A rede mundial de monitoramento de aerossóis AERONET é composta por radiômetros espectrais solares automáticos fabricados pela empresa francesa CIMEL Eletronique. Estes radiômetros realizam medidas durante o período diurno continuamente e são instrumentos com elevada precisão. Sendo suas observações comumente utilizadas em validações de propriedades ópticas dos aerossóis obtidas em sensoriamento remoto por satélite, especialmente em validações do produto de $A O D$ do sensor MODIS (Remer et al., 2002; Chu et al., 2002; Ichoku et al., 2002a).

Neste trabalho, as observações de propriedades ópticas dos aerossóis realizadas pelo radiômetro CIMEL da rede AERONET, localizado no sítio experimental de Abracos Hill, região de Ji-Paraná-Rondônia, foram utilizadas na construção dos chamados modelos ópticos de aerossóis. As medidas de $A O D$ por sua vez foram utilizadas na validação dos resultados de $A O D$, com alta resolução espacial, obtidos a partir das observações de radiância realizadas pelo sensor MODIS.

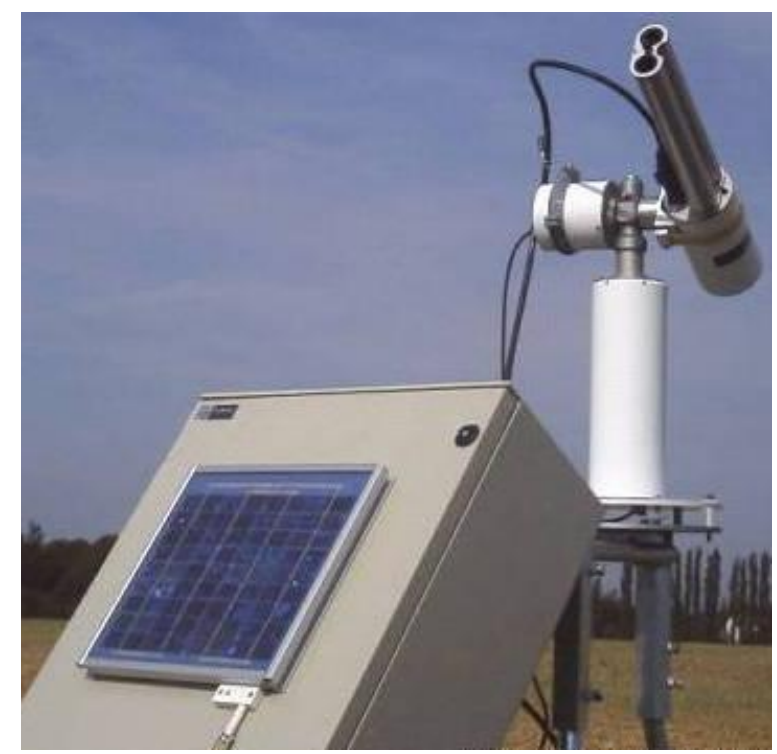

Figura IV.1: Foto do radiômetro CIMEL (http://www.cimel.fr/photo/sunph_us.htm). 


\section{IV.2.1 - Medidas da radiação solar direta e difusa realizadas pelo radiômetro CIMEL}

O radiômetro CIMEL, Figura IV.1, realiza tanto medidas diretas da radiação solar, em 8 comprimentos de onda $(1020 \mathrm{~nm}, 940 \mathrm{~nm}, 870 \mathrm{~nm}, 676 \mathrm{~nm}, 500 \mathrm{~nm}$, $440 \mathrm{~nm}, 380 \mathrm{~nm}, 340 \mathrm{~nm}$ ) a cada 15 minutos em média, quanto medidas de radiação difusa, em quatro comprimentos de onda $(1020 \mathrm{~nm}, 870 \mathrm{~nm}, 670 \mathrm{~nm}, 440 \mathrm{~nm})$, a cada hora. As medidas diretas da radiação solar permitem a obtenção da $A O D$ e da quantidade de água precipitável (QAP). Com o auxílio de modelos de inversão, a partir das medidas de radiação difusa do céu são obtidos parâmetros físicos das partículas na coluna atmosférica, tais como distribuição de tamanho, função de fase e índice de refração complexo. A partir destes parâmetros, é possível calcular outras propriedades como albedo simples e parâmetro de assimetria (Nakajima et al., 1983; Dubovik e King, 2000). Uma descrição detalhada do cálculo destas propriedades físicas e ópticas pode ser encontrada em Yamasoe, 1999 e Procópio, 2005.

As medidas realizadas pelo radiômetro CIMEL são transmitidas a cada hora para satélites geoestacionários, que as retransmitem para a central de controle na NASA Goddard Space Flight Center, em Greenbelt, EUA, onde são processadas. As medidas diretas e os produtos de inversões são disponibilizados no site http://aeronet.gsfc.nasa.gov/.

O coeficiente de Ångström ( $\alpha$ ) é obtido a partir da atenuação da radiação direta medida para vários comprimentos de onda. A $A O D$ é calculada a partir da Lei de Beer-Lambert-Bouguer (Holben et al., 1998), e corrigida pela atenuação devido ao espalhamento Rayleigh (Bucholtz, 1995). Uma pequena absorção pelo ozônio é levada em consideração, utilizando-se valores de climatológicos de concentração de ozônio (London et al., 1976). A QAP é obtida a partir das observações realizadas no canal de $940 \mathrm{~nm}$, pois neste comprimento de onda há uma forte banda de absorção pelo vapor de água (Bruegge et al., 1992).

A radiância difusa é medida no almucântar solar, para posição solar próxima ao horizonte, e no plano principal para posição solar próxima ao zênite, Figura IV.2. O almucântar é definido a partir de um plano horizontal definido dado um ângulo solar zenital fixo, Figura IV.2 (b). O plano principal é definido a partir de um plano vertical definido dado ângulo azimutal fixo do Sol, Figura IV.2. 


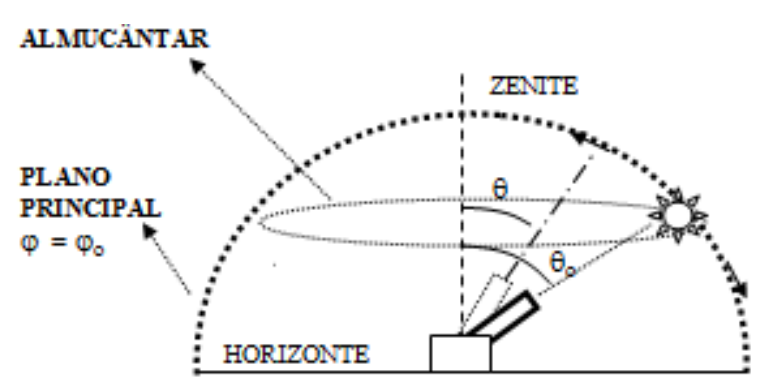

(a)

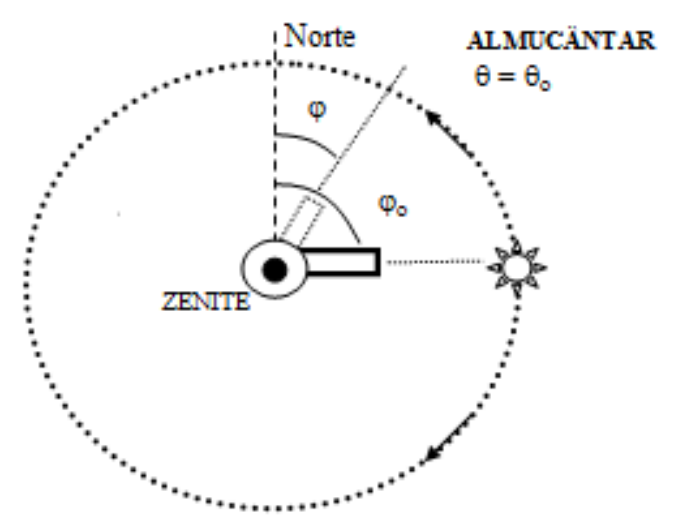

(b)

Figura IV.2: Esquema dos posicionamentos do radiômetro para a realização do Plano Principal (a) e Almucântar (b), onde $\varphi_{o}$ é o ângulo azimutal do Sol, $\varphi$ é o ângulo azimutal do sensor, $\theta_{\mathrm{o}}$ é o ângulo zenital do Sol, $\theta$ é ângulo zenital do sensor (Figura extraída de Castanho, 2005).

Os ângulos do radiômetro, tanto do almucântar quanto do plano principal, são definidos sempre em relação à posição do Sol. Desta forma, as medidas do almucântar variam do ângulo zero na direção do Sol (espalhamento frontal) até $180^{\circ}$ (espalhamento traseiro), em sentido horário (ângulos positivos) e anti-horário (ângulos negativos). Da mesma forma, o ângulo no Plano Principal é definido como zero na direção do Sol, sendo negativo para baixo do Sol e positivo para cima.

Visando a manutenção da confiabilidade nas medidas realizadas pelo fotômetro da rede AERONET, estes são calibrados em geral uma vez ao ano na NASA Goddard Space Flight Center (GSFC) por meio da inter-comparação com um instrumento de referência que opera na GSFC.

O instrumento de referência da GSFC por sua vez é calibrado no observatório de Mauna Loa no Hawai, pela técnica de Langley, técnica esta que independe da calibração de outros instrumentos. A técnica de calibração de Langley exige que durante todo o procedimento de calibração, a AOD permaneça constante, inviabilizando a aplicação desta técnica de calibração em todos os radiômetros da rede AERONET. A manutenção das condições atmosféricas é o motivo pelo qual esse procedimento é realizado no observatório de Mauna Loa, local de alta altitude e 
isolado de fontes locais e regionais de poluentes, que favorece a estabilidade das radiâncias atmosféricas medidas nas primeiras horas da manhã. Detalhes a respeito da metodologia de calibração empregada pela NASA, podem ser encontrados em Holben et al., 1998.

\section{IV.2.2 - Identificação das observações contaminadas pela presença de nuvens}

As observações de $A O D$ realizadas pelo fotômetro CIMEL da rede AERONET correspondem a uma seqüência de três medidas (chamadas tripletos). A variação dos valores medidos em cada tripleto é um indicativo da presença de nuvens no caminho óptico no qual as observações foram realizadas. Isso porque a cobertura de nuvens varia mais rapidamente que a camada de aerossóis, acarretando assim uma maior variabilidade nas radiâncias observadas pelo fotômetro. Para determinar se a medida representada pelo tripleto está livre da presença de nuvens, esta passa por dois filtros:

1. A medida é considerada contaminada por nuvens se a diferença entre o máximo e o mínimo da $A O D$ (em $670 \mathrm{~nm}$ ), medida no tripleto for superior a 0,02 ;

2. O segundo filtro analisa a segunda derivada do logaritmo de $A O D(\lambda)$ em função do tempo com o objetivo de identificar rápidas variações nos valores da $A O D$ observada (Smirnov et al., 2000).

Nas medidas do almucântar, valores de radiâncias assimétricos em relação aos dois hemisférios definidos pelo plano principal fazem com que estas sejam descartadas. Essa não simetria das radiâncias observadas pode ser devido à presença de nuvens ou mesmo da não-homogeneidade das condições atmosférica.

\section{IV.2.3 - Incertezas das observações realizadas pelo radiômetro CIMEL}

A partir de uma série de testes de sensibilidade das propriedades ópticas de aerossóis obtidas a diferentes condições de erros instrumentais aleatórios ou sistemáticos, Dubovik e colaboradores (2000) constataram que as incertezas das propriedades ópticas dependem da $A O D$, conforme podemos ver na Tabela IV.1. O radiômetro CIMEL é extremamente estável e preciso (Tabela IV-1). 


\begin{tabular}{ccc}
\hline Propriedade Óptica & \multicolumn{2}{c}{ Incertezas do $\tau(\mathbf{4 4 0 )}$ ou $\boldsymbol{A O D}(\mathbf{4 4 0})$} \\
& $\leq \mathbf{0 , 2} \pm \mathbf{0 , 0 2}$ & $\mathbf{\mathbf { 0 , 5 }}$ \\
\hline \hline$\omega_{\mathrm{o}}(\lambda)$ - albedo simples & $\sim 0,05-0,07$ & $\sim 0,03$ \\
\hline $\mathrm{n}(\lambda)$ - parte real do índice de refração & $\sim 0,05$ & $\sim 0,04$ \\
\hline $\mathrm{k}(\lambda)$ - parte imaginária do índice de refração & $80-100 \%$ & 30 a $50 \%$ \\
\hline
\end{tabular}

Tabela IV.1: Incertezas das propriedades ópticas, medidas pelos radiômetros CIMEL da rede AERONET, obtidas por meio de testes de sensibilidades realizados por Dubovik e colaboradores (2000).

As incertezas das distribuições de tamanho são significativas e mostraram-se adequadas para $\tau_{\mathrm{a}}(440) \geq 0,05$, condição na qual está incluída a maioria das situações. As maiores incertezas ocorrem nas regiões limítrofes da distribuição de tamanho, ou seja, no limite da moda de acumulação $(0,05 \leq \mathrm{r}<0,1)$ e da moda grossa $(7<\mathrm{r} \leq 15 \mu \mathrm{m})$, pois nestas faixas de tamanho do aerossol o espalhamento da radiação solar apresenta pouca sensibilidade à variação dos comprimentos de onda detectados pelo radiômetro da AERONET $(0,44 \mu \mathrm{m} ; 0,67 \mu \mathrm{m} ; 0,87 \mu \mathrm{m}$ e $1,02 \mu \mathrm{m})$. Estas incertezas, entretanto, não são preocupantes, pois as distribuições de tamanho possuem, em geral, valores reduzidos nas bordas.

Nos cálculos dos produtos de inversão, realizados pelos algoritmos da AERONET, os aerossóis são considerados esferas homogêneas, apesar de serem esferóides e por vezes não homogêneas. O impacto desta hipótese em situações nas quais ela não se aplica é mostrado por Dubovik et al., 2000, e a correção desta aproximação é abordada por Dubovik et al., 2002b.

\section{IV.3 - Modelo de transferência radiativa SBDART (Santa Babara DISORT Atmospheric Radiative Transfer)}

O modelo de transferência radiativa SBDART resolve a equação de transferência radiativa, considerando uma atmosfera plano-paralela com ou sem a presença de nuvens (Ricchiazzi et al., 1998). Tem como base o código DISORT Discret Ordinate Radiative Transfer (Wiscombe et al., 1977; 1980), que apresenta a solução exata das equações de transferência radiativa (ETR).

A intensidade da radiação espalhada ou emitida pode ser obtida em até 50 níveis diferentes de altitudes e direções (até 20 ângulos zenitais e azimutais). $\mathrm{O}$ modelo não inclui efeitos de polarização. $\mathrm{O}$ método utiliza no intervalo de onda 
curta uma extensão da aproximação delta-Eddington. Considera-se a função de fase delta de Dirac para espalhamento frontal e a aproximação de Henyey-Greenstein para o retro-espalhamento.

O modelo de transferência radiativa SBDART possui uma biblioteca com propriedades padrão que modelam as características de diferentes condições atmosféricas como: tipos de aerossol, nuvens, moléculas de gás e propriedades da superfície terrestre. Entretanto, também permite que o usuário defina, por exemplo, o modelo óptico de aerossol que deverá ser utilizado.

O modelo de transferência radiativa SBDART é codificado em Fortran77, e opera no sistema operacional UNIX ou na versão para o sistema operacional Windows (http://arm.mrcsb.com/sbdart/), que é atende às necessidades ligadas ao ensino da transferência radiativa na atmosfera terrestre, por apresentar uma didática interface.

Neste trabalho, o código de transferência radiativa SBDART foi utilizado em diversas etapas. Inicialmente com o intuito de verificar se os modelos ópticos de aerossóis construídos eram adequados para descrever a camada de aerossóis da região, estes foram utilizados como parâmetro para simular o fluxo de radiação solar incidente, item V.4.5. Posteriormente simulou-se a radiância no topo da atmosfera sob diferentes refletâncias de superfície e para cada modelo óptico de aerossol construído. Com esses resultados construiu-se um conjunto de equações, que recuperam o valor de $A O D$ no local e dia analisado com base na radiância observada no topo da atmosfera pelo sensor MODIS, as chamadas equações de inversão, item V.6. Os efeitos de espalhamento Rayleigh e de absorção por ozônio também foram corrigidos utilizando o código de transferência radiativa SBDART, para que fosse possível recuperar as informações da refletância da superfície analisada. 


\section{PROfundidade ÓPtica de AEROSSÓIs COM ALTA RESOluçÃo ESPACIAL- MÉTODO UTILIZADO}

O método utilizado neste trabalho para obter a $A O D$ com alta resolução espacial, utilizando observações de radiância realizadas pelo sensor MODIS foi desenvolvido por Castanho (2005) para utilização em áreas urbanas, com aplicação realizada para a região metropolitana de São Paulo. A resolução espacial disponível atualmente dos produtos regulares do sensor MODIS é de $10 \mathrm{~km}$ x $10 \mathrm{~km}$. Neste trabalho, o método desenvolvido foi aplicado na região de Ji-Paraná - Rondônia, para aerossóis de queimadas.

Resumidamente, o método pode ser descrito da seguinte forma: por meio de simulações realizadas com o código de transferência radiativa SBDART, é obtida a $A O D$ como função da radiância no topo da atmosfera, parâmetro que é observado pelo sensor MODIS. Ao invés de simplesmente fazer referência ao trabalho de Castanho, 2005, optou-se por dedicar um capítulo exclusivamente à descrição minuciosa do método utilizado, por se tratar de um processo com muitos detalhes que não é composto de um passo após o outro, mas sim por etapas concomitantes.

O fluxo de radiação solar no topo da atmosfera (TOA Top Of Atmosphere), pode ser incidente ou emergente. Ao incidir na atmosfera, ocorre a interação com a camada de aerossóis e gases ao longo da coluna atmosférica, fazendo com que parte desse fluxo seja absorvida e parte seja espalhada. Uma fração do que foi espalhado pode continuar na atmosfera (espalhado frontalmente) e outra fração pode retornar ao espaço (retro-espalhado). A parte da radiação que chega à superfície, por sua vez, é refletida novamente para atmosfera, de acordo com a refletância da superfície $\left(\rho_{\text {sup }}(\lambda)\right)$, realimentando assim o processo. Deste modo, o fluxo de radiação no TOA emergente é resultado da somatória desse conjunto de interações.

A intensidade dessa interação, assim como qual fração corresponderá à absorção, ao espalhamento frontal e ao retro-espalhamento dependerão da quantidade de aerossóis presente na atmosfera e de como esse aerossol interage com a radiação. A quantidade integrada é expressa pela $A O D(\tau(\lambda))$, e o tipo da interação pelas propriedades ópticas do aerossol, que são: albedo simples $\left(\omega_{0}(\lambda)\right)$, parâmetro de assimetria $(g(\lambda))$, função de fase $(P(\Theta, \lambda))$ e eficiência de extinção $\left(Q_{\text {ext }}(\lambda)\right)$. 


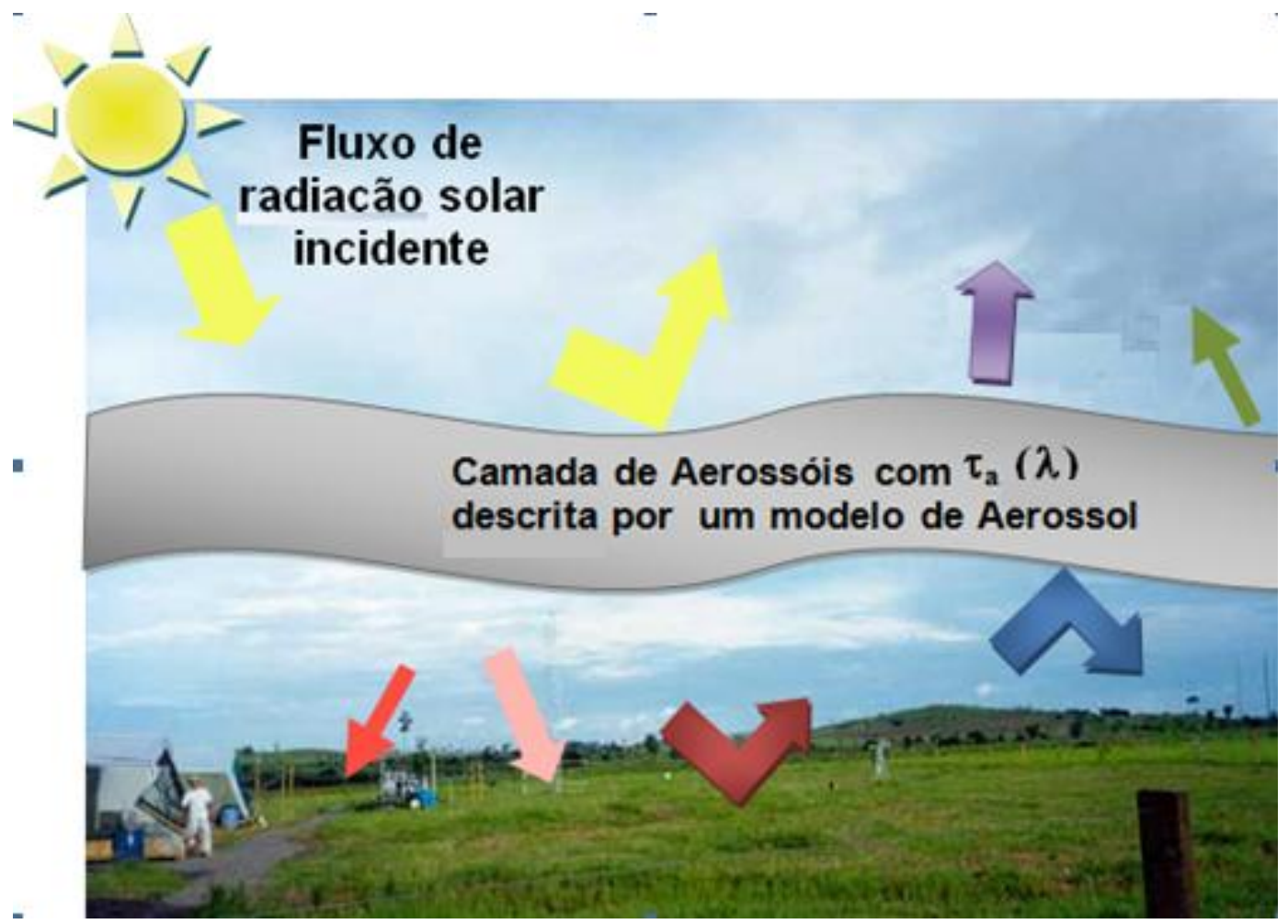

Figura V.1: Desenho esquemático das interações do fluxo de radiação solar incidente com a atmosfera, camada de aerossóis e refletância de superfície).

Como os valores de $A O D$ com alta resolução espacial serão obtidos a partir das observações de radiância no topo da atmosfera, é preciso conhecer os principais fatores que afetam tais observações, esquematizados na Figura V.1, e os principais componentes necessários para o cálculo desses fatores, apresentados a seguir:

1. O fluxo de radiação solar incidente no topo da atmosfera. Componente necessário: fluxo espectral de maior resolução disponível na biblioteca do SBDART Lowtran_7;

2. As posições angulares relativas entre o Sol e a Terra e entre o Sol e o sensor Componente necessário: arquivos de georreferenciamento do MODIS;

3. As propriedades ópticas dos aerossóis presentes na atmosfera (para inferir a interação do fluxo de radiação solar incidente com estes, caracterizando assim o material particulado da região). Componente necessário: construção de um modelo baseado nas propriedades ópticas dos aerossóis medidas pelo fotômetro da rede AERONET na região de estudo (capítulo V.4);

4. Radiância resultante no topo da atmosfera, após as interações com a atmosfera, camada de aerossóis e superfície. Componente necessário: medidas realizadas pelo sensor MODIS, com resolução de 500x500 m; 
5. Discriminar, dentre a fração da radiação solar incidente que voltou ao topo da atmosfera, a parte que corresponde à interação com a camada de aerossóis, que é a responsável pela $A O D$ (É importante enfatizar que a interação com a camada de aerossóis depende do tipo de aerossol presente na atmosfera, identificado dentre os modelos ópticos construídos, e que a radiação disponível para interação com a camada de aerossóis depende do quanto esta radiação é refletida pela superfície $\left(\rho_{\text {sup }}(\lambda)\right)$. Componente necessário: obter a $A O D$ esperada como função da radiância no topo da atmosfera, de acordo com cada modelo óptico de aerossol e com a refletância de superfície, por meio de simulações realizadas com o código de transferência radiativa SBDART, gerando assim, as chamadas Equações de Inversão, item V.6. Como a refletância de superfície não é constante ou homogênea, as simulações foram realizadas para um intervalo de valores fisicamente representativos. Os passos necessários para o cálculo da profundidade óptica em alta resolução e o item nos quais eles serão discutidos em detalhe estão sumarizados na FiguraV.2. 


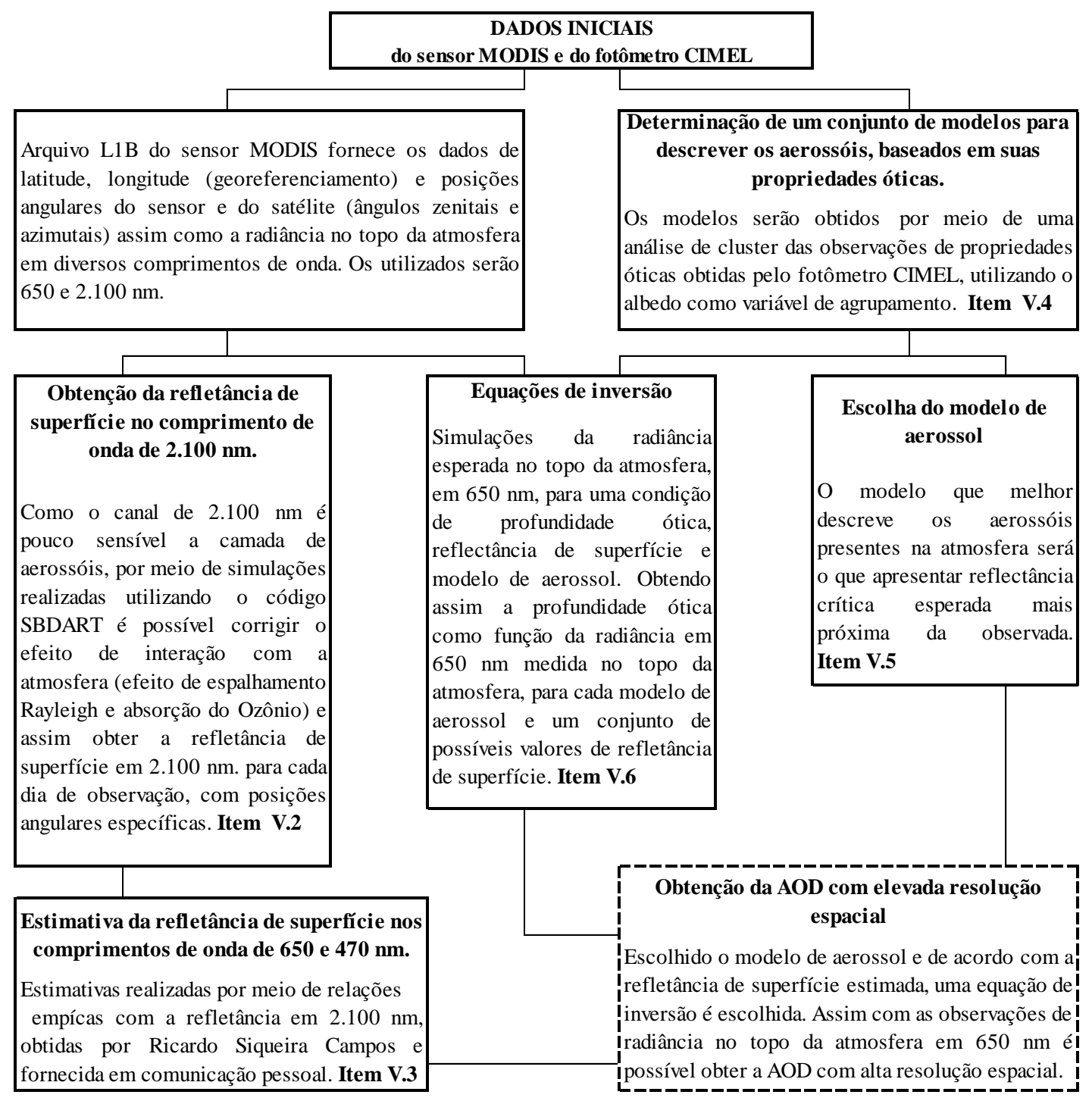

Figura V.2: Resumo das etapas para o cálculo da $A O D$ com alta resolução espacial, bem como os itens nos quais essas etapas serão detalhadas. 


\section{V.1 Configuração angular do sol e do sensor em relação à região de estudo}

A geometria das posições angulares do sensor e do Sol em relação à região observada (em cada 'pixel') é essencial para o cálculo da $A O D$. Foram utilizados valores médios das respectivas posições angulares, nos cálculos da $A O D$ dos pixels contidos na área de estudo, para cada dia analisado.

A Figura V.3 ilustra as posições zenitais do sensor $(\theta)$ e do Sol $\left(\theta_{\mathrm{o}}\right)$ no horário de passagem do satélite TERRA (10h30min horário local). No trabalho de Castanho (2005) foram consideradas apenas situações em que o sensor realizou observações em torno do zênite $\left(\theta<30^{\circ}\right)$, evitando observações com grandes inclinações angulares, que possuem resolução espacial reduzida. Neste trabalho, entretanto, consideraram-se ângulos zenitais superiores a $30^{\circ}$, conforme apresentado na Figura V.4, pois apesar de haver uma redução na resolução espacial, bons resultados são esperados também nestas situações.

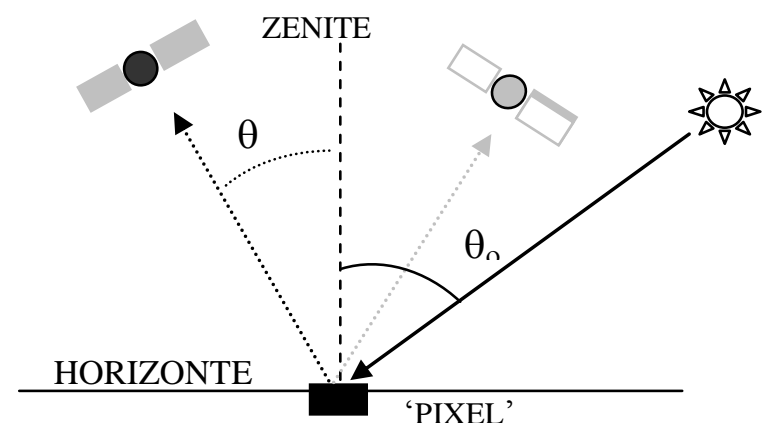

Figura V.3: Ilustração dos ângulos zenitais do satélite $(\theta)$ e do Sol $(\theta 0)$ na passagem do satélite TERRA (10h30min horário local). O ângulo zenital é sempre positivo nas situações indicadas no esquema (Castanho, 2005). 


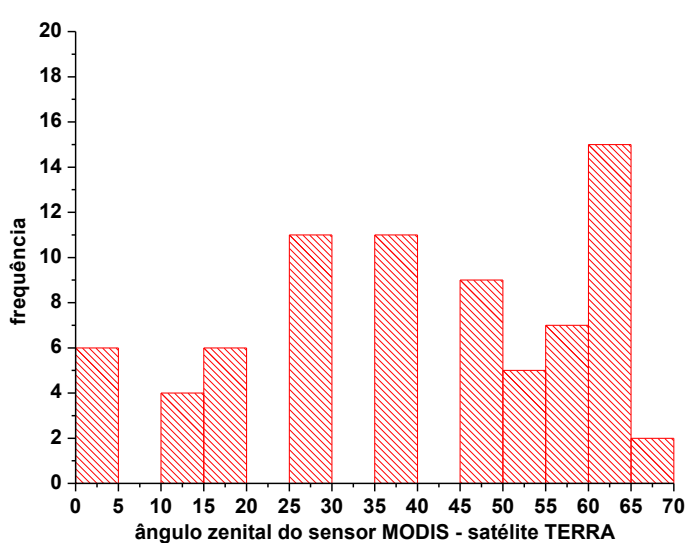

(a)

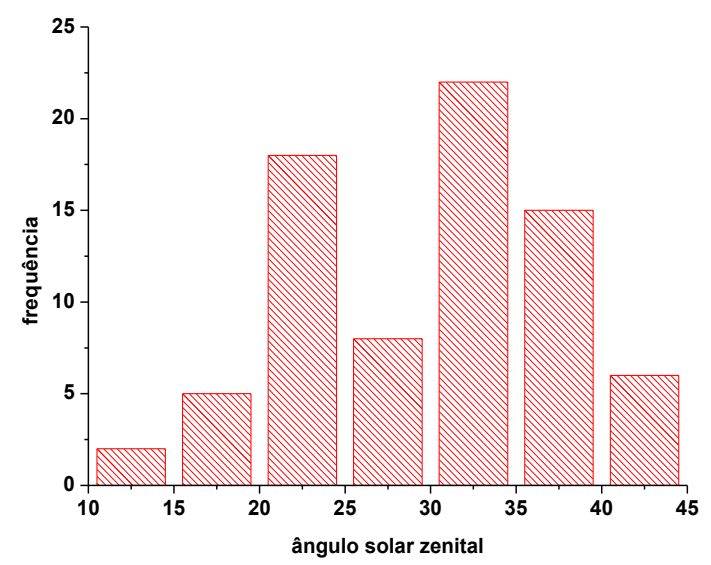

(b)

Figura V.4: Histograma representativo dos ângulos zenitais do sensor MODIS no satélite TERRA (a) e do ângulo zenital do Sol (b), para os casos estudados entre os anos de $2000 \mathrm{e}$ 2005.

A Figura V.5 ilustra as posições angulares azimutais do sensor $(\varphi)$ e do Sol $\left(\varphi_{\mathrm{o}}\right)$ no horário da passagem do satélite TERRA (10h30min horário local). Com relação ao norte, no sentido horário, os valores de $\varphi$ são positivos, e no sentido oposto são negativos. No código de transferência radiativa SBDART, é considerado o ângulo azimutal relativo entre o sensor e o Sol (phi SBDART), mostrado também na Figura V.5.

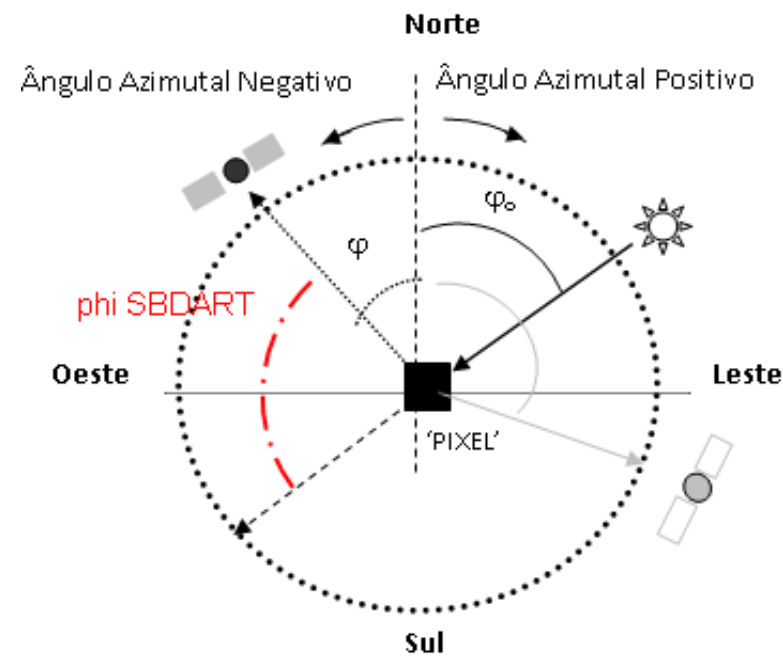

Figura V.5: Ilustração dos ângulos azimutais do satélite $(\varphi)$ e do Sol $\left(\varphi_{0}\right)$ na passagem do satélite TERRA (10h30min horário local). O ângulo azimutal é positivo no sentido horário em relação ao norte e negativo no sentido oposto. Outra posição possível do sensor é ilustrada na forma sombreada (Castanho, 2005). 
A Figura V.6 apresenta o histograma dos ângulos azimutais do sensor e do Sol para os casos estudados neste trabalho.

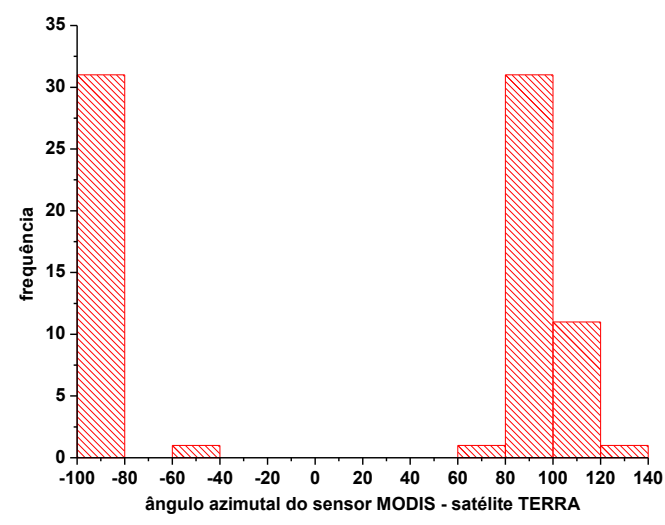

(a)

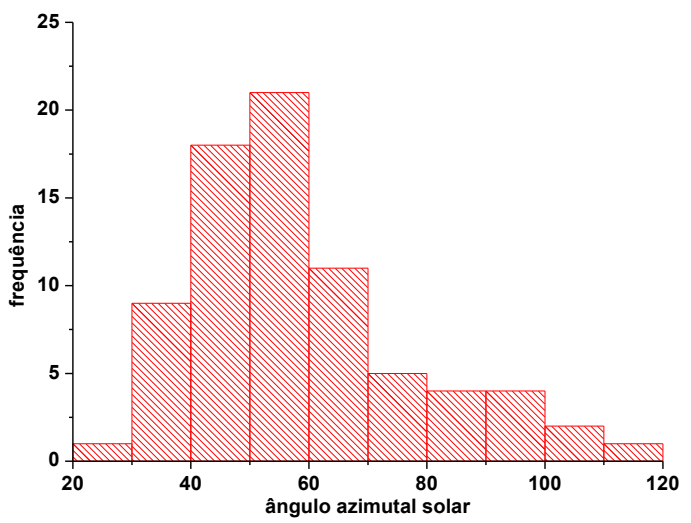

(b)

Figura V.6: Histograma representativo dos ângulos azimutais do sensor MODIS no satélite TERRA (a) e do ângulo azimutal do Sol (b), para os casos estudados entre os anos de 2000 e 2005.

Neste trabalho, para a definição das equações de inversão, as refletâncias foram calculadas com as posições angulares médias da região de estudo específicas de cada dia analisado.

\section{V.2 Determinação da refletância de superfície no comprimento de onda de $2.100 \mathrm{~nm}$}

De acordo com Kaufman (1993), a radiância medida no topo da atmosfera sofre uma interação com os aerossóis presentes na coluna atmosférica. Essa interação diminui com $\lambda^{-1}$ (predomínio da moda de acumulação) e $\lambda^{-2}$ (predomínio da moda grossa), principalmente para aerossóis da moda fina, partículas com diâmetro inferior a 2,5 m. A interação dos aerossóis com a radiância em comprimentos de onda longos como $2.100 \mathrm{~nm}$ é bastante reduzido, e por esta razão que este comprimento de onda é utilizado para obtenção da refletância de superfície, que é um parâmetro básico em sensoriamento remoto de aerossóis.

Deste modo, será considerado que a radiância medida pelo sensor MODIS em $2.100 \mathrm{~nm}$ é a refletância da superfície após a interação desta com a atmosfera devido ao espalhamento Rayleigh e à absorção da radiação pelo conteúdo de vapor de água na coluna. Neste comprimento de onda, a absorção radiativa por moléculas de ozônio pode ser considerada desprezível. 
A Figura V.7 apresenta a distribuição das refletâncias de superfície em $2.100 \mathrm{~nm}$, na região em torno do sítio experimental Ji-Paraná-RO, onde está localizado o fotômetro CIMEL (ponto vermelho no centro da imagem). Nota-se a existência de acentuadas áreas de desmatamento, o que gera alta variabilidade espacial nos valores de refletância.

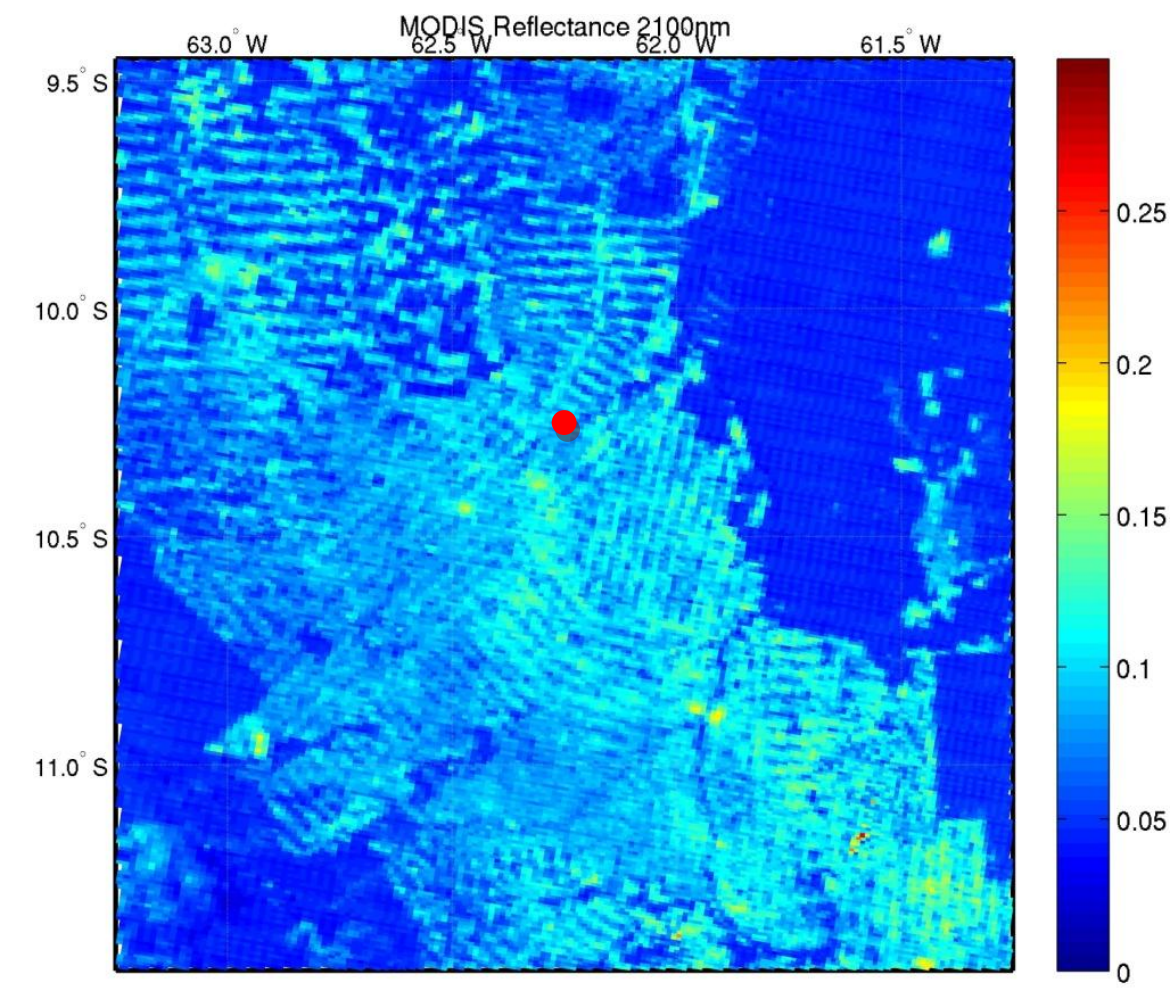

Figura V.7: Refletância de superfície no comprimento de onda de $2.100 \mathrm{~nm}$ obtida para o dia 11 de setembro de 2002, corrigido o efeito da atmosfera por meio do código de transferência radiativa SBDART.

Para recuperar a refletância de superfície em $2.100 \mathrm{~nm}$ foi realizada uma correção atmosférica, utilizando o código de transferência radiativa SBDART, tendo como parâmetros as mesmas variáveis utilizadas para construção das equações de inversão (item V.6), considerando $A O D$ nula e a geometria sol/sensor (item V.1) observada em cada dia de estudo. 


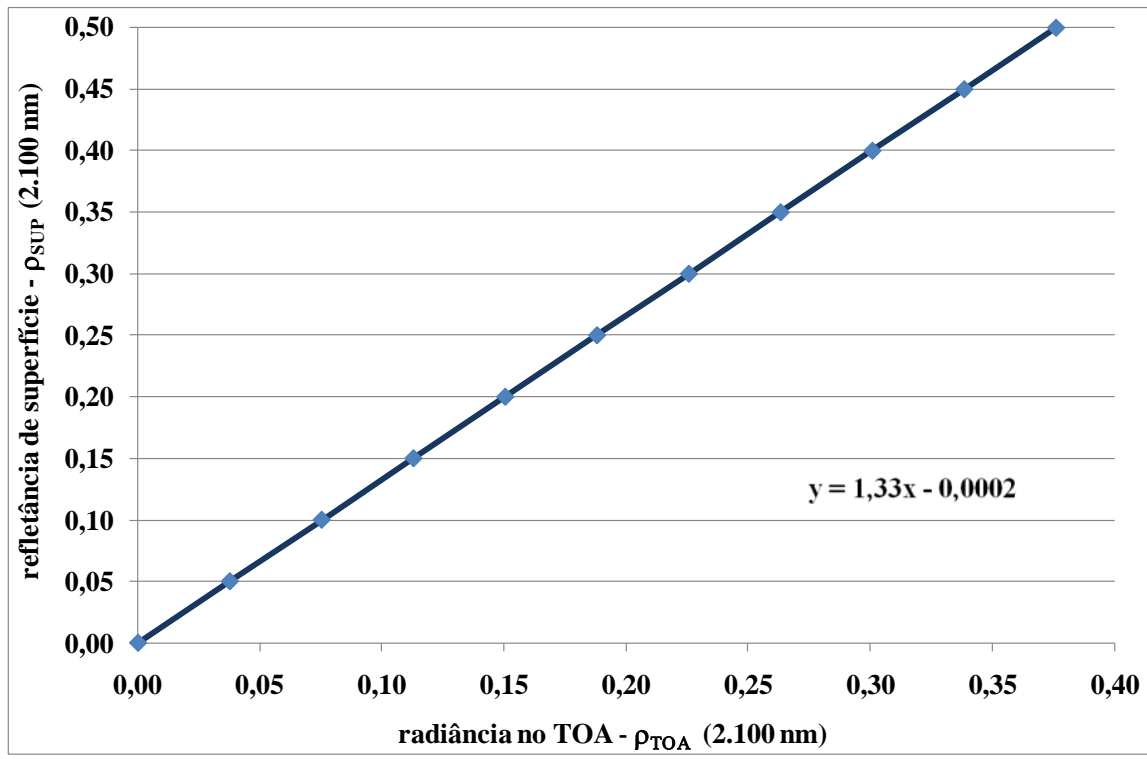

Figura V.8: Regressão linear utilizada para corrigir o efeito da atmosfera na refletância no topo em $2.100 \mathrm{~nm}$ e assim obter a refletância de superfície em $2.100 \mathrm{~nm}$, com a geometria do dia 2 de agosto de $2002\left(\theta 0=38.31^{\circ}\right.$, phi SBDART $\left.=34.9^{\circ}\right)$.

A Figura V.8 é um exemplo de regressão linear entre a refletância na superfície, considerando $A O D=0$, em função da refletância medida no topo da atmosfera no comprimento de onda de $2.100 \mathrm{~nm}$. Neste caso foi corrigida a interação da radiação solar com a camada atmosférica, para uma condição livre de aerossóis, o que chamamos de correção atmosférica.

\section{V.3 Estimativa da refletância de superfície nos comprimentos de onda de $650 \mathrm{~nm}$ e $470 \mathrm{~nm}$.}

O cálculo da $A O D$ com alta resolução espacial depende da refletância da superfície nos comprimentos de onda de $650 \mathrm{~nm}$ e $470 \mathrm{~nm}$. Entretanto, como o satélite mede a radiância no topo da atmosfera, para recuperar a refletância da superfície nesses comprimentos de onda, além de corrigir os efeitos da atmosfera como foi feito para o comprimento de onda de $2.100 \mathrm{~nm}$, é necessário conhecer a composição atmosférica tanto no que se refere a gases como aerossóis. Isso ocorre porque na faixa do espectro visível a interação de gases e partículas com a radiação não pode ser desprezada. Além disso, a refletância de superfície não se trata de uma grandeza homogênea em todas as direções, e sim de uma função que varia com a distribuição angular, chamada de "distribuição da refletância bidirecional (BRDF)", que é característica da superfície e das condições ambientais (Kaufman e Remer 1994). Kaufman e colaboradores (1997) obtiveram relações empíricas entre a refletância de 
superfície no infravermelho e no visível (nas faixas do azul e vermelho). Essas relações vêm sendo verificadas em outros trabalhos (Chu et al., 2002; Kaufman et al., 2002a), apresentando bons resultados quando a refletância de superfície em $2.100 \mathrm{~nm}$ está entre valores de 0.005 e 0.25. O algoritmo do MODIS utiliza as relações estudadas por Kauffman et al., 1997b, conforme descrito na seção IV.1.2.

Neste trabalho também foram utilizadas equações empíricas, porém definidas especificamente para a região de Ji-Paraná por Ricardo Siqueira Campos, na época mestrando do Instituto de Astronomia e Geofísica - USP (comunicação pessoal). Para tanto, utilizou-se modelos ópticos de aerossóis e informações específicas da região de estudo. Assim como o algoritmo do sensor MODIS, a superfície é considerada Lambertiana, ou seja, o espalhamento da radiação na superfície é considerado homogêneo em todas as direções.

Conforme pode ser visto na Figura V.9, a relação entre as refletâncias de superfície para cada comprimento de onda são:

$$
\begin{aligned}
& \rho_{470}=\rho_{2.100} * 0,21 \\
& \rho_{670}=\rho_{2.100} * 0,55
\end{aligned}
$$



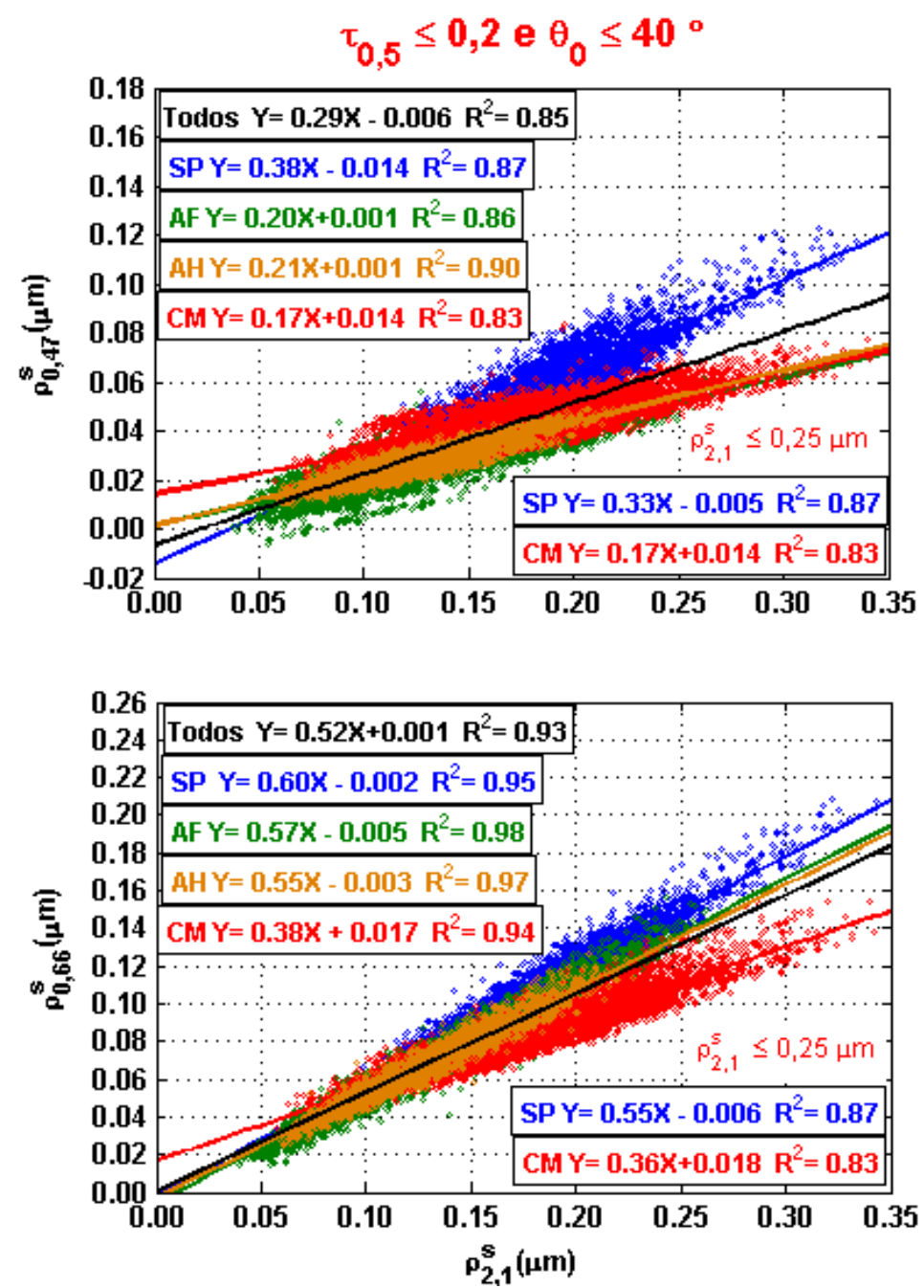

Figura V.9: Relações entre as refletâncias de superfície no vermelho (670 nm) e no azul (470 $\mathrm{nm})$ em relação ao infravermelho $(2.100 \mathrm{~nm})$, para as regiões de São Paulo (SP), Ji-Paraná $(\mathrm{AH})$, Alta Floresta (AF) e Cuiabá Miranda (CM).

Dessa maneira, admitindo que o aerossol sub-micrométrico seja transparente à radiação no comprimento de onda $2.100 \mathrm{~nm}$, e fazendo a correção atmosférica do valor de radiância medida pelo MODIS, é possível estimar, através das relações empíricas citadas, informações acerca da refletância de superfície no visível, necessárias para o cálculo da $A O D$ com alta resolução espacial. 


\section{V.4 Determinação de um conjunto de modelos para descrição das propriedades ópticas dos aerossóis.}

As propriedades ópticas dos aerossóis e a quantidade de material suspenso na atmosfera são determinantes no efeito radiativo dos aerossóis (Shettle e Fenn, 1979; Ferrare et al., 1998; Martins, 1999). Deste modo, caracterizar as propriedades ópticas das partículas de aerossóis a partir de modelos ópticos bem estruturados e com base física e experimental é essencial para obter valores de $A O D$ com alta resolução espacial e boa acurácia.

Inicialmente será apresentada a variabilidade mensal de algumas propriedades ópticas dos aerossóis, com posterior análise detalhada destas durante o período de queimadas em comparação a aerossóis presentes na região urbana de São Paulo (Castanho, 2005) no período do inverno, com o intuito de verificar as semelhantes e diferenças existentes entre a camada de aerossóis existentes nas duas regiões. Por fim, os modelos ópticos de aerossóis construídos para representar os aerossóis da região no período de queimadas, bem como a validação da representatividade destes serão apresentados.

\section{V.4.1 Variabilidade mensal das propriedades ópticas dos aerossóis na região de Ji-Paraná}

Este item destina-se à análise da variabilidade mensal de algumas características dos aerossóis de Ji-Paraná bem como a variabilidade da quantidade QAP. Os resultados apresentados neste item foram obtidos com o fotômetro da rede AERONET no sítio experimental de Ji-Paraná em Rondônia, de 1999 a 2005, com qualidade assegurada em relação à presença de nuvens e calibração do radiômetro (utilizaram-se os produtos do nível 2.0). A confiabilidade das informações fornecidas pela AERONET apresenta uma limitação: os produtos de inversões, como o albedo simples de espalhamento, só têm qualidade garantida quando a $A O D$ em $440 \mathrm{~nm}$ é superior a 0,4. Deste modo, visando garantir a representatividade estatística dos resultados, considerou-se somente o período de queimadas para construção dos modelos de aerossol, pois neste período os valores de $A O D$ são mais elevados e a frequência de medidas é maior devido, sobretudo à menor incidência de nuvens.

A Figura V.10 apresenta a frequiência de observações realizadas pelo fotômetro da rede AERONET em Ji-Paraná. Verifica-se que a frequência de observações é 
notadamente superior nos meses em que há a menor ocorrência de nuvens: período de seca (junho-julho) e de queimadas (agosto - outubro).

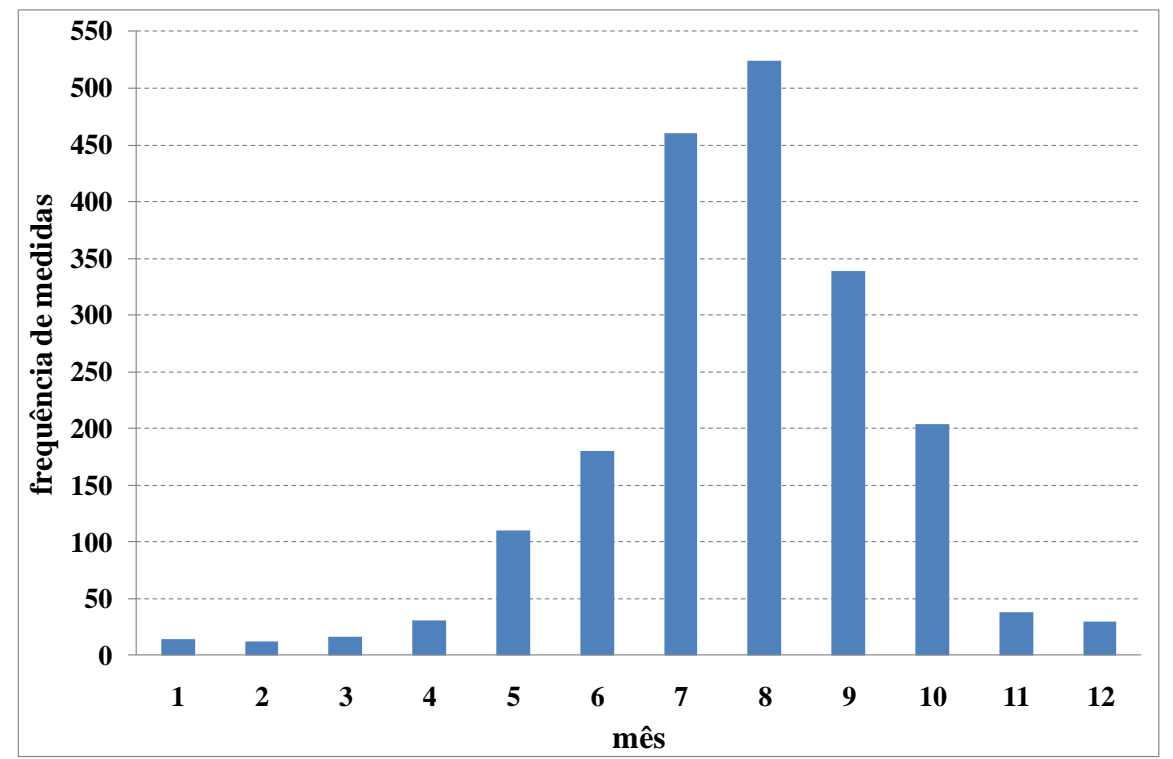

Figura V.10: Freqüência mensal de medidas de propriedades ópticas realizadas pelo fotômetro da rede AERONET em Ji-Paraná, de 1999 a 2005.

As médias mensais da QAP são apresentadas na Figura V.11. A redução da QAP, de maio a outubro, período de menor taxa de precipitação, coincide com a estação seca, com a ocorrência de queimadas de florestas e pastos a partir de agosto. A redução da QAP favorece a obtenção da $A O D$ por sensoriamento remoto, pois ocorre uma diminuição da formação de nuvens e torna menos relevante os erros cometidos na correção da presença do vapor na coluna atmosférica. Os valores de QAP variam em torno de 4 a 4,5 cm nas épocas de chuva (novembro - abril), e de 3 a $4 \mathrm{~cm}$ na época de seca e queimadas na região de Ji-Paraná. Observa-se em novembro um aumento da QAP, devido à transição para a época de chuvas. 


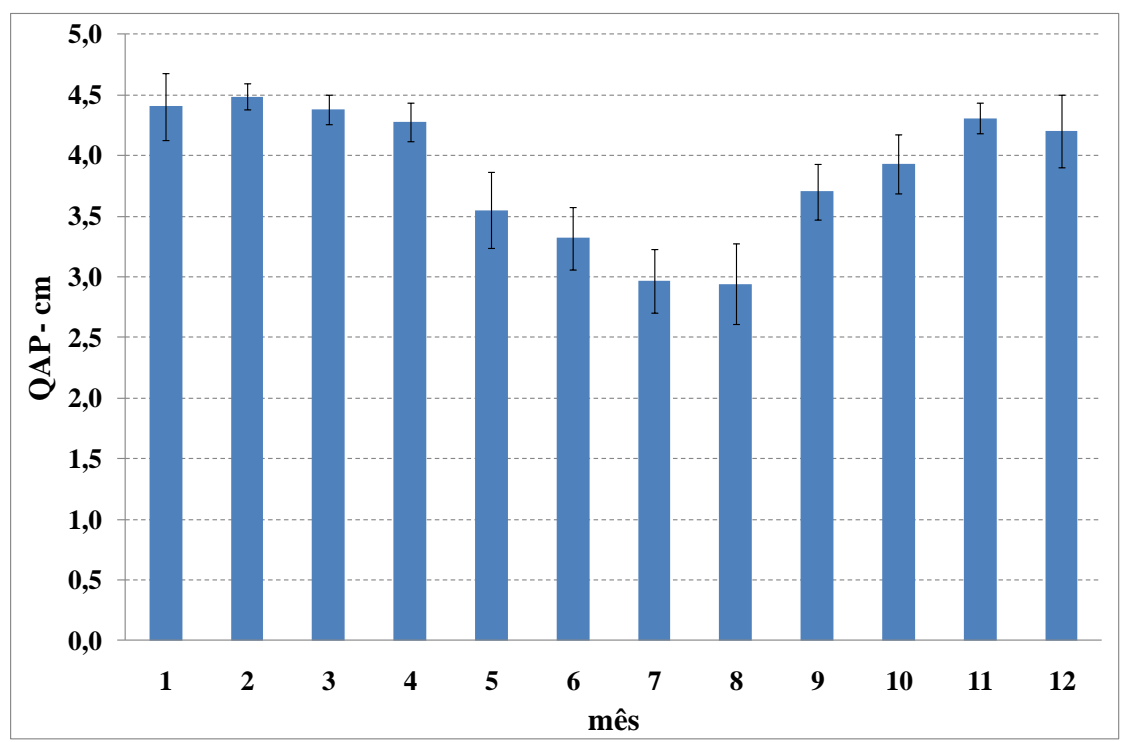

Figura V.11: Médias mensais da quantidade de água precipitável na coluna atmosférica (QAP), obtidas por meio das observações realizadas em Ji-Paraná de 1999 a 2005, no sítio experimental da rede AERONET. As barras representam o desvio padrão das observações de QAP do mês correspondente.

As médias mensais da $A O D$ em $500 \mathrm{~nm}(A O D(500))$, apresentadas na Figura V.12, revelam um aumento muito significativo na quantidade de aerossóis no período afetado pela incidência das queimadas (agosto - outubro). Valores extremos da $A O D$, na estação de queimadas, ilustrados na Figura V.13, explicam o alto desvio padrão desse período, observado na Figura V.12.

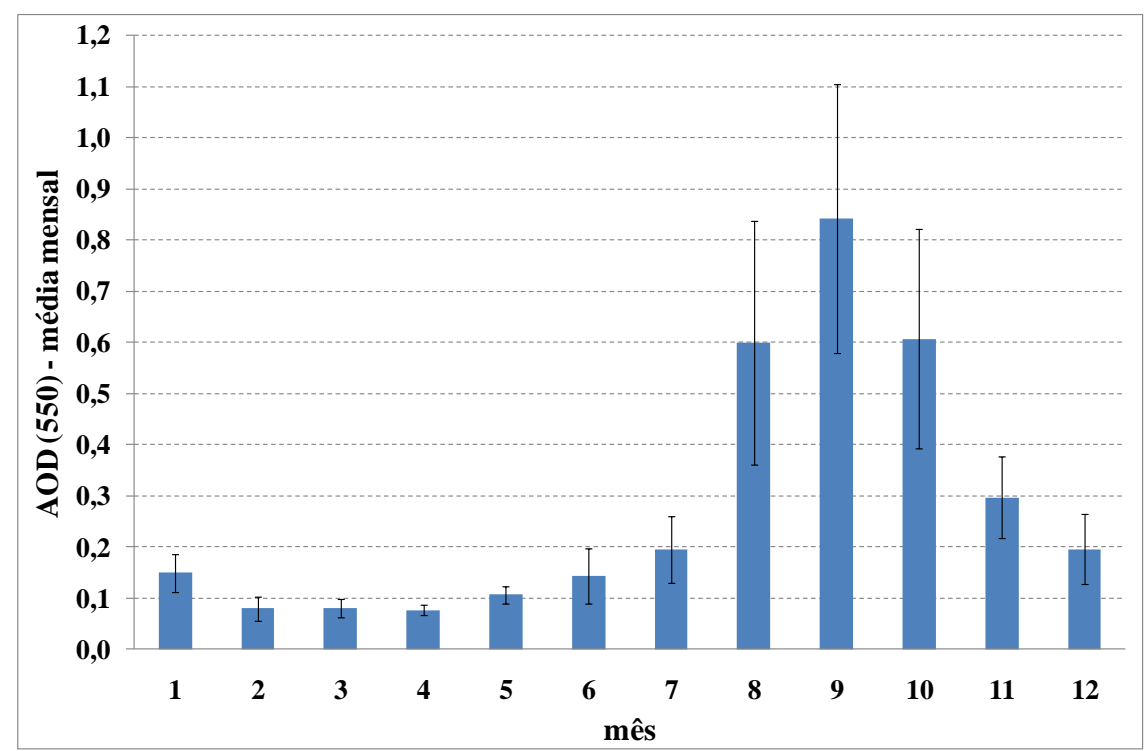

Figura V.12: Médias mensais da $A O D(500 \mathrm{~nm})$, obtidas por meio das observações realizadas, pelo fotômetro da rede AERONET, em Ji-Paraná de 1999 a 2005. As barras representam o desvio padrão dos valores de $A O D$ observados no mês correspondente. 


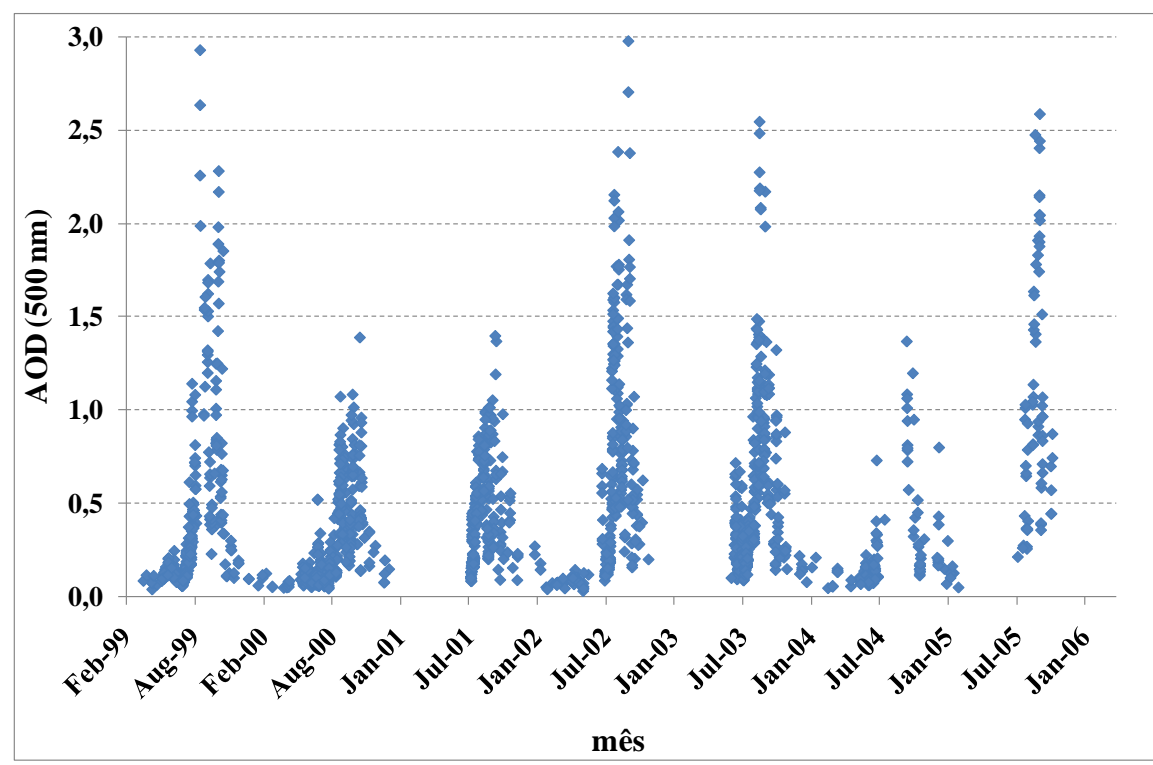

Figura V.13: Série temporal da $A O D(500 \mathrm{~nm})$ de 1999 a 2005. Os pontos representam observações realizadas a cada 15 minutos, durante o dia, pelo fotômetro da rede AERONET, em Ji-Paraná.

Observou-se um aumento significativo dos valores da $A O D$ com a incidência das queimadas. Na Figura V.14 é possível observar que a dependência espectral da $A O D$ de aerossóis emitidos durante estes meses apresenta o mesmo comportamento que nos demais meses do ano, entretanto com um aumento bem mais acentuado para menores comprimentos de onda. Isso se deve principalmente à alteração na distribuição de tamanho e nas propriedades ópticas dos aerossóis.

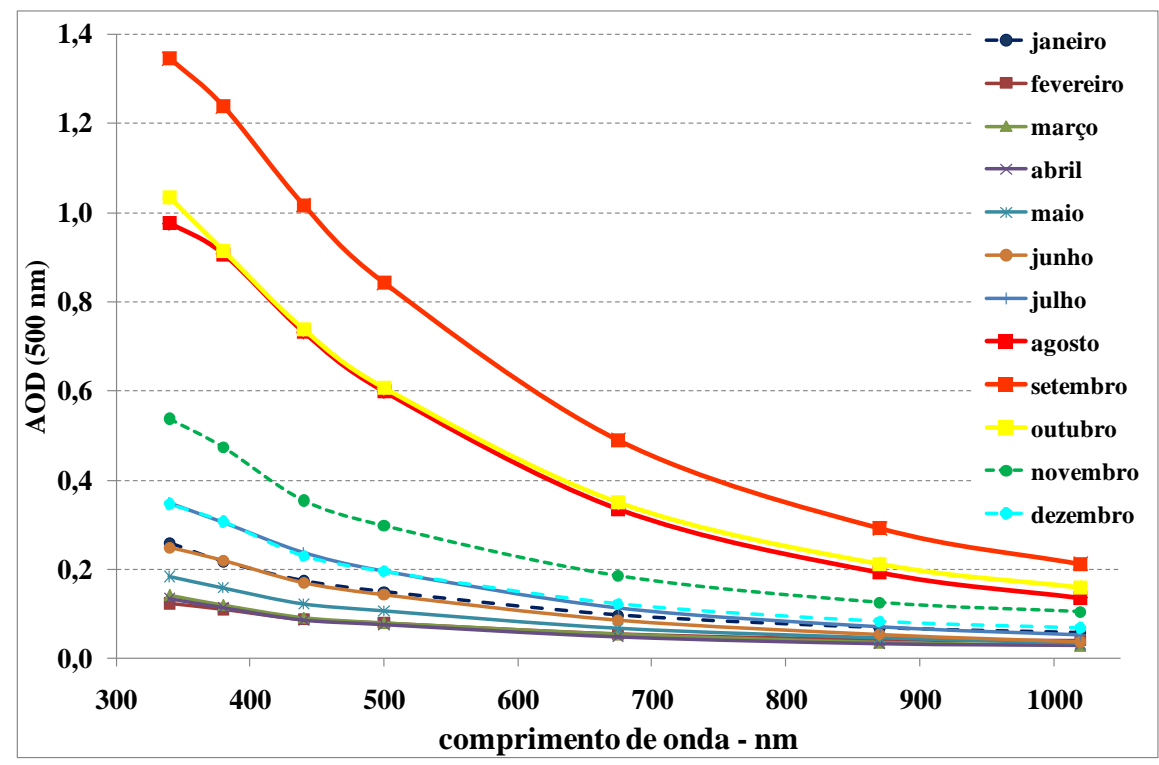

Figura V.14: Dependência espectral da $A O D$ em função das médias mensais. Observações realizadas pelo fotômetro da rede AERONET, em Ji-Paraná, de 1999 a 2005. 
A Figura V.15 e a Figura V.17 apresentam as médias mensais, de 1999 a 2005, do albedo simples $\left(\omega_{0}\right)$ e parâmetro de assimetria (g) das partículas, respectivamente. Na Figura V.15 é possível observar que o $\omega_{0}(441 \mathrm{~nm})$ apresenta, em média, valores menores durante a estação seca $(0,90 \pm 0,04)$ do que durante a estação chuvosa $(0,92 \pm 0,05)$, indicando um aerossol mais absorvedor de radiação na estação seca. Os aerossóis amostrados durante o período de queimadas (de agosto a outubro) apresentam valores de $\omega_{0}(441 \mathrm{~nm})$ semelhantes aos da estação chuvosa $(0.93 \pm 0,03)$. Nos meses de janeiro e fevereiro, onde ocorre à predominância de aerossóis biogênicos, os aerossóis mostram-se absorvedores. A dependência espectral do albedo dos aerossóis da estação de queimadas e na estação chuvosa é semelhante, conforme mostra a Figura V.16.

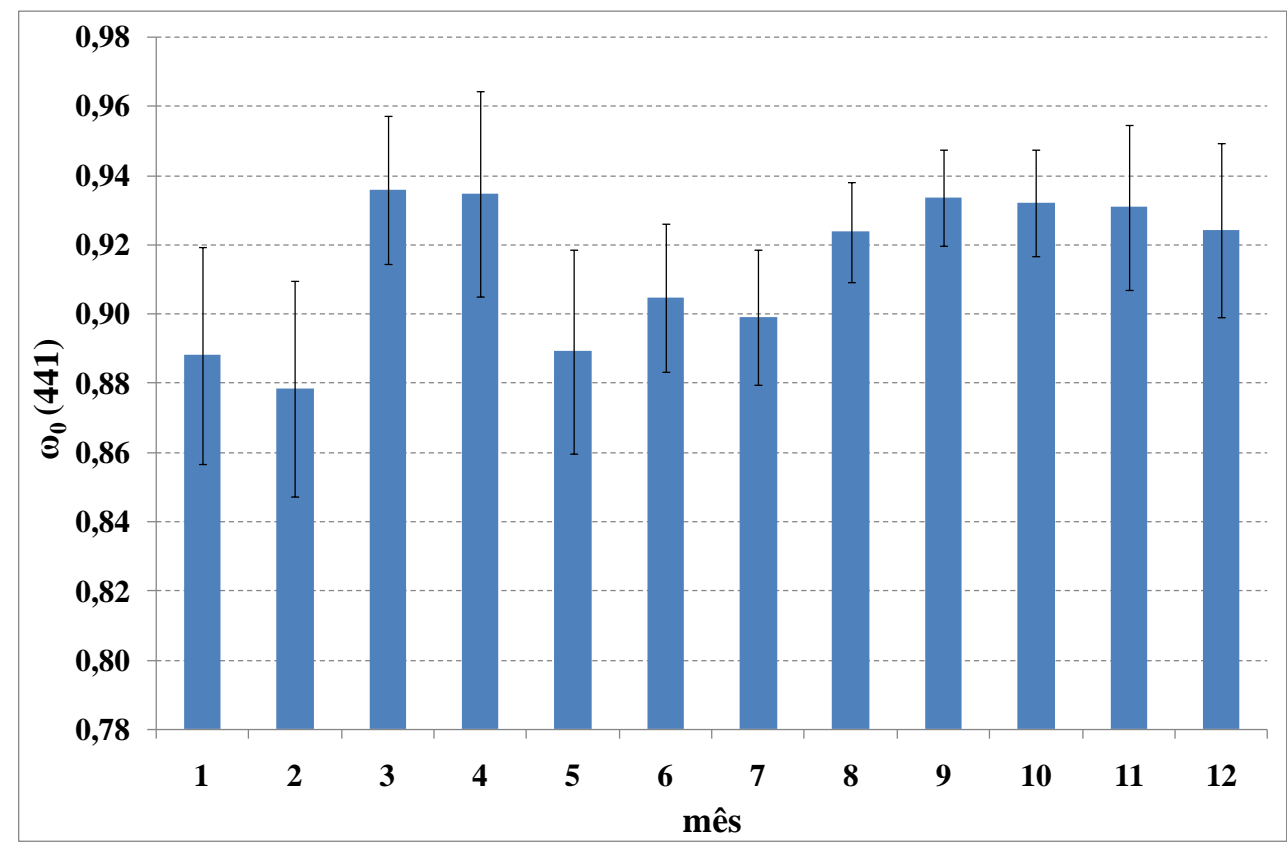

Figura V.15: Médias mensais do albedo simples em $441 \mathrm{~nm}$. As barras representam o desvio padrão das medidas, no mês correspondente. Os valores de albedo são resultados de inversões que utilizam observações realizadas pelo fotômetro da rede AERONET em JiParaná de 1999 a 2005. 


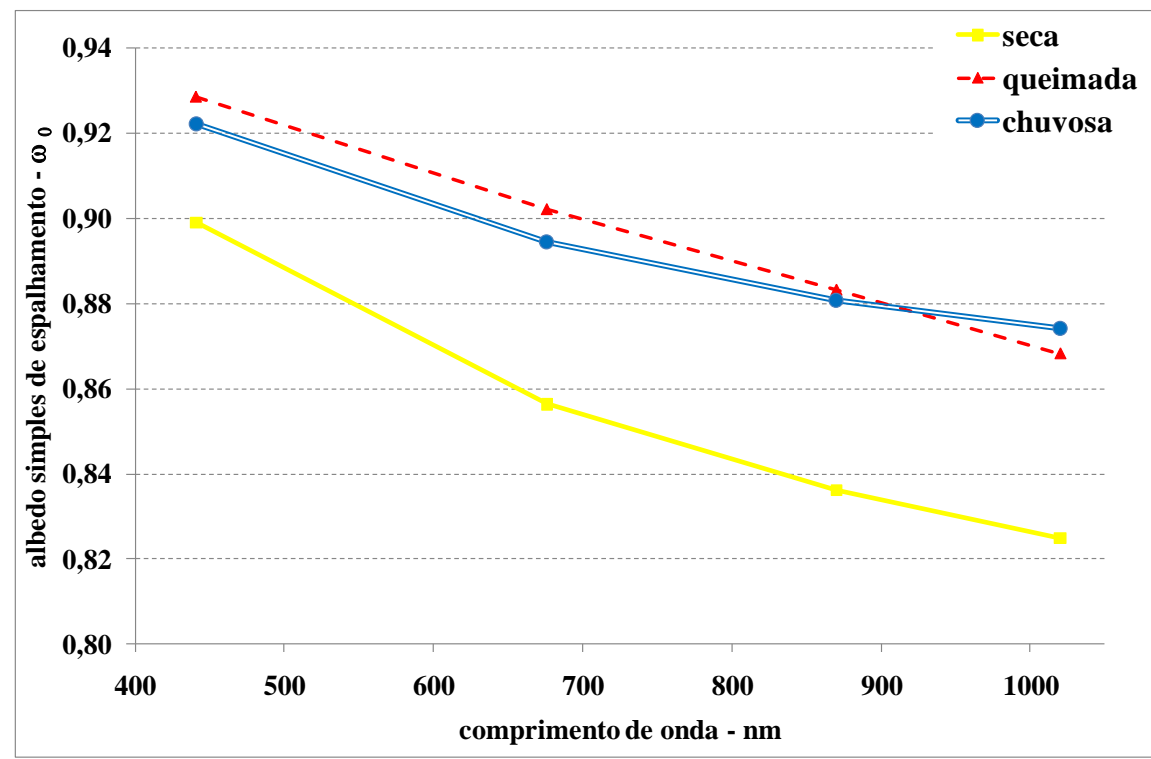

Figura V.16: Dependência espectral média do albedo simples $\left(\omega_{0}\right)$ de espalhamento médio para as estações chuvosa, seca e de queimada. Os valores de albedo são resultados de inversões que utilizam observações realizadas pelo fotômetro da rede AERONET em JiParaná de 1999 a 2005.

As médias mensais do parâmetro de assimetria (g), para Ji-Paraná (1999 a 2005) e Balbina (1999 a 2002) são apresentadas na Figura V.17. O parâmetro de assimetria é razoavelmente constante durante o ano na região de Ji-Paraná. Nota-se que as médias dos valores de $g$ para setembro (mês de maior incidência de queimadas na região de Ji-Paraná) são semelhantes nos dois sítios experimentais. Deste modo verifica-se que a pequena variabilidade do parâmetro de assimetria do aerossol em JiParaná está mais relacionada à época do ano do que às queimadas, já que a região de Balbina não é significativamente afetada pelas plumas de queimadas na Amazônia de agosto a outubro. 


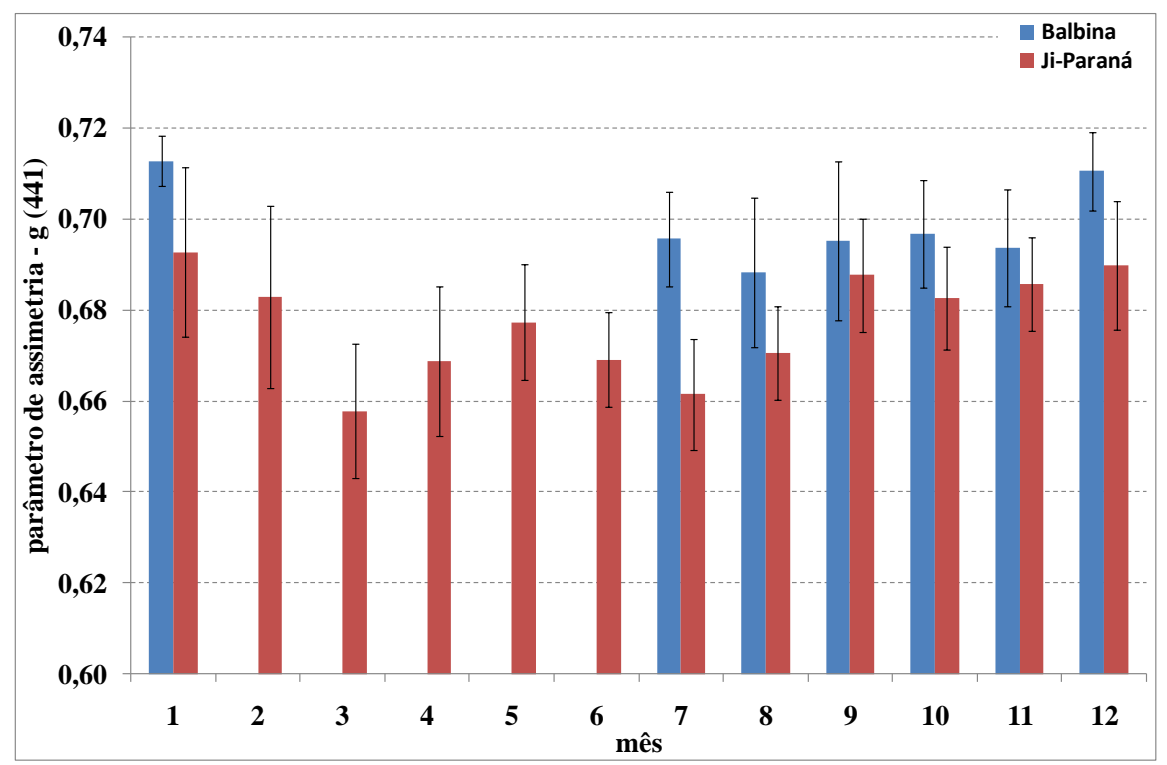

Figura V.17: Médias mensais do parâmetro de assimetria (g), em $440 \mathrm{~nm}$. As barras representam o desvio padrão das medidas no mês correspondente. Os valores de parâmetro de assimetria são resultados de inversões que utilizam observações realizadas pelo fotômetro da rede AERONET, em Ji-Paraná de 1999 a 2005.

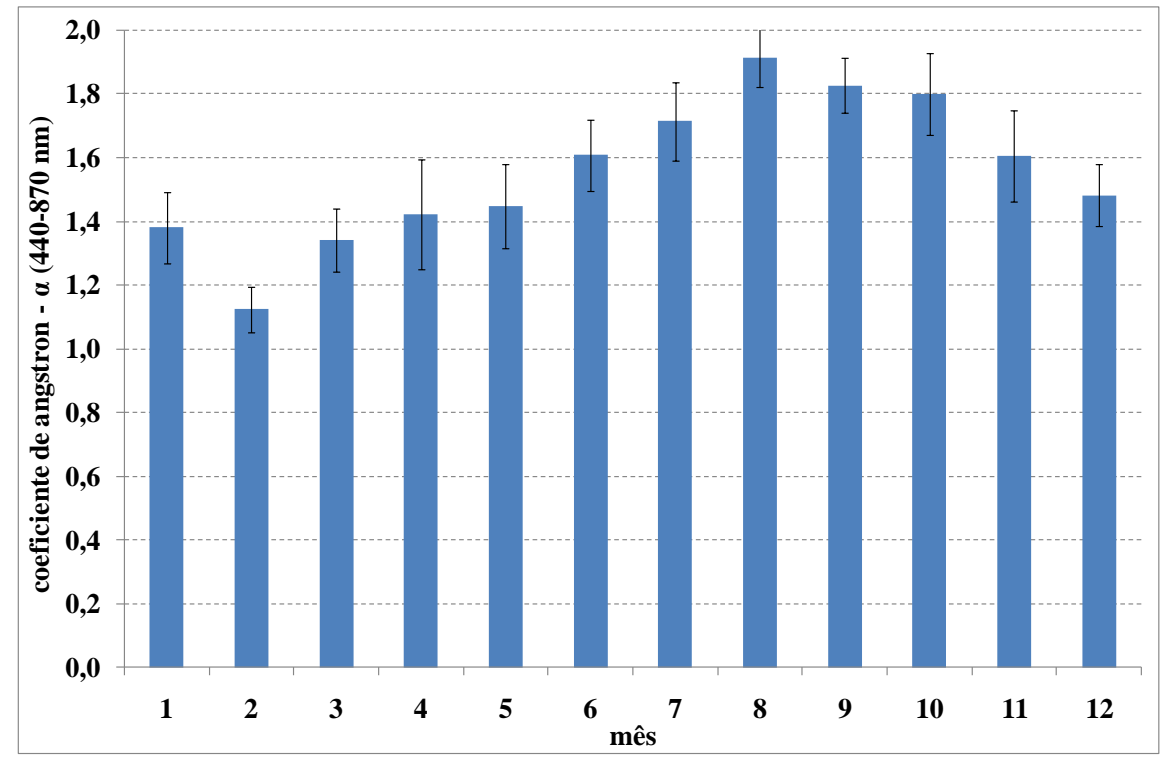

Figura V.18: Médias mensais do coeficiente de Ångström $(\alpha)$, calculado a partir dos valores de profundidade óptica dos aerossóis em 440 e $870 \mathrm{~nm}$. As barras representam o desvio padrão das medidas no mês correspondente. Observações realizadas, pelo fotômetro da rede AERONET, em Ji-Paraná de 1999 a 2005.

O aumento das médias mensais do coeficiente de Ångström nas épocas de seca $(\alpha \sim 1,6)$ e queimadas $(\alpha \sim 1,8)$ em relação à estação chuvosa $(\alpha \sim 1,2)$, conforme mostra a Figura V.18, indica a presença de partículas menores nas épocas de seca e queimadas. Para efeito de comparação, em locais onde há predomínio de aerossóis da 
moda grossa, como por exemplo, partículas provenientes de poeira de deserto do Saara, o coeficiente de Ångström fica em geral abaixo de 1,0 (Ansmann et al., 2009).

A elevada dependência espectral da $A O D$ no período de queimadas, apresentada na Figura V.14, assim como o aumento no coeficiente de Ångström é justificada pelo predomínio da moda de acumulação em relação à moda grossa, como mostra a distribuição de volume média ilustrada na Figura V.19.

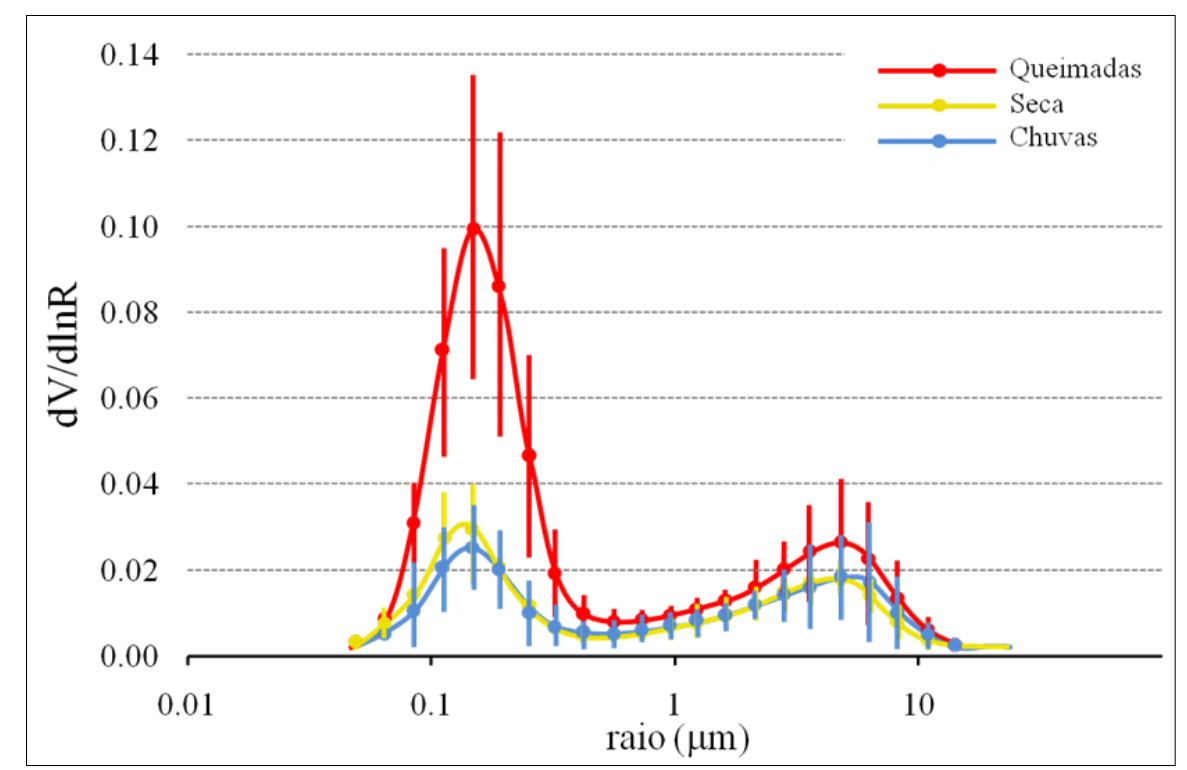

Figura V.19: Distribuição de tamanho volumétrica média para as estações chuvosa, seca e de queimada. Os valores que compõem a distribuição de tamanho são resultados de inversões que utilizam observações realizadas pelo fotômetro da rede AERONET, em JiParaná de 1999 a 2005. Nesta figura observa-se o predomínio da moda de acumulação durante a estação de queimadas.

As análises das propriedades ópticas dos aerossóis e dos padrões meteorológicos revelam que os períodos de seca e de queimadas destacam-se do período chuvoso. A estação seca apresenta condições mais favoráveis ao monitoramento de aerossóis por sensoriamento remoto, devido essencialmente à baixa umidade relativa, diminuição da cobertura de nuvens e níveis elevados de profundidade óptica (Procópio et al., 2004). 


\section{V.4.2 - Análise das propriedades ópticas dos aerossóis na região de Ji-Paraná, no período de seca e de queimadas.}

O objetivo deste item é analisar mais detalhadamente as propriedades ópticas dos aerossóis no período de queimada na região de Ji-Paraná, por meio da comparação de algumas dessas propriedades com os valores encontrados para São Paulo no período do inverno, mapeando as principais diferenças entre os aerossóis das duas regiões. Ao todo, a base de observações contou com 1067 medidas de cada propriedade óptica analisada, considerando somente observações livres da presença de nuvens (dados do fotômetro da rede AERONET - nível 2.0).

A razão entre a $A O D$ da fração fina e a $A O D$ total versus a própria $A O D$ total é apresentada na Figura V.20. Observa-se que a moda fina predomina na determinação da $A O D$ de extinção total, $\tau_{\text {total }}$, e isso ocorre porque a fração $\tau_{\text {fino }} / \tau_{\text {total }}$ é superior a $60 \%$ (escala do eixo y), além de crescer assintoticamente com a $A O D$ de extinção total.

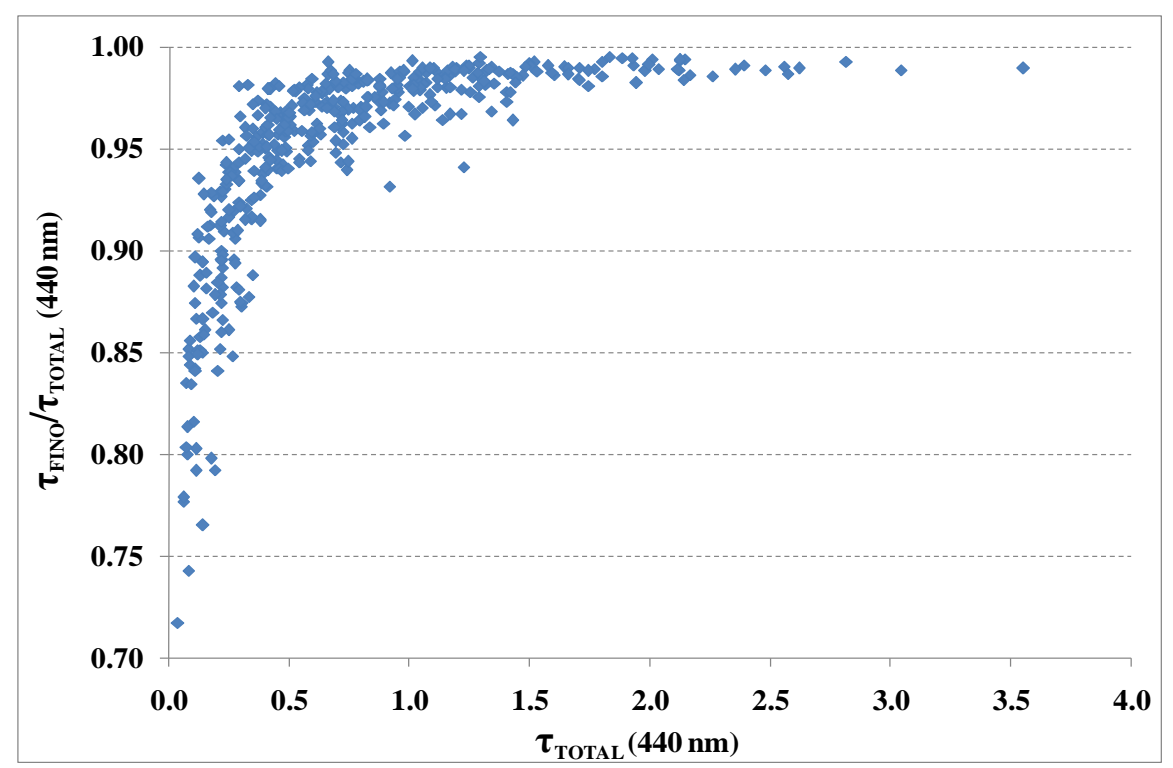

Figura V.20: Comparação entre a razão da $A O D$ de extinção da moda fina $\left(\tau_{\text {fino }}\right)$ e $\tau_{\text {total }}\left(\tau_{\text {total }}=\tau_{\text {fina }}+\tau_{\text {grossa }}\right)$, versus $\tau_{\text {total }}$, no comprimento de onda de $440 \mathrm{~nm}$. Observações realizadas em Ji-Paraná no período de queimadas entre os anos de 1999 a 2005.

É possível observar, na Figura V.21, que o coeficiente de Angstrom apresenta um crescimento assintótico em função da $A O D$ total (440nm), para um valor de cerca de 2.0. Segundo Holben et al., 2001, observa-se uma forte relação entre os parâmetros $\alpha$ e $A O D$ em regiões onde ocorre a predominância de um único tipo de aerossol. A relação entre essas variáveis é de crescimento, devido ao fato de que 
variação da $A O D$ na região amazônica é praticamente ocasionada pelo aumento da emissão de material particulado fino em relação ao grosso (Figura V.21 e Figura V.20). Esta relação não é observada em Cabo Verde, por exemplo, onde o aumento da $A O D$ ocorre em eventos de elevada concentração na moda grossa, pela entrada de poeira do deserto do Saara, causando uma redução assintótica do coeficiente de Ångström (Ansmann et al., 2009).

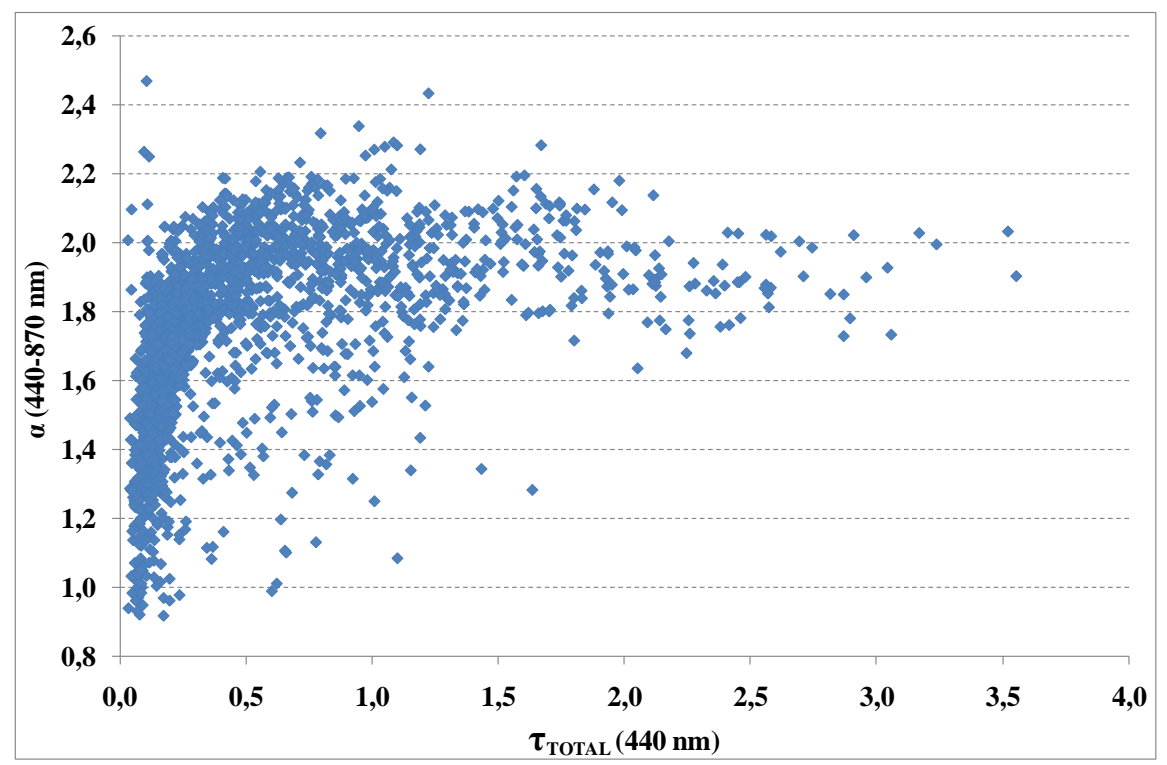

Figura V.21: Relação entre o Coeficiente de Ångström, $\alpha$, calculado entre 440 e 870 nm, e a $A O D$ de extinção total em $440 \mathrm{~nm}$. Observações realizadas em Ji-Paraná no período de queimadas entre os anos de 1999 a 2005.

A Figura V.22 revela que a $A O D$ da fração fina $\left(\tau_{\text {fino }}\right)$ é correlacionada com a concentração volumétrica de partículas da moda fina, mas este não é o único fator que contribui para os valores de $A O D$ da fração fina. Nas observações apresentadas na Figura V.22, verificou-se que os pontos com índice de refração real superior a 1.4 em $440 \mathrm{~nm}$, apresentam uma maior eficiência de extinção, o que significa que, para uma mesma concentração volumétrica, quanto maior o índice de refração real maior a $A O D$ de extinção. Resultado semelhante é apresentado por Castanho, 2005 para a região de São Paulo. 


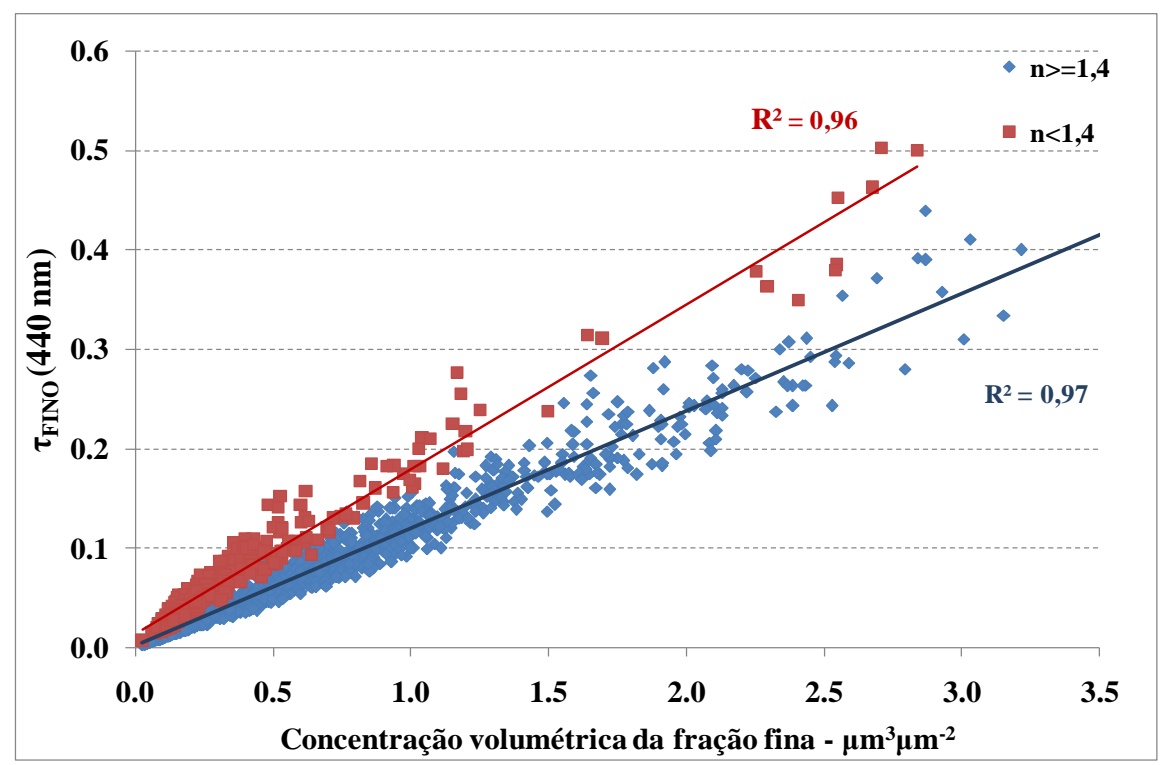

Figura V.22: Relação entre $A O D$ de extinção da fração fina $\left(\tau_{\text {fino }}(440 \mathrm{~nm})\right)$ e a concentração volumétrica da moda fina em Ji-Paraná no período de queimadas. Observações realizadas em Ji-Paraná no período de queimadas entre os anos de 1999 a 2005.

O padrão de dispersão dos dados obtidos para os valores de $A O D$ da fração fina, mesmo após a separação pelo índice de refração real (Figura V.22), sugere a presença de outras variáveis a serem consideradas. Entretanto, como pode ser verificado pelo coeficiente de correlação linear da razão da $A O D$ de extinção pela concentração volumétrica de partículas com o raio médio destas $\left(\mathrm{R}^{2} \sim 0.22\right)$ (Figura V.23), estas outras variáveis, se existem, a apresentar menor influência na $A O D$ de extinção, vista a alta correlação linear desta com o índice de refração real e com a concentração das partículas (que possui $\mathrm{R}^{2} \sim 0.97$ ). 


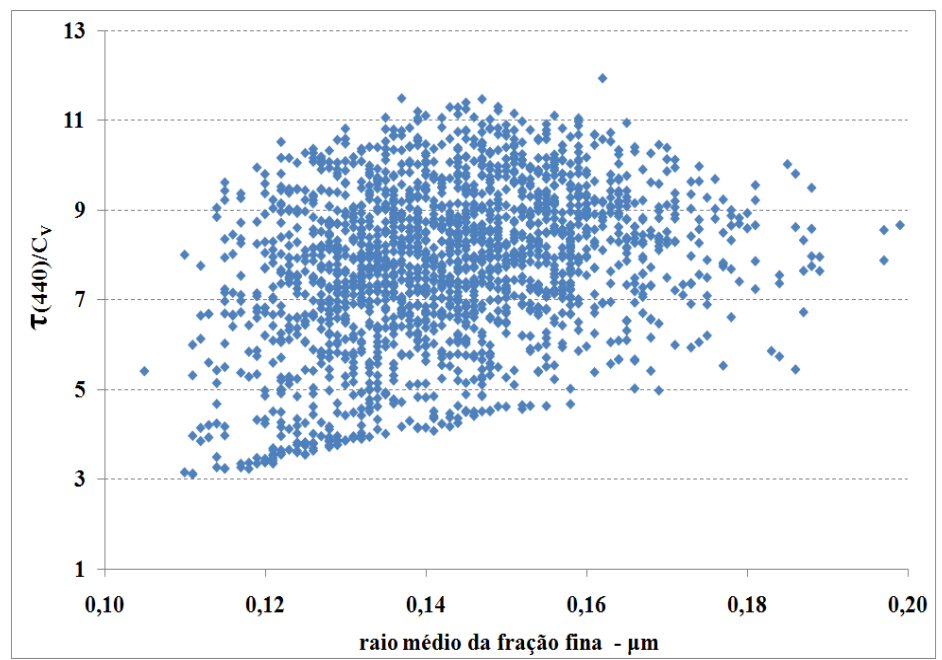

Figura V.23: Relação entre a razão da profundidade óptica de extinção da fração fina dos aerossóis pela concentração volumétrica de partículas da moda fina $\left(\mathrm{C}_{\mathrm{V}}\right)$, e o raio médio dos aerossóis da moda fina. Observações realizadas em Ji-Paraná no período de queimadas entre os anos de 1999 a 2005.

Com o objetivo de comparar a eficiência de extinção das modas fina e grossa em relação à concentração volumétrica na região de Ji-Paraná, verificou-se a relação da concentração volumétrica da moda grossa com a $A O D$ da fração grossa $\left(\tau_{\text {grosso }}\right)$, Figura V.24.

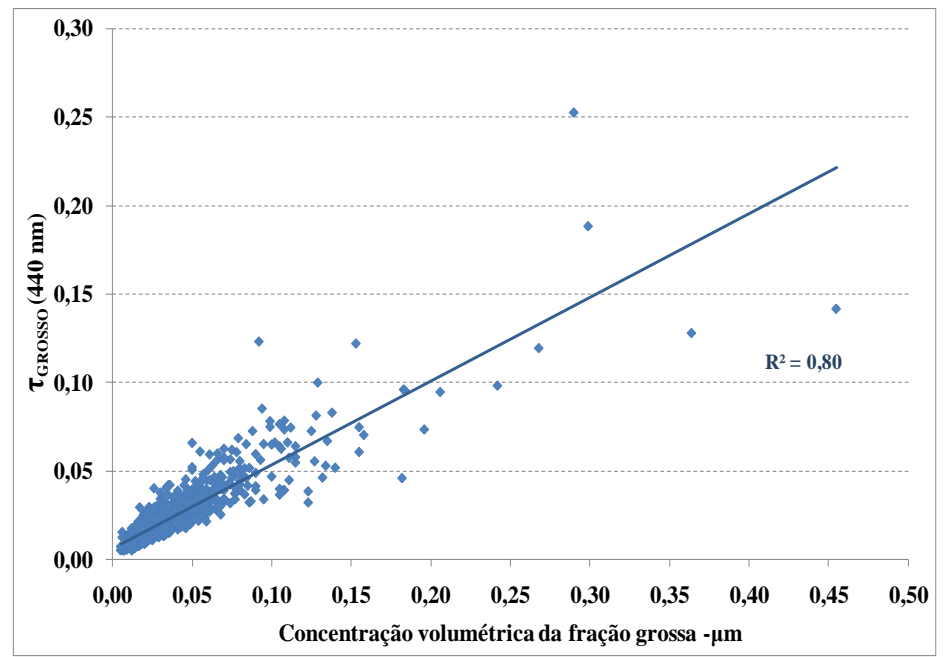

Figura V.24: Relação entre a $A O D$ de extinção da moda grossa $\left(\tau_{\text {grosso }}(440 \mathrm{~nm})\right)$ e a concentração volumétrica da moda grossa para Ji-Paraná, no período de queimadas.

A concentração volumétrica de aerossóis na moda grossa, tanto para Ji-Paraná, Figura V.24, quanto para São Paulo (Castanho, 2005), apresenta alta correlação com a $A O D$ na moda grossa. Comparando curvas ajustadas às observações apresentadas nas 
Figuras V.22 e V.24, observa-se que a eficiência de extinção da moda grossa é menor do que a da moda fina.

A higroscopicidade dos aerossóis sobre suas propriedades ópticas também foi estudada neste trabalho. As Figuras V.25(a), V.25(b) e V.25(c) mostram, respectivamente, a dependência do albedo simples, da $A O D$ e do raio médio fino dos aerossóis em Ji-Paraná (sítio Abracos Hill) em relação ao conteúdo de vapor d'água (QAP). É possível observar que o albedo simples sofre pouca influência pela variação nos valores de QAP, $A O D$ e raio médio fino dos aerossóis, indicando uma baixa higroscopicidade dos aerossóis da região de Ji-Paraná. Esta dependência em Ji Paraná é muito diferente do que para aerossóis urbanos, nos quais uma acentuada correlação linear entre QAP e AOD é observada (Hegg et al., 1997; Castanho, 2005; Holben et al., 2001). Isso se deve ao pequeno fator de crescimento higroscópico, da ordem de 1,13, de aerossóis de queimadas da Amazônia (Rissler et al., 2004). 


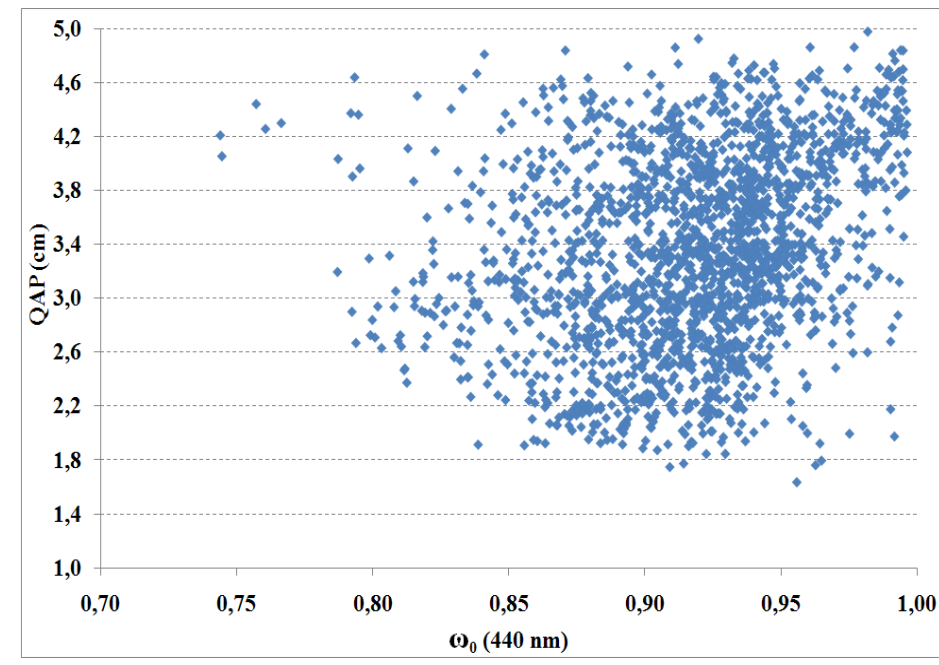

(a)

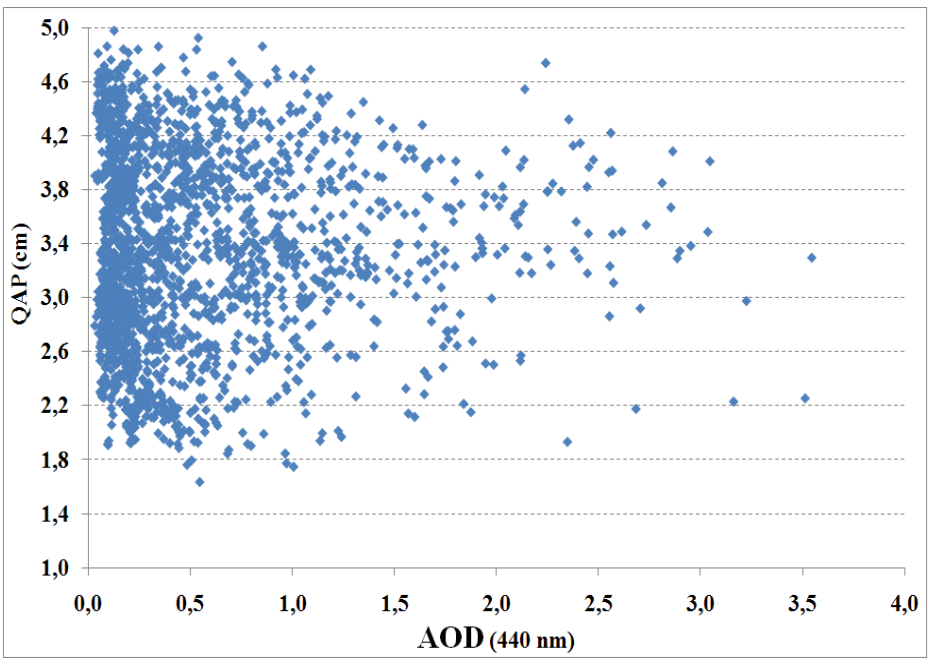

(b)

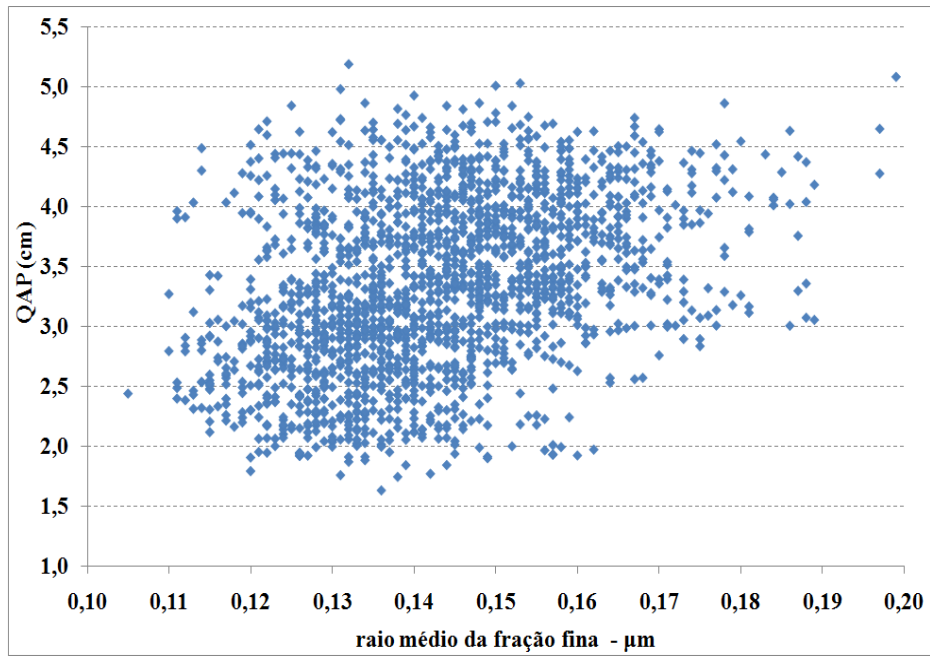

(c)

Figura V.25: Relação entre o conteúdo de vapor de água (QAP) e (a) o albedo simples $\left(\omega_{0}\right)$ em $440 \mathrm{~nm}$; (b) a $A O D$ ( $\tau$ ) em $440 \mathrm{~nm}$; (c) raio médio do volume fino em $\mu \mathrm{m}$. Observações realizadas no sítio experimental de Abracos Hill, em Ji-Paraná, no período de queimadas entre os anos de 1999 a 2005. 
Da mesma forma como foi feito para a $A O D$, foram analisados possíveis fatores que influenciem na variabilidade do albedo simples. As Figuras V.26 (a) e V.26 (b) mostram, respectivamente, a relação entre o albedo simples e o raio médio do volume fino, e entre o albedo simples e o parâmetro de assimetria, com $R^{2}$ de 0,12 e 0,07 respectivamente. Apesar destes baixos coeficientes de correlação linear, a disposição das observações na Figura V.27 (a) indica que aerossóis com alto raio efetivo tendem a possuir alto albedo, apesar do contrário não ser necessariamente verdade.

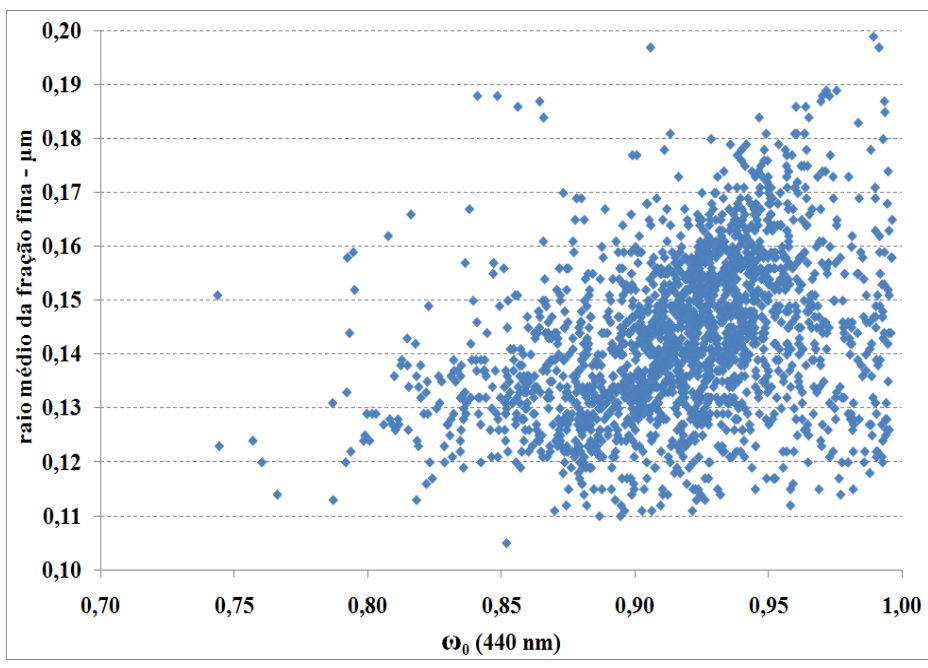

(a)

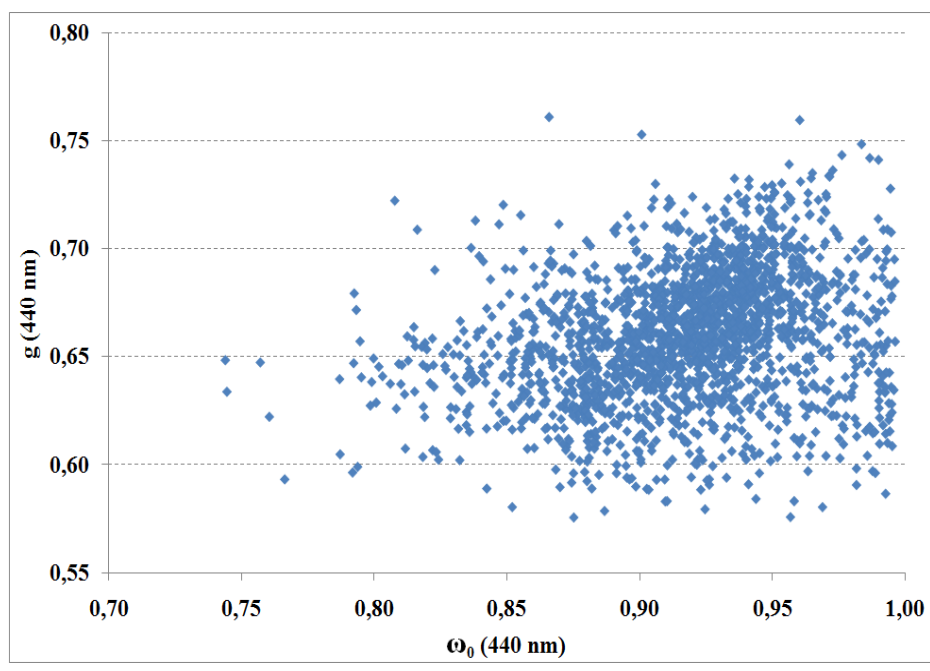

(b)

Figura V.26: Relação entre o raio médio do volume fino e o albedo simples $\left(\omega_{0}\right)$ em $440 \mathrm{~nm}$ (a); entre o parâmetro de assimetria $(\mathrm{g})$ e o albedo simples $\left(\omega_{0}\right)$ ambos em $440 \mathrm{~nm}$. Medidas realizadas em Ji-Paraná, no período de queimadas entre os anos de 1999 a 2005. 


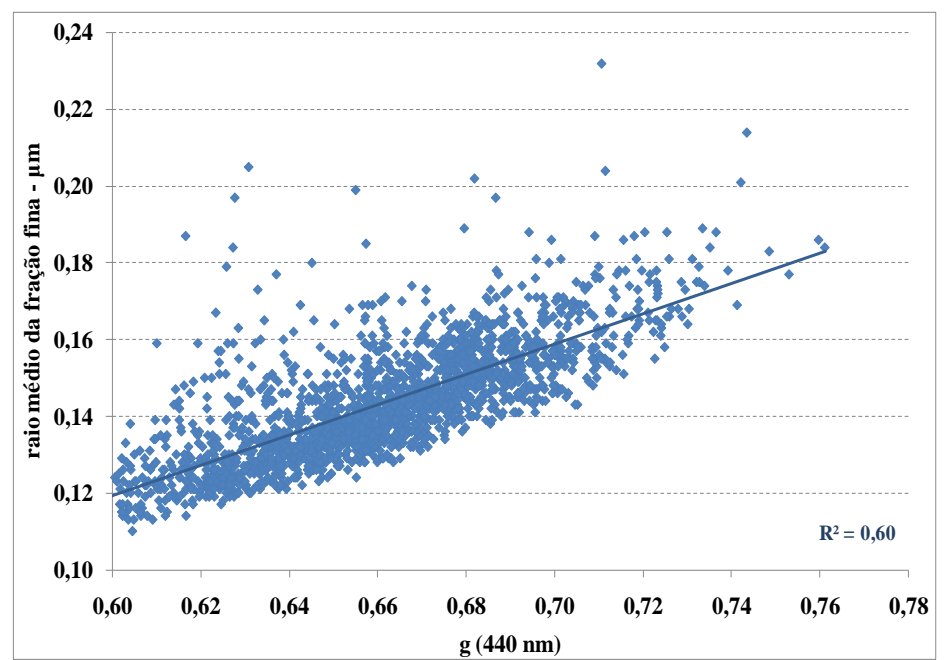

Figura V.27: Relação entre o raio médio do volume fino e parâmetro de assimetria em $440 \mathrm{~nm}$. Medidas realizadas em Ji-Paraná, no período de queimadas entre os anos de 1999 a 2005.

A Figura V.27 mostra a relação entre o raio efetivo dos aerossóis da moda fina e o respectivo parâmetro de assimetria. Verifica-se neste caso que a correlação linear é mais significativa, se comparada às partes (a) e (b) da Figura V.26. Esta dependência é esperada, pois a fração de radiação retroespalhada depende do tamanho da partícula.

A relação entre $A O D$ e albedo simples de espalhamento é mostrada na Figura V.28. Observou-se uma grande variabilidade do albedo simples de espalhamento para valores de $A O D$ abaixo de 0,4 (intervalo em que a AERONET não garante a qualidade dos produtos de inversões). A variabilidade do albedo simples de espalhamento diminui à medida que a $A O D$ aumenta, com valores variando entre 0,92 e 0,96 . 


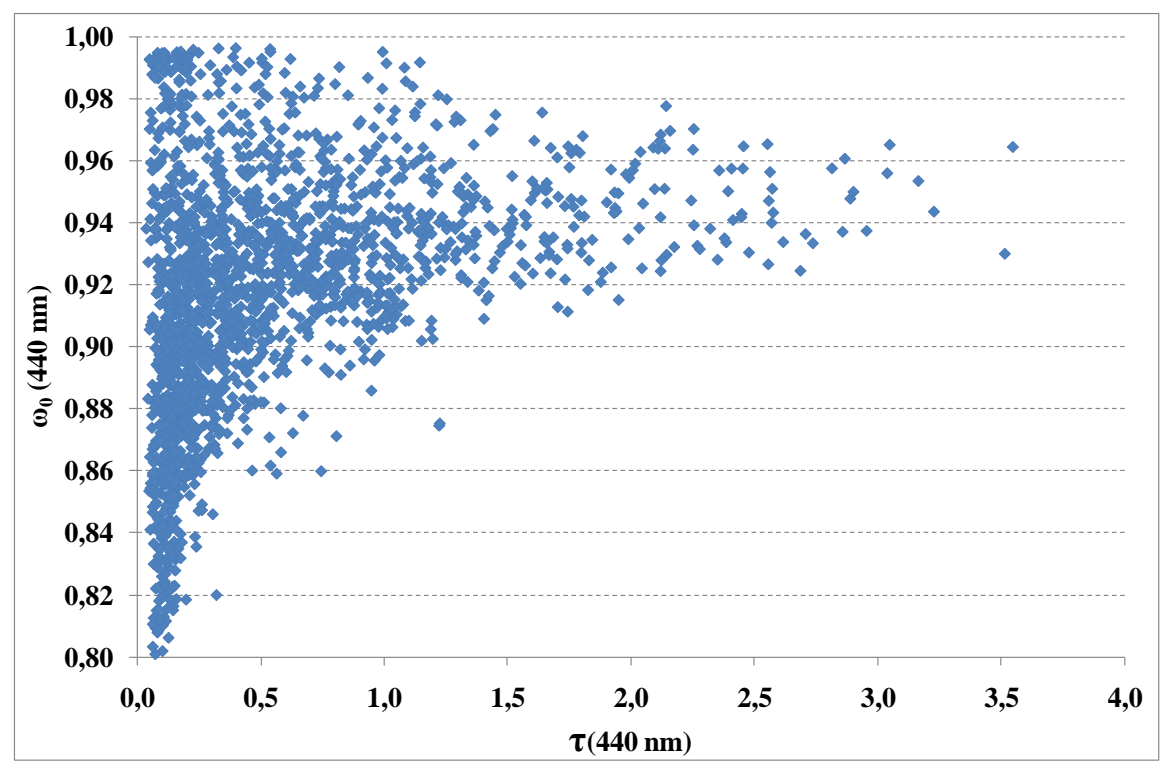

Figura V.28: Relação entre albedo simples e a $A O D$ em $440 \mathrm{~nm}$. Os valores de albedo simples de espalhamento são resultados de inversões que utilizam observações realizadas pelo fotômetro da rede AERONET, em Ji-Paraná de 1999 a 2005.

De forma geral, observou-se que o conteúdo de vapor d'água não é o fator mais relevante na variabilidade das propriedades ópticas de aerossóis encontrados na região de Ji-Paraná. Observou-se também que altos valores de raio efetivo médio da moda fina comportam-se como um fator limitante aos valores de albedo simples na região. Por outro lado, o raio efetivo médio da moda fina e seu parâmetro de assimetria, apresentaram forte dependência linear.

\section{V.4.3 Determinação de um conjunto de modelos ópticos, para descrever os aerossóis da região de Ji-Paraná.}

Nesta seção é apresentado um conjunto de modelos de aerossóis, construídos a partir das propriedades ópticas medidas com o fotômetro CIMEL, com o intuito de representar de forma mais precisa a variabilidade espacial e temporal dos aerossóis emitidos durante os períodos de queimadas para a região de Ji-Paraná.

Os modelos de aerossóis construídos tiveram como parâmetros o fator de assimetria $(g(\lambda))$, a eficiência de extinção $($ Qext $(\lambda))$ e o albedo simples $\left(\omega_{0}(\lambda)\right)$, nos comprimentos de onda $440 \mathrm{~nm}, 676$ nm, 870 nm e 1020 nm. Para obtenção desses parâmetros utilizou-se o código de inversão de transferência radiativa de Mie (Wiscombe, 1977; 1980) tendo como input as partes reais e imaginárias do índice de refração e a distribuição de tamanho, medidos pelo fotômetro da AERONET em JiParaná, apresentados na Tabela V.1. 


\begin{tabular}{ccccc}
\hline \multirow{2}{*}{ Modelo } & \multicolumn{5}{c}{ Índice de refração $(\boldsymbol{\lambda})$} \\
\cline { 2 - 5 } & $\mathbf{4 4 0} \mathbf{~ n m}$ & $\mathbf{6 7 0} \mathbf{~ n m}$ & $\mathbf{8 7 0} \mathbf{~ n m}$ & $\mathbf{1 . 0 2 0} \mathbf{~ m m}$ \\
\hline \hline 1 & $1,471+\mathrm{i} 0,0136$ & $1,475+\mathrm{i} 0,0143$ & $1,478+\mathrm{i} 0,0141$ & $1,476+\mathrm{i} 0,0143$ \\
\hline 3 & $1,463+\mathrm{i} 0,0083$ & $1,474+\mathrm{i} 0,0072$ & $1,478+\mathrm{i} 0,0067$ & $1,477+\mathrm{i} 0,0066$ \\
\hline
\end{tabular}

\begin{tabular}{crrrrrrrrrrr}
\hline \multirow{2}{*}{ Modelo } & \multicolumn{10}{c}{ Distribuição de tamanho } \\
\cline { 2 - 12 } & $\mathbf{0 . 0 5}$ & $\mathbf{0 . 0 7}$ & $\mathbf{0 . 0 9}$ & $\mathbf{0 . 1 1}$ & $\mathbf{0 . 1 5}$ & $\mathbf{0 . 1 9}$ & $\mathbf{0 . 2 6}$ & $\mathbf{0 . 3 3}$ & $\mathbf{0 . 4 4}$ & $\mathbf{0 . 5 8}$ & $\mathbf{0 . 7 6}$ \\
\hline \hline 1 & 0.001 & 0.006 & 0.029 & 0.069 & 0.095 & 0.076 & 0.035 & 0.013 & 0.006 & 0.005 & 0.005 \\
\hline 3 & 0.001 & 0.009 & 0.038 & 0.096 & 0.145 & 0.137 & 0.078 & 0.030 & 0.012 & 0.008 & 0.007 \\
\hline
\end{tabular}

\begin{tabular}{rrrrrrrrrrrr}
\hline & $\mathbf{0 . 9 9}$ & $\mathbf{1 . 3 0}$ & $\mathbf{1 . 7 1}$ & $\mathbf{2 . 2 4}$ & $\mathbf{2 . 9 4}$ & $\mathbf{3 . 8 6}$ & $\mathbf{5 . 0 6}$ & $\mathbf{6 . 6 4}$ & $\mathbf{8 . 7 1}$ & $\mathbf{1 1 . 4 3}$ & $\mathbf{1 5 . 0 0}$ \\
\hline \hline 1 & 0.006 & 0.008 & 0.010 & 0.014 & 0.018 & 0.024 & 0.026 & 0.021 & 0.011 & 0.004 & 0.001 \\
\hline 3 & 0.007 & 0.008 & 0.011 & 0.016 & 0.020 & 0.024 & 0.024 & 0.018 & 0.010 & 0.004 & 0.001 \\
\hline
\end{tabular}

Tabela V.1: Parâmetros utilizados para a construção dos modelos óticos de aerossóis utilizados neste trabalho.

Para construção dos modelos utilizou-se apenas observações realizadas sob condições de $A O D(440 \mathrm{~nm})>0,4$, pois os algoritmos da AERONET não garantem a qualidade das propriedades ópticas dos aerossóis provenientes de inversões (distribuição de tamanho e índice de refração, por exemplo) obtidas com sob condições de $A O D$ em $440 \mathrm{~nm}$ inferior a 0,4. Esta restrição aos valores da $A O D$ fez com que fosse possível construir modelos ópticos de aerossóis apenas para o período do ano mais afetado pelas queimadas, que se estende de agosto a outubro.

Os modelos ópticos de aerossóis foram construídos utilizando a técnica de Análise de Clusters não hierárquica, disponível no aplicativo SPSS. A variável de agrupamento escolhida foi $\omega_{0}$, para assim viabilizar a aplicação do método da refletância crítica na escolha do modelo óptico de aerossóis mais adequado para o dia e a região de estudo, conforme método proposto por Castanho, 2005, para a obtenção da $A O D$ com alta resolução espacial. O método da escolha do modelo de aerossol por meio da refletância crítica será apresentado no item V.5.

A análise de clusters agrupou as observações em dois clusters principais, que serão chamados de modelo 1 e 3. Calculou-se a média dos dois modelos, que será chamada de modelo 2 ou de modelo médio, para o caso de não ser possível identificar o modelo dinamicamente através do método da refletância crítica.

Foram realizadas 841 medidas com AOD (440) >0.4, durante os meses de agosto, setembro e outubro, de 1999 a 2005, correspondendo a 291 dias de medidas. 
O cluster de menor albedo (modelo 1) possui 405 pontos, enquanto que o cluster de maior albedo (modelo 3) possui 436 pontos. Dos 291 dias, 98 dias (34\%) tiveram todas as observações classificadas como sendo referentes ao modelo 1, 73 dias (25\%) tiveram todas as observações classificadas como sendo referentes ao modelo 3 , e os 120 dias (41\%) restantes tiveram parte das observações classificadas como sendo referentes ao modelo 1 e parte como sendo referentes ao modelo 3 , conforme o exemplo apresentado na Figura V.29. Deste modo verifica-se que embora o número de observações que cada cluster contém seja aproximadamente o mesmo, 75\% dos dias possuem observações classificadas no modelo 1 e $66 \%$ dos dias possuem observações classificadas no modelo 3 .

\begin{tabular}{ccc}
\hline Dia & Horário da Medida & Modelo \\
\hline $6 / 8 / 2001$ & $11: 54: 37$ & 1 \\
& $12: 41: 45$ & 1 \\
& $13: 09: 44$ & 1 \\
& $14: 17: 24$ & 1 \\
& $15: 17: 26$ & 1 \\
& $17: 17: 29$ & 1 \\
\hline & $12: 33: 51$ & 3 \\
$18 / 8 / 2002$ & $13: 00: 43$ & 3 \\
& $14: 15: 31$ & 3 \\
& $19: 29: 51$ & 3 \\
& $19: 56: 43$ & 3 \\
\hline & $11: 14: 45$ & 1 \\
$6 / 9 / 2001$ & $11: 35: 32$ & 3 \\
& $12: 19: 29$ & 1 \\
& $12: 45: 03$ & 3 \\
& $14: 10: 27$ & 1 \\
& $15: 10: 22$ & 1 \\
& $17: 10: 25$ & 3 \\
\hline
\end{tabular}

Figura V.29: Exemplos de medidas realizadas em um mesmo dia e que foram classificadas em um mesmo modelo (dias 8/6/2001 e 18/8/2002) ou tiveram parte classificadas em um modelo e parte em outro (dia 6/9/2001).

Os modelos obtidos, 1 e 3, possuem albedos simples médios respectivamente iguais a $\omega_{\mathrm{o}}(676 \mathrm{~nm})=0,88$ e $\omega_{\mathrm{o}}(676 \mathrm{~nm})=0,94$. As dependências espectrais dos parâmetros utilizados para definir os modelos de aerossóis, estão apresentadas na Figura V.30. 


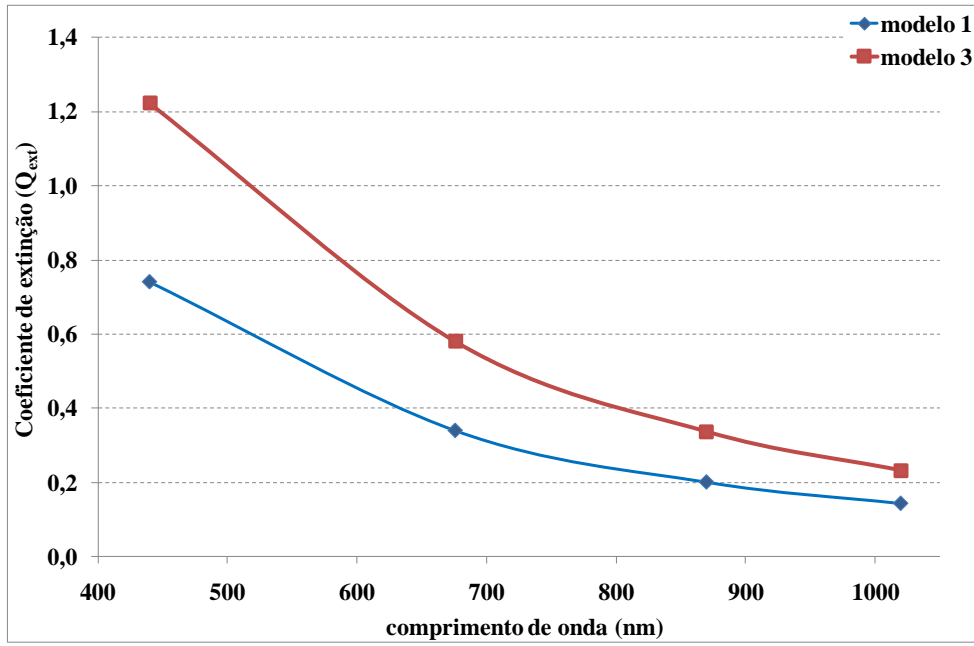

(a)

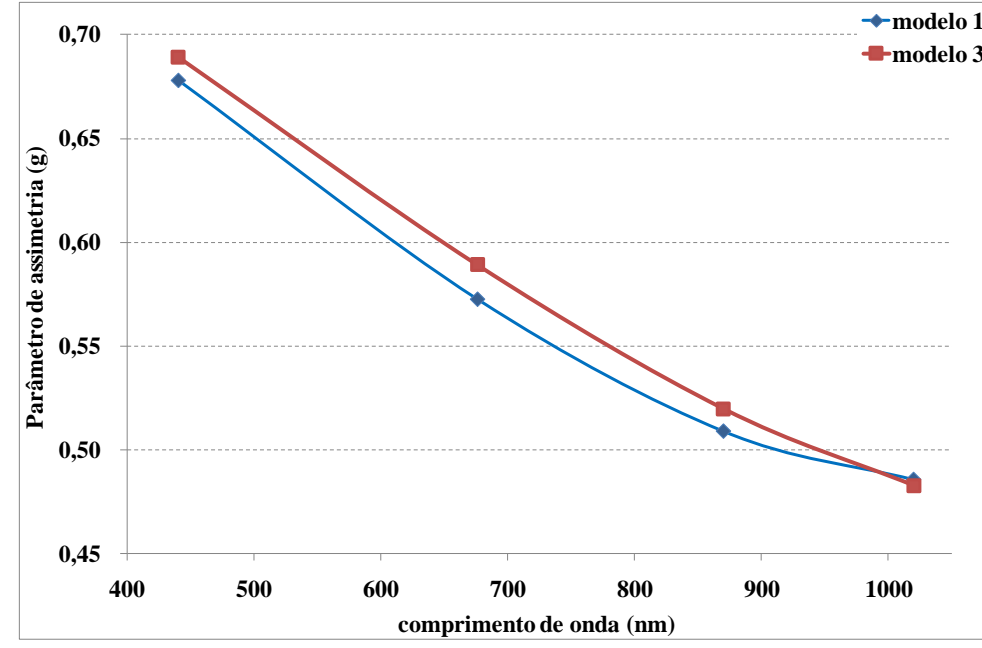

(b)

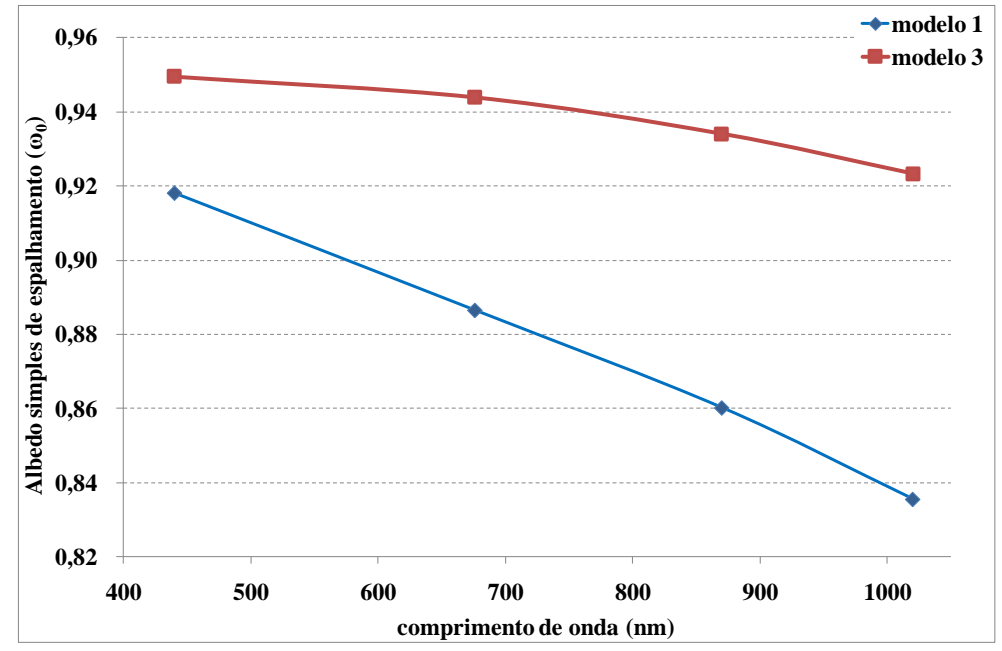

(c)

Figura V.30: Modelos ópticos dos aerossóis, obtidos por meio da análise de clusters, tendo o albedo simples como variável de agrupamento. É apresentada a dependência espectral dos parâmetros dos modelos, coeficiente de extinção (a), parâmetro de assimetria (b) e albedo simples de espalhamento (c). 


\section{V.4.4 - Extrapolação espectral das propriedades ópticas utilizadas na construção dos modelos ópticos}

Como já apresentado no início deste capítulo, as observações de propriedades ópticas da rede AERONET estão disponíveis em 4 comprimentos de onda: $440 \mathrm{~nm}$, $670 \mathrm{~nm}, 870 \mathrm{~nm}$ e $1.020 \mathrm{~nm}$. Não há, na literatura, medidas extensivas e atuais para um intervalo espectral mais abrangente. Para a realização das simulações utilizando o programa SBDART, é preciso utilizar informações para comprimentos de onda de até $2.100 \mathrm{~nm}$, tornando necessário extrapolar, de alguma forma, as observações fornecidas pela AERONET, para valores acima de $1.020 \mathrm{~nm}$.

O método de extrapolação utilizado no trabalho de Castanho, 2005, foi assumir que as propriedades ópticas sejam constantes acima de $1.020 \mathrm{~nm}$. Neste trabalho quatro diferentes métodos de extrapolação, identificados pela numeração de 1 a 4 , foram testados:

1. Deixar a cargo do próprio modelo de transferência radiativa SBDART, pois caso as observações sejam fornecidas apenas nos quatro comprimentos de onda, originais da AERONET, o SBDART realiza a extrapolação necessária;

2. Supor que as propriedades ópticas dos aerossóis sejam constantes e iguais aos valores observados no maior comprimento de onda disponibilizado pela AERONET (1.020 nm), como Castanho, 2005;

3. Calcular um polinômio que melhor se ajuste às observações e que mantenha o significado físico da curva;

4. Fazer uma estimativa a partir do estudo realizado por Procópio, 2005, que calculou de forma aproximada a depência espectral do índice de refração para uma mistura de aerossóis analisada por Artaxo et al., 1998, durante a estação seca na Amazônia, usando a "Regra da Mistura de Bruggeman" (Chýlek e Srivastava, 1993).

Os quatro métodos de extrapolação testados originaram quatro conjuntos de modelos ópticos de aerossóis com diferentes dependências espectrais a partir de $1.020 \mathrm{~nm}$. Deste modo, escolheu-se como método de extrapolação mais adequado aquele que originou modelos ópticos de aerossóis com melhores resultados de validação, resultados estes que serão apresentados no item V.4.5. 


\section{V.4.5 - Validação dos modelos ópticos de aerossol obtidos para a região de Ji-Paraná}

Os modelos ópticos de aerossóis construídos foram validados com base nos resultados das simulações de fluxo de radiação solar incidente (radiação direta + difusa) em comparação ao fluxo de radiação solar observado pelo piranômetro da rede AERONET, localizado em Ji-Paraná. As simulações foram realizadas com o código de transferência radiativa SBDART, tendo os modelos ópticos de aerossóis construídos como parâmetro. $\mathrm{O}$ fluxo de radiação incidente foi utilizado no processo de validação, pois é de alto interesse nas medidas de sensoriamento remoto por satélite.

Inicialmente, com o objetivo de decidir qual método de extrapolação é mais adequado, foi simulado um fluxo de radiação solar incidente de sete dias, utilizando como parâmetro os modelos ópticos de aerossóis resultantes de cada método de extrapolação, item V.4.4, totalizando 28 simulações.

Os dias simulados foram escolhidos de forma a obedecer aos seguintes critérios:

- Contemplar uma larga gama de valores de $A O D$, pois quanto maior o valor de $A O D$, maior a sensibilidade ao modelo óptico de aerossol;

- Os valores de albedo enquadrados em um mesmo modelo óptico de aerossol, para facilitar a automatização das simulações;

- As observações de fluxo de radiação solar incidente sem variações bruscas ao longo do dia ou mesmo interrupções, pois isso pode ser sinal da presença de nuvens.

A Figura V.31 mostra (a) um exemplo de curva considerada sem interrupções, porém com flutuações a partir de 13h30min UTC aproximadamente, e (b) um exemplo de curva considerada com interrupções, porém sem flutuação significativa no trecho observado. 

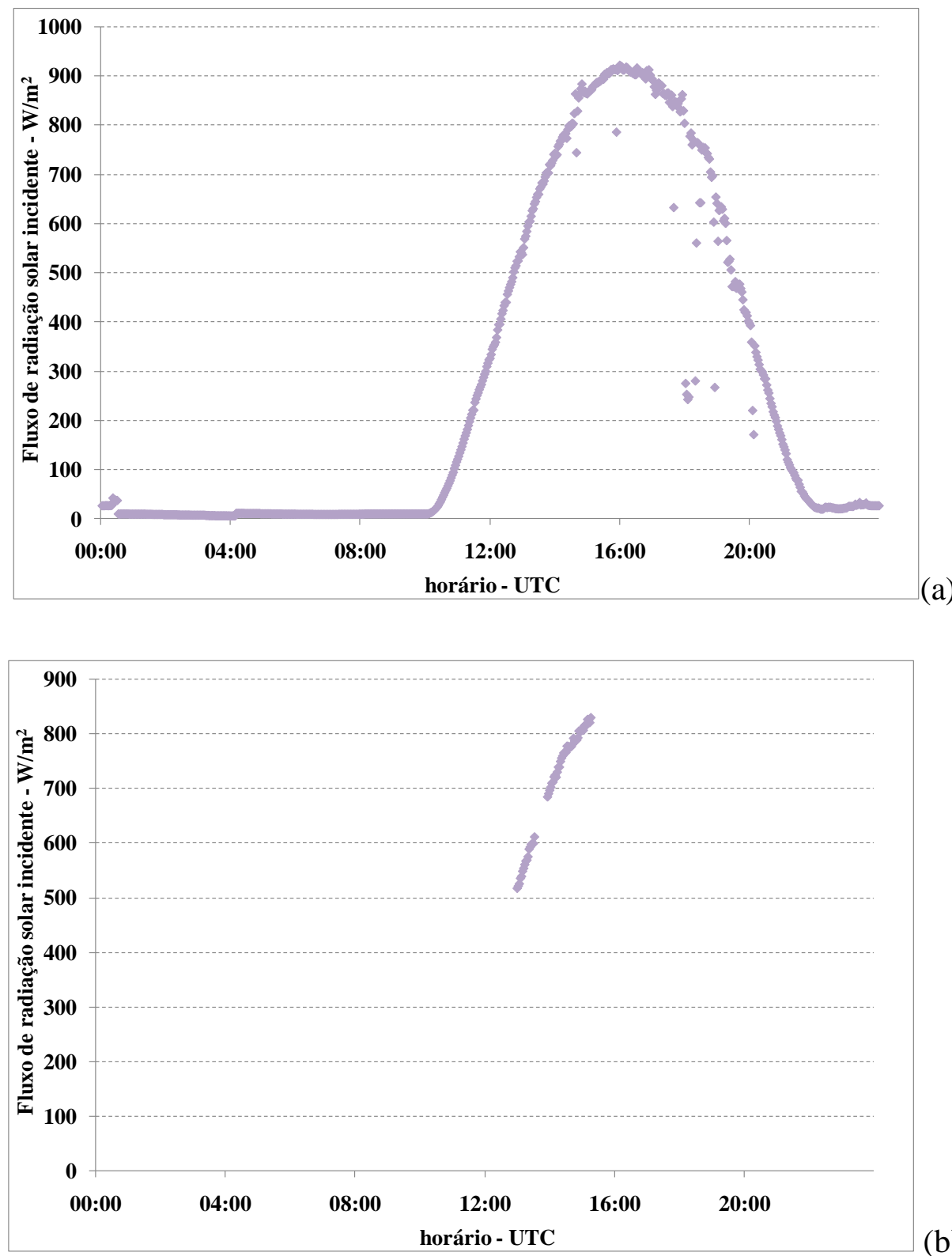

(b)

Figura V.31: fluxo de radiação solar incidente medidos pelo radiômetro CIMEL. (a) e (b) são os valores, obtidos para os dias 06/09/2001 e 30/08/2003 respectivamente. Sendo (a) um exemplo de curva considerada sob o efeito de nuvens devido à ausência de um comportamento contínuo por volta das 16h00min s e (b) um exemplo de curva não completa, ou seja, que não possui observações suficientes para representar o dia todo.

O método de extrapolação com o qual se obteve menores desvios relativos entre o fluxo de radiação solar incidente simulado e o valor observado pelo piranômetro da AERONET é o próprio método de extrapolação do SBDART. Estes desvios, entretanto, não são significativamente diferentes (Figura V32 e Tabela V.1). Por esse motivo, e devido à maior facilidade de implantação, os modelos ópticos dos 
aerossóis foram utilizados como parâmetros das simulações realizadas no SBDART nos quatro comprimentos de onda fornecidos pela AERONET.

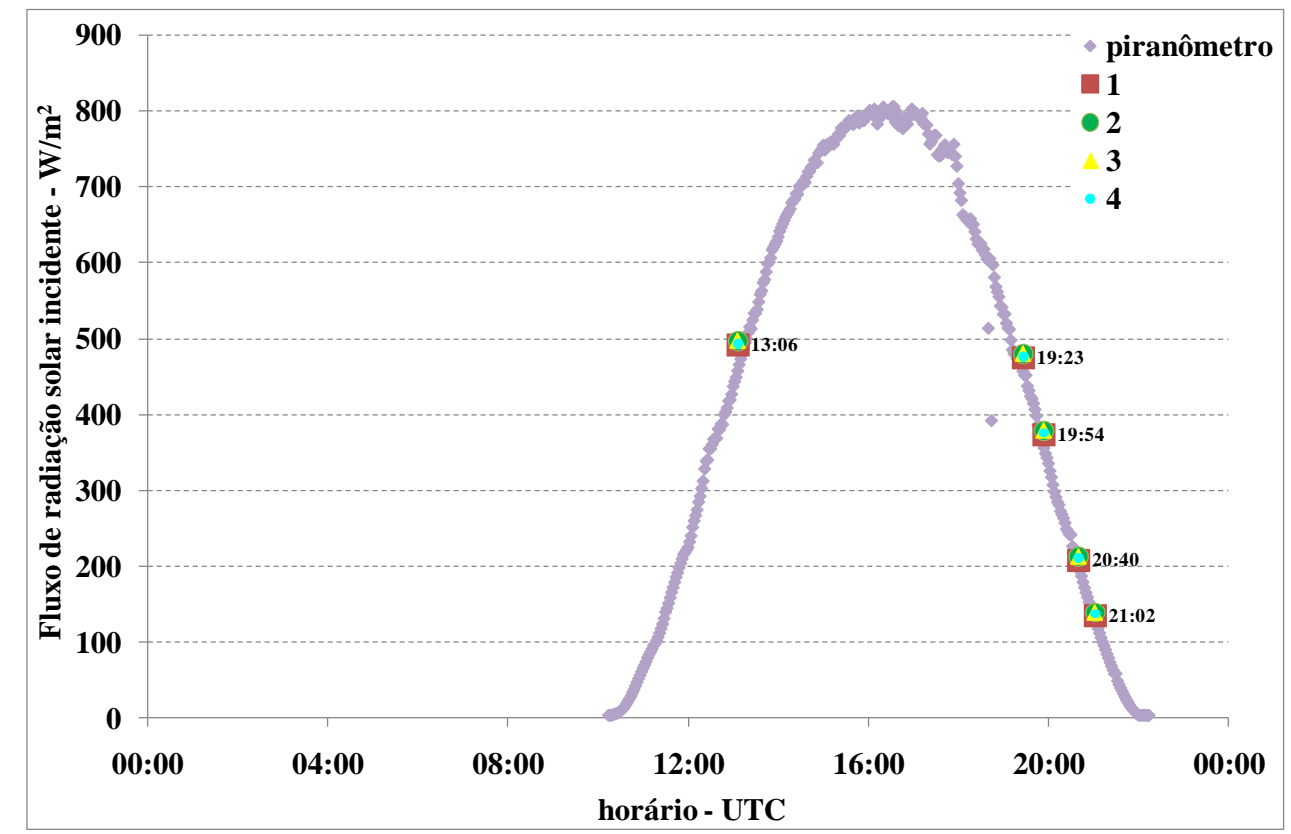

Figura V.32: Fluxo de radiação solar incidente observado pelo piranômetro localizado em JiParaná, em 11/08/2002. A mesma figura mostra uma comparação entre as possíveis formas de extrapolação apresentadas no item V.4.4. Sendo 1: extrapolação realizada pelo SBDART; 2: supor constante e igual ao observado em $1.020 \mathrm{~nm}$; 3: extrapolação realizada a partir de um ajuste polinomial; 4: extrapolação a partir do estudo realizado por Procópio, 2005.

\begin{tabular}{ccccccc}
\cline { 3 - 7 } & & \multicolumn{5}{c}{ Horário UTC } \\
& & $13: 06$ & $19: 26$ & $19: 54$ & $20: 40$ & $21: 02$ \\
\hline \multirow{3}{*}{$\begin{array}{c}\text { Método de } \\
\text { extrapolação }\end{array}$} & $-7,6 \%$ & $-3,9 \%$ & $-4,9 \%$ & $-4,6 \%$ & $-4,2 \%$ \\
\cline { 2 - 7 } & 2 & $-8,7 \%$ & $-5,0 \%$ & $-6,5 \%$ & $-7,2 \%$ & $-7,7 \%$ \\
\cline { 2 - 7 } & 3 & $-8,8 \%$ & $-5,1 \%$ & $-6,5 \%$ & $-7,3 \%$ & $-7,7 \%$ \\
\cline { 2 - 7 } & 4 & $-8,0 \%$ & $-4,3 \%$ & $-5,6 \%$ & $-6,1 \%$ & $-6,1 \%$
\end{tabular}

Tabela V.1: Desvio relativo entre a observação do fluxo de radiação solar incidente realizada pelo piranômetro e a simulação deste utilizando o SBDART, ambas apresentadas na Figura V.32.

Após definir que a extrapolação espectral dos modelos ópticos construídos seria deixada a cargo do SBDART, foi feita uma simulação para tentar representar o fluxo de radiação solar incidente para 22 dias, que foram escolhidos segundo os critérios já citados. O maior desvio relativo entre os valores de fluxo de radiação solar incidente observado e simulado foi de $8,5 \%$ e a média dos desvios relativos foi de $3,6 \%$. 
Exemplos dos resultados das simulações realizadas dos fluxos de radiação solar incidente são apresentados na Figura V.33. A Figura V.33(a) refere-se ao dia 06/08/2001, sendo a camada de aerossóis presente neste dia na atmosfera classificada de acordo com o modelo 1 e o valor de $A O D(550 \mathrm{~nm}) \cong 0,3$, e a Figura V.33(b) refere-se ao dia 03/09/2002, sendo a camada de aerossóis presente neste dia na atmosfera classificada de acordo com o modelo 3, e o valor de $A O D(550 \mathrm{~nm}) \cong 0,7$.
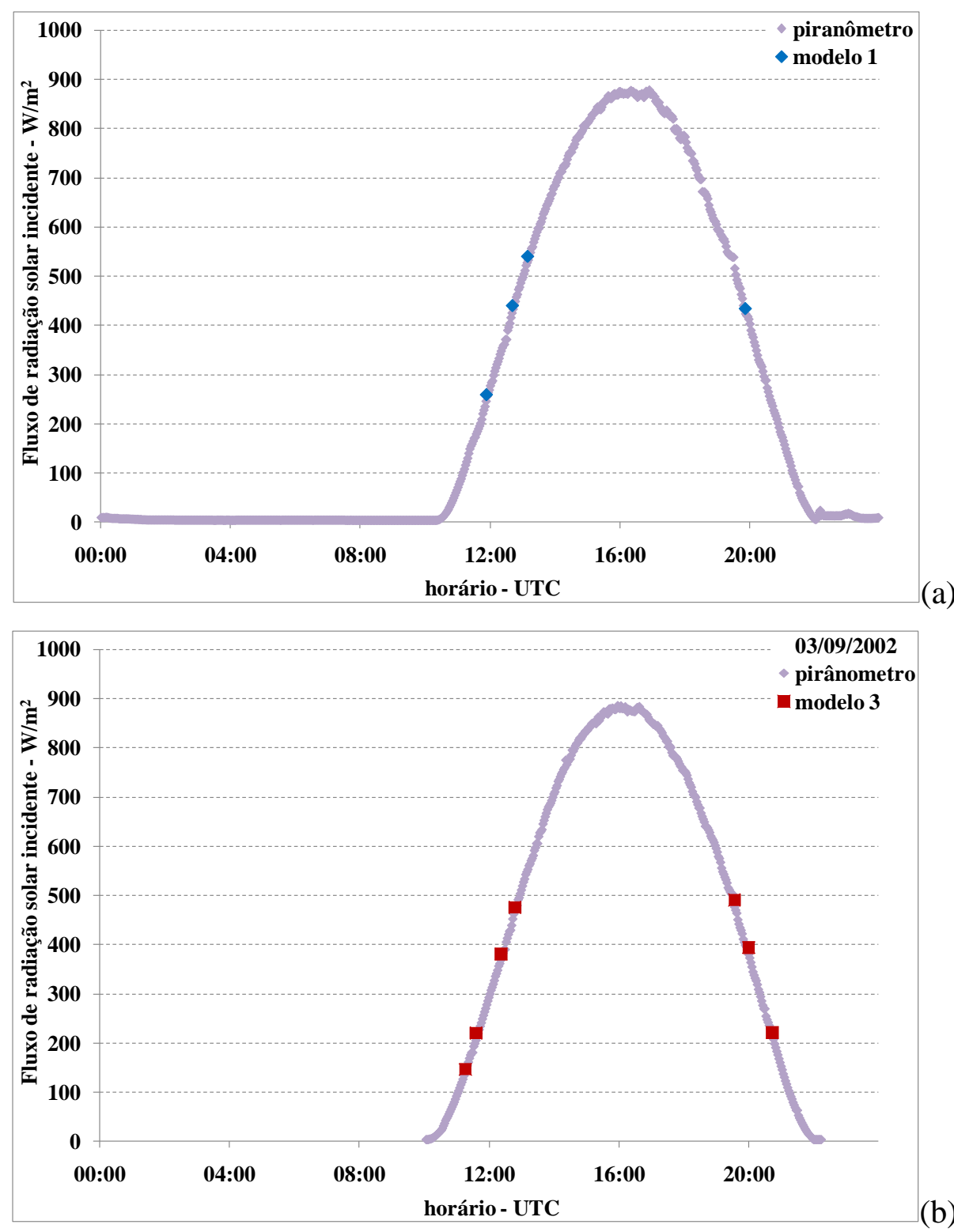

Figura V.33: Ciclo diário do fluxo de radiação solar incidente. Sobreposição das observações experimentais fornecidas pelo piranômetro da rede AERONET e das simuladas com o SBDART, utilizando os modelos ópticos de aerossóis (a) 06/08/2001 - modelo 1 - AOD $(550) \cong 0.30$, (b) 03/09/2002 - modelo $3-A O D(550) \cong 0.70$. 
Neste capítulo foram apresentadas as etapas percorridas para a construção dos modelos ópticos de aerossóis. Este procedimento visou reduzir as incertezas envolvidas no cálculo da $A O D$ com alta resolução espacial. A escolha de qual modelo óptico de aerossol construído melhor descreve a camada de aerossóis da região estudada no período da passagem do satélite ocorreu de forma dinâmica por meio do método da refletância crítica, método este descrito a seguir, no item V.5.

\section{V.5 Escolha do modelo óptico mais adequado para descrever os aerossóis existentes, em cada dia analisado na região de estudo}

A atmosfera, por se tratar de um sistema dinâmico, faz com que o tipo de aerossol em uma mesma região varie espacial e temporalmente, com variações rápidas como o decorrer de algumas horas. Deste modo, para definir qual é o modelo que melhor descreve o aerossol presente na atmosfera no intervalo de tempo próximo à passagem do satélite foi utilizado o método da Refletância Crítica, desenvolvido por Kaufman et al., 1987 e Martins, 1999.

A refletância crítica é uma propriedade intrínseca do aerossol relacionada principalmente ao seu albedo simples, ou seja, um valor de radiância medida no topo da atmosfera que independe da profundidade óptica do aerossol. O albedo, por sua vez, é uma propriedade óptica com alto poder de discriminação da interação da radiação solar com a camada de aerossóis.

Para obtenção de uma equação que descreva a refletância crítica teórica, a equação da refletância no topo da atmosfera ( $\rho_{T O A}$, equação III.33), foi reescrita para duas situações distintas: atmosfera poluída e atmosfera limpa:

$$
\begin{aligned}
& \rho_{\mathrm{TOA}} \text { Poluída }\left(\lambda, \theta_{0}, \theta, \varphi_{0}, \varphi\right)=\rho_{\mathrm{OPol}}+\frac{\mathrm{F}_{\mathrm{dPol}} \mathrm{T}_{\mathrm{Pol}}}{(1-\mathrm{s} \rho)} \rho_{\text {SUP }} \\
& \rho_{\mathrm{TOA}} \text { Limpa }\left(\lambda, \theta_{0}, \theta, \varphi_{\mathrm{o}}, \varphi\right)=\rho_{\mathrm{OLim}}+\frac{\mathrm{F}_{\mathrm{dLim}} \mathrm{T}_{\mathrm{Lim}}}{(1-\mathrm{s} \rho)} \rho_{\text {SUP }} \\
& \frac{\rho_{\mathrm{TOA}} \text { Poluída }-\rho_{\mathrm{OPol}}}{\rho_{\mathrm{TOA}} \text { Limpa }-\rho_{\mathrm{OLim}}}=\frac{\mathrm{F}_{\mathrm{dPol}} \mathrm{T}_{\mathrm{Pol}}}{\mathrm{F}_{\mathrm{dLim}} \mathrm{T}_{\mathrm{Lim}}}, \text { onde } \beta=\frac{\mathrm{F}_{\mathrm{dPol}} \mathrm{T}_{\mathrm{Pol}}}{\mathrm{F}_{\mathrm{dLim}} \mathrm{T}_{\mathrm{Lim}}} \\
& \rho_{\mathrm{TOA}} \text { Poluída }=\beta \rho_{\mathrm{TOA}} \operatorname{Limpa}+\left(\rho_{\mathrm{OPol}}-\rho_{\mathrm{OLim}} \beta\right)
\end{aligned}
$$


A equação V.2 apresenta a relação linear entre a radiância medida no topo da atmosfera em um dia poluído ( $\rho_{\mathrm{TOA}}$ Poluída ) e em um dia limpo ( $\rho_{\mathrm{TOA}}$ Limpa ). Nesta relação, observa-se que o coeficiente angular $\beta$ é tanto menor quanto maior for a profundidade óptica, pois esta é diretamente proporcional à transmitância. O aumento da refletância de superfície, por sua vez, aumentará o coeficiente linear $\left(\rho_{\text {OPol }}-\rho_{\text {OLim }} \beta\right)$.

Para cada modelo de aerossol, por meio de simulações utilizando o código de transferência radiativa SBDART, a relação entre radiância no topo da atmosfera em um dia poluído versus radiância no topo da atmosfera em um dia limpo (equação V.2), foi obtida para uma série de valores de profundidade óptica $(0 ; 0,1$; $0,2 ; 0,3 ; 0,4 ; 0,5 ; 0,6 ; 0,7 ; 0,8 ; 0,9 ; 1,0 ; 1,2 ; 1,5)$ o que gerou um conjunto de curvas para cada dia de estudo. A intersecção dessas curvas, previsto teoricamente como coincidente com a reta 1:1, representa a refletância crítica do tipo de aerossol em questão. A Figura V.34 ilustra os resultados obtidos para a relação entre $\rho_{T O A}(650$ $\mathrm{nm}$ ) para alguns valores de $A O D$ (dia poluído) em função de $\rho_{T O A}(650 \mathrm{~nm})$ para $A O D$ equivalente a zero (dia limpo).

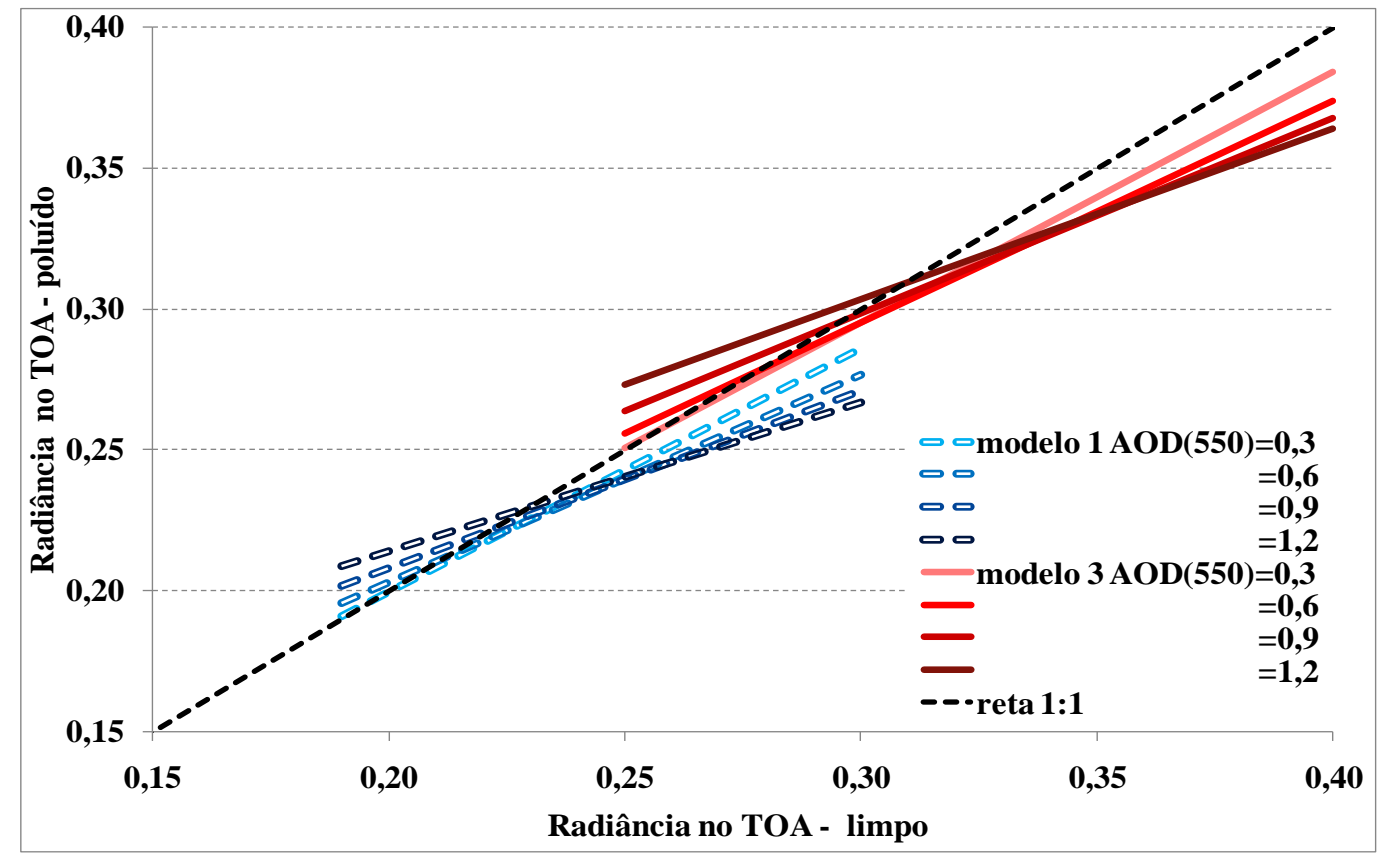

Figura V.34: Radiância no topo da atmosfera em um dia poluído $(A O D(550 \mathrm{~nm})=0,3 ; 0,5$; $0,7 ; 1,5)$ com relação à radiância no topo da atmosfera em um dia limpo $(A O D(550 \mathrm{~nm})=0)$. As refletâncias críticas esperadas para cada modelo óptico de aerossol construído são definidas pelo ponto de intersecção entre as curvas de cada modelo. 
Após determinar a refletância crítica teórica de cada modelo óptico de aerossol construído para cada dia estudado, foi possível construir o gráfico apresentado na Figura V.35, resultado da média das refletâncias críticas teóricas obtidas para cada modelo, com o respectivo desvio padrão $(\sim 14 \%)$ em função do albedo simples do modelo em questão. A refletância crítica é uma propriedade intrínseca do aerossol. O valor obtido em cada dia estudado apresentou oscilações, e o método da refletância crítica foi utilizado para decidir entre o modelo 1 e 3, fazendo com que a zona de compatibilidade entre as refletâncias críticas dos dois modelos ocorra dentro de 2 desvios-padrão.

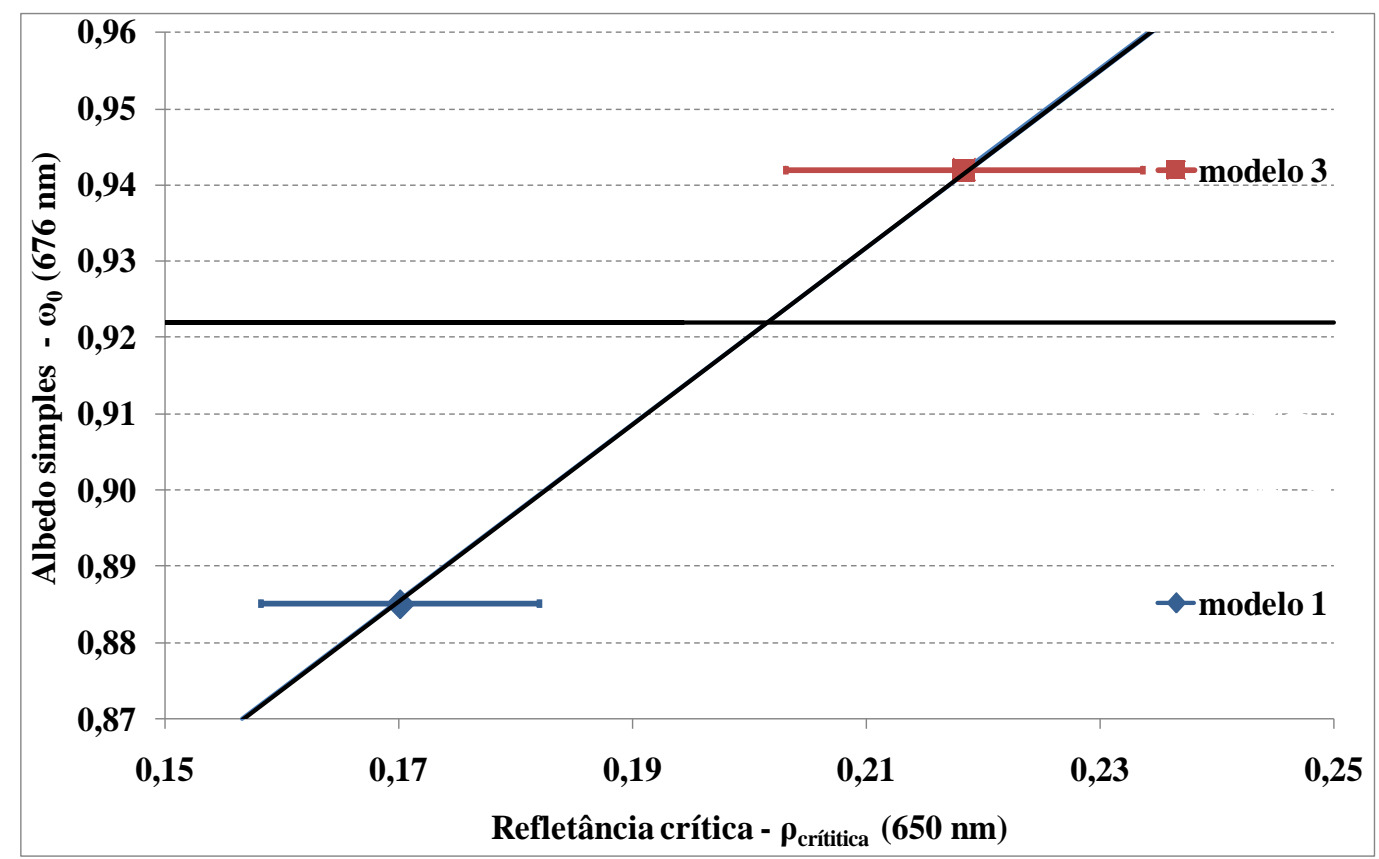

Figura V.35: Relação unívoca entre albedo simples de espalhamento no comprimento de onda de $676 \mathrm{~nm}$ e refletância crítica do aerossol no comprimento de onda de $650 \mathrm{~nm}$.

A refletância crítica foi calculada a partir dos dados fornecidos pelas observações realizadas pelo sensor MODIS. A partir daí, a comparação do valor obtido com a curva apresentada na Figura V.35 permite decidir qual modelo óptico de aerossol é o mais adequado para descrever a camada de aerossóis presente em um período específico. 
O cálculo da refletância crítica experimental, baseado nas observações do sensor MODIS (radiância no topo da atmosfera em $650 \mathrm{~nm}$ e $2.100 \mathrm{~nm}$ ), foi realizado da maneira listada a seguir.

- A refletância de superfície em $2.100 \mathrm{~nm}$ foi obtida a partir da radiância no topo da atmosfera (TOA) em $2.100 \mathrm{~nm}$, observada pelo sensor MODIS, por meio da equação de correção atmosférica, apresentada no item V.2, lembrando que a radiância no comprimento de onda de $2.100 \mathrm{~nm}$ é utilizada por sofrer pouca interação a camada de aerossóis ( $A O D$ muito próxima de zero);

- De acordo com relações empíricas propostas por Kaufman et al., 1997b, e adaptadas por Siqueira et al., 2006 à região de estudo, a refletância de superfície em $650 \mathrm{~nm}$ é obtida a partir a refletância de superfície em $2.100 \mathrm{~nm}$;

- Dado que a refletância de superfície em $650 \mathrm{~nm}$ foi obtida sob condições de $A O D$ próxima de zero, é possível obter, por meio da equação de correção atmosférica, a radiância que seria observada no topo da atmosfera em condições de $A O D$ nula.

Deste modo, com as informações de radiância no topo da atmosfera, fornecidas pelo sensor MODIS e com as informações de radiância no topo da atmosfera estimada para $A O D$ nula, é possível realizar o ajuste exemplificado na Figura V.34, o que permite calcular a refletância crítica experimental a cada $3 \times 3$ pixels $(4,5 \mathrm{~km} \times 4,5 \mathrm{~km})$ da imagem obtida pelo sensor MODIS. Com o valor de refletância crítica obtido é possível escolher, por meio da Figura V.35, o modelo óptico de aerossol mais adequado para descrever a camada de aerossóis da subárea (3x3 pixels) do local de estudo, de maneira independente da profundidade óptica.

A Figura V.36 exemplifica modelos ópticos de aerossóis identificados para cada subárea de $3 \times 3$ pixels em uma área de aproximadamente $50 \mathrm{~km}$ x $50 \mathrm{~km}$. Nota-se que a distribuição espacial dos modelos identificados muda de região para região e de dia para dia, por isso o método de escolha do modelo óptico de aerossol é chamadi interativo e dinâmico. 

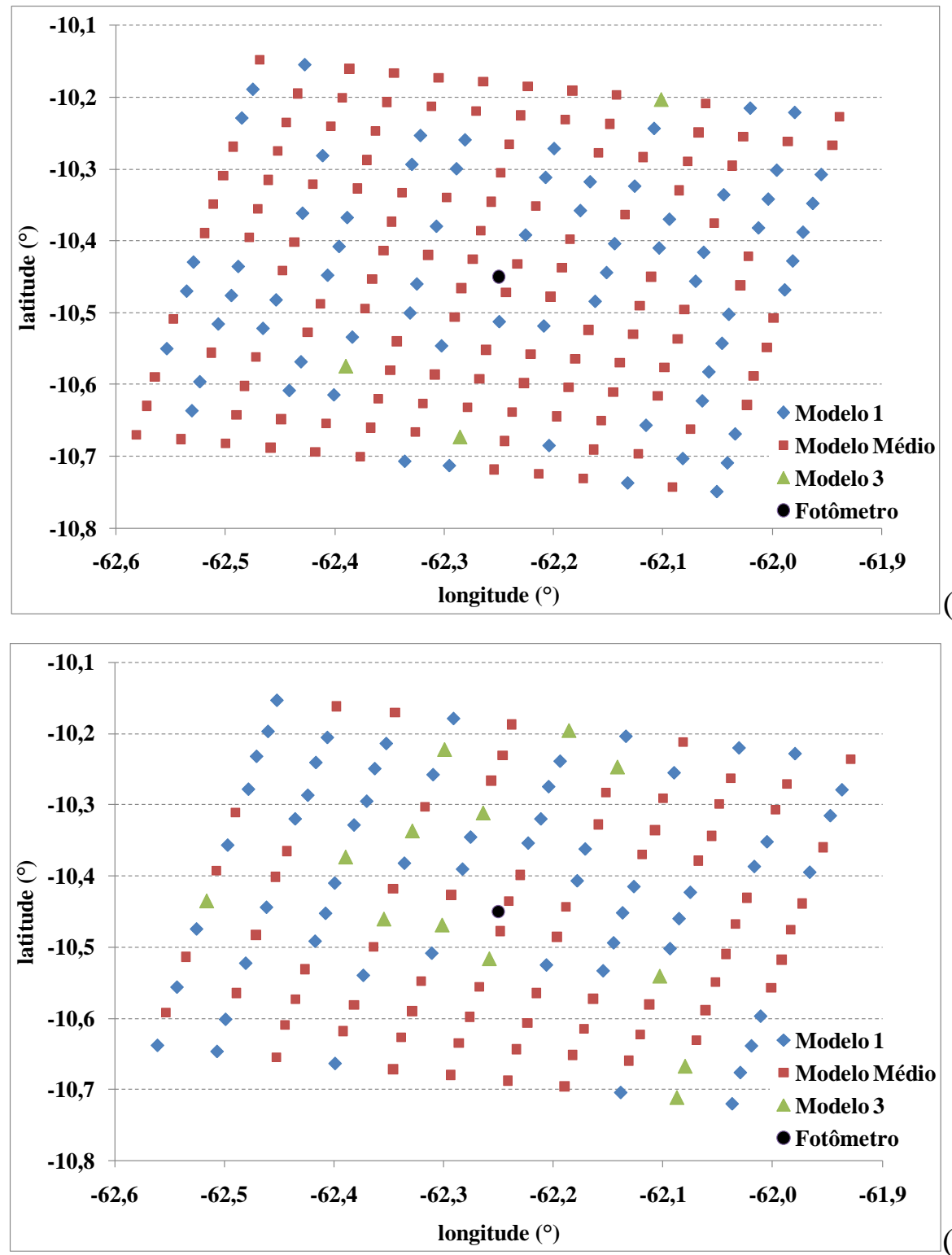

Figura V.36: Distribuição espacial dos modelos ópticos de aerossóis atribuídos pelo algoritmo, sendo (a) a representação do dia 3 de agosto de 2003 e (b) a representação do dia 5 de agosto de 2003.

Nas áreas de 3x3 pixels em que a relação entre radiância no TOA, observada pelo sensor MODIS (atmosfera poluída), e a radiância no TOA estimada considerando uma atmosfera limpa (Figura V.34) apresentou coeficiente de correlação linear $\mathrm{R}^{2}$ inferior a 0,8 (valor sugerido por Castanho, 2005) não foi possível calcular a refletância crítica. Nestas situações o modelo médio foi utilizado para descrever a camada de aerossóis. Este método de escolha de modelo óptico de aerossóis difere de trabalhos anteriores, nos quais a $A O D$, variável dependente, é tomada como variável de parametrização dos modelos de aerossol (Remer et al., 1997; 1998). 


\section{V.6 Equações de inversão - profundidade óptica dos aerossóis como função da radiância medida pelo sensor MODIS no topo da atmosfera}

Equação de inversão é o termo escolhido, neste trabalho, para descrever a equação que descreve a profundidade óptica dos aerossóis como função da radiância no topo da atmosfera, variável observada pelo sensor MODIS. As equações de inversão utilizadas foram obtidas por meio de simulações realizadas com o código de transferência radiativa SBDART.

Um fluxograma explicativo dos parâmetros utilizados para obtenção das equações de inversão é apresentado na Figura V.37. A descrição desses parâmetros por sua vez já foi apresentada anteriormente.

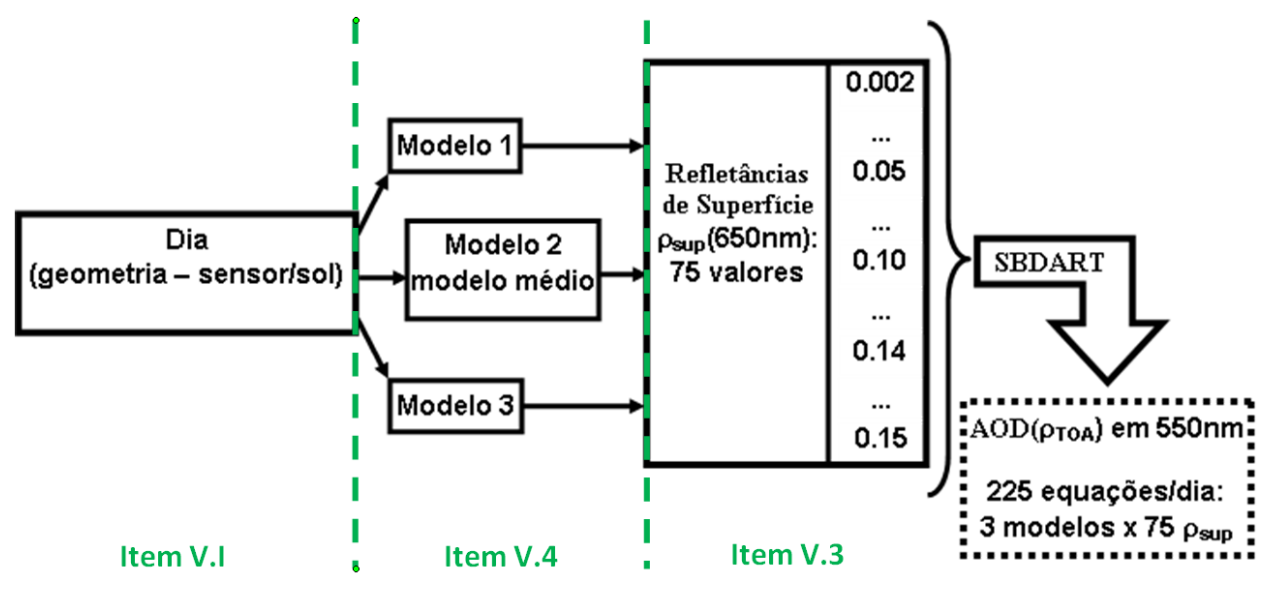

Figura V.37: Ilustração dos parâmetros utilizados na definição das equações de inversão das radiâncias observadas no topo da atmosfera em profundidade óptica dos aerossóis.

Um conjunto de equações foi gerado para todas as situações ilustradas no esquema da Figura V.37. É preciso identificar o modelo de aerossol para a região de 3x3 pixels; conhecer a geometria do sensor e do Sol e estimar a refletância de superfície. A partir daí escolhe-se a equação de inversão que melhor descreva a condição experimental e, tendo a radiância medida no topo da atmosfera pelo sensor como variável independente, determina-se a $A O D$ na sub-região da área de estudo. Exemplos de equações de inversão obtidas de acordo com o procedimento apresentado na Figura V.37 são apresentadas na Figura V.38 e Tabela V.2. 


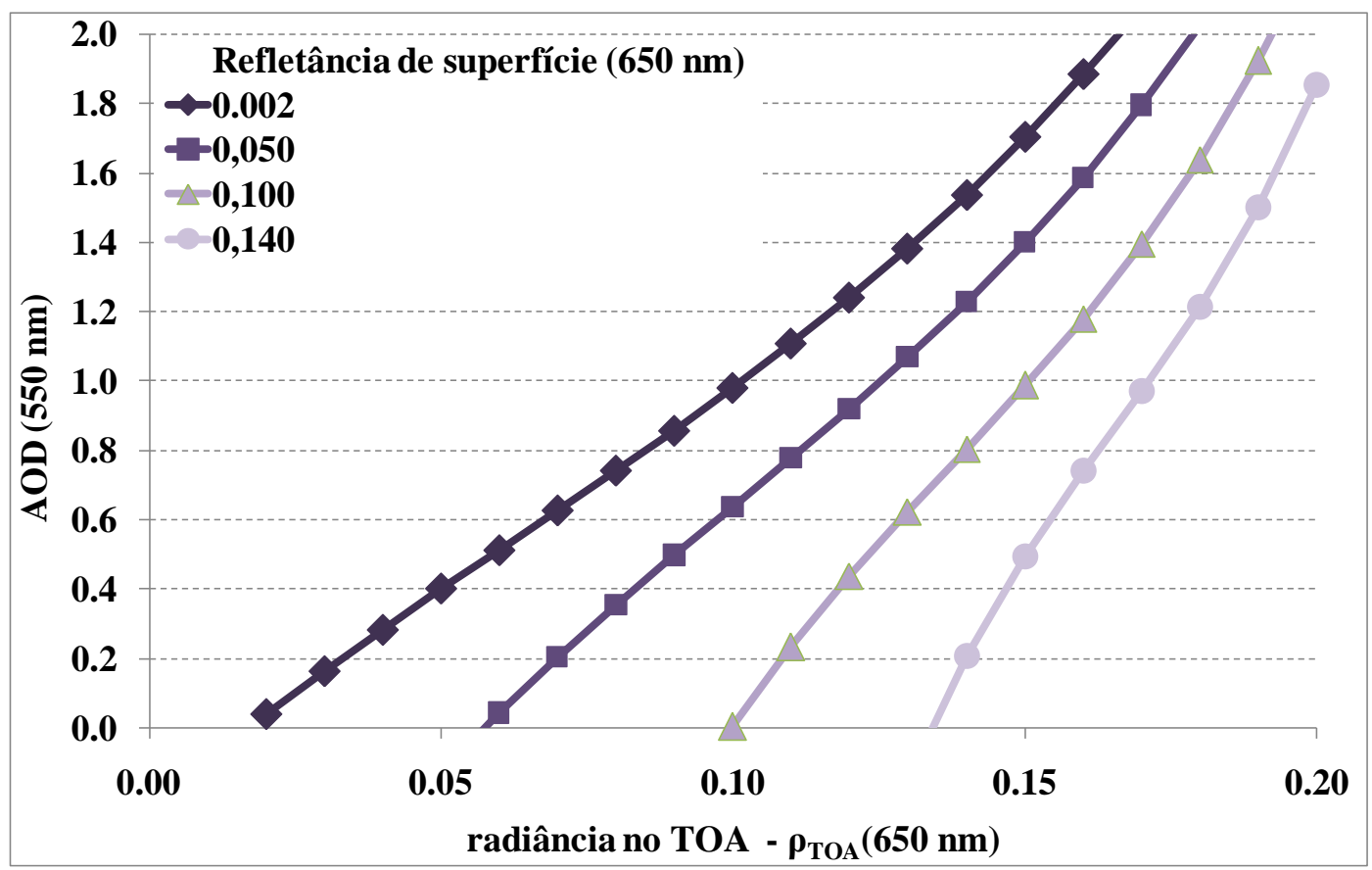

Figura V.38: Representação das equações de inversão da radiância no TOA em profundidade óptica $(A O D)$, obtidas a partir da geometria do dia 02 de agosto de 2002 $\left(\theta_{0}=38.31^{\circ}\right.$, phi $\left.\operatorname{SBDART}=34.9^{\circ}\right)$, para o modelo de aerossol 1 e algumas refletâncias de superfície $\left(\rho_{\text {sup }}(650)=0,002 ; 0,05 ; 0,1 ; 0,15\right)$.

\begin{tabular}{|c|c|c|c|c|c|}
\hline \multirow{2}{*}{$\begin{array}{c}\text { Refletância de } \\
\text { Superfície }(650 \mathrm{~nm})\end{array}$} & \multicolumn{4}{|c|}{$A O D(550 \mathrm{~nm})=\mathbf{A}^{*} \rho_{\mathrm{TOA}}{ }^{3}+\mathbf{B}^{*} \rho_{\mathrm{TOA}}{ }^{2}+\mathbf{C}^{*} \rho_{\mathrm{TOA}}+\mathrm{D}$} & \multirow{2}{*}{$\mathbf{R}^{2}$} \\
\hline & $\mathbf{A}$ & $\mathbf{B}$ & $\mathbf{C}$ & D & \\
\hline 0,002 & 262,42 & $-49,60$ & 14,44 & $-0,23$ & $0, \overline{99}$ \\
\hline 0,050 & 557,34 & $-168,54$ & 30,90 & $-1,32$ & 0,99 \\
\hline $\mathbf{0 , 1 0 0}$ & 1553,14 & $-642,15$ & 106,46 & $-5,77$ & 0,99 \\
\hline 0,140 & 4765,95 & $-2361,89$ & 413,03 & $-24,40$ & 0,99 \\
\hline
\end{tabular}

Tabela V.2: Parâmetros das equações de inversão da radiância no TOA em profundidade óptica dos aerossóis $(A O D)$, obtidas a partir da geometria do dia 02 de agosto de 2002 $\left(\theta_{0}=38.31^{\circ}\right.$, phi $\left.\operatorname{SBDART}=34.9^{\circ}\right)$, para o modelo de aerossol 1 e algumas refletâncias de superfície $\left(\rho_{\text {sup }}(650)=0,002 ; 0,05 ; 0,1 ; 0,15\right)$.

Para a obtenção das equações de inversão (profundidade óptica dos aerossóis em função da radiância no topo da atmosfera observada pelo sensor MODIS), algumas condições foram impostas:

- Foram considerados apenas dias, identificados por meio da máscara de nuvens do próprio MODIS, da máscara de nuvens desenvolvida por Castanho et al., 2008, e das imagens no visível sobre a região; 
- A influência de aerossóis estratosféricos foi considerada desprezível;

- Para a caracterização dos perfis atmosféricos de temperatura e gases constituintes da atmosfera, foi considerado o modelo de perfil tropical da biblioteca padrão do SBDART;

- Ao invés de tomar um valor médio para todo o período estudado (procedimento adotado por Castanho, 2005), o conteúdo de vapor de água atmosférico do perfil (obtido com o radiômetro, CIMEL da AERONET) foi considerado como sendo o valor medido durante a passagem do satélite.

- Considerou-se um valor médio para a pressão de superfície na região de $841,1 \mathrm{hPa}$, Fisch, 2004;

- Fluxo solar constante (padrão Lowtran_7 do SBDART);

- Fator de distância solar: 0,9688 $\left(\mathrm{UA}^{-2}\right)$.

- Geometrias do Sol e do sensor (ângulos zenital e azimutal) específicos de cada dia estudado;

- Dois modelos de aerossol foram definidos a partir de propriedades ópticas $\left(\omega_{0}, g\right.$, $\mathrm{Q}_{\text {ext }}$ ), os quais são chamados de modelos 1 e 3;

- Foram utilizados valores de refletância de superfície entre 0.002 e 0.150, em intervalos de 0.002 , totalizando 75 valores de refletância;

- Foi considerada a aproximação de atmosfera plano-paralela, com a ocorrência de múltiplos espalhamentos, e uma superfície Lambertiana. 


\section{Profundidade ÓPTICA de Aerossóis COM ALTA RESOLUÇÃo ESPACIAL - EXEMPLOS}

A seguir são apresentados exemplos dos produtos de $A O D$ em $550 \mathrm{~nm}$ com resolução espacial de $1,5 \mathrm{~km}$ x 1,5 km obtidos sobre a região de Ji-Paraná, a partir de modelos ópticos de aerossóis específicos para região de estudo e escolhidos de forma dinâmica. Foram selecionados cinco dias que abrangessem situações diversas de cobertura de aerossóis, ou seja, desde dias pouco impactados pela presença de aerossóis até dias com presença de plumas de queimadas. Os resultados de $A O D$ obtidos são comparados aos resultados operacionais da NASA, que possui resolução espacial de $10 \mathrm{~km} \times 10 \mathrm{~km}$. A escala de cores das figuras abaixo vão de $A O D$ nula até $A O D$ igual a 3, e as regiões em branco são regiões nas quais não foi possível calcular a $A O D$, ou seja regiões impactadas pela presença de nuvens.

A Figura VI.1 apresenta um dia pouco impactado pela presença de aerossóis. O produto com alta resolução espacial, entretanto, foi capaz de identificar uma área à esquerda da figura, concentrações mais elevadas de aerossóis.
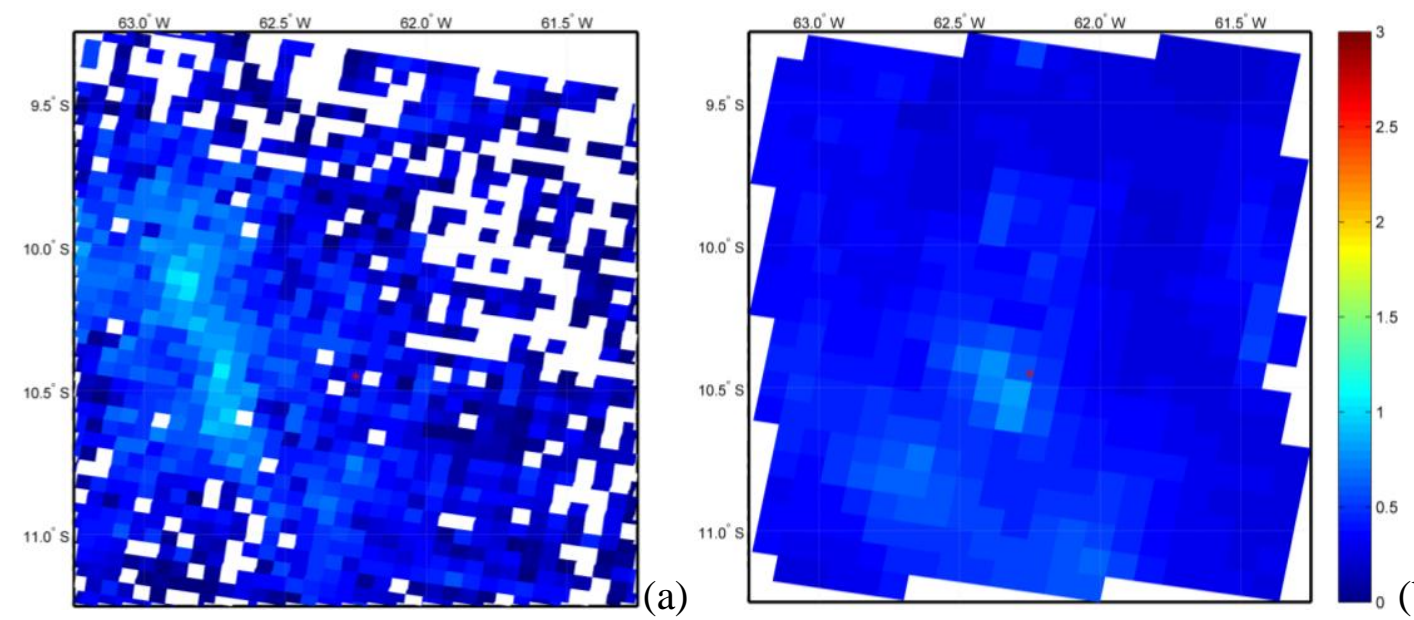

(b)

Figura VI.1: Distribuição espacial da profundidade óptica dos aerossóis, em 550 nm, em uma área de $2^{\circ} \times 2^{\circ}$ em torno do fotômetro da região de Ji-paraná do dia 19 de setembro de 2001, (a) Produto deste trabalho com resolução espacial de 1,5 kmx1,5km, (b) Produto operacional da NASA com resolução espacial de $10 \mathrm{~km} \times 10 \mathrm{~km}$. A barra de cores indica $A O D(550 \mathrm{~nm})$ de zero (azul) a 3 (vermelho). 
A Figura VI.2 apresenta uma situação na qual aumento da resolução espacial foi capaz de identificar dentro de uma região supostamente impactada pela presença de nuvens (regiões em branco a direita da figura), sub-regiões nas quais foi possível calcular a $A O D$.
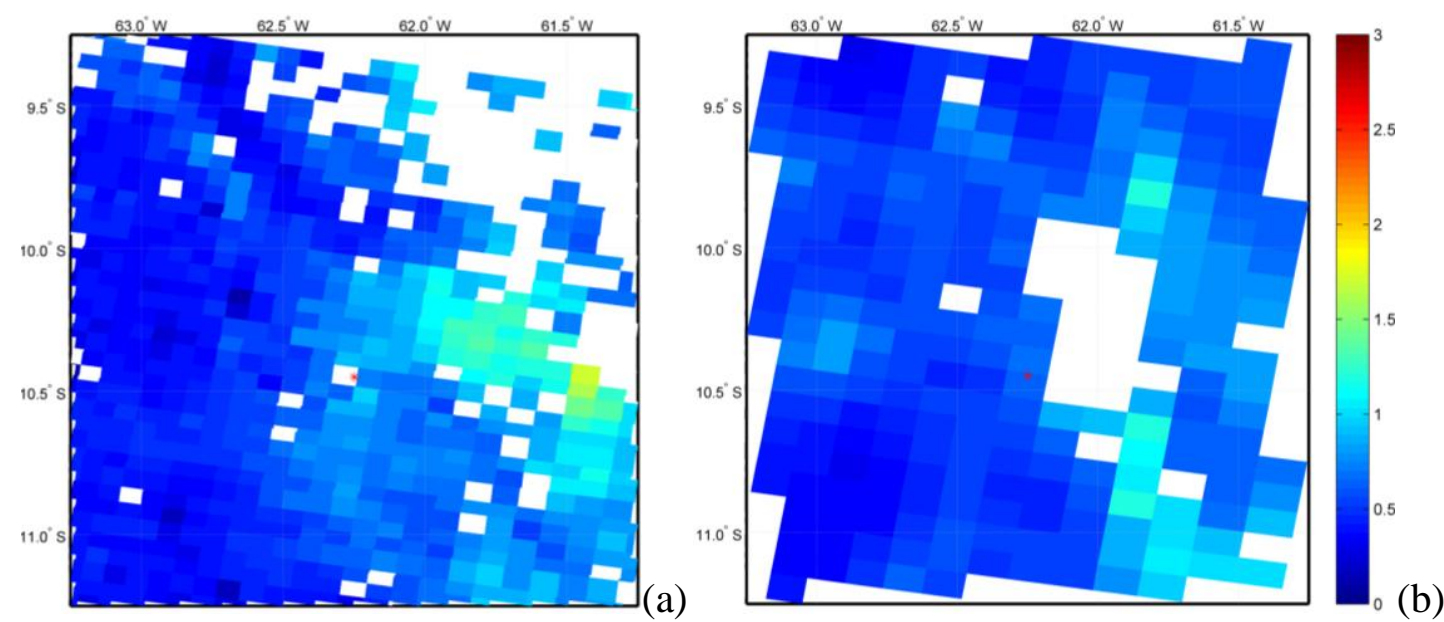

Figura VI.2: Distribuição espacial da profundidade óptica dos aerossóis, em 550 nm, em uma área de $2^{\circ} \times 2^{\circ}$ em torno do fotômetro da região de Ji-paraná do dia 20 de setembro de 2002 , (a) Produto deste trabalho com resolução espacial de 1,5 kmx1,5km, (b) Produto operacional

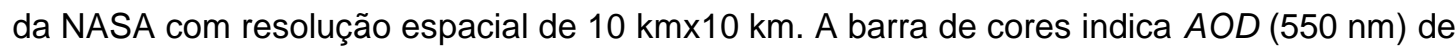
zero (azul) a 3 (vermelho).

As Figuras VI.3 e VI.4 apresentam situações nas quais regiões com $A O D$ significativamente superiores ao seu em torno foram identificadas, em contrapartida aos resultados operacionais de $A O D$ da NASA, que classificaram essas regiões como contaminadas por nuvens ou esses valores foram diluídos em sua região. 

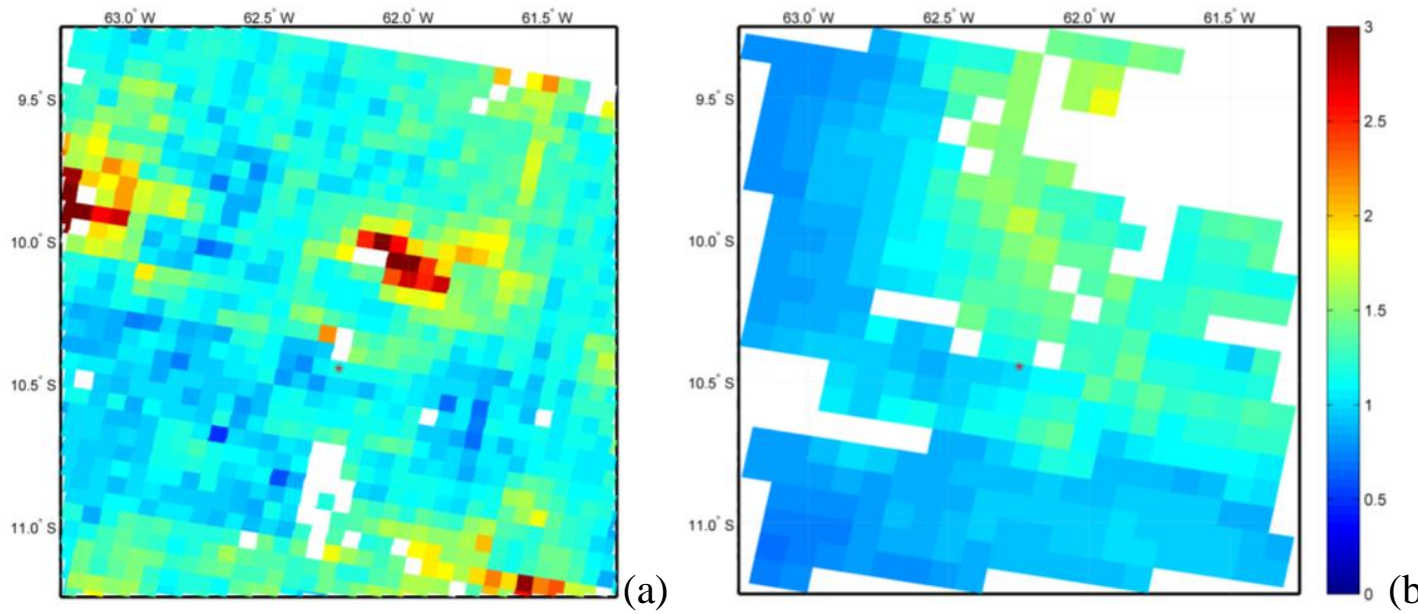

(b)

Figura VI.3: Distribuição espacial da profundidade óptica dos aerossóis, em 550 nm, em uma área de $2^{\circ} \times 2^{\circ}$ em torno do fotômetro da região de Ji-paraná do dia 26 de agosto de 2003 , (a) Produto deste trabalho com resolução espacial de 1,5 km×1,5km, (b) Produto operacional da NASA com resolução espacial de $10 \mathrm{~km} \times 10 \mathrm{~km}$. A barra de cores indica $A O D(550 \mathrm{~nm}) \mathrm{de}$ zero (azul) a 3 (vermelho).
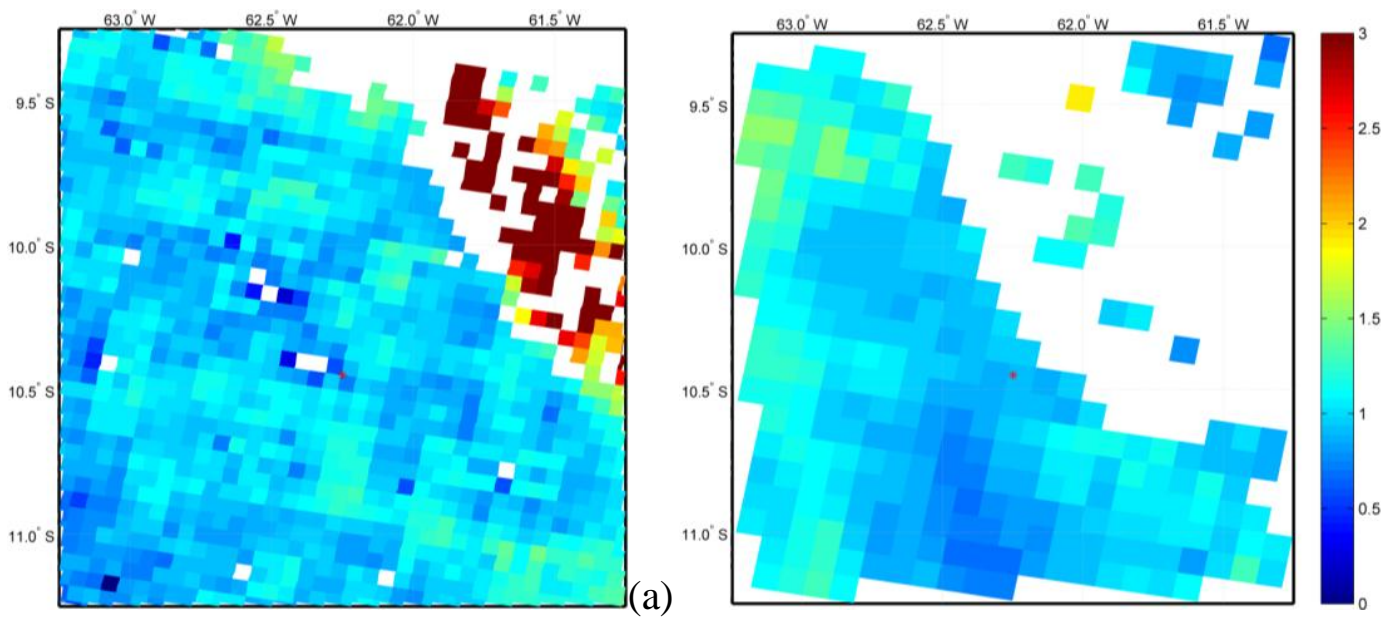

(b)

Figura VI.4: Distribuição espacial da profundidade óptica dos aerossóis, em 550 nm, em uma área de $2^{\circ} \times 2^{\circ}$ em torno do fotômetro da região de Ji-paraná do dia 15 de setembro de 2008 , (a) Produto deste trabalho com resolução espacial de 1,5km×1,5km, (b) Produto operacional da NASA com resolução espacial de $10 \mathrm{~km} \times 10 \mathrm{~km}$. A barra de cores indica $A O D(550 \mathrm{~nm})$ de zero (azul) a 3 (vermelho).

A Figura VI.5 apresenta uma dia fortemente impactado pela presença de aerossóis, a parte inferior da figura entretanto trata-se do limite dos dados fornecidos pelo sensor e não da identificação da presença de nuvens. Assim como nas duas figuras anteriores, neste caso foi possível calcular $A O D$ em pixels operacionalmente identificados como contaminados por nuvens e obter um maior detalhamento da distribuição espacial de $A O D$. 

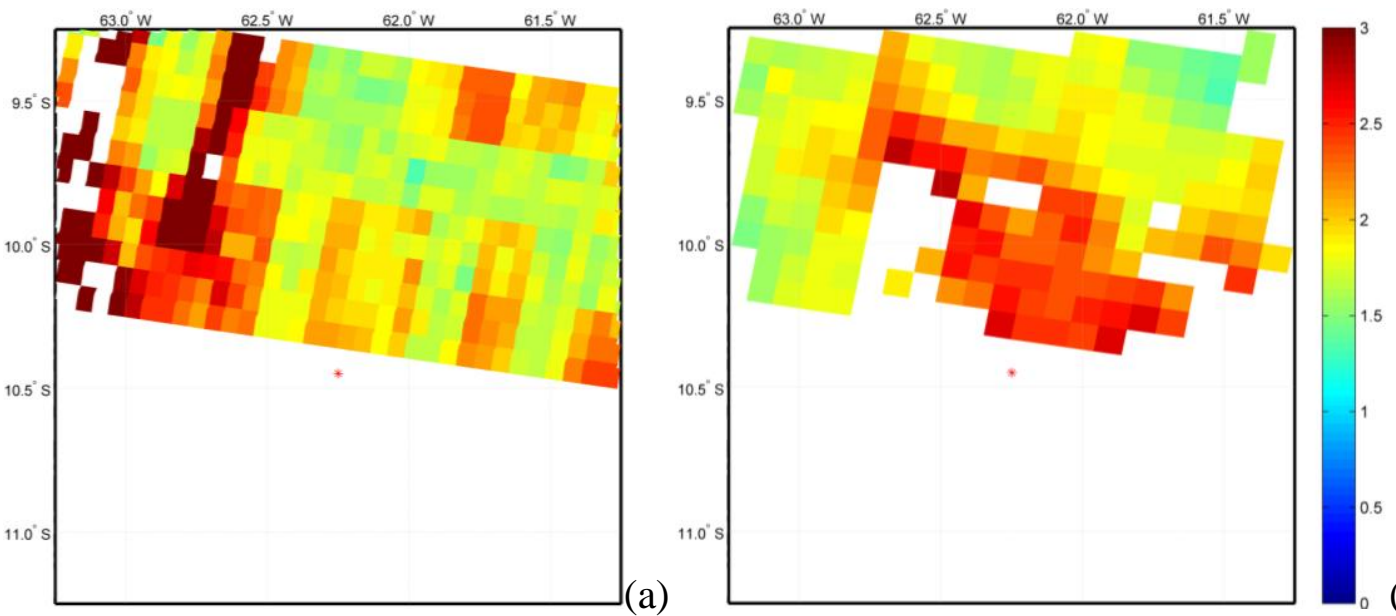

(b)

Figura VI.5: Distribuição espacial da profundidade óptica dos aerossóis, em 550 nm, em uma área de $2^{\circ} \times 2^{\circ} \mathrm{em}$ torno do fotômetro da região de Ji-paraná do dia 22 de setembro de 2002 , (a) Produto deste trabalho com resolução espacial de 1,5 kmx1,5km, (b) Produto operacional da NASA com resolução espacial de $10 \mathrm{~km} \times 10 \mathrm{~km}$. A barra de cores indica $A O D(550 \mathrm{~nm})$ de zero (azul) a 3 (vermelho).

$\mathrm{O}$ aumento da resolução espacial dos valores de $A O D$ obtidos permite uma análise da distribuição de poluentes com mais detalhes sobre a região de estudo. Os resultados de $A O D$, com alta resolução espacial obtidos, demonstraram serem consistentes, por meio do processo de validação, revelando a potencialidade do método na identificação automática do modelo de aerossol para a determinação de $A O D$ baseado em informações obtidas em satélite, mesmo em regiões com aerossóis mais homogêneos como a região amazônica.

\section{VALIDAÇÃo dOS VALORES DE PROFUNDIDADE ÓPTICA dOS AEROSSÓIS COM ALTA RESOLUÇÃO ESPACIAL}

A validação dos valores de $A O D$ obtidos é uma etapa de fundamental importância na análise dos resultados que fora apresentados no capítulo anterior. O objetivo deste capítulo é apresentar os resultados da validação dos produtos de $A O D$ com resolução espacial de 1,5 km x 1,5 km, obtidos a partir das observações de radiâncias realizadas pelo sensor MODIS, a bordo do satélite TERRA. O processo de validação consistiu basicamente na comparação do produto de $A O D$ derivado do MODIS com as observações de $A O D$ realizadas pelo radiômetro solar de superfície da rede AERONET, localizado em Ji-Paraná durante o período de 2000 a 2005. Após esse período, o fotômetro deste sítio experimental foi transferido para outro local. 
A validação do produto de $A O D$ com resolução espacial de $1,5 \mathrm{~km}$ x $1,5 \mathrm{~km}$ foi realizada a partir da $A O D$ média obtida pelo algoritmo desenvolvido neste trabalho, em áreas de $10 \mathrm{~km}$ x10 km e $50 \mathrm{~km} \times 50 \mathrm{~km}$. A região foi escolhida tendo como ponto central a localização do fotômetro da rede AERONET. Os valores médios de $A O D$ com alta resolução espacial foram comparados com os valores de $A O D$ obtidos pelo fotômetro da rede AERONET: no horário mais próximo ao horário de passagem do satélite; com os valores médios das observações de $A O D$ obtidos em intervalos de 30 minutos e em 1 hora em torno do horário de passagem do satélite. Com o intuito de comparar situações físicas que fossem o mais similares possível, dentro da área de $10 \mathrm{~km} \mathrm{x10} \mathrm{km} \mathrm{analisada,} \mathrm{selecionou-se} \mathrm{a} \mathrm{região} \mathrm{de} 3 \times 3$ pixels (que corresponde a uma área física de 4,5 km x 4,5 km), que contemplava a localização do fotômetro da rede AERONET. O valor médio de $A O D$ obtido para esta sub-região foi comparado com o obtido pelo fotômetro da rede AERONET no horário mais próximo ao horário de passagem do satélite. As diversas validações realizadas estão listadas na Tabela VII.1.

\begin{tabular}{|c|c|c|c|c|}
\hline & & \multicolumn{3}{|c|}{$A O D$ com alta resolução espacial } \\
\hline & & $\begin{array}{l}\text { Média em } \\
50 \times 50 \mathrm{~km}\end{array}$ & $\begin{array}{l}\text { Média em } \\
10 \mathrm{~km} \mathrm{x} \\
10 \mathrm{~km} \\
\end{array}$ & $\begin{array}{c}\text { Média em } \\
3 \times 3 \text { pixels } \\
(4,5 \times 4,5 \mathrm{~km}) \\
\end{array}$ \\
\hline \multirow{3}{*}{$\begin{array}{c}\text { Observações } \\
\text { de } A O D \\
\text { realizadas } \\
\text { pelo } \\
\text { fotômetro } \\
\text { da rede } \\
\text { AERONET }\end{array}$} & $\begin{array}{l}\text { Média em } 60 \text { minutos em torno do } \\
\text { horário de passagem do satélite. }\end{array}$ & $\sqrt{ }$ & $\sqrt{ }$ & \\
\hline & $\begin{array}{l}\text { Média em } 30 \text { minutos em torno do } \\
\text { horário de passagem do satélite. }\end{array}$ & & $\sqrt{ }$ & \\
\hline & $\begin{array}{l}\text { Observação realizada mais próxima } \\
\text { ao horário de passagem do satélite, } \\
\text { no intervalo de } 30 \text { minutos. }\end{array}$ & & & \\
\hline
\end{tabular}

Tabela VII.1: Tipos de comparações realizadas entre os valores de $A O D$ com alta resolução espacial, obtidos neste trabalho, e as observações de $A O D$, realizadas pelo fotômetro da rede AERONET

O método de comparação utilizado neste trabalho e explicitado na Tabela VII.1, foi baseado no trabalho de Ichoku, 2002. Segundo Ichoku, a velocidade de transporte horizontal do aerossol na atmosfera sobre o oceano é de aproximadamente $50 \mathrm{~km} / \mathrm{h}$. Deste modo, uma única observação registrada pelo fotômetro pode representar adequadamente a camada de aerossóis de uma área de 10 $\mathrm{km} \times 10 \mathrm{~km}$, visto que o fotômetro da rede AERONET realiza observações em média a cada 10 ou 15 minutos. Espera-se que a velocidade de advecção sobre a Amazônia seja menor que sobre o oceano, devido à cobertura vegetal que atenua o deslocamento 
horizontal de massas de ar. Assim, uma área de $10 \mathrm{~km} \mathrm{x} 10 \mathrm{~km}$, sobre a floresta, pode ser bem representada pela média das observações realizadas a cada meia hora ou mesmo de hora em hora.

A validação do produto de profundidade óptica do aerossol operacional, Figura VII.1, foi realizada da maneira como é realizada pela NASA, conforme apresentada no site http://MODIS-atmos.gsfc.nasa.gov/MOD04_L2/validation.html.a, A média dos valores de $A O D$ obtidas operacionalmente com resolução espacial de 10 km x 10 km em áreas 50x50 km é comparada a média das observações realizadas pelo fotômetro da rede AERONET no intervalo de 1 hora em torno do horário de passagem do satélite.

Um dos problemas importantes na comparação dos produtos do MODIS é a questão da cobertura de nuvens. A presença de nuvens foi identificada a partir do produto de máscara de nuvens do próprio MODIS, das imagens do visível sobre a região, e da máscara de nuvens baseada nos limites fisicamente aceitáveis de refletâncias de superfície (Castanho et al., 2008). Devido à alta concentração de nuvens identificada na região à quantidade de dados e dias disponíveis para a validação foi severamente reduzida. No total, temos no máximo 75 dias de comparação, variando de acordo com o tamanho da área utilizada para validação, 10 $\mathrm{km} \times 10 \mathrm{~km}$ ou $50 \times 50 \mathrm{~km}$.

Analisando os períodos disponíveis para validação, verifica-se que a maioria deles apresentaram valores de $A O D$ (550) inferiores a 1,0, não indo ao encontro do que é esperado segundo a série temporal de observações de $A O D$ realizadas pelo fotômetro da rede AERONET, Figura V.13, na qual se observa valores acima deste limite de 1,5, já considerando a diferença entre os comprimentos de onda nos quais as informações são apresentadas. A grande maioria dos dias que apresentaram valores de $A O D(500 \mathrm{~nm})$ observados pelo fotômetro da rede AERONET superiores a 1,0 não puderam ser analisados, principalmente porque as observações realizadas pelo sensor MODIS correspondentes foram tratadas como observações contaminadas pela presença de nuvens, por algum dos critérios utilizados na construção da máscara de nuvens.

A constatação de que as observações realizadas pelo sensor MODIS em dias com elevados níveis de $A O D$ foram classificados como estando sob a influência de nuvens, fez com que a $A O D$ com alta resolução espacial precisasse ser calculada para 
alguns desses dias, independentemente do critério de classificação da presença de nuvens. É importante salientar que quanto maior os valores da $A O D$ mais sensíveis são os resultados do algoritmo de alta resolução espacial ao modelo óptico de aerossol escolhido. Dentre os dias inicialmente excluídos dos cálculos, obteve-se a $A O D$ com alta resolução espacial para os dias nos quais o fotômetro da AERONET realizou observações dentro do intervalo de uma hora em torno do horário de passagem do satélite, indicando que ao menos nesse período o fotômetro não identificou a presença de nuvens na direção na qual ele realizou a observação. Os dias inicialmente excluídos serão diferenciados dos demais nos gráficos apresentados.

Inicialmente será apresentada a validação da $A O D$ obtida operacionalmente pela NASA, Figura VII.1, para comparação com a validação da $A O D$ com alta resolução espacial obtidas neste trabalho, Figura VII.2. Ambas as validações utilizaram o $A O D$ médio em 50x50 km.

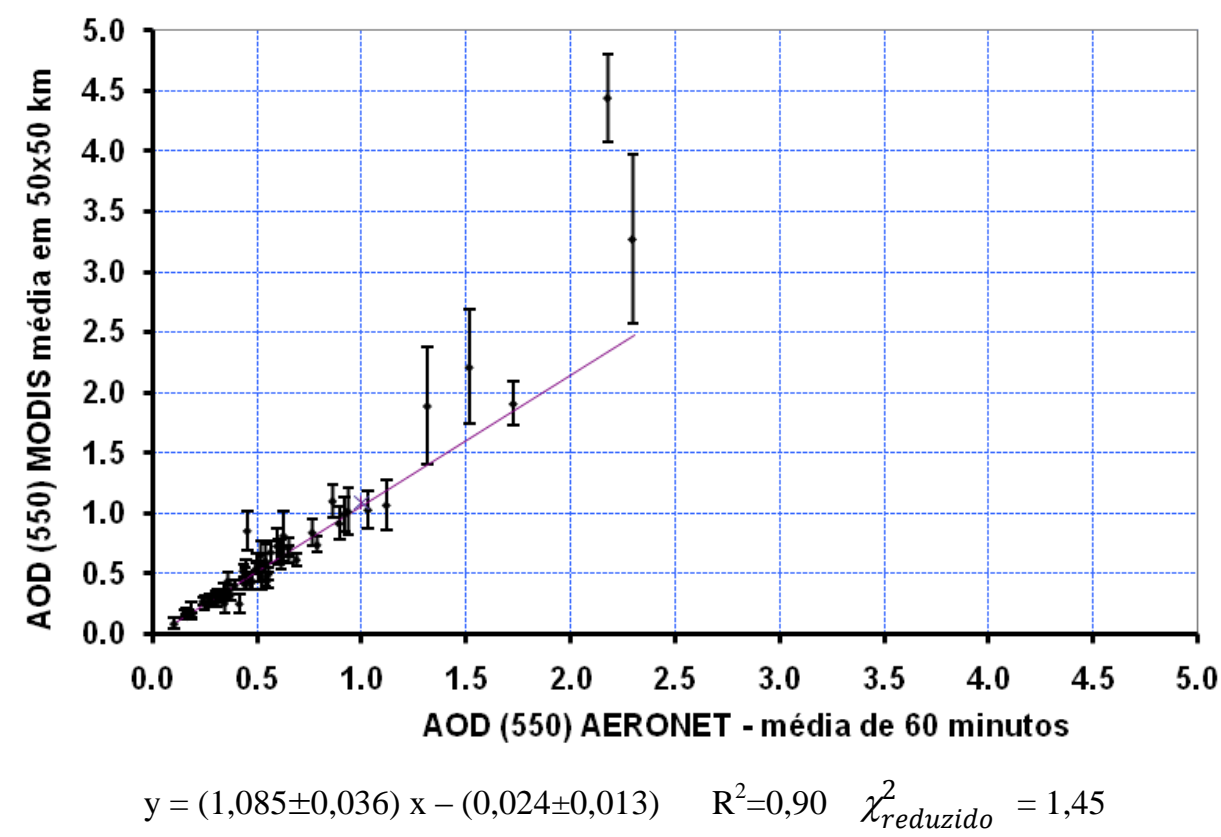

Figura VII.1: Média em áreas de $50 \mathrm{~km} \times 50 \mathrm{~km}$, da $A O D$ (550) com resolução espacial de $10 \mathrm{~km} \times 10 \mathrm{~km}$, obtida operacionalmente pela NASA a partir de observações de radiância no topo da atmosfera realizadas pelo sensor MODIS, comparadas à média das medidas obtidas com o radiômetro CIMEL da AERONET no intervalo de 60 minutos, em torno do horário de passagem do satélite. A equação do ajuste, o coeficiente de correlação linear e o Qui2 reduzido estão abaixo do gráfico. 


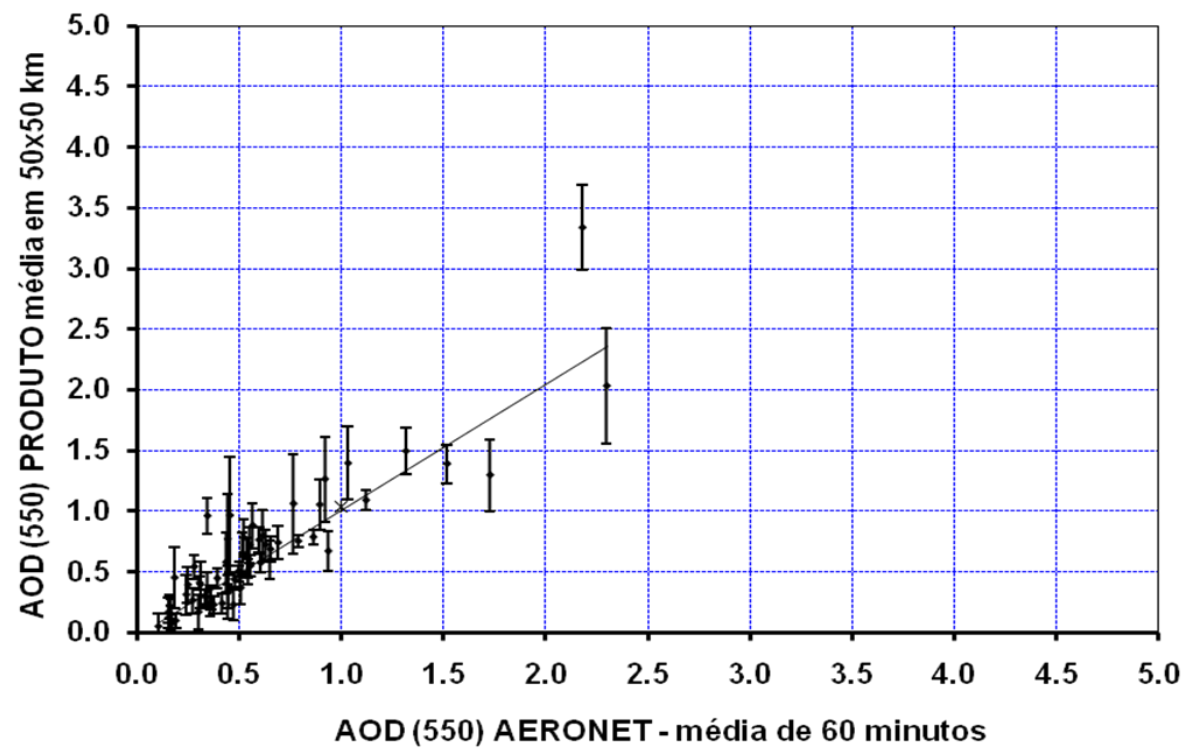

$$
\mathrm{y}=(1,041 \pm 0,044) \mathrm{x}-(0,034 \pm 0,022) \quad \mathrm{R}^{2}=0,81 \quad \chi_{\text {reduzido }}^{2}=1,40
$$

Figura VII.2: Média em áreas de $50 \mathrm{~km} \times 50 \mathrm{~km}$, da $A O D$ (550) com resolução espacial de $1,5 \mathrm{~km} \times 1,5 \mathrm{~km}$, obtida neste trabalho, a partir de observações de radiância no topo da atmosfera realizadas pelo sensor MODIS comparadas à média das medidas obtidas com o radiômetro CIMEL da AERONET no intervalo de 60 minutos, em torno do horário de passagem do satélite. A equação do ajuste, o coeficiente de correlação linear e o Qui2 reduzido estão abaixo do gráfico.

Os resultados de validação, apresentados na da Figura VII.1 e da Figura VII.2, são compatíveis com o esperado, pois apontam para um coeficiente angular de $(1,085 \pm 0,036)$ e $(1,041 \pm 0,044)$ respectivamente, enquanto o coeficiente linear é próximo a zero (valores de 0,034 $\pm 0,022$ e 0,024 $\pm 0,013$ ). O $\chi_{\text {reduzido }}^{2}$ dos ajustes por sua vez, estão na dentro da faixa que define um intervalo de confiança de $98 \%$, de 0,6 a 1,5 , revelando que as barras de erro quantificam adequadamente as incertezas envolvidas. As barras de erro apresentadas nos ajustes das Figuras VII.1 e VII.2 são o desvio padrão dos valores de AOD calculados na área de $50 \mathrm{~km}$ x50 km. Vale resaltar que é esperado que os valores, médios em uma área de $50 \mathrm{~km}$ x50 km, operacionais do MODIS apresentem menor flutuação que os valores em alta resolução, e que por sua vez apresentará, menor flutuação do que a média realizada em áreas menores. Deste modo, o desvio padrão foi capaz também de traduzir as incertezas envolvidas no algoritmo utilizado.

Este resultado indica que o método utilizado neste trabalho, recupera de forma consistente os resultados do algoritmo operacional, apesar das aproximações consideradas e da maior variabilidade esperada para os resultados (dado que a resolução espacial do método utilizado é superior em mais de 40 vezes a resolução 
espacial do produto operacional).Vale ressaltar entretanto que os valores de $A O D$ com alta resolução espacial, Figura VII.2, apresentam a vantagem do coeficiente angular do ajuste ser compatível com o esperado dentro de apenas uma incerteza.

Como já dito anteriormente, o produto operacional de $A O D$ da NASA, utiliza apenas quatro modelos de propriedades ópticas dos aerossóis para descrever os aerossóis de todo o globo. Destes, apenas um é escolhido para cada região, de acordo com a dependência espectral entre o azul e vermelho, a região do globo e a época do ano. Deste modo, regiões com aerossóis mais homogêneos possuem maiores chances de serem bem descritos por um único modelo. Exemplo disso são os bons resultados de validação do produto operacional da NASA para região de Ji-Paraná na época de queimadas, se comparados aos resultados obtidos para regiões urbanas como São Paulo, conforme estudo de Castanho, 2005, no qual foi obtido coeficiente angular de apenas 0.38 e $\mathrm{R}^{2}=0.67$.

O objetivo do estudo foi obter um produto de profundidade óptica de aerossóis com alta resolução espacial, e por isso o desenvolvimento de modelos ópticos específicos para a região de estudo foi ao encontro de tentar captar as heterogeneidades existentes na pluma de aerossóis e ao menos manter a acurácia dos valores obtidos operacionalmente com resolução espacial de 10 kmx10 km.

A Tabela VII.2 apresenta os ajustes lineares resultantes da comparação dos valores de profundidade óptica do aerossol, com alta resolução espacial de 1,5x1,5 km, com valores médios das observações de profundidade óptica dos aerossóis realizadas pelo fotômetro da rede AERONET, Foram calculados valores médios em áreas de $10 \mathrm{~km} \times 10 \mathrm{~km}$, e médias temporais de 30 minutos e de 1 hora em torno do horário de passagem do satélite. Também foi realizada a comparação dos valores com a medida realizada pelo fotômetro que seja mais próxima ao horário de passagem do satélite sobre a região, no intervalo máximo de 30 minutos em torno do horário de passagem do satélite.

Considerou-se como incerteza dos valores médios das observações de $A O D$, realizadas pelo fotômetro da rede AERONET, o desvio padrão das várias observações. Para a observação realizada mais próxima ao horário de passagem do satélite, considerou-se a incerteza como sendo $4 \%$ do valor observado (média do desvio padrão das observações realizadas no intervalo de 30 minutos em torno do horário de passagem do satélite). 
Critério de comparação dos

valores de $A O D$ com alta

resolução espacial com as

observações de $A O D$ realizadas

pelo fotômetro da rede

AERONET

Média das observações realizadas

no intervalo de 1 hora em torno do

horário de passagem do satélite

Média das observações realizadas

no intervalo de 30 minutos em torn

do horário de passagem do satélite

Observação mais próxima ao

horário de passagem do satélite, no

intervalo de 30 minutos em torno do

$y=(1,22 \pm 0,04) x-(0,08 \pm 0,02) \quad 0,84$

$\mathbf{R}^{2} \quad \chi_{\text {reduuzido }}^{2}$

Ajuste linear

$y=(1,20 \pm 0,04) x-(0,07 \pm 0,02) \quad 0,84$

3,83

$y=(1,21 \pm 0,04) x-(0,07 \pm 0,02) \quad 0,84$

4,15

horário de passagem do satélite

Tabela VII.2: Ajustes lineares resultantes da comparação dos valores $A O D$ com alta resolução com os valores fornecidos pela AERONET, em médias de 30 e de 60 minutos. Também foi considerada a medida mais próxima ao horário de passagem do satélite.

Analisando os resultados apresentados na Tabela VII.2, verifica-se que os parâmetros dos ajustes lineares das 3 análises são compatíveis entre si dentro de uma barra de erro. Verifica-se também que os ajustes apresentam coeficientes de correlação linear similares. $\mathrm{O} \chi_{\text {reduzido }}^{2}$ dos ajustes não estão na dentro da faixa que define um intervalo de confiança de $98 \%$, de 0,4 a 1,8. As barras de erro que originaram as incertezas dos ajustes apresentados na Tabela VII.2 são o desvio padrão dos valores de AOD calculados na área de $10 \mathrm{~km}$ x10 km. Como era esperado e pode ser observado na Figura VII.3, em comparação com a Figura VII.1 e VII.2, revelando o desvio padrão entre os valores de AOD calculado em uma área de $10 \times 10 \mathrm{~km}$ não foi capaz de traduzir também as incertezas envolvidas no algoritmo utilizado. Podendo, ser este o fator que explique a não compatibilidade estatística, dentro de 3 sigmas, dos parâmetros dos ajustes, apresentados na Figura VII.2, com os valores esperados.

A validação dos valores de $A O D$ obtidos com alta resolução espacial realizada por meio da comparação com a média horária das observações realizadas pelo fotômetro da AERONET é apresentada na Figura VII.3, pois foi a que apresentou resultados mais próximo do esperado. Os pontos em vermelho e de maior tamanho em relação aos demais correspondem aos dias nos quais a $A O D$ foi calculada independentemente dos critérios de identificação da presença de nuvens, conforme explicado anteriormente. 


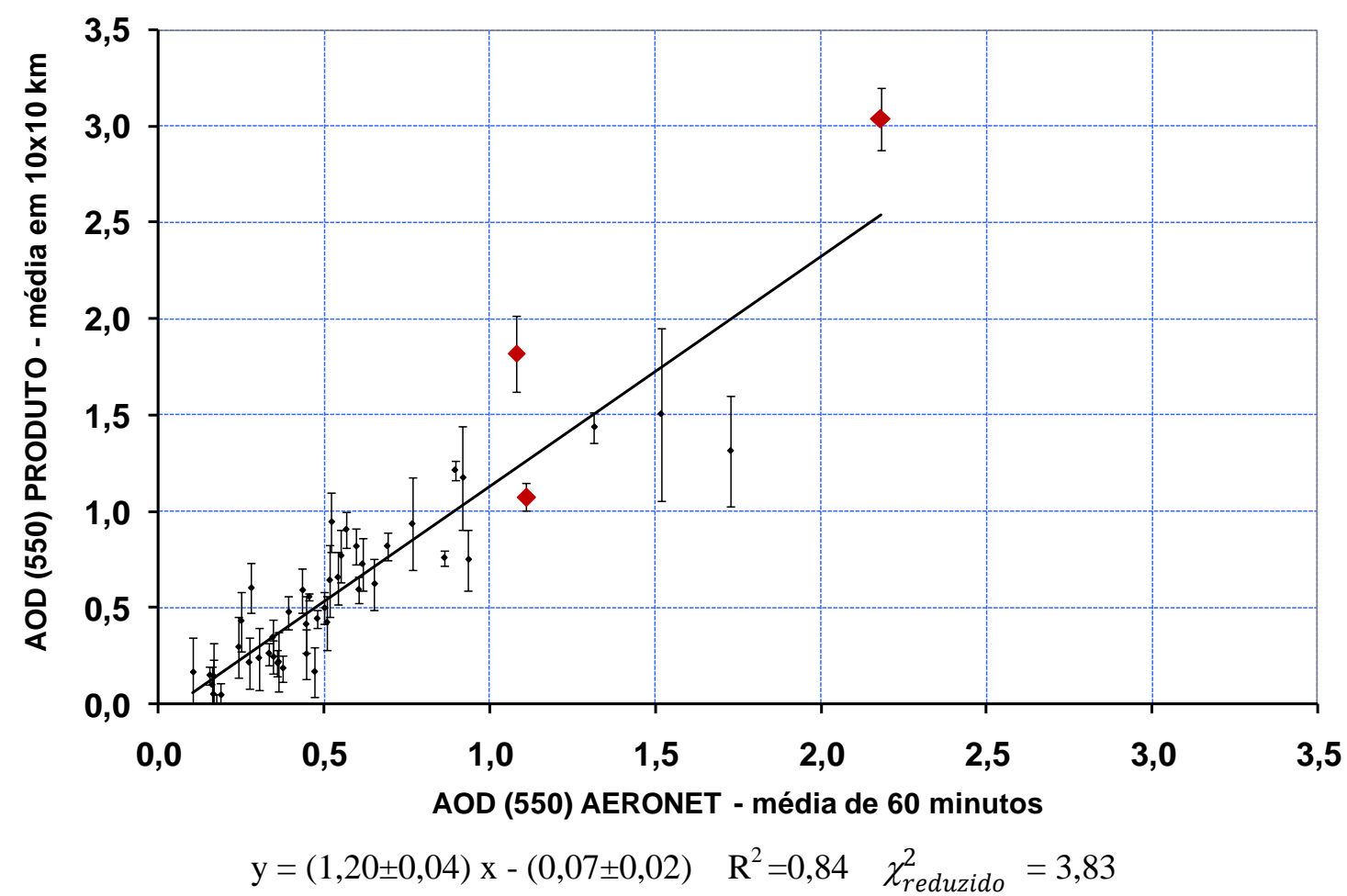

Figura VII.3: Média dos valores de $A O D$ (550), obtidos com o algoritmo utilizado neste

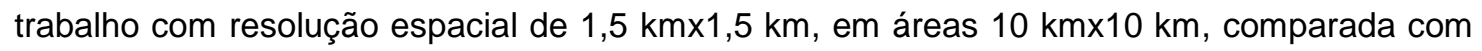
a média das medidas realizadas com o radiômetro CIMEL da rede AERONET, no intervalo de 60 minutos em torno do horário de passagem do satélite. A equação do ajuste, o coeficiente de correlação quadrado e o Qui2 reduzido estão abaixo do gráfico.

A compatibilidade estatística dos ajustes lineares apresentados na Tabela VII.2 Tabela VII.2, revela que tanto medidas pontuais quanto médias das medidas realizadas pelo fotômetro da rede AERONET, descrevem de forma similar uma área de $10 \mathrm{~km}$ x $10 \mathrm{~km}$ da camada de aerossóis da região, seja devido à homogeneidade ou da velocidade de advecção da camada de aerossóis.

A seguir, na Figura VII.4, é apresentada o valor médio de $A O D$, com alta resolução espacial, na área de 3x3 pixels mais próxima ao fotômetro da rede AERONET, dentro de uma área de $10 \mathrm{~km}$ x10 km, comparado ao valor de $A O D$ obtido pela AERONET que fosse mais próximo ao horário de passagem do satélite no intervalo de 30 minutos. 


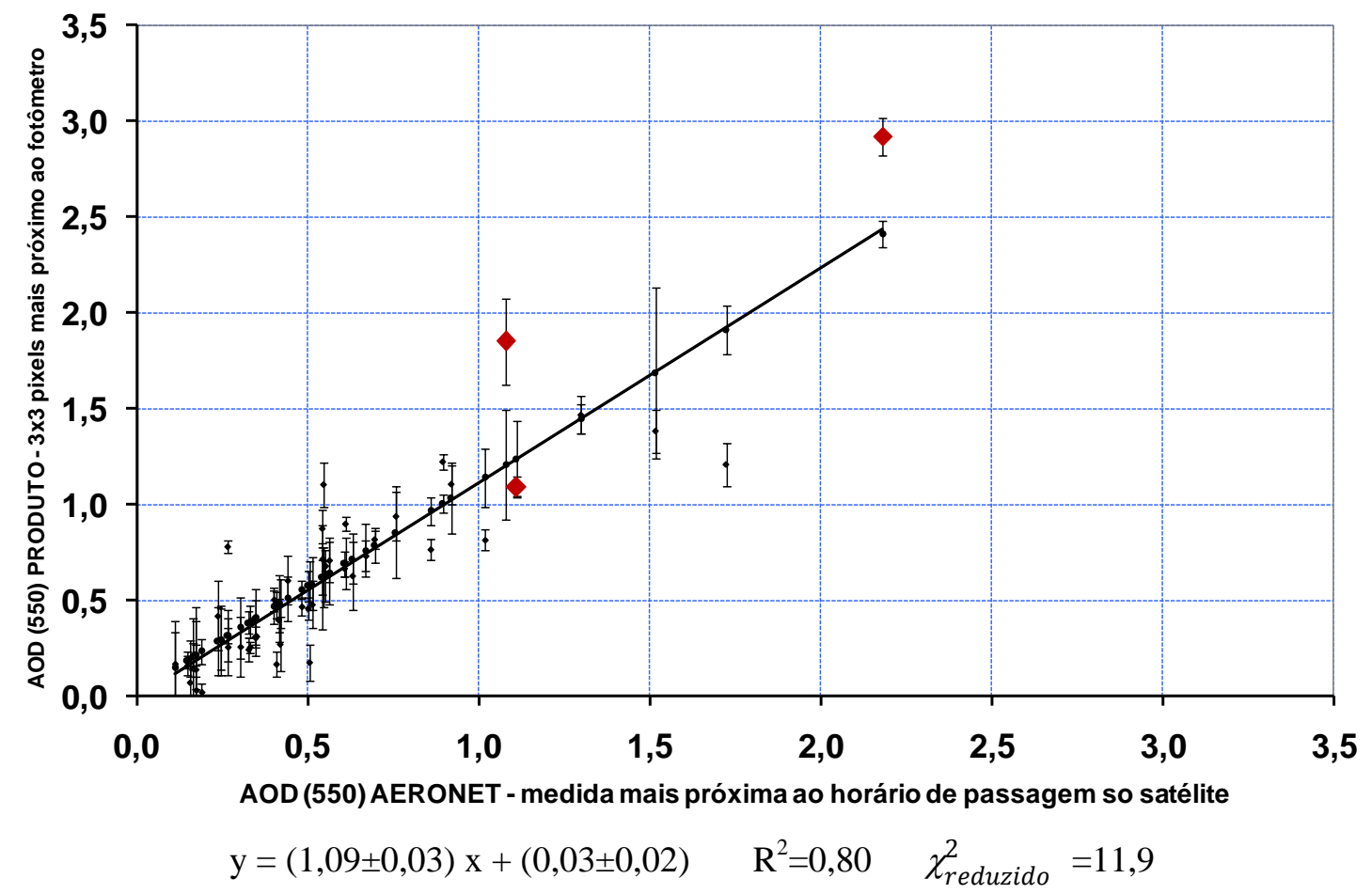

Figura VII.4: Média dos valores de $A O D$ (550) obtidos, com o algoritmo utilizado neste trabalho na área de $3 \times 3$ pixels mais próxima à localização do fotômetro da rede AERONET, comparada a observação realizada por este que fosse mais próxima ao horário de passagem do satélite em um intervalo de meia hora. A equação do ajuste, o coeficiente de correlação quadrado e o Qui2 reduzido estão abaixo do gráfico.

Com base na comparação do valor de $A O D$ obtido na área de 3x3 pixels, mais próxima da localização do fotômetro com a medida realizada pelo fotômetro da rede AERONET mais próxima ao momento de passagem do satélite sobre a região de estudo, verifica-se que os o coeficiente angular obtido $(1,09 \pm 0,03)$ é compatível estatisticamente com o esperado, um, dentro de 3 sigmas. O coeficiente linear obtido $(0,03 \pm 0,02)$ é compatível estatisticamente com o esperado, zero, dentro de 2 sigmas. Estes resultados mostram uma excelente concordância entre o produto derivado neste trabalho e a medida de $A O D$ da rede AERONET. Os pontos em vermelho e de maior tamanho em relação aos demais correspondem aos dias nos quais a $A O D$ foi calculada independentemente dos critérios de identificação da presença de nuvens, conforme explicado anteriormente.

$\mathrm{O} \chi_{\text {reduzido }}^{2}$ do ajuste apresentado na Figura VII.4, 11,9, está mais distante da faixa que define um intervalo de confiança de $98 \%$, de 0,4 a 1,8, do que as médias realizadas em $10 \mathrm{~km} \times 10 \mathrm{~km}$. Visto que, as barras de erro são o desvio padrão dos valores de AOD calculados na área de $3 \times 3$ pixels e quanto menor a área maior a homogeneidade da mesma, 
diminuindo assim o valor do desvio padrão e subestimando ainda mais as incertezas envolvidas nos valores apresentados.

A utilização do desvio padrão como barra de erro se faz necessária em estudos de validação de produtos de sensoriamento remoto, pois as situações experimentais comparadas não são idênticas e a consideração da variabilidade tem a função de tornar essas observçãoes comparáveis e foi esta a abordagem realizada neste trabalho. Entretando vimos que para produtos com alta resolução espacial, se faz necessário um estudo focado na quantificação das incertezas envolvidas no algoritmo utilizado, para que essas incertezas possam ser acopladas a variabilidade encontrada.

Os coeficientes lineares dos ajustes apresentados são influenciados por fatores que não são considerados no algoritmo, entre eles os efeitos do aerossol da moda grossa na correção da atmosfera para 2.110 nm (comunicação pessoal, Martins, 2004), ficando assim como sugestão de melhoria para trabalhos futuros. Este efeito é pequeno, mas pode não ser desprezível em algumas ocasiões, visto que o aerossol biogênico natural da Amazônia ocorre predominantemente na fração grossa (Artaxo et al. 2002a, 2005).

Vale ressaltar neste ponto, que as restrições de geometria apresentadas no item III.1, como ângulo de espalhamento $<140^{\circ}$ (para assegurar válidas as aproximações feitas nas simulações realizadas com o código de transferência radiativa SBDART) e ângulo zenital do sensor $<30^{\circ}$ (centro da região de estudo - para evitar a baixa resolução nas bordas da imagem obtida pelo sensor MODIS) não foram utilizadas, pois somente 4 dias atendiam simultaneamente às duas restrições citadas. Dispondo de uma base de observações mais ampla, é possível melhorar a acurácia destes resultados.

Deste modo, sugere-se que, em estudos futuros para a Região Amazônica, sejam utilizados os polinômios de Legendre para descrever a função de fase de espalhamento, equação III.16, na obtenção das equações de inversão ao invés de descrever a função de fase de espalhamento a partir do parâmetro de assimetria. Deste modo, a restrição de ângulo de espalhamento $<140^{\circ}$ não se fará mais necessária. Como já foi discutido no item V.6, as equações de inversão deste estudo não foram obtidas utilizando os polinômios de Legendre, podendo ser estes com 100 termos, devido a limitações computacionais enfrentadas na época em que os resultados foram obtidos.

O algoritmo utilizado neste estudo foi aperfeiçoado em relação ao método original desenvolvido por Castanho (2005). Neste trabalho incluímos um estudo do 
melhor método de extrapolação espectral dos modelos ópticos de aerossóis construídos. Também neste trabalho o valor da $Q A P$ não foi considerado constante nas simulações realizadas com o código de transferência radiativa SBDART. Aprimoramos também o método de validação, onde além da $A O D$, com alta resolução espacial, média em áreas de $10 \mathrm{~km}$ x10 km utilizou-se a $A O D$, com alta resolução espacial, média em áreas de 3x3 pixels mais próxima a localização do fotômetro da rede AERONET. Na escala temporal, também exploramos a comparação com o fotômetro da AERONET em períodos de 30 minutos em torno do horário de passagem do satélite e ao valor observado mais próximo ao horário de passagem do satélite.

Com base nos resultados apresentados até o momento, não é possível afirmar que o modelo óptico de aerossol utilizado para descrever a camada de aerossóis foi escolhido de forma dinâmica, utilizando o método da refletância crítica, pois mesmo que isso não fosse possível o algoritmo poderia utilizar o modelo médio de aerossol no cálculo da $A O D$ com alta resolução espacial. Com o objetivo de verificar quantos dos dias analisados tiveram o modelo de aerossol escolhido de forma dinâmica estes resultados foram apurados. A Figura VII.5 (a) apresenta os valores de AOD com alta resolução espacial obtidos em uma área de 9x9 pixels e a Figura VII.5 (b) apresenta qual foi o modelo de aerossol escolhido, a cada $3 \times 3$ pixels, na obtenção de tais resultados. No exemplo apresentado na Figura VII.5, contabilizou-se que o modelo 1 foi escolhido cinco vezes e o modelo médio uma vez. A célula em branco da Figura VII.5 (a), foi uma região na qual não foi possível calcular a $A O D$, pois foi classificada como contaminada por nuvens.

\begin{tabular}{|l|l|l|l|l|l|}
\hline 0.94 & 1.04 & 1.09 & 1.03 & 1.03 & 1.21 \\
\hline 0.65 & 0.73 & 1.03 & 0.90 & 1.33 & 1.04 \\
\hline 0.66 & 0.98 & 1.04 & 0.84 & & 0.92 \\
\hline 0.94 & 0.91 & 0.91 & 1.23 & 1.27 & 1.20 \\
\hline 0.95 & 0.81 & 0.95 & 0.98 & 1.10 & 1.08 \\
\hline 0.89 & 0.73 & 0.94 & 0.93 & 1.13 & 1.02 \\
\hline 1.00 & 0.93 & 0.87 & 0.74 & 0.86 & 1.01 \\
\hline 0.86 & 0.95 & 1.01 & 0.91 & 0.90 & 0.83 \\
\hline 0.59 & 0.80 & 0.88 & 0.82 & 0.82 & 0.83 \\
\hline
\end{tabular}

(a)

\begin{tabular}{|c|c|}
\hline modelo 1 & $\begin{array}{c}\text { modelo } \\
\text { médio }\end{array}$ \\
\hline modelo 1 & modelo 1 \\
\hline modelo 1 & modelo 1 \\
\hline
\end{tabular}

(b)

Figura VII.5: Exemplo de verificação de qual modelo óptico de aerossol foi escolhido para realização do cálculo de $\mid A O D$ com alta resolução espacial. A parte (a) apresenta o mapa de $A O D(550 \mathrm{~nm})$ com alta resolução espacial obtido e a parte (b) o modelo óptico de aerossol escolhido a cada $3 \times 3$ pixels, para o dia 7 de agosto de 2002 . 
Sumarizadas as frequências com que cada modelo óptico de aerossol foi escolhido, conforme exemplificado na Figura VII.5, obteve-se que em 52\% das áreas de 3x3 pixels o modelo óptico foi escolhido segundo o critério da refletância critica. Em $45 \%$ das áreas foi escolhido o modelo 1 e em $7 \%$ o modelo 3, revelando assim a alta homogeneidade dos aerossóis da região de estudo no período analisado, o que é um ponto favorável para este tipo de análise.

Com intuito de verificar se a metodologia da refletância crítica conseguiu recuperar a classificação dos dias feita pela análise de cluster, estes resultados foram comparados, e são apresentados na Figura VII.6. Lembrando que para a construção dos modelos não foram utilizadas medidas de $A O D(440 \mathrm{~nm})$ inferiores a 0,4 , deste modo só foi possível confrontar esse resultados nos dias em que a AERONET obteve $A O D(440 \mathrm{~nm})>0.4$, totalizando 42 dias.

De acordo com a Figura VII.6, verificou-se que quando mais de um modelo foi utilizado para classificar as medidas realizadas pelo fotômetro da rede AERONET no intervalo de uma hora em torno da passagem do satélite, em geral o método da refletância critica não foi capaz de escolher entre um dos dois modelos, retornando assim o modelo médio, o que representou $21 \%$ dos dias apresentados (células amarelas - cor indicativa de atenção).

Ainda com base na análise da Figura VII.6, em 40\% das observações, que puderam ser confrontadas, houve um ganho de se escolher o modelo óptico mais adequado ao invés do modelo médio, pois o método da refletância crítica escolheu o modelo óptico de aerossol de acordo com o resultado da análise de cluster (células verdes - cor indicativa de acerto).

\begin{tabular}{cccrc}
\cline { 2 - 5 } & \multicolumn{3}{c}{$\begin{array}{c}\text { Modelo escolhido por meio da } \\
\text { refletância crítica }\end{array}$} \\
\hline $\begin{array}{c}\text { Medida classificada } \\
\text { segundo a análise de } \\
\text { cluster }\end{array}$ & 1 & $38.1 \%$ & $9.5 \%$ & $7.1 \%$ \\
\cline { 2 - 5 } & 1 e 3 & & $21.4 \%$ & $2.4 \%$ \\
\hline
\end{tabular}

Legenda: comparação do modelo de aerossol escolhido pelo método da refletância crítica em comparação com os resultados da análise de cluster: verde - cor indicativa de acerto na escolha; amarelo - cor indicativa de atenção na escolha; vermelho - cor indicativa de erro na escolha.

Figura VII.6: Comparação da classificação de qual modelo óptico de aerossol foi mais adequado para descrever a camada de aerossol de cada dia analisado, segundo a análise e cluster versus a classificação realizada com o método da refletância critica. O cálculo foi feito com valores percentuais. Porcentagens calculadas em relação ao total de 42 dias. 
Verificou-se por meio da validação realizada e do nível de acertividade dos resultados que os modelos ópticos construídos e a metodologia utilizada são capazes de obter valores de $A O D$ com alta resolução espacial de qualidade comparável à obtida operacionalmente pelos algoritmos da NASA, para medidas na região de JiParaná. Cabe a estudos posteriores expandir a metodologia para toda a região Amazônica, e assim possibilitar a redução das incertezas envolvidas no cálculo da forçante radiativa dos aerossóis em questão.

É importante salientar que antes da implantação operacional deste novo método, faz-se necessário um esforço na direção de conseguir uma melhor separação das observações a contaminação oriunda da presença de nuvens. Isso possibilitaria a obtenção de séries temporais mais robustas de resultados, e por consequência uma validação com estatística também mais robusta. A separação da contribuição das nuvens na $A O D$ é um importante e delicado assunto que influencia fortemente os resultados de estudos que utilizam essa variável e a dificuldade em separar tais componentes afeta diretamente a $A O D$ observada. Por esse motivo melhores algoritmos de identificação de nuvens origina e ainda originará muitos estudos. 


\section{CONCLUSÕES}

A análise das propriedades ópticas dos aerossóis da região de Ji-Paraná revelou que no período de seca e queimadas o número de observações realizadas pelo fotômetro aumenta substancialmente, devido à diminuição da nebulosidade. A redução da precipitação também é um fator relevante neste caso, indicada pela diminuição da quantidade de água precipitável na coluna atmosférica durante a estação seca. Foi observado que no período fortemente impactado pelas queimadas há um aumento da dependência espectral da $A O D$. Este alteração é compatível com a observação de aumento nos valores do coeficiente de Angstrom e um aumento da moda de acumulação sobre a moda grossa observado na distribuição de volume média indicando que os aerossóis de queimada são compostos por partículas menores do que os aerossóis das demais épocas do ano. Esses efeitos podem ser também observados pela fração que a $A O D$ da moda fina representa da $A O D$ total, superior a $70 \%$. Uma observação importante foi à fraca relação da quantidade de água precipitável na coluna atmosférica com parâmetros críticos do aerossol, tais como o albedo simples de espalhamento, a profundidade óptica e o raio médio das partículas da fração fina. Este fato indica uma baixa higroscopicidade das partículas de aerossóis da região no período de queimadas. Estas observações vão de encontro a medidas realizadas no solo por Rissler et al., 2004, que mediram uma taxa de crescimento higroscópico de apenas 1,13 . Nossas medidas mostram que este valor pode também ser representativo de toda a coluna atmosférica, não somente na superfície. $\mathrm{O}$ vapor de água não altera fortemente as propriedades óticas dos aerossóis de queimadas na Amazônia.

Os dois modelos ópticos de aerossóis construídos foram capazes de descrever os aerossóis característicos da época de queimadas adequadamente. Podendo ser utilizados em regiões que apresentem propriedades ópticas semelhantes. Os modelos ópticos foram construídos com observações realizadas pelo fotômetro da rede AERONET em condições de $A O D(440 \mathrm{~nm})$ superior a 0,4, porém foram capazes de representar adequadamente condições de $A O D$ inferiores a 0,4 . Verificou-se que os métodos de extrapolação testados nas observações fornecida pelo fotômetro para comprimentos de onda de $1.020 \mathrm{~nm}$ a $2.100 \mathrm{~nm}$, intervalo necessário nos cálculos realizados pelo SBDART, não implicaram em diferenças significativas nos resultados de validação dos modelos ópticos de aerossóis construídos. 
A adaptação do método para obtenção da $A O D$ com alta resolução espacial desenvolvido por Castanho, 2005 apresentou resultados promissores para a Amazônia no período de queimadas. Sobretudo se considerarmos a validação realizada por meio da comparação do valor médio de $A O D$ em um conjunto $3 \times 3$ pixels, mais próximo a localização do fotômetro da rede AERONET, com o valor de $A O D$ observado mais próximo ao horário de passagem do satélite. Nesta condição obteve-se uma equação de regressão $\mathrm{y}=(1,09 \pm 0,03) \mathrm{x}+(0,03 \pm 0,02)$, com $\mathrm{R}^{2}=0,80$. Estes valores de regressão são excelentes, visto as diferenças fundamentais nos métodos de medida entre o MODIS e o fotômetro solar.

Deve-se salientar, entretanto, que um fator limitante para obtenção da $A O D$ pelo MODIS utilizando o método da refletância crítica, é a contaminação das medidas por nuvens, característica da região mesmo durante o período de queimadas. Esta limitação é muito importante para a resolução de $10 \mathrm{kmx} 10 \mathrm{~km}$, e é reduzida no produto de resolução de $1.5 \mathrm{~km}$ x1,5 km. O método da refletância crítica mostrou-se adequado na detecção do modelo de aerossol para a região de estudo, já que 52\% das regiões de 3x3 pixels apresentaram o modelo escolhido através desse método e houve um ganho na escolha de um modelo de aerossóis mais adequado que o um modelo único em torno de $40 \%$ dos dias. Os mapas de profundidade óptica gerados mostram a potencialidade do método em determinar a distribuição espacial de $A O D$ com alta resolução espacial. Abaixo estão descritos pontos que contribuíram para a boa qualidade dos resultados obtidos:

- O desenvolvimento de modelos ópticos de aerossóis específicos para a região de estudo e com observações que contemplem valores de $A O D$ (440) >0.4, ou seja, com valores de propriedades como o albedo, obtidos a partir de inversões, com qualidade assegurada pelos algoritmos da AERONET;

- Utilizar um coeficiente entre a refletância no infravermelho e visível obtido especificamente para a região de estudo, e não valores gerais;

- Utilização de valores diários de conteúdo de vapor água atmosférico e não uma média do período.

Como sugestões para trabalhos futuros colocamos um estudo focado na quantificação das incertezas envolvidas no algoritmo utilizado para que essas possam ser acolpadas na variabilidade dos valores utilizados para obtenção de valores médio e 
a extensão da obtenção do produto e sua validação da metodologia para a Amazônia como um todo. Entretanto, para que o produto seja operacionalizado e assim traga frutos efetivos, o desenvolvimento de algoritmos para a identificação mais eficaz da presença de nuvens é de suma importância. Pois somente assim será possível obter séries temporais de resultados mais robustas e com boa estatística. Com isso, teremos a possibilidade de conhecer melhor a distribuição espacial da camada de aerossóis, com maior precisão e resolução espacial superior à disponibilizada pelos produtos operacionais da NASA atualmente.

Outro ponto importante é a extensão dos produtos desenvolvidos neste trabalho para outros continentes, tais como África e Ásia. Existem propriedades similares intrínsecas às emissões de queimadas que podem ter aplicação direta a outros continentes. Os valores de single scatering albedo e distribuição de tamanho em queimadas na África são similares aos da Amazônia nas áreas de florestas tropicais africanas. Sabemos que em áreas de queimadas de savanas, os parâmetros óticos são diferentes, com aerosol mais absorvedor e menor quantidade de água. Novos modelos óticos poderiam ser construídos, e utilizados a mesma metodologia desenvolvida neste trabalho, em alta resolução espacial. 


\begin{tabular}{|c|c|}
\hline $\mathrm{ABO}$ & Alta da Bolívia \\
\hline AERONET & AErossol RObotic NETwork \\
\hline AOD & profundidade óptica de aerossóis \\
\hline $\mathrm{CCN}$ & Cloud Condensation Nuclei \\
\hline CMP & centro de máxima precipitação \\
\hline CPTEC & Centro de Previsão do Tempo e Estudos Climáticos \\
\hline DISORT & Discret Ordinate Radiative Transfer \\
\hline $\mathrm{Dp}$ & diâmetro \\
\hline EOS & Earth Observing System \\
\hline ETR & equação de transferência radiativa \\
\hline $\mathrm{g}$ & fator de assimetria \\
\hline Goddard DAAC & Distributed Active Archive Center \\
\hline GSFC & Goddard Space Flight Center \\
\hline hdf & Hierarchical Data File \\
\hline INMET & Instituto Nacional de METeorologia \\
\hline INPE & Instituto Nacional de Pesquisas Espaciais \\
\hline $\mathrm{k}$ & parte imaginária do índice de refração \\
\hline $\mathrm{k}_{\mathrm{e}}$ & coeficiente de extinção \\
\hline LFA & Laboratório de Física Atmosférica \\
\hline Lidars & Light Detection and Rangin \\
\hline Lis & Linhas de Instabilidade \\
\hline LWC & Liquid Water Content \\
\hline $\mathrm{m}$ & índice de refração \\
\hline MODAPS & MODIS Adaptive Processing System \\
\hline MODIS & Moderate-Resolution Imaging Spectroradiometer \\
\hline $\mathrm{n}$ & parte real do índice de refração \\
\hline $\mathrm{P}$ & função de fase \\
\hline QAP & quantidade de água precipitável \\
\hline Qesp & eficiência de espalhamento \\
\hline Qext & eficiência de extinção \\
\hline$Q \pi$ & eficiência de retroespalhamento \\
\hline SBDART & Santa Babara DISORT Atmospheric Radiative Transfer \\
\hline SDS & Scientific Data Set \\
\hline TOA & TOp of the Atmosphere \\
\hline VOCs & compostos orgânicos voláteis \\
\hline $\mathrm{x}$ & parâmetro de tamanho \\
\hline ZCIT & Zona de Convergência Intertropical \\
\hline$\alpha$ & expoente de Ångström \\
\hline$\varphi$ & ângulo azimutal \\
\hline$\Theta$ & ângulo de espalhamento \\
\hline$\theta$ & ângulo zenital \\
\hline$\lambda$ & comprimento de onda \\
\hline$\tau$ & profundidade óptica das partículas \\
\hline$\omega_{0}$ & albedo simples de espalhamento \\
\hline
\end{tabular}




\section{BiBLIOGRAFIA}

- Alheit, R.R., A.I. Flossmann, H.R. Pruppacher, A Theoretical Study of the Wet Removal of Atmospheric Pollutants. Part IV: The Uptake and Redistribution of Aerosol Particles through Nucleation and Impaction Scavenging by Growing Cloud Drops and Ice Particles. Journal of Atmospheric Sciences, 47(7), p. 870, 1990.

- Andreae, M.O., P. Artaxo, H. Fisher, S.R. Freitas, et al. Transport of biomass burning smoke to the upper troposphere by deep convection in the equatorial region. Geophysical Research Letters, vol. 28(6), p. 951, 2001.

- Andreae, M.O., D. Rosenfeld, P. Artaxo, A. A. Costa, G. P. Frank, K. M. Longo, and M. A. F. Silva-Dias, Smoking rain clouds over the Amazon. Science, Vol. 303, (5662) p. 1337, 2004.

- Ansmann, A., H. Baars, M. Tesche, D. Muller, D. Althausen, R. Engelmann, T. Pauliquevis, and Paulo Artaxo. Dust and smoke transport from Africa to South America: Lidar profiling over Cape Verde and the Amazon rainforest". Geophysical Research Letters, Vol. 36, L11802, 2009.

- Artaxo, P., H. Storms, F. Bruynseels, R. Vangrieken, W. Maenhaut, Composition and sources of aerosols from the amazon basin. Journal of Geophysical ResearchAtmospheres 93 (D2): p. 1605, 1988.

- Artaxo, P., W. Maenhaut, H. Storms, R. Vangrieken, Aerosol characteristics and sources for the amazon basin during the wet season. Journal of Geophysical Research-Atmospheres 95 (D10): p. 16971, 1990.

- Artaxo, P., A.D.A. Castanho. Aerosol Concentrations and Source Apportionment in the Urban Area of São Paulo, Brazil. IAEA (International Atomic Energy Agency) TEC DOC series, 1998.

- Artaxo, P., M.O. Andreae, A. Guenther, D. Rosenfeld, LBA Atmospheric Chemistry: Unveiling the lively atmosphere-biosphere interactions in the Amazon. IGBP Global Change Newsletter, LBA Special Issue, 45, p. 12, 2001.

- Artaxo, P., J.V. Martins, M.A. Yamasoe, A.S. Procópio, T.M. Pauliquevis, M.O. Andreae, P. Guyon, L.V. Gatti, A.M.C. Leal. Physical and chemical properties of aerosols in the wet and dry season in Rondônia, Amazonia. Journal of Geophysical Research, vol. 107(D20), p. 8081, 2002a.

- Artaxo, P. Aerosol sampling and analysis. Environmental Monitoring Handbook, Alex Guenther (editor), McGraw-Hill Professional, New York, USA, ISBN: 0-07135176-0, $2002 b$. 
- Artaxo, A., L.V. Gatti, A.M.L. Cordova, K.M. Longo, S.R. Freitas, L.L. Lara, T.M. Pauliquevis, A.S. Procopio, L.V. Rizzo, Química atmosférica na Amazônia: A floresta e as emissões de queimadas controlando a composição da atmosfera amazônica. Acta Amazônica, Edição especial projeto LBA, 35(2), p. 185, 2005.

- Artaxo, P. and Andreae, M.O. Biomass burning as a driver for atmospheric composition and ecosystem changes. iLEAPS Newsletter, issue 4, p. 12, 2007.

- Artaxo, P., L. V. Rizzo, M. Paixao, S. de Lucca, P. H. Oliveira, L. L. Lara, K. T. Wiedemann, M. O. Andreae, B. Holben, J. Schafer, A. L. Correia, and T. M. Pauliquevis. Aerosol particles in Amazonia: Their composition, role in the radiation balance, cloud formation and nutrient cycles. In: Amazonia and Global Change, Ed. M. Keller, M. Bustamante, J. Gash, P. S. Dias. American Geophysical Union, Geophysical Monograph Series 186, pg. 235-254, 2009.

- Artaxo, P., Mudanças Climáticas e a Amazônia. Scientific American Brasil Edição Especial Amazônia, p. 91, 2008.

- Barnes, W.L., T.S. Pagano, and V. Salomonson, Prelaunch characteristics of the Moderate Resolution Imaging Spectroradiometer (MODIS) on EOS AM-1. IEEE Trans. Geosci. Remote Sens.36, p. 1088,1998.

- Becker, B.K., Síntese do Processo de Ocupação da Amazônia - Lições do passado e desafios do presente. Causas e Dinâmica do Desmatamento na Amazônia, 5-28, Ministério do Meio Ambiente, Brasília, 2001.

- Bohren, C.F. and Huffman, D.R. Absorption and Scattering of Light by Small Particles. John Wiley \& Sons, EUA, ISBN: 9780471293408, 1983.

- Bowman, D.M.J.S., K.B. Jennifer, P. Artaxo, W.J. Bond, J.M. Carlson, M.A. Cochrane, C.M. D'Antonio, R.S. DeFries, J.C. Doyle, S.P. Harrison, F.H. Johnston, J.E. Keeley, M.A. Krawchuk, C.A. Kull, J.B. Marston, M.A. Moritz, I.C.Prentice, C.I. Roos, A.C. Scott, T.W. Swetnam, G.R. van der Werf, and S.J. Pyne, Fire in the Earth System. Science, 324, p. 481, 2009.

- Brasseur, G.P., R. G. Prinn, A. A.P. Pszenny (Eds.), Atmospheric Chemistry in a Changing World, Springer Verlag, Heidelberg, Alemanha, 2003.

- Bruegge, C.T., J.E. Conel, R.O. Green, J.S. Margolis, R.G. Holm, and G. Toon. Water vapor column abundance retrievals during FIFE. Journal of Geophysical Research, vol. 97, p. 18, 1992. 
- Bucholtz, A. Rayleigh-scattering calculations for the terrestrial atmosphere. Applied Optics, vol. 34, p. 2765, 1995.

- Castanho, A.D.A. Propriedades ópticas das partículas de aerossol e uma nova metodologia para a obtenção de espessura óptica via satélite sobre São Paulo. Tese de Doutorado, Instituto de Física da Universidade de São Paulo, São Paulo, 2005.

- Chu, D.A., Y.J. Kaufman, C. Ichoku, L.A. Remer, D. Tanré, and B.N Holben. Validation of MODIS aerosol optical depth retrieval over land. Geophysical Research Letters, vol. 29(12), p. 1617 MOD2-1-4, 2002.

- Chýlek, P., V. Srivastava, Dielectric constant of a composite inhomogeneous medium. Physical Review B, 27, no 8, p. 5098, 1993.

- Claeys, M., B. Graham, G. Vas, W. Wang, R. Vermeylen, V. Pashynska, J. Cafmeyer, P. Guyon, M.O. Andreae, P. Artaxo, and W. Maenhaut, Formation of secondary organic aerosols through photooxidation of isoprene. Science, 303, p. 1173, 2004.

- Cox, P.M., P.P. Harris, C. Huntingford, R.A. Betts, M. Collins, C.D. Jones, T.E. Jupp, J.A. Marengo, and C.A. Nobre, Increasing risk of Amazonian drought due to decreasing aerosol pollution. Nature, 453, p. 212, 2008.

- Culf, A.D., Esteves, J.L., Marques Filho, A.O., Ocha, H.R.1996. Radiation, temperature and humidity over forest and pasture in Amazonia. In: Gash, J.H.C.; Nobre, C.A.; Roberts, J.M (Eds). Amazonian Deforestation and Climate. J.M. Wiley and Sons, New York, p. 175, ISBN: 978-0471967347, 1996.

- D'Almeida, G. A. On the variability of desert aerosol radiative characteristics. Journal of Geophysical Research, vol. 93, p. 3017, 1987.

- Davidson, E.A. and Artaxo, P. Globally significant changes in biological processes of the Amazon Basin: Results of the Large-scale Biosphere-Atmosphere Experiment. Invited paper Global Change Biology, Vol. 10, No. 5, p. 1, 2004.

- Dias, M.A.F.S., J.C.P. Cohen, and A.W. Gandu, Clouds, rain and biosphere interactions in Amazon. Acta Amazonica, Manaus, 35 (2), 2005.

- Dubovik, O. and King, M.D. A flexible inversion algorithm for retrieval of aerosol optical properties from sun and sky radiance measurements. Journal of Geophysical Research, vol. 105, p. 20, 2000. 
- Dubovik, O., et al., Variability of Absorption and Optical Properties of Key Aerosol Types Observed in Worldwide locations. Journal of the Atmospheric Sciences. vol. 59, p. 590, 2002a.

- Dubovik, O., B.N. Holben, T. Lapyonok, A. Sinyuk, M.I. Mishchenko, P. Yang, and I. Slutsker. Non-spherical aerosol retrieval method employing light scattering by spheroids. Journal of Geophysical Research, vol. 29(10), p. 1415, 2002 b.

- Echalar, F., P. Artaxo, J.V. Martins, M. Yamasoe, F. Gerab, W. Maenhaut, B. Holben, Long-term monitoring of atmospheric aerosols in the Amazon Basin: Source identification and apportionment. Journal of Geophysical ResearchAtmospheres 103 (D24): p. 31849, 1998.

- Feingold, G., W.L. Eberhard, D.E. Veron, M. Previdi, First measurements of the Twomey indirect effect using ground-based remote sensors. Geophysical Research Letters, 30(6), p. 1287, 2003.

- Feitosa, J.R.P., R.F. Costa, G. Fisch, S.S. Souza, C.A. Nobre, Radiação solar global em áreas de floresta e pastagem na Amazônia. Revista Brasileira de Agrometeorologia, 6, 1, p. 1, 1998.

- Ferrare, R.A., S.H. Melfi, D.N. Whiteman, K.D. Evans, M. Poellot, and Y.J. Kaufman, Raman lidar measurements of aerosol extinction and backscattering 2. Derivation of aerosol refractive index, single-scattering albedo, and humidification factor using Raman lidar and aircraft size distribution measurements. Journal of Geophysical Research, vol. 103 D16, p. 19673, 1998.

- Fisch, G., J. Tota, L.A.T. Machado, M.A.F.S. Dias, R.F.D. Lyra, C.A. Nobre, A.J. Dolman, and J.H.C. Gash, The convective boundary layer over pasture and forest in Amazonia. Theoretical and Applied Climatology, 78, p. 47, 2004.

- Forster, P., V. Ramswamy, P. Artaxo, T. Berntsen, R.A. Betts, D.W. Fahey, J. Haywood, J. Lean, D.C. Lowe, G. Myhre, J. Nganga, R. Prinn, G. Raga, M. Schulz, R. Van Dorland. Changes in Atmospheric Constituents and Radiative Forcing. Chapter 2 of the Climate Change 2007: The Physical Science Basis, IPCC - Intergovernmental Panel on Climate Change Book, Cambridge University Press, United Kingdom, 2007.

- Flossmann, A.I., W.D. Hall, H.R. Pruppacher, A theoretical study of the wet removal of atmospheric pollutants. Part I: The redistribution of aerosol particles captured through nucleation and impaction scavenging by growing cloud drops. Journal of the Atmospheric Sciences, 42(6), p. 583, 1985. 
- Fraser, R.S. Satellite measurement of mass of Saharan dust in the atmosphere. Applied Optics., vol. 15, p. 2471, 1976.

- Fraser, R., Y.J. Kaufman. The relative importance of aerosol scattering and absorption in remote sensing. Transactions on geoscience and remote sensing, vol. GE-23(5), p. 625, 1985.

- Freitas, S.R., M.A.F.S. Dias, P.L.S. Dias, K.M. Longo, P. Artaxo, M.O. Andreae, H. Fischer, A convective kinematic trajectory technique for low-resolution atmospheric models. Journal of Geophysical Research-Atmospheres 105 (D19): p. 24375, 2000.

- Freitas, S. R., Longo, K. M., Dias, M. A. F. S., Dias, P. L. S. , Chatfield, R., Prins, E., Artaxo, P., Grell, G. A., Recuero, F. S. ; Monitoring the transport of biomass burning emissions in South America. Environmental Fluid Mechanics 5 (1-2): 135-167 2005.

- Freud, E., D. Rosenfeld, M.O. Andreae, A. Costa, and P. Artaxo. Robust relations between $\mathrm{CCN}$ and the vertical evolution of cloud drop size distribution in deep convective clouds. Atmospheric Chemistry and Physics, 8, p. 1661, 2008.

- Fuzzi, S., S. Decesari, M.C. Facchini, F. Cavalli, L. Emblico, M. Mircea, M.O. Andreae, I. Trebs, A. Hoffer, P. Guyon, P. Artaxo, L.V. Rizzo, L.L. Lara, T. Pauliquevis, W. Maenhaut, N. Raes, X. Chi, O.L. Mayol-Bracero, L. Soto, M. Claeys, I. Kourtchev, J. Rissler, E. Swietlicki, E. Tagliavi-ni, G. Schkolnik, A.H. Falkovich, Y. Rudich, G. Fisch, and L.V. Gatti, Overview of the inorganic and organic composition of size-segregated aerosol in Rondônia, Brazil, from the biomass burning period to the onset of the wet season. Journal of Geophysical Research, 2005.

- Gallagher, M.W., E. Nemitz, J.R. Dorsey, D. Fowler, M.A. Sutton, M. Flynn, J. Duyzer, Measurements and parameterizations of small aerosol deposition velocities to grassland, arable crops, and forest: Influence of surface roughness length on deposition. Journal of Geophysical Research, 107(D12), 2002.

- Gao, BO-CAI and Y.J. KAUFMAN. Water vapor retrievals using Moderate resolution Imaging Spectroradiometer (MODIS) near-infrared channels. Journal of Geophysical Research, vol. 108(13), p. 4389, 2003.

- Goody, R.M. and Yung, Y.L., Atmospheric Radiation - Theoretical Basis, $2^{\text {nd }}$ Edition, Oxford University Press, New York, ISBN 0195102916, 1989. 
- Graham, B., O.L. Mayol-Bracero, P. Guyon, G.C. Roberts, S. Decesari, M.C. Facchini, P. Artaxo, W. Maenhaut, P. Köll, M.O. Andreae, Water-soluble organic compounds in biomass burning aerosols over Amazonia: Characterization by NMR and GC/MS. Journal of Geophysical Research, 107(D20), p. 8047, 2002.

- Griggs, M., Measurements of atmospheric aerosol optical thickness over water using ERTS-1 data. J. Air Pollut. Control Assoc., vol. 25, p. 622, 1975.

- Guyon, P., B. Graham, G.C. Roberts, O.L. Mayol-Bracero, W. Maenhaut, P. Artaxo, M.O. Andreae, In-canopy gradients, composition,sources, and optical properties of aerosol over the Amazon forest. Journal of Geophysical Research, 108(D18), p. 4591, 2003.

- Guyon, P., B. Graham, G.C. Roberts, O.L. Mayol-Bracero, W. Maenhaut, P. Artaxo, and M.O. Andreae, Sources of optically active aerosol particlesover the Amazon forest. Atmospheric Environment, 38 (7), p. 1039, 2004.

- Hegg, D.A., J. Livingston, P.V. Hobbs, T. Novakov, and P. Russell, Chemical apportionment of aerosol column optical depth off the mid-Atlantic coast of the United States. Journal of Geophysical Research, vol. 102 D21, p. 25293, 1997.

- Hinds, W. C., Aerosol Technology: properties, behavior and measurement of airborne particles, John Wiley \& Sons, ISBN 0471087262, 1999.

- Holben, B.N., et al., An emerging ground-based aerosol climatology: Aerosol Optical depth from AERONET. Journal of Geophysical Research, vol. 106(D11), p. 12067, 2001.

- Holben, B.N., T.F. Eck, I. Slutsker, D. Tanre, J.P. Buis, A. Setzer, E. Vermonte, J.A. Reagan, Y.J. Kaufman, T. Nakajima, et al., AERONET - A federated instrument network and data archive for aerosol characterization. Remote Sens. Environ., vol. 66, p. 1, 1998.

- Hoppel, W.A., G.M. Frick, J.M. Fitzgerald, A cloud chamber study of the effect that non precipitating water clouds have on aerosol size distribution, Aerosol Science and Technology, 20, p. 1, 1994.

- Horel, J.D., A.N. Hahmann, J.E. Geisler, An investigation of the annual cycle of convective activity over the tropical Americas. Journal of Climate, 2, p. 1388, 1989 
- Ichoku, C., D.A. Chu, S. Mattoo, Y.J. Kaufman, L.A. Remer, D. Tanre', I. Slutsker, e B.N. Holben. A spatio-temporal approach for global validation and analysis of MODIS aerosol products. Geophysical Research Letters, vol. 29(12), p. 8006, 2002a.

- Ichoku, C., R. Levy, Y.J. Kaufman, L.A. Remer, R.R. Li, J.V. Martins, B.N. Holben, N. Abuhassan, I. Slutsker, T.F. Eck, e C. Pietras. Analysis of the performance characterisitcs of the five-channel Microtops II Sun photometer for measuring aerosol optical thicknes and precipitable water vapor. Journal of Geophysical Research, vol. 107(D13), AAC 5-1, p. 5, 2002b.

- IPCC2007 - Intergovernamental Panel on Climate Change. A plan for a Research Program on Aerossol Radiative forcing and climate change. Natl. Acad. Press., Washington, D.C., 2007.

- Jacobson, M.Z., Strong Radiative Heating due to the Mixing State of Black Carbon in Atmospheric Aerosols. Nature, 409, 695-697, 2001.

- Kaufman, Y.J., Satellite sensing of aerossol absorption. Journal of Geophysical Research, vol. 92, p. 4307, 1987.

- Kaufman, Y.J. B.C. Gao, B.C., Remote sensing of water vapor in the near IR from EOS/MODIS. IEEE Trans. Geosci. Remote Sensing, vol. 30, p. 871, 1992.

- Kaufman, Y.J., Measurements of the aerosol optical thickness and the path radiance - Implications on aerosol remote sensing and atmospheric corrections. Journal of Geophysical Research, vol. 98, p. 2677, 1993.

- Kaufman, Y.J., L.A. Remer. Remote sensing of vegetation in the mid-IR:the 3,7mm channels. IEEE J. Geosci. Remote Sens., vol. 32, p. 672-683, 1994.

- Kaufman, Y.J., R.S. Fraser. The effect of Smoke Particles on Clouds and Climate. Science, vol. 277, p. 1636, 1997.

- Kaufman, Y.J., D. Tanré, H.R. Gordon, T. Nakajima, J. Lenoble, R. Frouin, H. Brassl, B.M. Herman, M.D. King, and P.M. Teillet. Passive remote sensing of tropospheric aerosol and atmospheric correction for the aerosol effect. Journal of Geophysical Research, vol. 102(D14), p. 16815, 1997a.

- Kaufman, Y.J., D. Tanré, L.A. Remer, E.F. Vermote, A. Chu, and B.N. Holben. Operational remote sensing of tropospheric aerosol over land from EOS moderate resolution imaging spectroradiometer. Journal of Geophysical Research, vol. 102, p. 17051, $1997 b$. 
- Kaufman, Y.J., N. Gobron, B. Pinty, J. Widlowski, and M.M. Verstraete. Relationship between surface reflectance in the visible and mid-IR used in MODIS aerosol algorithm - theor. Journal of Geophysical Research, vol. 29(23), p. 2116, 2002a.

- Kaufman, Y.J., D. Tanré, and O. Boucher. A satellite view of aerosols in climate system. Insight review articles. Nature, vol. 419, p. 215, 2002 b.

- $\quad$ King, M.D., W.P. Menzel, Y.J. Kaufman, D. Tanré, B.C. Gao, S. Platnick, S.A. Ackerman, L.A. Remer, R. Pincus, and P.A. Hubanks. Cloud and aerosol properties, precipitable water, and profiles of temperature and water vapor from MODIS. IEEE Trans Geosci. Remote Sens., vol. 41(2), p. 442, 2003.

- Koren, I., Y.J. Kaufman, L.A. Remer, J.V. Martins. Measurement of the Effect of Amazon Smoke on Inhibition of Cloud Formation. Science, vol. 303, p. 1342, 2004.

- Lebsock, M.D., G.L. Stephens, and C. Kummerow, Multisensor satellite observations of aerosol effects on warm clouds, J. Geophys. Res., p. 113, 2008.

- Lenoble, J. and Brogniez C., A comparative review of radiation aerosol models. Beitraege zur Physik der Atmosphaere, vol. 57, p. 1, 1984.

- Liou, K.N., An Introduction to Atmospheric Radiation, Second Edition, 348 Academic, USA, ISBN 0124514502, 2002.

- London, J., R.D. Bojkov, S. Oltmans, and J.I. Kelly, Atlas of the global distribution of total ozone July 1957-June 1967. NCAR Tech. Note 133+STR, Natl. Cent. For Atmos. Res., Boulder, Colo, p. 276, 1976.

- Longo, K.M., Estudos de aerossóis e gases traços na atmosfera da Bacia Amazonica: Influência das circulações regionais e de larga escala. Tese de doutorado, Instituto de Física da USP, 1999.

- Malhi, Y., E. Pegoraro. A.C. Nobre, M.G.P. Pereira, J. Grace, and A.D. Culf, Energy and water dynamics of a central Amazonian rain forest. Journal of Geophysical Research, 107 (D20), p. 8061, 2002

- Martin, S.T., M.O. Andreae, P. Artaxo, D. Baumgardner, Q.Chen, A.H. Goldstein, A.Guenther, C.L. Heald, O.L. Mayol-Bracero, P.H. McMurry, T.Pauliquevis, U. Pöschl, K.A. Prather, G.C. Roberts, S.R. Saleska, M.A.S. Dias, D.V. Spracklen, Erik Swietlicki, and I., Trebs. Sources and Properties of Amazonian Aerosol Particles. In press at Review of Geophysics, 2009. 
- Martins, J.V., O Efeito de Partículas de Aerossol de queimadas da Amazônia no balanço Radiativo da Atmosfera. São Paulo. Tese de Doutorado. Instituto de Física, USP, 1999.

- Martins, J.V., P. Artaxo, C. Liousse, J.S. Reid, P.V. Hobbs, and Y.J. Kaufman. Effects of black carbon content, particle size, and mixing on light absorption by aerosols from biomass burning in Brazil. Journal of Geophysical Research, vol. 103, p. 32041, 1998.

- Martins, J.V., D. Tanré, L. Remen, J.Y. Kaufman, S. Mattoo, R. Levy, MODIS cloudscreening for remote sensing of aerosols over ocean using spatial variability. Geophysical Research Letters, vol. 29(12), 2002.

- $\quad$ Meneses, P.R., Fundamentos de Radiometria Óptica Espectral, In: Meneses, P.R. and Netto, J.S. (Org.) Sensoriamento Remoto: reflectância dos alvos naturais Brasília, DF. UnB; Planaltrina:Embrapa Cerrados, 2001.

- Motta, R.S. et al., O custo econômico do fogo na Amazônia. Texto para discussão n.o 912, IPEA, Ministério do Planejamento, Orçamento e Gestão, Rio de Janeiro, Outubro/2002.

- Nakajima, T., M., Tanaka, and T. Yamauchi. Retrieveal of the optical properties os aerosols from aureole and extinction data. Applied Optics, vol. 22, p. 2951, 1983

- Nepstad, D.C. et al., Large scale impoverishment of the Amazonian forest by logging and fire. Nature, 398, p. 505, 1999.

- Nepstad, D., G. Carvalho, A.C. Barros, A. Alencar, J.P. Capobianco, J. Bishop, P. Moutinho, P. Lefebvre, and U.L. Silva, Road paving, fire regime feedbacks, and the future of Amazon forests. Forest Ecology \& Met., v. 154, p. 395, 2001.

- Nepstad, D.C., C.M. Stickler, B. Soares-Filho, and F. Merry, Interactions among Amazon land use, forests and climate: Prospects for a near-term forest tipping point, Phil. Trans. R. Soc. Lond. B, 363, 2008.

- Nobre, C.A. et al., The Large Scale Biosphere-Atmosphere Experiment in Amazonia (LBA) - Concise Experimental Plan, INPE, Cachoeira Paulista, 1996.

- Pereira, M.C. and Setzer, A.W., Spectral characteristics of fire scars in Landsat-5 TM images of Amazonia, International Journal of Remote Sensing, 14(11), p. 2061, 1993. 
- Priante-Filho, N., G.L. Vourlitis, M.M.S Hayashi, J.S. Nogueira, J.H. Campelo, P.C. Nunes, L.S.E. Souza, E.G. Couto, W. Hoeger, F. Raiter, J.L. Trienweiler, E.J. Miranda, P.C. Priante, C.L. Fritzen, M. Lacerda, L.C. Pereira, M.S. Biudes, G.S. Suli, S. Shiraiwa, S.R. Paulo, and M. Silveira, Comparison of the mass and energy exchange of a pasture and a mature transitional tropical forest of the southern Amazon Basin during a seasonal transition, Global Change Biology, 10, p. 863, 2004.

- Procópio, A.S., Forçante radiativa direta dos aerossóis na Região Amazônica devido à queima de biomassa. Tese de Doutorado, Instituto de Astronomia, Geofísica e Ciências Atmosféricas da Universidade de São Paulo, São Paulo, 2005.

- Procopio, A.S., P. Artaxo, Y.J. Kaufman, L.A. Remer, J.S. Schafer, and B.N. Holben, Multiyear analysis of amazonian biomass burning smoke radiative forcing of climate. Geophysical Research Letters, 31, L03108, 2004.

- Raes, F., R.V. Dingenen, E. Vignati E., J. Wilson, J.-P. Putaud, J.H. Seinfeld, and P. Adams, Formation and cycling of aerosols in the global troposphere, Atmospheric Environment, 34(25), p. 4215, 2000.

- Ramanathan, V., P.J. Crutzen, J.T. Kiehl, and D. Rosenfeld. Aerosols, Climate, and the Hydrological Cycle. Science Compass Review, vol. 294, p. 2119, 2001.

- Ramaswamy, V. et al., Radiative Forcing of Climate Change. Em: Climate Change 2001: The scientific Basis. Contribution of Working Group I to the Third Assessment Report of the Intergovernmental Panel on Climate Change. Houghton, J.T., et al. (eds.), Cambridge University Press, USA, 2001.

- Remer, L.A., Y.J. Kaufman, and B.N. Holben. The size distribution of ambient aerosol particles: smoke vs. urban/industrial aerosol, accepted to Global Biomass Burning. The MIT press, Cambridge MA, 1996.

- Remer, L.A., S. Gassó, D.A. Hegg, Y.J. Kauafman, B.N. Holben. Urban/industrial aerosol: Ground-based Sun/sky radiometer and airborne in situ measurements. Journal of Geophysical Research, vol. 103(D24), p. 31879, 1997.

- Remer, L. A., and Y. J. Kaufman. Dynamic aerosol model: Urban/industrial aerosol. Journal of Geophysical Research, vol. 103, p. 13859, 1998.

- Remer, L.A., D. Tanré, Y.J. Kaufman, C. Ichoku, S. Mattoo, R. Levy, D.A. Chu, B.N. Holben, O. Dubovik, A. Smirnov, J.V. Martins, R.R. Li e Z. Ahmad. Validation of MODIS aerosol retrieval over ocean. Journal of Geophysical Research, vol. 29(12), p. 1618, MOD3-1-4, 2002. 
- Ricchiazzi, P., Yang, S., Gautier, C., Sowle, D., SBDART: A research and teaching software tool for plane-parallel radiative transfer in the Earth's atmosphere. Bulletin of the American Meteorological Society, 79, 2101, 1998.

- Rissler, J., E. Swietlicki, J. Zhou, L.V. Gatti, G. Roberts, M.O. Andreae, P. Artaxo, Physical properties of the sub-micrometer aerosol over the Amazon rain forest during the wet-to-dry season transition - Comparison of modeled and measured CCN concentrations. Atmospheric Chemistry and Physics, 4: 2119-2143 Nov. 2, 2004.

- Salati, E., Marques, J., Climatology of the Amazon region. Em: Sioli, H. (ed.), The Amazon - Limnology and landscape ecology of a mighty tropical river and its basin, Junk Publishers, 1984.

- Martins, J.V., D. Tanré, L. Remen, J.Y. Kaufman, S. Mattoo, R. Levy, MODIS cloudscreening for remote sensing of aerosols over ocean using spatial variability. Geophysical Research Letters, vol. 29(12), 2002.

- Satheesh, S.K. and Moorthy, K.K. Radiative effects of natural aerosols: A review. Atmospheric Environment, 11(39), p. 2089, 2005.

- Schafer, J.S., B.N. Holben, T.F. Eck, M.A. Yamasoe, P. Artaxo, Atmospheric effects on insolation in the Brazilian Amazon: Observed modification of solar radiation by clouds and smoke and derived single scatter albedo of fire aerosols. Journal of Geophysical Research, 107(D20), P. 8074, 2002.

- Schafer, J.S., T.F. Eck, B.N. Holben, P. Artaxo, A. Duarte. Characterization of the optical properties of atmospheric aerosols in Amazonia from long term AERONET monitoring (1993-1995;1999-2006). Journal of Geophysical Research - Atmospheres, Vol. 113, Issue: D4, 2008.

- Schmid, B. and Wehrli, C., Comparison of Sun photometer calibration by use of the Langley technique and the standard lamp. Applied Optics, vol. 34, p. 4500, 1995.

- Seinfeld, J.H. and Pandis, SN., Atmospheric Chemistry and Physics from Air Pollution to Climate Change. Wiley and Sons Ed., New York, U.S.A., 1998.

- Sekiguchi, M., T. Nakajima, K. Suzuki, K. Kawamoto, A. Higurashi, D. Rosenfeld, I. Sano, and S. Mukai, A study of the direct and indirect effects of aerosols using global satellite data sets of aerosol and cloud parameters, $J$. Geophys. Res, 108, 2003. 
- Shettle, E.P., and Fenn, R.W., Models for the aerosols of the lower atmosphere and the effects of humidity variations on their optical properties. AFGL-TR-790214. Environmental Research Papers, $n^{\circ}$ 676. Air Force Geophysics Laboratory, Hanscom AFB, Massachusetts, 1979.

- Shettle, E.P., Optical and radiative properties of a desert aerosol model. Proc. Symposium on Radiation in the Atmosphere, G. Fiocco Ed., A. Deepak Publishing, p. 74, 1984.

- Smirnov, A., B.N. Holben, T.F. Eck, O. Dubovik, and I. Slutsker, Cloud screening and quality control algorithms for the AERONET database. Remote Sens. Environ., vol. 73(3), p. 337, 2000.

- Tanré, D., Y.J. Kaufman, M. Herman, and S. Mattoo, Remote sensing of aerosol properties over oceans using the MODIS/EOS spectral radiances. Journal of Geophysical Research, vol. 102, p. 16971, 1997.

- Tanré, D., Y.J. Kaufman, M. Herman, and S. Mattoo, Retrieval of aerosol optical thickness and size distribution over ocean from the MODIS airborne simulator during TARFOX. Journal of Geophysical Research, vol. 104(D2), p. 2261, 1999.

- Thomas, G.E. and Stamnes, K. Radiative Transfer in the Atmosphere and Ocean. Cambridge University Press, 1999.

- Thomason, L.W., B.M. Herman, and J.A. Reagan. The effect of atmospheric attenuators with structured vertical distributions on air mass determinations and Langley plot analyses. Journal of the Atmospheric Sciences, vol. 40, p. 1851, 1983.

- Torres O. et al., A long-term record of aerosol optical depth from TOMS observationand comparison to AERONET measurements. Journal of Atmospheric Science, vol. 59, p. 398, 2002.

- Twomey, S.A.: The influence of pollution on the shortwave albedo of clouds. Journal of Atmospheric Science, 34, p. 1149, 1977.

- Von Randow, C., A.O. Manzi, B. Kruijt, P.J. Oliveira, F.B. Zanchi, R.L. Silva, M.G. Hodnett, J.H.C. Gash, J.A. Elbers, M.J. Waterloo, F.L. Cardolo, and P. Kabat, Comparative measurements and seasonal variations in energy and carbon exchange over forest and pasture in South West Amazonia. Theoretical and Applied Climatology, 78(1-3), p. 5, 2004.

- Wallace, J.M. and Hobbs, P.V., Atmospheric Science - An Introductory Survey. Academic Press, Inc. San Diego, California, 1977. 
- Wesely, M.L. and Hicks, B.B., A review of the current status of knowledge on dry deposition. Atmospheric Environment 34, p. 2261, 2000.

- Williams, M.R. and Fisher, T.R., Chemical composition and deposition of rain in the central Amazon, Brazil. Atmospheric Environment, 31(2), p. 207, 1997.

- Wiscombe, W. J., The Delta-M Method: Rapid Yet Accurate Radiative Flux Calculations for Strongly Asymmetric Phase Functions. Journal of Atmospheric Sciences, vol. 34, p. 1408, 1977.

- Wiscombe, W.J., Improved Mie scattering algorithms. Applied Optics, vol. 19(9), 1980.

- Yamasoe, M.A. Estudo de Propriedades Ópticas de Partículas de Aerossóis a partir de uma Rede de Fotômetros. São Paulo. Tese de Doutorado. Instituto de Física, USP, 1999. 


\section{Capítulo de livro publicado: Aerosol Particles in Amazonia: Their Composition, Role in the Radiation Balance, Cloud Formation, and Nutrient Cycles.}

Artaxo, P., L. V. Rizzo, M. Paixao, S. de Lucca, P. H. Oliveira, L. L. Lara, K. T. Wiedemann, M. O. Andreae, B. Holben, J. Schafer, A. L. Correia, and T. M. Pauliquevis. Aerosol particles in Amazonia: Their composition, role in the radiation balance, cloud formation and nutrient cycles. In: Amazonia and Global Change, Ed. M. Keller, M. Bustamante, J. Gash, P. S. Dias. American Geophysical Union, Geophysical Monograph Series 186, pg. 235-254, ISBN: 978-0-87590-449-8, 2009. 